\author{
UNIVERSIDADE DE SÃO PAULO \\ USP \\ Programa Interunidades de Pós-Graduação em Energia \\ PIPGE \\ (EP/FEA/IEE/IF)
}

\title{
AQUECIMENTO DE ÁGUA NO SETOR RESIDENCIAL
}

Patrícia Abdala Raimo

São Paulo

2007 
PATRICIA ABDALA RAIMO

\section{AQUECIMENTO DE ÁGUA NO SETOR RESIDENCIAL}

Dissertação apresentada ao Programa Interunidades de Pós-Graduação em Energia da Universidade de São Paulo (Escola Politécnica / Faculdade de Economia e Administração / Instituto de Eletrotécnica e Energia e Instituto de Física) para a obtenção do Título de Mestre em Energia.

Orientador: Prof. Dr. Murilo Tadeu Werneck Fagá

São Paulo 


\begin{abstract}
AUTORIZO A REPRODUÇÃO E DIVULGAÇÃO TOTAL OU PARCIAL DESTE TRABALHO, POR QUALQUER MEIO CONVENCIONAL OU ELETRÔNICO, PARA FINS DE ESTUDO E PESQUISA, DESDE QUE CITADA A FONTE.
\end{abstract}

FICHA CATALOGRÁFICA

Raimo, Patrícia Abdala.

Aquecimento de água no setor residencial / Patrícia Abdala Raimo; Orientador Murilo Tadeu Werneck Fagá São Paulo, 2007.

125 p.: il.; $30 \mathrm{~cm}$.

Dissertação (Mestrado - Programa Interunidades de Pós-Graduação em Energia) - EP / FEA / IEE / IF da Universidade de São Paulo.

1. Energia solar 2. Fontes alternativas de energia 3.Aquecimento de água solar 4. Consumo residencial 5.Sistema de aquecimento elétrico e a gás I. Título. 


\title{
UNIVERSIDADE DE SÃO PAULO
}

PROGRAMA INTERUNIDADES DE PÓS-GRADUAÇÃo EM ENERGIA

$$
\text { EP - FEA - IEE - IF }
$$

\section{PATRÍCIA ABDALA RAIMO}

\author{
"Aquecimento de Água no Setor Residencial"
}

Dissertação defendida e aprovada em 28/08/2007 pela Comissão Julgadora:

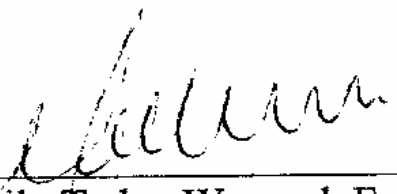

Prof. Dr. Murilo Tadeu Werneck Fagá - PIPGE-IEE/USP

Orientador e Presidente da Comissão Julgadora
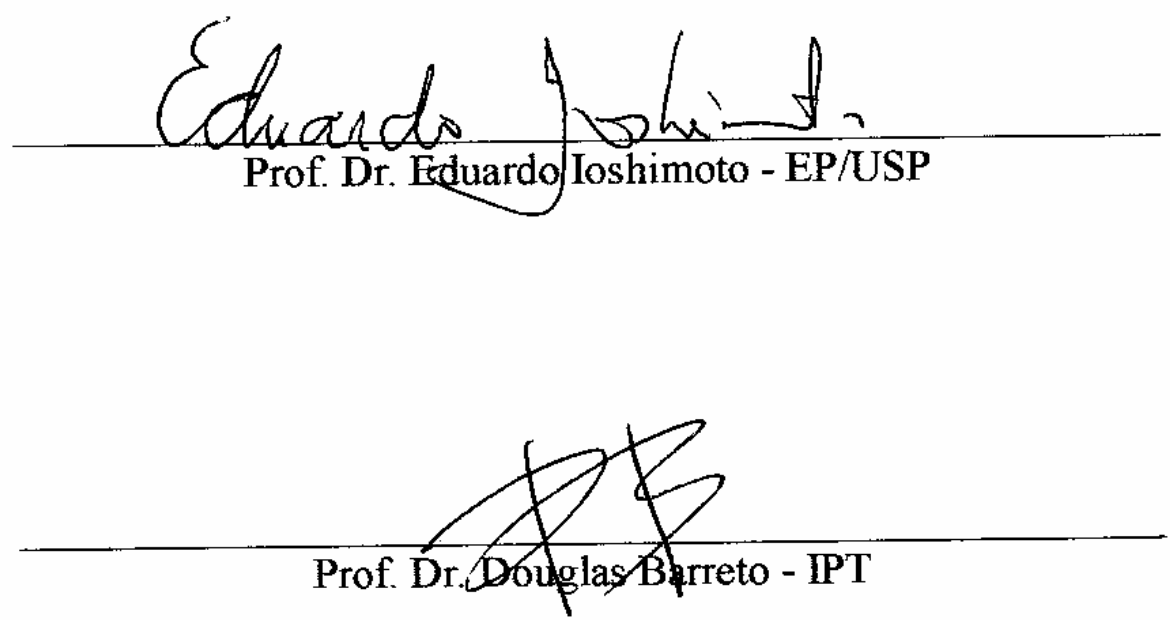
Andréa, Kátia e Vitor

Rafael

Sílvia e Isaías 


\section{AGRADECIMENTOS}

Ao Prof. Dr. Murilo Tadeu W. Fagá, a quem admiro e respeito, que com suas idéias inusitadas muito enriqueceu este trabalho. Pela paciência, compreensão e amizade.

Aos Prof. Dr. Edmilson M. dos Santos, Profa. Dra.Virginia Parente e Prof. Dr. Miguel E. Morales Udaeta o meu reconhecimento e estima pelo apoio.

Aos professores do Programa Interunidades de Pós Graduação em Energia, em especial aos Prof. Dr. Roberto Zilles, Prof. Dr Célio Bermann e Prof. Dr. Ildo Sauer, pela formação acadêmica.

Ao Prof. Dr. Eduardo loshimoto pelas contribuições feitas a esta pesquisa no campo das instalações hidráulicas.

Ao corpo de apoio do PIPGE, em especial à Rosa, Adriana, Vilma, Daniele, Maria de Fátima, Maria Penha, Maria de Lourdes, Vivian, Gisele e Júlio.

Aos amigos que surgiram no IEE, em especial aos colegas da didática pela interação e agradável convivência.

Aos profissionais e entidades que contribuíram através de elementos para a realização deste trabalho:

Adilson Luiz da Costa (ETE Guaracy Silveira), Alberto José Fossa (Comitê Brasileiro de Normas Técnicas CB-09 e CB-55), Alessandro Barghini (IEE), Aloysio Costa (INMETRO), Antônio Carlos Correia (TG), Ayrton Zanon Jr. (ABAGAS), Benjamim Novais Carrasco (PETROBRAS), Carlos Alexandre Cella (ABINIEE), Carlos Felipe da Cunha Faria (ABRAVA), Cláudio Antonio Scarpinella (IEE), Daniel Cirne Amstalden (ABAGAS), Eugênio Pierrobon Neto (COMGAS), Felipe Romano (Projeto P\&D - COMGAS), José Aquiles Baesso Grimoni (IEE), José Jorge Chaguri (CALTHERM), José Jorge Chaguri Junior (Projeto P\&D - COMGAS), Jacques Neto (GAS BRASILIANO), Judas Tadeu da Costa F. Néri (CTGAS), José Carlos Saraiva (COMGAS), Luis Felipe Amorim (CEG), Marcelo Sigoli (ELETROPAULO), Márcio Eidi Enokibara (COMGAS), Pablo Y. Y. Matsuo (ABAGAS), Ricardo de Souza (CUMULUS), Roberto Domingos D'Oliveira (ORBIS), Robespierre Sentella (IEE), Sally Freddi (TRANSSEN), Samuel Castor da Mata (ETE Guaracy Silveira) e Vitor Eduardo Isaias da Silva (GAS NATURAL).

Ao Programa de Recursos Humanos da Agência Nacional do Petróleo (PRH04-ANP) e à COMGAS pela contribuição para a realização deste trabalho. 


\section{Resumo}

RAIMO. A. P. Aquecimento de água no setor residencial. 2007. 125 p. Dissertação de Mestrado - Programa Interunidades de Pós -Graduação em Energia. Universidade de São Paulo.

O setor residencial reflete a cultura do uso excessivo da eletricidade para aquecimento de água. Para este uso final, a inclusão de gás e complementação com energia termo-solar pode apresentar vantagem por se tratar de energia final mais compatível com os processos de transformação em energia útil na forma de calor. A inclusão destas fontes pode propiciar uma diminuição de sobrecarga no sistema elétrico e da eletrotermia no setor residencial.

Este trabalho faz uma avaliação econômica dos sistemas de aquecimento de água elétrico, a gás e solar. Os sistemas são analisados considerando custos de infra-estrutura, com diferentes disponibilidades de uso, custos de equipamentos e de operação para vários níveis de consumo. A avaliação é aplicada a 3 tipologias de edificações verticais representativas no mercado da construção civil da Região Metropolitana de São Paulo. Os custos de serviço de aquecimento de água quente estão apresentados em função do volume de água consumido.

Palavras-chave: Aquecimento de água residencial, Consumo residencial, Sistema de aquecimento solar, Sistema de aquecimento elétrico e a gás. 


\begin{abstract}
RAIMO. A. P. Residential water heating. 2007. 125 p. Master"s Dissertation Program of Post-Graduation in Energy - Universidade de São Paulo, São Paulo.

The residential sector reflects the culture of the indiscriminate use of electricity water heating. Inclusion of gas and thermosolar energy to the electrical supply system may present advantages as they are more compatible to consumer"s heat transformation processes. In addition these new sources of energy may decrease the electrical and electrothermal system overload in the residential sector.

This study is an economic evaluation of the electric, gas and solar water heating systems. The heating systems are analyzed taking in consideration infrastructure costs, and equipment and operation costs for different levels of consumption. The evaluation is applied to three typologies of vertical residential edifications that represent the civil construction market of the São Paulo metropolitan area. The costs of water heating service are presented in function of the consumed volume of water.
\end{abstract}

Keywords: Domestic water heating, Domestic consumption, Solar water heating, Electricity and natural gas consumption; 


\section{LISTA DE FIGURAS}

Figura 1.1 Consumo nacional residencial por fonte

Figura 1.2 Evolução do consumo energético residencial por fonte do Estado de São Paulo ................................................. 18

Figura 1.3 Consumo final residencial do Estado de São Paulo............... 19

Figura 3.1 Configurações dos sistemas de aquecimento elétrico, gás e solar

Figura 4.1 Exemplo de requisitos de ventilação mínima e instalação de dutos

Figura 5.1 Diagrama unifilar da distribuição das cargas elétricas 44

Figura 5.2

Chuveiro elétrico com resistência blindada 45

Figura 5.3

Aquecedor instantâneo central elétrico 46

Figura 5.4 Esquema do circuito de alimentação e proteção do aquecedor elétrico

Figura 5.5 Custo na infra-estrutura de gás por potência instalada na unidade consumidora - Tipologia 3 Dormitórios 48

Figura 5.6 Ilustração do aquecedor instantâneo e de acumulação 49

Figura 5.7

Esquema de sistema de aquecimento conjugado a gás .... 50

Figura 5.8 Custo da infra-estrutura elétrica da edificação exclusiva para aquecimento; por potência instalada na unidade consumidora, para as tipologias de 2, 3 e 4 Dormitórios

Figura 5.9 Custo da infra-estrutura de gás da edificação exclusiva para aquecimento; por potência instalada na unidade consumidora, para as tipologias de 2, 3 e 4 Dormitórios.

Distribuição de gás por prumada coletiva.

Figura 5.10 Custo da infra-estrutura de gás da edificação exclusiva para aquecimento; por potência instalada na unidade consumidora, para as tipologias de 2, 3 e 4 Dormitórios.

Distribuição de gás por prumada individual

Figura 5.11 Custo da Infra-estrutura para aquecimento Elétrico e a Gás; Tipologia: 2 Dormitórios 
Figura 5.12 Custo da Infra-estrutura para aquecimento elétrico e a gás; Tipologia: 3 Dormitórios

Figura 5.13 Custo da Infra-estrutura para aquecimento elétrico e a gás;

Tipologia: 4 Dormitórios

Figura 5.14 Custo infra-estrutura para alternativa mista de energia; Tipologia: 3Dormitórios

Figura 5.15 Custo infra-estrutura para alternativa mista de energia;

Tipologia: 4Dormitórios

Figura 6.1 Custos do serviço de aquecimento de água residencial em função do volume de utilização; $r=12 \% a$ a.; Tipologia: 2Dormitórios; Tempo de análise do investimento $=10$ anos; Sistema elétrico e gás natural

Figura 6.2 Custos do serviço de aquecimento de água residencial em função do volume de utilização, $r=12 \%$ a.a. Tipologia: 3Dormitórios; Tempo de análise do investimento $=10$ anos; Sistema elétrico e gás natural

Figura 6.3 Custos do serviço de aquecimento de água residencial em função do volume de utilização, $r=12 \%$ a.a. Tipologia: 4Dormitórios; Tempo de análise do investimento $=10$ anos; Sistema elétrico e gás natural

Figura 6.4 Custo parcial considerando custo equipamento e custo energia, em função do volume de utilização, $r=12 \%$ a.a. Tipologia: 2Dormitórios; Tempo de análise do investimento $=10$ anos; Sistema elétrico e gás natural

Figura 6.5 Custo parcial considerando custo equipamento e custo energia, em função do volume de utilização, $r=12 \% a$ a. Tipologia: 3 e 4 Dormitórios; Tempo de análise do investimento $=10$ anos; Sistema elétrico e gás natural .

Figura 6.6 Custo do serviço de aquecimento de água para 30 minutos

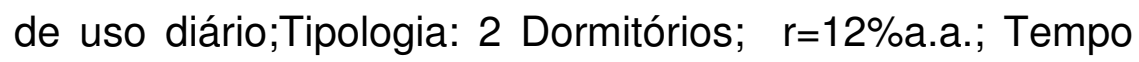
de análise 10 anos. 
Figura 6.7 Custo do serviço de aquecimento de água para 40 minutos de uso diário; Tipologia : 3 Dormitórios; r=12\%a.a.; Tempo de análise 10 anos

Figura 6.8 Custo do serviço de aquecimento de água para 50 minutos

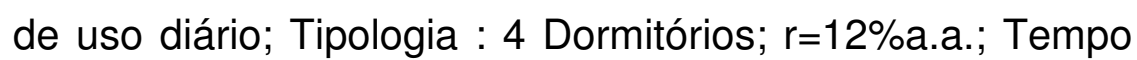
de análise 10 anos

Figura 6.9 Custos do serviço de aquecimento de água residencial em função do volume de utilização; $r=12 \%$ a.a.; Tipologia: 3Dormitórios; Tempo de análise do investimento $=10$ anos; Sistema a gás liquefeito de petróleo e gás natural

Figura 7.1 Tempo de Retorno Coletor Solar - comportamento $\eta \times$ TCS - com energia final auxiliar elétrica - taxa de juro $12 \%$ a.a.

Figura 7.2 Tempo de Retorno Coletor Solar - comportamento $\eta \times$ TCS - com energia final auxiliar a gás - taxa de juro 12\% a.a....

Figura 7.3 Tempo de retorno sistema solar com auxilio elétrico; $r=12 \%$ a.a.

Figura 7.4 Tempo de retorno sistema solar com auxilio a gás; $r=12 \%$ a.a.

Figura 7.5 Custo do serviço de aquecimento de água solar comparado ao convencional; Tipologia 2D; 30 minutos diário

Figura 7.6 Custo do serviço de aquecimento de água solar comparado ao convencional; Tipologia 3D; 40 minutos diário

Figura 7.7 Custo do serviço de aquecimento de água solar comparado ao convencional; Tipologia 4D; 50 minutos diário 


\section{LISTA DE TABELAS}

Tabela 1.1 Evolução de população, PIB e consumo energético residencial por fonte, do Estado de São Paulo. .................... 18

Tabela 1.2 Produção e importação de aquecedores ............................. 20

Tabela 5. 1 Tubo de água quente e condutividade ................................ 51

Tabela 5.2 Pontos de uso considerados para dimensionamento das instalações elétrica e hidráulica ........................................... 54

Tabela 5.3 Potência instalada por UC e custo na edificação; Tipologia: 2 Dormitórios .................................................................... 55

Tabela 5.4 Potência instalada por UC e custo na edificação; Tipologia:

3 Dormitórios ............................................................. 55

Tabela 5.5 Potência instalada por UC e custo na edificação; Tipologia:

4 Dormitórios ....................................................................... 56

Tabela 6.1 Vida útil dos equipamentos ............................................... 64

Tabela 6.2 Eficiências dos aquecedores ………................................. 65

Tabela 6.3 Perda de calor nas tubulações ............................................. 67

Tabela 6.4 Simulação de preço de energia com impostos ...................... 68

Tabela 6.5 Preço do MWh ............................................................. 69 


\section{SUMÁRIO}

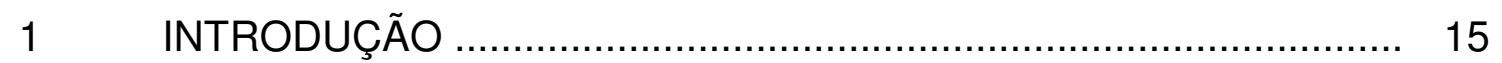

$1.1 \quad$ Relevância do tema e objetivo ……………........................... 15

$1.2 \quad$ Estrutura capitular do trabalho ……………............................ 16

1.3 Panorama do consumo de energia residencial .............................. 17

$1.4 \quad$ Mercado nacional de aquecedores ............................................. 20

1.5 Revisão bibliográfica .................................................................. 21

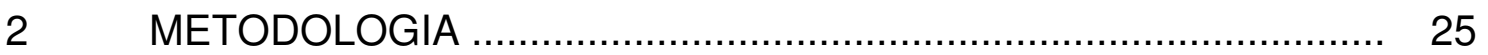

2.1 Análise econômica das alternativas para aquecimento elétrico e de

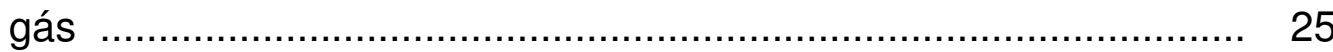

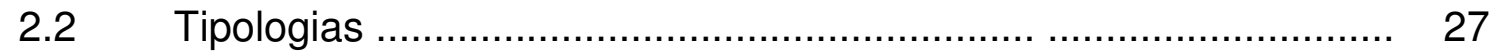

2.3 Parâmetros adotados para comparação econômica das

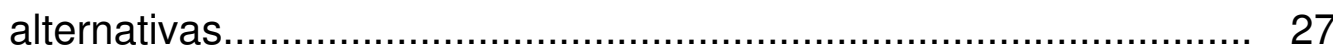

2.4 Análise econômica utilizando energia solar como economia de energia paga pelo usuário ...................................................... 28

3 SISTEMAS DE AQUECIMENTO DE ÁGUA ................................. 29

3.1 Conversão de energia final em útil .............................................. 29

3.1.1 Eletricidade como fonte de calor ............................................. 30

3.1.2 Gás como fonte de calor ......................................................... 31

3.1.3 Sol como fonte de calor .......................................................... 31

3.2 Configurações das alternativas dos sistemas de aquecimento 32

3.3 Características de funcionamento .............................................. 34

4 CONFORMIDADE DOS SISTEMAS DE AQUECIMENTO ÀS REGULAMENTAÇÕES ............................................................. 35

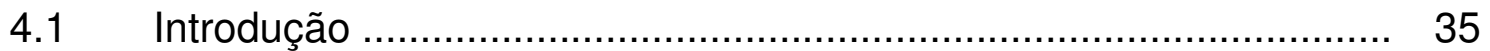

4.2 Aquecimento elétrico ................................................................ 35

4.3 Aquecimento a gás .................................................................. 36

4.4 Sistema solar e as externalidades …………….......................... 39

4.5 Programa de eficiência no uso final ............................................ 40

4.6 Considerações ..................................................................... 41 
CARACTERIZAÇÃO DAS INFRA-ESTRUTURAS ELÉTRICA E HIDRÁULICA PARA DIFERENTES DEMANDAS DE ÁGUA QUENTE

5.1 Infra-estrutura para aquecimento de água ................................ 42

$5.2 \quad$ Infra-estrutura elétrica ...................................................... 43

5.2.1 Dimensionamento da infra-estrutura elétrica ............................ 43

5.2.2 Requisitos necessários à infra-estrutura elétrica de água quente 45

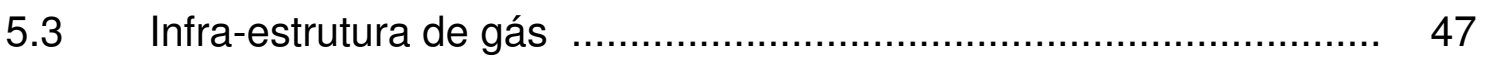

5.3.1 Dimensionamento de gás ................................................ 47

5.3.2 Requisitos necessários de infra-estrutura de gás ........................ 49

5.4 Dimensionamento da infra-estrutura de água quente ................... 50

5.5 Dimensionamento dos reservatórios ...................................... 52

5.6 Caracterização da disponibilidade na infra-estrutura elétrica e hidráulica ..................................................................... 53

5.7 Potência Instalada e custo total exclusivo para aquecimento .......... 54

5.8 Sistema misto de energia final ............................................... 61

$6 \quad$ ANÁLISE ECONÔMICA DAS ALTERNATIVAS ........................... 63

$6.1 \quad$ Parâmetros adotados ....................................................... 63

6.1.1 Tempo de análise e taxa de desconto, vida útil dos equipamentos e infra-estrutura ............................................................. 63

6.1.2 Custos de equipamentos 64

6.1.3 Eficiência na conversão $\left(\eta_{\mathrm{c}}\right)$ dos aquecedores .......................... 65

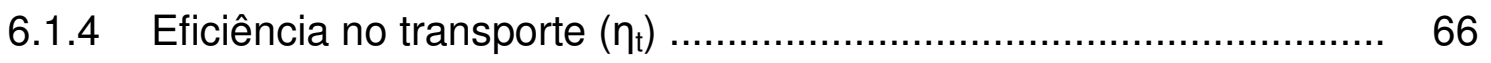

6.1 .5 Preço da energia .......................................................... 67

6.2 Resultados entre custos de serviço de aquecimento de água: Elétrico e Gás Natural ........................................................ 69

6.2.1 Resultados dos custos de serviço de aquecimento de água: Elétrico e a Gás Natural em função do volume de utilização .......... 70

6.2.2 Resultados entre custos parciais de aquecimento de água: Elétrico e a Gás Natural em função do volume de utilização, desconsiderando infra-estrutura 
6.2.3 Resultados entre custos de serviço de aquecimento de água: Elétrico e a Gás Natural; por tempo de utilização

6.2.4 Resultados entre custos de serviço de aquecimento de água : gás natural e gás liquefeito de petróleo ............................................ 78

7 ENERGIA SOLAR COMO ECONOMIA DE ENERGIA PAGA ......... 80

7.1 Inclusão do sistema de aquecimento solar ................................... 80

7.2 Avaliação do tempo de retorno dos sistemas de aquecimento solar 81

7.3 Análise econômica utilizando energia solar como economia de

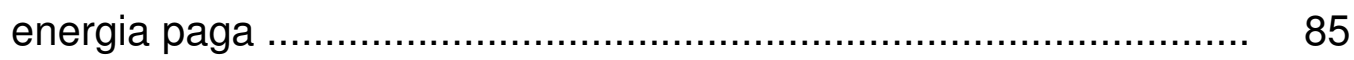

7.4 Resultados entre custos de serviço de aquecimento de água com sistema solar ........................................................................ 86

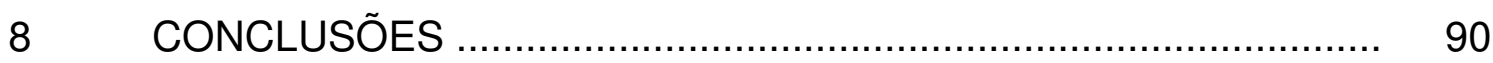

REFERENCIAS BIBLIOGRÁFICAS .......................................... 92

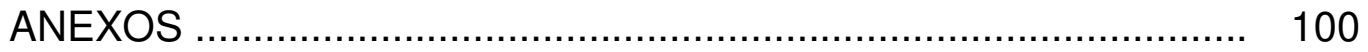




\section{INTRODUÇÃO}

\subsection{Relevância do tema e objetivo}

No Brasil, a energia hidráulica é hoje o recurso natural predominante na geração de energia elétrica, cerca de $90 \%$ da eletricidade consumida tem origem nas turbinas movidas pela água vertida dos reservatórios. A partir dos anos $70 \mathrm{e}$ durante quase duas décadas, com a inserção significativa dos aproveitamentos hidrelétricos no país e a dependência do petróleo importado, disseminou-se a cultura da utilização da eletricidade para processos térmicos, substituindo derivados de petróleo na obtenção de energia útil na forma de calor, denominada de eletrotermia.

Cerca de $22 \%$ do consumo total da energia elétrica ${ }^{1}$ gerada no país é consumida pelo segmento residencial, e desses, uma parcela é utilizada para aquecimento de água, variando com a região e a condição sócio econômica. Para aquecimento, a inclusão do uso do gás e complementação com energia termo-solar, quando possível, apresenta vantagem por se tratar de energia final mais compatível com os processos de transformação em energia útil na forma de calor. A diversificação da fonte de calor para uso final térmico pode propiciar uma diminuição de sobrecarga no sistema elétrico e a diminuição da eletrotermia no setor residencial.

O objetivo deste trabalho é avaliar os sistemas de aquecimento de água elétrico, a gás e solar. Os sistemas são analisados considerando custos de infraestrutura, com diferentes disponibilidades de uso, custos de equipamentos e de energia para vários níveis de consumo. A avaliação é aplicada a 3 tipologias de edificações verticais representativas no mercado da construção civil da Região Metropolitana de São Paulo. Neste trabalho os custos de investimentos são somados aos custos de operação, fornecendo o custo do serviço de aquecimento de água em função da energia útil consumida.

Este estudo pode contribuir com a redução da demanda de energia elétrica no horário de ponta, a racionalidade do consumo de energia primária e com o planejamento de uso destes recursos energéticos em edificações ao longo de sua vida útil.

\footnotetext{
${ }^{1}$ BEN, 2006, Ministério de Minas e Energia, (base 2005)
} 
1.2 Estrutura capitular do trabalho

Este capítulo apresenta a relevância do tema, objetivo, estrutura do trabalho, panorama energético do setor residencial no Brasil, e o uso de fontes de calor para aquecimento de água no estado de São Paulo e o mercado de aquecedores.

No segundo capítulo está descrita a metodologia, a qual analisa o custo do serviço de aquecimento. O modelo permite a combinação de custo de infra-estrutura da edificação associado ao do aquecedor utilizado no aquecimento e o preço da energia da fonte de calor.

O terceiro capítulo apresenta as alternativas de sistemas de aquecimento de água. Evidencia os requisitos comuns e os específicos a cada um dos sistemas e mecanismos para desempenho e segurança.

O quarto capítulo aborda pontos em que as regulamentações e requisitos de operação dos sistemas de aquecimento de água influenciam culturas de uso e aumentam custos que inibem investidores, projetistas, fabricantes e usuários na diversificação de fonte de calor para o uso destes sistemas.

O quinto capítulo caracteriza as tipologias e diferentes disponibilidades de água quente a serem analisadas. Foi construída uma planilha para dimensionamento da infra-estrutura elétrica e outra planilha foi utilizada para o dimensionamento hidráulico. As planilhas de dimensionamento da infra-estrutura fazem parte do Projeto de P\&D elaborado para a COMGAS, cujo escopo é o aquecimento de água no setor residencial.

A análise econômica está apresentada no capítulo seis, no estudo de caso em três edificações verticais, onde são inseridos os parâmetros que interferem nesta análise.

O sétimo capítulo avalia a energia solar como economia de energia paga. Esta avaliação inclui o custo do serviço de aquecimento de água solar.

O oitavo capítulo apresenta as conclusões obtidas da comparação entre as alternativas de sistemas de água quente. 
1. 3 Panorama do consumo de energia residencial

A demanda energética residencial representa $12 \%$ do total de 178.152 mil $\mathrm{TEP}^{2}$ de energia final consumida no Brasil. Destes $12 \%$ predomina o consumo para cocção de alimentos, utilizando gás liquefeito de petróleo e lenha, ambas com participação de 63,9\% e consumo para iluminação, refrigeração e aquecimento de água, utilizando eletricidade com participação de $32,8 \%$. O gráfico da figura 1.1 mostra o consumo nacional residencial por fonte.

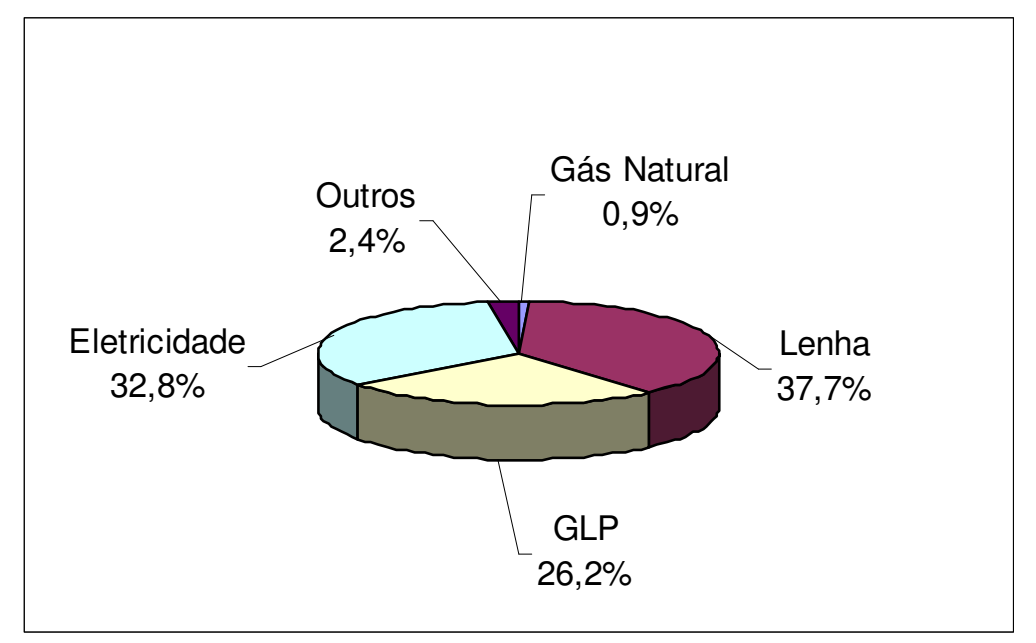

Figura 1.1 Consumo Nacional Residencial por Fonte

Fonte: BEN 2006, MME

O Estado de São Paulo consome $31,7 \%$, dos $12 \%$ do consumo nacional residencial. A tabela 1.1 apresenta, para o Estado de São Paulo, a evolução da população, produto interno bruto (PIB) e consumo energético residencial por fonte.

Observar, pela tabela 1.1, que apesar do aumento do PIB e da população, constata-se a continuidade da intensidade energética do estado na ordem de $1 \mathrm{x}$ $10^{3} \mathrm{kcal} / \mathrm{R} \$$ e do consumo residencial anual de $1 \times 10^{3} \mathrm{kcal} / 100$ mil habitantes.

\footnotetext{
${ }^{2}$ BEN 2006,Ministério de Minas e Energia
} 
Tabela 1.1- Evolução de população, PIB e consumo energético residencial por fonte, do Estado de São Paulo.

\begin{tabular}{|c|c|c|c|c|c|c|c|c|c|}
\hline & & & & & & \multicolumn{4}{|c|}{ Valores de consumo energético em $10^{9} \mathrm{kcal} / \mathrm{ano}$} \\
\hline \multirow[b]{3}{*}{ ANO } & \multirow[b]{3}{*}{ População } & \multirow[b]{3}{*}{$P I B$} & \multirow[b]{3}{*}{ Cons Total } & \multirow[b]{3}{*}{ Residencial } & \multicolumn{5}{|c|}{ Consumo residencial por fonte } \\
\hline & & & & & & & & & Querosene e \\
\hline & & & & & Eletricidade & GLP & Lenha & GN & Carvão vegeta \\
\hline & milhões hab & milhões $R \$$ & No ESP & & & & & & \\
\hline 2001 & 38 & 490.695 & 524.189 & 40.142 & 19.982 & 16.061 & 3.274 & 592 & 233 \\
\hline 2002 & 39 & 494.700 & 527.668 & 40.064 & 19.571 & 16.049 & 3.628 & 665 & 151 \\
\hline 2003 & 39 & 494.814 & 544.244 & 40.136 & 20.482 & 15.252 & 3.522 & 762 & 118 \\
\hline 2004 & 40 & 531.925 & 588.442 & 41.302 & 21.327 & 15.434 & 3.563 & 868 & 110 \\
\hline 2005 & 40 & 547.350 & 598.566 & 42.289 & 22.445 & 15.215 & 3.643 & 892 & 94 \\
\hline
\end{tabular}

Fonte: Balanço Energético do Estado de São Paulo, 2006 - Secretaria de Energia do Estado de São Paulo.

A figura 1.2 mostra a evolução do consumo energético residencial por fonte, entre os anos de 2001 e 2005 no Estado de São Paulo.

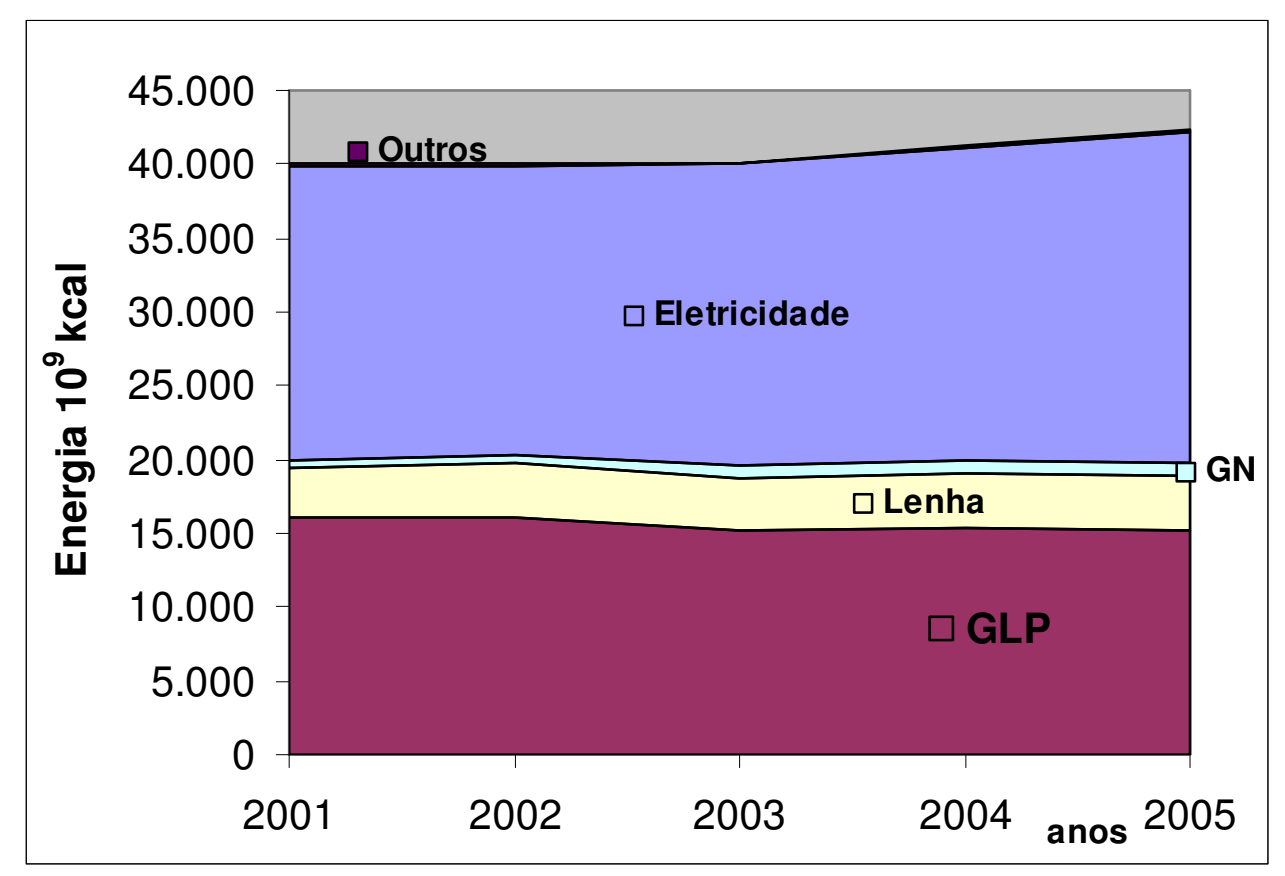

Figura 1.2 Evolução do consumo energético residencial por fonte do Estado de São Paulo

Fonte: BEESP de 2006 
A distribuição da energia final por fonte do setor residencial em 2005, do Estado de São Paulo, está demonstrada na figura 1.3. Estima-se que $33 \%$, da energia elétrica residencial seja destinada ao aquecimento de água, sendo o equipamento mais utilizado o chuveiro elétrico (MATAJS,1997, pg 14-16).

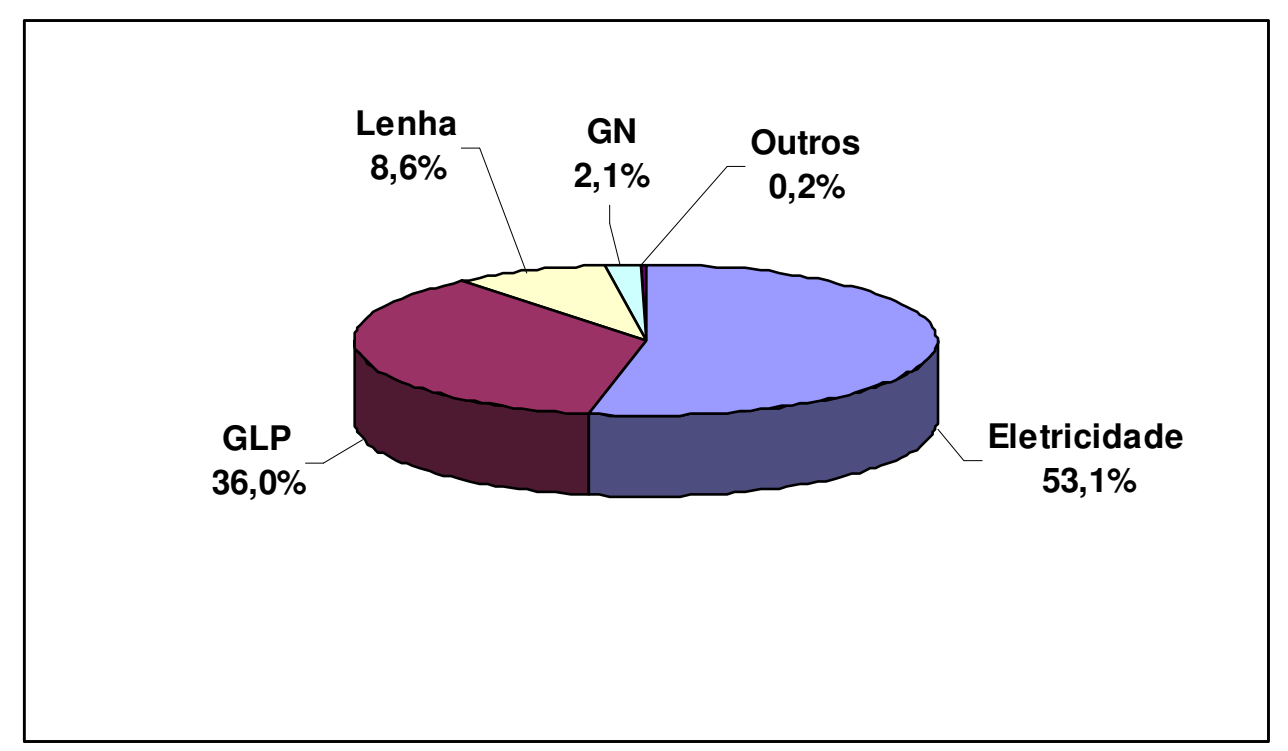

Figura 1.3 Consumo Final Residencial do Estado de São Paulo

Fonte: BEESP de 2006

O gás natural apesar da grande penetração na última década, na estrutura produtiva do país e de ser uma energia primária mais compatível para obtenção de calor do ponto de vista termodinâmico, tem a sua participação bastante inexpressiva no setor residencial, sendo mais utilizado para cocção.

Uma energia compatível com o aquecimento de água é a solar, ambientalmente limpa se comparada à elétrica e ao gás. Esta energia não aparece contabilizada no Balanço Energético Nacional.

Dados da Associação Brasileira de Refrigeração, Ar Condicionado, Ventilação e Aquecimento (ABRAVA) indicam que a economia anual de energia elétrica para aquecimento, com uso do sistema solar foi de $333,2 \mathrm{GWh}$, no ano de 2005, o que representou $0,40 \%$ dos $83.193 \mathrm{GWh}^{3}$ do consumo nacional de eletricidade do setor residencial do mesmo ano.

\footnotetext{
${ }^{3}$ Balanço Energético Nacional, 2006. Ministério de Minas e Energia
} 
Em 2004, o Brasil apresentou uma área coletora acumulada de $2.200 .458 \mathrm{~m}^{2}$ (FARIA, 2006), gerando uma potência térmica acumulada de 1.540,32 MW ${ }^{4}$, que resulta em uma capacidade instalada de 0,89 MW/100 mil habitantes. Quando se compara a área coletora instalada do Brasil com a de outros países, tais como Israel, Grécia e China que implantam a tecnologia do aquecimento solar, evidencia-se o quanto o Brasil pode explorar esta tecnologia, uma vez que se tem o potencial solar a ser aproveitado. Israel, Grécia e China apresentam respectivamente a potência térmica acumulada de 52, 19 e 3,33 MW por 100 mil habitantes (EIA, 2004).

\subsection{Mercado nacional de aquecedores}

Levantamento da Pesquisa Industrial Anual - PIA ${ }^{5}$ mostra a produção nacional de aquecedores e o levantamento do Ministério do Desenvolvimento da Indústria e do Comércio exterior mostra a importação de aquecedores. O resultado destes levantamentos, do ano de 2003, está apresentado na Tabela 1.2 - Produção e importação de aquecedores.

Tabela 1.2- Produção e importação de aquecedores.

\begin{tabular}{ccc}
\hline Produto & $\begin{array}{c}\text { Produção } \\
\text { quantidade (un) }\end{array}$ & $\begin{array}{c}\text { Importação } \\
\text { quantidade (un) }\end{array}$ \\
\hline Aquecedor a gás ou energia solar & 31.487 & - \\
Aquecedor instantâneo a gás & & 100.952 \\
Aquecedor elétrico de água & 282.598 & - \\
Chuveiro elétrico & 24.095 .563 & - \\
\hline \hline
\end{tabular}

Fontes: Pesquisa anual de produção PIA ( 2003); Importação de produtos - Ministério do desenvolvimento da Indústria e do comercio exterior, $(2003)^{7}$

Pela tabela destaca-se o uso da eletricidade para aquecimento de água e a importação dos aquecedores instantâneos a gás.

\footnotetext{
${ }^{4} 1 \mathrm{~m}^{2}$ de coletor solar gera $0,7 \mathrm{kWth}$ - Fator de conversão adotado pelo IEA

${ }^{5}$ IBGE, Pesquisa Anual de Produção PIA - 2003. Tabela 1 - Produção e vendas dos produtos e ou serviços segundo classes de atividade e descrição de produtos - Brasil - 2003 http://www.ibge.gov.br/home/estatistica/economia/industria/pia/produtos/produto2003/pprodutos2003. pdf

${ }^{6}$ Dado do Ministério do desenvolvimento Industria e comercio exterior. Site: http://aliceweb.desenvolvimento.gov.br/default.asp . Acesso em 12/01/2007

${ }^{7}$ As fontes não detalham o tipo de equipamento.
} 
1.5Revisão bibliográfica

As referências citadas a seguir contribuíram para a configuração do trabalho apresentado:

Fantinelli (2006) em sua tese de doutorado aborda a difusão da tecnologia termo-solar na moradia de interesse social. Um estudo sobre a aplicação da tecnologia termo-solar no Bairro Sapucaias mostra o comportamento desta população e a economia ocorrida com a redução da conta de energia elétrica. $O$ projeto Sapucaias ou Projeto Eletrobrás Solar foi desenvolvido na cidade de Contagem, no estado de Minas Gerais, por ação do setor público através da Eletrobrás, PROCEL, CEMIG e pesquisa do GREEN Solar da PUC-MG.

Fossa (2006) analisa a possibilidade de substituição de energia elétrica pelo gás natural no processo de aquecimento de água para uso em instalações prediais residenciais. A análise aborda o impacto econômico das alternativas em locais onde ocorra a adoção de políticas públicas de incentivo ao uso do gás natural considerando obrigatória a instalação hidráulica de água quente em habitações independentemente do tipo de sistema de aquecimento.

Benders, et al(2005) diferencia os programas de redução de energia residencial em dois tipos: específica e rápida ou generalizada e longa. Observa que os programas são destinados ao setor residencial, mas metade da energia residencial é de consumo direto, a outra metade é de consumo indireto. Foi utilizada uma ferramenta da web, para analisar o efeito dos programas de redução de energia residencial em 300 residências dos países baixos. Como resultado constatou-se uma redução de $8,5 \%$ na energia consumida diretamente, enquanto a redução na energia indireta se mostra estatisticamente insignificante.

Cohen et al (2005) em sua pesquisa aplica, um modelo para calcular o total de energia sobre bens e serviços em residências de diferentes classes sociais de onze cidades brasileiras. Para o propósito da pesquisa, 112 tipos de consumo foram agrupados em 12 itens: alimentação, cocção, vestuários, calçados, moradia, transporte, utilidades, remédios, educação, papelaria, comunicação e outros. Tem-se como resultado que (a) $76 \%$ da energia consumida é distribuída em 3 categorias: utilidades (31\%), transporte (28\%) e moradia (17\%) e (b) existe alto consumo indireto de energia, que deve ser planejado. 
Strapasson (2004) em seu estudo sobre energia térmica e o paradoxo da eficiência energética apresenta o elevado consumo de energia no setor residencial em usos finais térmicos, como calor de processo e aquecimento direto. Em calor de processo o chuveiro elétrico é o principal equipamento utilizado. Sendo que o Brasil poderia obter uma economia de energia elétrica com a substituição do chuveiro elétrico pelo sistema a gás ou através do uso de coletores solares.

Wong e Wang (2004) fazem uma revisão sobre os vários conceitos de Edifício Inteligente em diferentes direções. $O$ trabalho pontua níveis de necessidade do local de trabalho considerando o tempo de vida da edificação, seus equipamentos e investimentos permitindo desempenho técnico, bom investimento de construção, operação e manutenção, bem como uma flexibilidade futura, de modo a maximizar o investimento.

A Federação das Indústrias Termo Solares Européia (ESTIF, 2004) cita que sistemas de aquecimento termo-solar é uma implantação clássica de aproveitamento solar. Alguns modelos são fabricados desde 1953. Alguns paises como Israel, Turquia e China, utilizam estes sistemas, considerados uma solução popular, em residências.

Almeida (2003) faz uma avaliação econômica e ambiental da substituição de combustível elétrico e a gás natural no uso final residencial. É realizado um levantamento do uso de 17 combinações de equipamentos para aquecimento de água, aquecimento de ambiente e cocção elétrico e a gás natural. Considera-se a energia elétrica proveniente de planta de carvão.

Como resultado, a combinação de aquecimento de água e ambiente elétrico e a cocção a gás natural apresentam menor custo e promove menor emissão de carbono. Esta combinação apresenta elevado investimento, com tempo de retorno de 15 anos e apresenta uma relação de emissões de poluentes 3,5 vezes menor que a combinação mais poluidora.

$\mathrm{O}$ uso do gás natural implica em baixas emissões de $\mathrm{CO}_{2}$ e elimina a emissão de $\mathrm{SO}_{2}$ quando comparado ao uso de carvão e óleo. Contudo este estudo mostra que esta implicação não é linear, considerando que os impactos ambientais não são somente dependentes da fonte de energia, mas também de transformação na cadeia da geração à energia útil. 
Santos (2002) aponta o setor residencial como uma das estratégias para o uso do gás natural, na diversificação da matriz energética brasileira. Identifica que o uso do gás natural para aquecimento de ambiente nos países mais desenvolvidos do hemisfério norte é grande, enquanto que em regiões tropicais, esta necessidade é substancialmente menor. Na realidade brasileira o potencial do gás tem sido subestimado, pois uma vez que o gás natural chegue ao consumidor, ele pode apresentar versatilidade de usos representando uma parcela significativa da energia consumida. A eletrotermia não deve ser mantida, pois os custos para a sua manutenção a longo prazo são extremamente elevados. A política mais sustentável é promover a substituição da energia elétrica pelo gás natural nos diferentes processos térmico presentes em residências.

Diakoulaki (2001) explora a importância da tomada de decisão quanto ao investimento no uso de sistema de aquecimento de água solar fundamentado em custos que refletem os impactos ambientais e outros benefícios na Grécia. Grande parte dos recursos energéticos é garantida por petróleo e a eletricidade de uso residencial é gerada com linhito desde a crise do petróleo de 1970. O uso da eletricidade no setor da construção é crescente seguindo padrões altos, apesar das taxas elevadas impostas pelo governo. O linhito abastece $75 \%$ do total da demanda elétrica do país, causando grande impacto ambiental com alto índice de emissões de $\mathrm{CO}^{2}$ e particulados. O principal benefício incluído na análise é a energia elétrica economizada, o impacto ambiental evitado e a criação de empregos. Além disto o uso de coletores solares resultam em benefícios sociais quando em substituição pela eletricidade e óleo diesel, mas não sobre o GN, que entrou no mercado a partir de 1998.

Roland, Francis, Richard, et al. (1994) descrevem a teoria básica e seus parâmetros para aplicação de um modelo denominado de Sistema de planejamento em uso final residencial, desenvolvido pelo Instituto de Pesquisa de Energia Elétrica do estado da Califórnia (EUA). Este modelo aplicado essencialmente aos usos finais residenciais considera diferentes ambientes, levando em conta o padrão de residência, a região, o clima, os preços de combustíveis, o tipo e os custos de equipamentos, a distribuição de energia, a renda familiar, os sistemas de conversão de equipamentos e suas eficiências, o mercado local, o poder de compra dos consumidores. Os resultados permitem o planejamento e a supervisão da cadeia de produção, custo e mercado dos equipamentos, com o propósito de, a nível nacional, 
criar padrões de conservação de energia. Como uma das conclusões se observa que a simples comparação de números resultantes do modelo não é suficiente para direcionar políticas de energia. O poder de decisão fica entre o preço e custo de operação do equipamento. Sobre aquecedores de água, é estimado um modelo para prever uma divisão de mercado baseado no tipo de combustível.

loshimoto (1990), em seu estudo para análise de projetos de sistemas prediais de gás combustível considera alternativas que podem resultar em soluções técnicas e economicamente viáveis. O estudo propõe um dimensionamento hidráulico comum aos tipos de gases do mercado. 


\section{METODOLOGIA}

A análise das alternativas de sistemas de aquecimento de água determina 0 custo do serviço de água quente, em edificações, ao longo de sua vida útil, considerando-se os custos de investimento e operações.

A análise é aplicada a 3 tipologias residenciais representativas no setor da construção civil da Região Metropolitana de São Paulo (RMSP). Estão adotados parâmetros técnicos e econômicos de combinação de custos de implantação do sistema e do preço de energia final. Este custo está apresentado em função do volume de água quente consumido no ponto de uso.

\subsection{Análise econômica das alternativas para aquecimento elétrico e de gás}

Os sistemas de aquecimento de água possuem alternativas de fontes de calor, configurações e equipamentos. Para o serviço de água quente em edificações é necessária uma infra-estrutura específica para suprir os equipamentos e pontos de uso, garantindo a operação do sistema com segurança e otimização de recursos.

O custo total (ct) é a soma dos custos de investimentos (cl), mais o custo da energia para a operação $(c e)$ e os custos de manutenção $(\mathrm{cm})$, na produção de energia útil do sistema.

$$
c t=c i+c e+c m
$$

O custo de investimento $(c l)$ é o custo de infra-estrutura da edificação (linf) somado aos custos dos equipamentos (le) necessários para a disponibilidade da alternativa de aquecimento na edificação. Os custos parciais de investimento (linf e le) são multiplicados pelo respectivo fator de recuperação de capital $(F R C)$. 0 resultado é dividido pela quantidade de energia útil produzida anualmente.

$$
c i=\frac{I \inf ^{*} F R C \inf }{\text { Energia útil }}+\frac{I e^{*} F R C e}{\text { Energia útil }}
$$


O Fator de Recuperação de Capital $(F R C)$ utiliza o juro anual e fornece um coeficiente que permite, a partir do valor do investimento, calcular o custo fixo anual referente a este. Este cálculo considera a vida útil de utilização da infra-estrura ou do equipamento ao longo do período da análise econômica ( $\mathrm{Nj}$ ).

$$
F R C=\frac{i}{1-(1+i)^{-N j}}
$$

Onde:

$$
\begin{aligned}
& N j=\frac{\text { vida útil }}{\text { horas de utilização }} \\
& \text { Energia útil }=m^{*} c^{*} \Delta T
\end{aligned}
$$

Onde:

$m$ = massa de água aquecida

$c=$ calor específico da água

$\Delta T=$ acréscimo da temperatura da água

O custo de energia final (ce) considera o preço da energia $(P e)$ e a eficiência do $\operatorname{sistema}\left(\eta_{s}\right)$.

$$
c e=\frac{P e}{\eta_{s}}
$$

A eficiência do sistema é a eficiência na conversão $\left(\eta_{c}\right)$ e no transporte $\left(\eta_{t}\right)$ de água quente.

$$
\eta_{s}=\eta_{c} * \eta_{t}
$$

Os custos de manutenção incluem limpezas e substituições ao longo da vida útil dos equipamentos e sistemas. Durante o levantamento dos procedimentos de manutenção e seus custos, as informações apresentaram grandes divergências (variando de irrelevante a muito significativa) entre fabricantes, instaladores, projetistas e pesquisadores. Portanto, devido a estas divergências este trabalho não 
considera o custo manutenção dos sistemas, mas a substituição do mesmo ao término de sua vida útil.

Assim o modelo de análise apresenta o custo anualizado de investimento e operação dos sistemas.

\subsection{Tipologias}

Como o universo de infra-estrutura e demanda de água quente é amplo este estudo caracteriza três tipologias, com diferentes disponibilidades de uso de água quente. Estas tipologias são consideradas típicas nas vendas de construção civil na Região Metropolitana de São Paulo ${ }^{8}$ e representam as vendas de $28,5 \%, 27,1 \%$ e $36,3 \%$ de edificações com respectivamente 2 dormitórios e 1 banheiro, 3 dormitórios e 3 banheiros e 4 dormitórios e 4 banheiros e um lavabo ${ }^{9}$. As características destas tipologias podem ser consultadas com maiores detalhes no ANEXO A.

Verifica-se que as tipologias atendem aos requisitos necessários para as instalações dos sistemas de aquecimento em estudo, em conformidade com as normas técnicas e de segurança das distribuidoras de energia e código de obras e edificações da região metropolitana de São Paulo.

\subsection{Parâmetros adotados para comparação econômica das alternativas}

Para a aplicação do modelo econômico, parâmetros foram adotados para cada uma das alternativas dos sistemas de aquecimento. Tempo da análise econômica, tempo de vida útil de cada equipamento, eficiência na conversão e transporte de calor, custos de infra-estrutura, custo de equipamentos e preços de energia são os parâmetros definidos e apresentados no capítulo 6 , para a análise econômica das alternativas.

\footnotetext{
${ }^{8}$ Pesquisa realizada pelo SECOVI-SP Sindicato das Empresas de Compra, Venda, Locação e Administração de Imóveis Residenciais e Comerciais de São Paulo http://www.secovi.com.br/empty.php?local=/pesquisa/mercado/index.htm. Setembro de 2006. ${ }^{9}$ O mercado da construção civil a identifica a quantidade de banheiros separadamente em social, serviço e lavabo.
} 
2.4 Análise econômica utilizando energia solar como economia de energia paga pelo usuário

O sistema solar de aquecimento de água não é autônomo, depende de parâmetros meteorológicos, exigindo, portanto uma energia auxiliar.

Com o uso da tecnologia solar, o custo anual de energia para o serviço de aquecimento de água altera-se. No custo investimento acrescenta-se os custos dos coletores solares somados aos da infra-estrutura hidráulica e no custo energia considera-se a Taxa de Cobertura Solar (TCS).

$$
\text { onde : } \quad c e=\frac{P e}{\eta_{s}}(1-T C S)
$$

Para a aplicação do modelo econômico com a inclusão do sistema solar, adota-se parâmetro de irradiação solar, Taxa de Cobertura Solar e eficiência média diária anual do coletor solar. Os parâmetros estão apresentados no capítulo 7 Energia solar como economia de energia paga pelo usuário. 


\section{SISTEMAS DE AQUECIMENTO DE ÁGUA}

Os projetos de sistemas de aquecimento de água devem atender aos mecanismos para o melhor desempenho de seus aquecedores e a otimização de recursos energéticos e dos custos de operação. Entre os diferentes sistemas de aquecimento, este estudo compara aqueles que utilizam gás ou eletricidade, com e sem energia termo-solar, por transferência direta de calor para a água. A transferência direta não utiliza fluído intermediário. Os sistemas de aquecimento de água são constituídos de aquecedores e mecanismos que devem estar compatíveis com a infra-estrutura da edificação e demandas necessárias ao usuário. Este capítulo apresenta os sistemas de aquecimento e as características técnicas necessárias à operação.

\subsection{Conversão de energia final em útil}

Os parâmetros de conversão de energia final em útil são associados às fontes térmicas, potência dos aquecedores e eficiências na conversão e transporte de calor.

a) Energia útil: quantidade de calor no ponto de uso. A demanda de água quente necessária no ponto de uso define esta energia.

b) Energia final: quantidade de energia fornecida ao sistema de aquecimento. Esta energia depende da fonte de calor utilizado no sistema e das eficiências na conversão e transporte da água aquecida.

c) Potência útil do aquecedor $(P u)$ : quantidade de calor por unidade de tempo absorvida pela água, expressa em $\mathrm{kW}$ ou $\mathrm{kcal} / \mathrm{min}$.

d) Potência nominal do aquecedor $(P n)$ : quantidade de calor por unidade de tempo fornecida pela fonte de calor ao aquecedor, expressa em $\mathrm{kW}$ ou $\mathrm{kcal} / \mathrm{min}$.

e) A eficiência do sistema $(\eta s)$ é a eficiência na conversão $\left(\eta_{c}\right)$ e no transporte $\left(\eta_{t}\right)$ de calor.

$$
\eta_{s}=\eta_{c}^{*} \eta_{t}
$$


f) Eficiência de conversão $\left(\eta_{c}\right)$ : relação entre a potência útil e a potência nominal do aquecedor, expressa em porcentagem.

$$
\eta_{c}=\frac{P u}{P n}
$$

g) Eficiência de transporte $\left(\eta_{t}\right)$ : é o resultado da perda de calor na infra-estrutura da edificação.

$$
\eta_{t}=\frac{P_{n} * \eta_{c}-P_{d}}{P_{n} * \eta_{c}}
$$

onde:

$$
\begin{aligned}
& P_{n} * \eta_{c}=\text { potência de saída do equipamento } \\
& P_{d} \text { é a potência dissipada na tubulação. }
\end{aligned}
$$

h) Para equipamentos de acumulação são necessárias as caracterizações do volume do reservatório e a capacidade de recuperação de calor.

\subsection{1 - Eletricidade como fonte de calor}

A transferência de calor ocorre através do contato de um resistor, aquecido eletricamente, imerso em água. Este resistor, quando conectado à energia da rede de distribuição elétrica, aquece-se com a circulação de corrente, fenômeno denominado de efeito Joule.

A quantidade de calor por unidade de tempo $(P n)$ liberada pelo resistor é função da tensão de alimentação $(U)$ e do valor do resistor $(R)$. O controle de potência do equipamento $(P n)$ se faz pela alteração do valor do resistor .

$$
P n=\frac{U^{2}}{R}
$$




\subsection{2 - Gás como fonte de calor}

A geração de calor a gás ocorre com a combustão do gás com o ar atmosférico, a partir de uma centelha, no queimador. $O$ calor gerado atinge um trocador que transfere a maior parte desta energia para a água.

A quantidade de calor por unidade de tempo $(P n)$ liberada pela combustão do gás é dependente do poder calorífico superior $(P C S)$ e da vazão volumétrica $\left(V_{o}\right)$ do gás. O controle de potência do equipamento $(P n)$ se faz pela alteração da vazão do gás no queimador.

$$
P n=P C S \cdot v_{o}
$$

\subsubsection{Sol como fonte de calor}

O sol emite energia sob forma de ondas eletromagnéticas denominadas de radiação solar. O coletor solar tem como propriedade absorver e transferir o calor destas ondas, em geral para a água que circula em tubos em seu interior.

A irradiação solar diária incidente $(H t)^{10}$ no plano do coletor determina a quantidade de calor por unidade de tempo fornecida ao coletor solar. Esta irradiação varia em função dos parâmetros meteorológicos e geográficos do lugar onde o coletor se encontra localizado, tais como latitude local, número de horas diárias de insolação, refletividade do solo e inclinação do coletor solar.

A energia absorvida pelo coletor (Qcs) é proporcional à irradiação solar diária incidente no plano do coletor $(H t)$, em função de sua área $(A)$ e de sua eficiência média diária solar $\left(\eta_{c}\right)$.

$$
Q_{c s}=H t \cdot A \cdot \eta_{c}
$$

Na prática não é realizado o controle sobre a potência fornecida pelo coletor.

\footnotetext{
${ }^{10}$ Energia incidente por metro quadrado
} 
3.2 Configurações das alternativas dos sistemas de aquecimento

Para o aquecimento existem alternativas de sistemas que variam em função das fontes de calor e configurações dos aquecedores. Os sistemas podem atender um ou mais pontos de uso em edificações unifamiliares ou multifamiliares.

Os aquecedores podem ser instantâneos ou de acumulação. $O$ aquecedor instantâneo aquece a água no momento do uso, devendo ter uma potência nominal $(\mathrm{Pn})$ que propicie o acréscimo instantâneo de temperatura na água.

O aquecedor de acumulação utiliza uma menor potência nominal (Pn) aquecendo a água de forma mais lenta. Conseqüentemente a água precisa ser armazenada e mantida aquecida em um reservatório, de maneira que permita o seu uso em uma demanda pré-dimensionada em volume e temperatura.

Portanto, em função das características do aquecedor e do serviço de água quente, pode-se ter várias alternativas para o aquecimento de água. Os sistemas se diferenciam essencialmente:

$>$ na forma de energia final;

$>$ no circuito de distribuição de água quente;

$>$ nos componentes de vazão de água e potências dos aquecedores;

$>$ no armazenamento da água quente.

Este estudo considera como sistema de aquecimento o conjunto de componentes do aquecedor da entrada da fonte de calor aos pontos de uso.

As configurações das alternativas de sistemas de aquecimento estão aqui denominadas de acordo com o tipo de aquecedor e distribuição de água quente:

(1) Sistema instantâneo individual (II). Composto por aquecedor instantâneo individual, cada aquecedor atende um só ponto. Nesta classificação encontramse os chuveiros. Este sistema é privativo.

(2) Sistema instantâneo central (IC). Aquecedor distante do(s) ponto(s) de uso e atende a uma residência. Este aquecedor é denominado de instantâneo central ou de passagem. Este sistema é privativo.

(3) Sistema acumulação privativo (AP). Aquecedor com reservatório e atende a uma residência. Este aquecedor é também conhecido como boiler elétrico ou a gás.

(4) Sistema acumulação coletivo (AC).Aquecedor com reservatório e atende a várias residências. Sistema conhecido como central coletivo. 
A figura 3.1 apresenta as alternativas das configurações dos sistemas de aquecimento elétrico, a gás e solar.

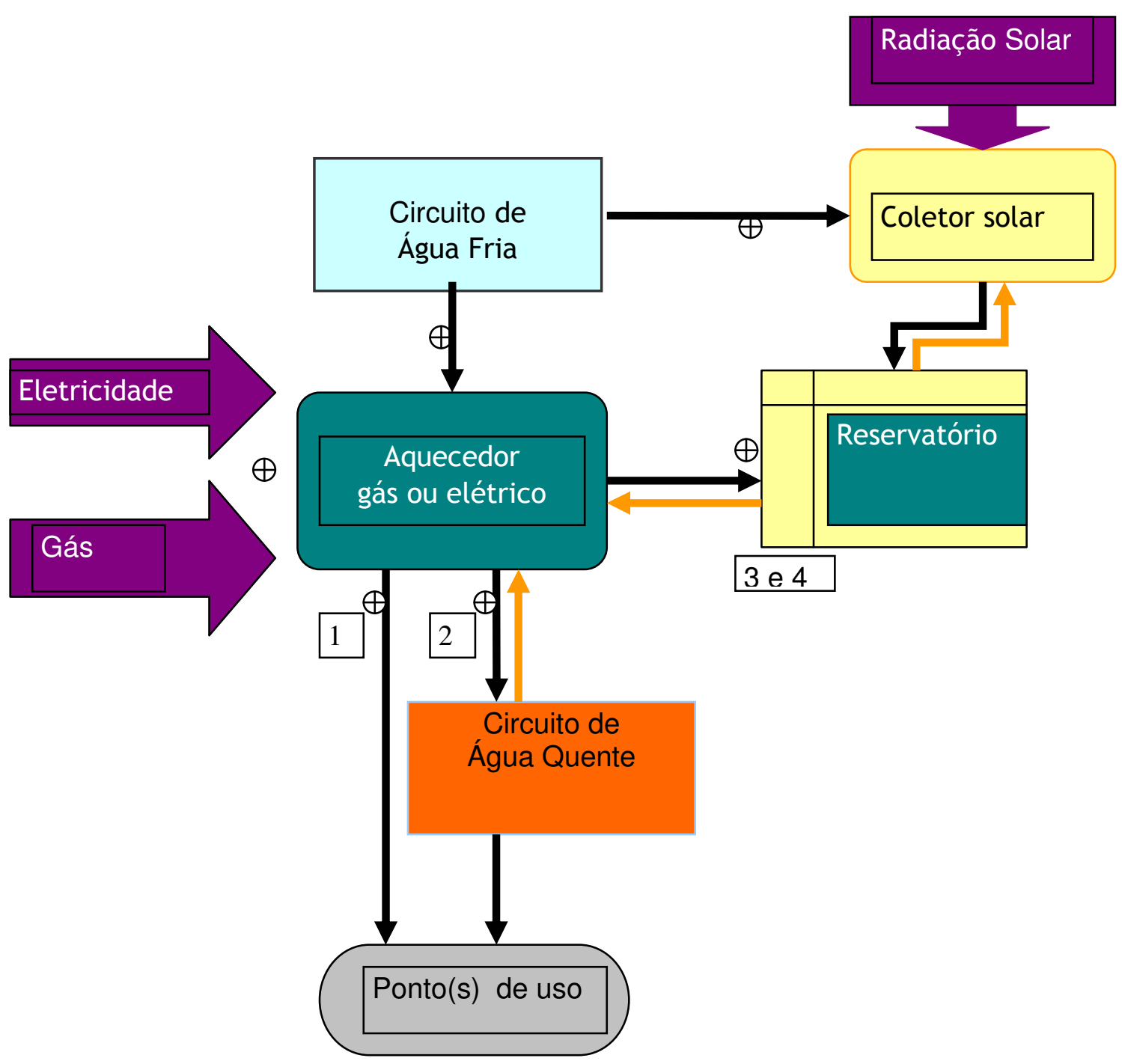

Fig 3.1 Configurações dos sistemas de aquecimento elétrico, gás e solar

Para dimensionamento de infra-estrutura de água quente os sistemas de aquecimento anteriores são classificados em uma edificação como individual (1), central privado (2 e 3) e central coletivo (4) (ILHA, et al.;1996). O sistema central privado é o unifamiliar enquanto o central coletivo é o multifamiliar. 


\subsection{Características de funcionamento}

Os aquecedores e seus sistemas devem funcionar dentro dos padrões estabelecidos pela Associação Brasileira de Normas Técnicas (ABNT): instalações hidráulicas de água fria e água quente, instalações elétricas de baixa tensão, instalações de aparelhos a gás e requisitos dos ambientes, redes de distribuição interna de gases combustíveis e instalações de aquecimento solar de água ${ }^{11}$.

Para este estudo primeiramente foram relacionados os equipamentos disponíveis no mercado, com suas características técnicas e seus requisitos necessários ao adequado desempenho. Esta relação foi realizada junto a Associação Brasileira da Indústria Elétrica e Eletrônica (ABINEE), Associação Brasileira de Aquecimento a Gás (ABAGAS), Associação Brasileira de Refrigeração, Ar condicionado, Ventilação e Aquecimento (ABRAVA), Programa Brasileiro de Etiquetagem (PBE), Instituto Nacional de Metrologia, Normalização e Qualidade Industrial (INMETRO), e fabricantes ou revendedores de equipamentos. O ANEXO B apresenta esta relação ${ }^{12}$.

Nem todos os dados estão facilmente disponíveis em catálogos, manuais e mesmo referenciados nos regulamentos do Programa Brasileiro de Etiquetagem (PBE). Por este motivo o ANEXO B apresenta lacunas, devido à indisponibilidade ou até mesmo a uma falta de padronização de características comuns aos aquecedores para as diferentes formas de calor.

Os aquecedores devem receber alimentação pré-estabelecida da fonte de calor e água na pressão especificada para que ocorra o adequado desempenho da conversão e transferência de energia nos aquecedores elétricos, a gás e solar. Para que este adequado desempenho ocorra a infra-estrutura deve ser dimensionada em conformidade com estes requisitos.

A relação dos aquecedores apresentados no Anexo $B$, mostra uma tendência à uniformização nas entradas de água fria, saída de água quente e entrada de gás nos quesitos pressão e diâmetro das tubulações. Esta tendência à uniformização facilita o dimensionamento e a instalação da infra-estrutura dos circuitos de água fria e água quente para diferentes potências e vazões de funcionamento dos aquecedores.

\footnotetext{
${ }^{11}$ Conjunto de normas técnicas que estão referenciadas ao longo do texto.

12 Levantamento realizado entre agosto e outubro de 2006.
} 


\section{Conformidade dos sistemas às regulamentações}

\subsection{Introdução}

No Brasil políticas nacionais de conservação e uso racional de energia vêm sendo adotadas, com a criação de órgãos direcionados a promover a racionalização do uso da energia elétrica e de combustíveis. Órgãos públicos, ministérios, agências reguladoras federais e estaduais, em conjunto com outras do mercado têm o dever de estabelecer padrões através de regulamentos e normas que visem à qualidade do serviço no fornecimento da energia final, conservação, uso racional e segurança para o funcionamento dos sistemas de conversão de energia final em útil.

Cada um dos sistemas de aquecimento de água requer requisitos próprios, a dificuldade se encontra em estabelecer limites entre padrões de qualidade e segurança com o interesse de investimento dos empreendedores. Estes requisitos impõem limites que aumentam os custos de instalações e operação dos sistemas de aquecimento que devem ser repassados ao mercado consumidor; quanto maior estes padrões, maior o custo do investimento.

Este capítulo de conformidade dos sistemas de aquecimento às regulamentações procura descrever alguns requisitos técnicos dos sistemas de aquecimento.

\subsection{Aquecimento elétrico}

A norma NBR-5410: Instalações elétricas de baixa tensão, em sua revisão de 2004, no item Proteção contra choques elétricos, provocados por equipamentos e seus circuitos apresenta dois tipos de proteção: a básica e a supletiva. A proteção básica solicita (a) isolação ou separação básica, (b) uso de barreira ou invólucro e (c) funcionamento nos limites de tensão, enquanto que a proteção supletiva inclui (d) equipotencialização das cargas, (e) isolação suplementar e separação elétrica.

As exigências para as instalações de aquecedores de acumulação elétrica não representam nenhum obstáculo significativo diferente de qualquer outro equipamento elétrico em uma residência.

As restrições mais significativas concentram-se quando a opção é o aquecimento elétrico instantâneo. Este, popularmente denominado de chuveiro elétrico, contém as proteções básicas, consideradas parciais contra choque elétrico. 
Esta proteção parcial é admitida mediante colocação do chuveiro fora de alcance, em locais acessíveis somente para pessoas advertidas, mediante aviso obrigatório, ou pessoas qualificadas.

Como regra geral, a proteção contra choque elétrico deve conter a proteção básica e a supletiva. Os chuveiros elétricos com resistência blindada, denominados de duchas, atendem a proteção básica e suplementar contra choque elétrico, mas este é encontrado no mercado a um preço cerca de dez vezes maior que o do chuveiro popular e é vendido por propiciar um banho mais confortável e não por estar dentro dos padrões de segurança. A aquisição do popular chuveiro elétrico é feita pelo próprio usuário, que na maioria das vezes desconhece a diferença de segurança, mas enxerga a grande diferença de preço entre eles.

O chuveiro elétrico é considerado um democratizador do uso de água quente para a população brasileira devido ao seu baixo custo de aquisição e facilidade de instalação e manutenção. Os chuveiros utilizados simultaneamente, em função de hábitos de consumo, exigem do sistema elétrico uma maior capacidade instalada para suprir esta demanda, no denominado horário de ponta. Em cidades grandes de regiões frias do Brasil, pode aparecer a necessidade de investir recursos financeiros com este propósito.

\subsection{Aquecimento a gás}

O mercado de gás está se acomodando ao novo cenário nacional residencial, com a retirada do subsidio do gás liquefeito de petróleo e o aumento de oferta de gás natural. Recentemente, normas pertinentes ao setor residencial estão em processo de revisão para uniformizar o uso dos diferentes gases disponíveis no mercado: gás natural, gás liquefeito do petróleo e gás manufaturado reformado. Estas normas são: (a) Projeto Norma 402.02-051- Redes de distribuição interna de gases combustíveis - Projeto e execução ${ }^{13}$. (b) NBR-13.103 - Instalações de aparelhos a gás para uso residencial - Requisitos dos ambientes e (c) NBR 13.523Central de Gás Liquefeito de Petróleo

$\mathrm{Na}$ cidade de São Paulo as edificações novas, ou as que sofrem grandes reformas, são obrigadas a terem instalação permanente de gás, no mínimo para

\footnotetext{
${ }^{13}$ Em consulta pública 20/03/2007. Fonte: ttp://www.abntnet.com.br/consultanacional/default.aspx
} 
fogão, independente se o logradouro é abastecido por redes de gás canalizado ou não ${ }^{14}$. Esta lei facilita o uso do sistema de aquecimento de água a gás: uma vez que a edificação possua infra-estrutura de gás para cocção, fica mais fácil utilizar o gás para a produção de água quente. O projeto de norma CB-09:402.02-051- Redes de distribuição interna de gases combustíveis - Projeto e execução, regulamenta a instalação para os diferentes gases do mercado. Apesar destes apresentarem diferentes características, esta norma prevê uma única instalação de rede interna para os diferentes gases combustíveis propiciando ao consumidor, alternativa na escolha do tipo de gás.

Quanto ao uso do gás para aquecimento de água alguns requisitos são necessários para a segurança do ambiente. Necessariamente 0 aquecedor deve possuir válvula de gás totalmente mecânica acionada pela força e fluxo da água, e também a chama piloto de funcionamento permanente ou não para a ignição do sistema. Sem a presença desta chama, o gás não é liberado para o queimador. Além desses sistemas de segurança, existe também o sensor de temperatura no queimador, sensor analisador de oxigênio e para alguns modelos o controle de fuligem na exaustão. Os dispositivos de segurança aumentam o custo do aquecedor e com a criação de diversos modelos, surgem diferentes modos de instalação para o mesmo serviço, que exige conhecimento detalhado de projetistas, instaladores e usuários.

Na utilização do sistema de aquecimento a gás, o projeto de infra-estrutura predial deve prever uso em ambiente com volume de no mínimo $6 \mathrm{~m}^{3}$, com ventilação permanente e, para a maioria dos modelos, duto que assegura 0 escoamento dos gases da combustão do aquecedor ao ambiente externo ${ }^{15}$. Estes requisitos de ventilação mínima e instalação de dutos estão exemplificados na figura 4.1. Os requisitos de volume, ventilação e duto refletem no aumento de custo da infra-estrutura, necessidade de espaço disponível para a instalação do sistema e na sua instalação.

\footnotetext{
${ }^{14}$ Código de obras de SP. Vei n¹1.228/ 25-06-1992 e Decreto nํ32.329/23-09-1992

${ }^{15}$ Especificado na norma NBR- 13103 - Instalações de aparelhos a gás para uso residencial Requisitos dos ambientes.
} 


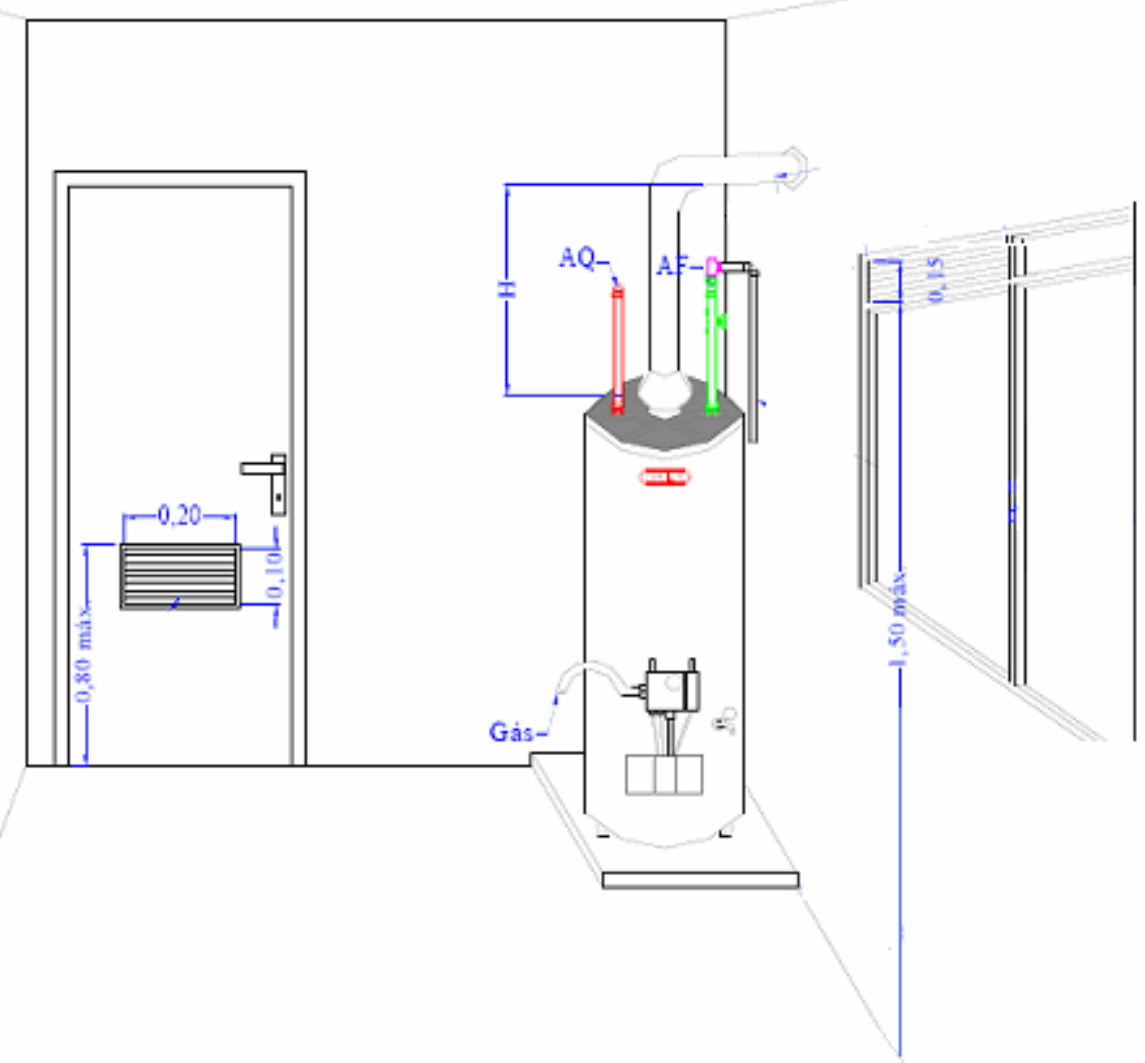

Figura. 4.1 Exemplo de requisitos de ventilação mínima e instalação de dutos

Fonte: Cumulus - Produtos: Manual Aquecedor de acumulação

As especificações da norma de instalações NBR-13.103, a partir de 2006 passam a permitir a instalação do aquecedor instantâneo individual, diretamente no ponto de uso. Este aquecedor, conhecido como chuveiro a gás, tem em média a potência de $4.500 \mathrm{kcal} / \mathrm{h}$ (aproximadamente 5,3kW) e vazão de 3 litros por minuto.

No Estado do Rio de Janeiro, o regulamento de instalações prediais de gás já autorizava esta instalação, e a CEG Rio, desde o começo dos anos 80 , vem atuando fortemente no mercado popular da construção civil com a instalação destes aquecedores instantâneos individuais em grandes condomínios ${ }^{16}$.

\footnotetext{
${ }^{16}$ Condomínio Pontões da Barra, na Barra da Tijuca e o Condomínio Riocentro em Jacarepaguá .Informação verbal fornecida por Departamento Gerencia Norte, CEG em maio de 2004.
} 
A norma de instalações é de nível nacional, o que faz com que distribuidoras de gás de regiões mais frias, como é o caso da COMGAS, sejam mais cautelosas neste uso devido a diferenças climáticas e falta de cultura no uso deste sistema.

A Petrobrás (2004) ${ }^{17}$ em seu Projeto de Avaliação e Desenvolvimento de Novos Equipamentos Domésticos para uso de gás Natural - Gasdoméstico versus Eletrodomésticos, compara os chuveiros a gás e elétrico nos quesitos: custo de aquisição e operação, comodidades, facilidades, acessórios e aparência física, aspectos construtivos, durabilidade e instalação (segurança) e chega ao resultado de que ambos são competitivos. Argumentos desfavoráveis em termos de design ou operacionalidade do chuveiro a gás são rebatidos pela grande vantagem em termos econômicos ${ }^{18}$.

\subsection{Sistema Solar e as externalidades}

A simples inserção do sistema de aquecimento de água solar não significa um bom aproveitamento desta fonte. O não conhecimento das características deste sistema pode levar a uma instalação em que a energia solar não é bem aproveitada, provocando a operação do sistema auxiliar de energia que utiliza as fontes convencionais de energia (gás e eletricidade).

As instalações solares necessitam ser corretamente dimensionadas, instaladas e mantidas. Para isso, aspectos externos aos requisitos técnicos devem ser verificados, tais como: (a) sombra nos coletores, por exemplo, causada por antenas e caixa de água; (b) sombra no sensor de temperatura do reservatório; (c) posicionamento conveniente da superfície do coletor; (d) menor trajeto na rede hidráulica entre coletores e o reservatório; (e) boa avaliação para a definição da logística adequada para a instalação dos componentes do sistema; (f) instalação elétrica para circuito de controle de temperatura; (g) identificação de dificuldades de acessibilidade aos coletores para manutenção; (h) estrutura de obra civil para a instalação dos componentes do sistema. O projeto de norma NBR- 12.269 -

\footnotetext{
${ }^{17}$ P044 - Avaliação e desenvolvimento de novos equipamentos domésticos para o uso de GN (NAEDGN) Fonte: RedeGas-Energia da Petrobrás.

${ }^{18}$ Os cálculos econômicos foram baseados nos seguintes critérios: Custos operacionais calculados à base das tarifas : CEG RIO S.A. - Gás Natural, consumidor residencial - faixa $24-83 \mathrm{~m}^{3} / \mathrm{mês}=\mathrm{R} \$$ $3,2041 / \mathrm{m}^{3}$ e LIGHT RIO S.A. - Eletricidade, consumidor residencial $=\mathrm{R} \$ 0,44173 / \mathrm{kWh}$
} 
Instalação de sistemas de aquecimento solar de água em circuito direto Procedimento ${ }^{19}$, procura orientar o projetista e instalador para estas verificações.

\subsection{Programas de eficiência no uso final}

Criado em 1981, o CONSERVE foi o primeiro programa significativo de eficiência energética a nível nacional, como conseqüência dos impactos sobre o preço do petróleo durante a década de 70 surgiram dois programas expressivos de substituição de petróleo, o CONSERVE e o PROALCOOL. Sob a coordenação do Ministério da Indústria e Comércio, o CONSERVE tinha como objetivo a substituição de derivados do petróleo por eletricidade, para a obtenção de energia útil na forma de calor, pela disponível eletricidade de origem hidráulica. Este programa que teve grande repercussão foi incentivado através de financiamento para a substituição de derivados de petróleo pela eletricidade, e com isso o consumo elétrico aumentou de forma desordenada.

Em 1985, é criado o Programa Nacional de Conservação de Energia Elétrica (PROCEL) e em 1991 é criado o Programa Nacional da Racionalização do Uso dos Derivados do Petróleo e do Gás Natural (CONPET). Atualmente PROCEL e CONPET são órgãos direcionados a promover a eliminação do desperdício e reduzir os custos e investimentos setoriais, e são reportados ao Ministério de Minas e Energia, que em conjunto com o INMETRO, procuram atender ao decreto 4.059 de 19 de dezembro de 2001, o qual prescreve:

"Art. 10 Os níveis máximos de consumo de energia, ou mínimos de eficiência energética, de máquinas e aparelhos consumidores de energia fabricados ou comercializados no país, bem como as edificações construídas, serão estabelecidos com base em indicadores técnicos e regulamentação específica a ser fixada nos termos deste Decreto, sob a coordenação do Ministério de Minas e Energia."

Este decreto regulamenta a avaliação da eficiência energética em equipamentos bem como nas edificações, pelo Comitê Gestor de Indicadores e Níveis de Eficiência Energética (CGIEE). O Balanço de Energia Útil (BEU) aplicado ao uso final da energia por setor econômico permitiu a criação de critérios de avaliação de eficiência energética, implementado, assim, o Programa Brasileiro de

\footnotetext{
${ }^{19}$ NBR - 12.269 - Instalação de sistemas de aquecimento solar de água em circuito direto Procedimento
} 
Etiquetagem (PBE) para a melhoria ou substituição de equipamentos e conservação de energia.

Os aquecedores de água elétricos e a gás, coletores e reservatórios solares estão inseridos no PBE, o qual fornece a Etiqueta Nacional de Conservação de Energia (ENCE). O PBE, criado em meados dos anos 90, regulamenta os testes dos equipamentos coordenados pelo Instituto Nacional de Metrologia, Normalização e Qualidade Industrial (INMETRO) o qual é responsável pela etiquetagem, conferindo a garantia de conservação de energia.

Este programa poderia permitir uma padronização em seus testes e informações entre sistemas de diferentes fontes de calor. As informações divergentes são de níveis de consumo, capacidade, níveis de temperatura mínima. Esta diversidade de informações pode ser verificada pelo ANEXO B - Lista de equipamentos e também pelas Tabelas de consumo e eficiência energética fornecidas pelo INMETRO ${ }^{20}$.

Até o presente momento, o fato de um modelo de aquecedor ser certificado como energeticamente eficiente não é suficiente para definir que o sistema de aquecimento está sendo utilizado de forma eficiente. Para isso a eficiência deve considerar o planejamento de recursos integrados ao longo da cadeia de energia, da transformação de energia primária em útil.

\subsection{Considerações}

As imposições de regulamentações, que estabelecem limites de qualidade e segurança mínima, acabam exigindo procedimentos de funcionamento de equipamentos, instalações e operações dos sistemas de aquecimento que acarretam em aumento de custos. Estes custos acabam sendo repassados ao mercado consumidor, que por desconhecimento técnico é atraído pelo equipamento de menor custo inicial.

\footnotetext{
${ }^{20} \mathrm{http}: / /$ www.inmetro.gov.br/consumidor/tabelas.asp
} 


\section{CARACTERIZAÇÃO DAS INFRA-ESTRUTURAS ELÉTRICA E HIDRÁULICA PARA DIFERENTES DEMANDAS DE ÁGUA QUENTE}

\subsection{Infra-estrutura para aquecimento de água}

A infra-estrutura necessária para o aquecimento de água é determinada pela energia final da alternativa do sistema de água quente e da disponibilidade do serviço (número de pontos de uso na unidade consumidora).

Em edificações residenciais, os diferentes níveis de consumo de água quente estão relacionados com o número de pessoas e com o número de pontos de uso, parâmetros estes que podem ser estimados, através do número de dormitórios e de banheiros (ILHA, 1991). O número de pontos de uso de água quente é definido pela infra-estrutura da edificação. Um morador aciona o sistema de água quente no momento e na intensidade correspondentes a sua necessidade, conforme idade, hábito pessoal, estilo de vida.

Quanto à avaliação da infra-estrutura para aquecimento duas planilhas eletrônicas foram elaboradas, uma de dimensionamento elétrico e outra de dimensionamento de gás. As planilhas calculam os custos das instalações exclusivas para aquecimento de água das alternativas dos sistemas de aquecimento instantâneo e de acumulação que utilizem gás natural ou eletricidade.

Estas planilhas foram desenvolvidas no âmbito do projeto de pesquisa e desenvolvimento (P\&D) de Capacitação de Profissionais no Tema: Aquecimento de Água - Sistema Elétrico e Gás Natural nas Edificações Residenciais, desenvolvidos pela Fundação para o Desenvolvimento Tecnológico da Engenharia a pedido da COMGAS.

Os custos apresentados seguem cotação da Tabela de Composição de Preços para Orçamentos - PINI - TCPO 10, preço do mês de fevereiro de 2006 (Revista Construção e Mercado) e taxa de Benefícios e Despesas Indiretas (BDI) de $30 \%$. Os custos aqui apresentados não devem ser utilizados indiscriminadamente como preço exato final da infra-estrutura, pois em função de negociação construtoras obtêm descontos com fornecedores em relação aos preços pesquisados pela PINI. 
Este capítulo caracteriza a infra-estrutura destinada ao uso dos sistemas de aquecimento de água elétrico e a gás natural para três diferentes disponibilidades de água quente, para cada uma das tipologias. Cada uma das potências instalada para aquecimento está apresentada com o seu respectivo custo.

O sistema de aquecimento solar está apresentado no capítulo7 - Energia solar como economia de energia paga.

\subsection{Infra-estrutura elétrica}

\subsubsection{Dimensionamento da Infra-estrutura elétrica}

Neste estudo de infra-estrutura para aquecimento de água em edificações, a planilha de dimensionamento elétrico foi elaborada pelo autor para permitir a análise entre potência instalada para aquecimento de água e custos correspondentes. Esta planilha apresenta os (1) cálculos da demanda da entrada geral e da distribuição de energia do ramal de entrada à unidade consumidora, considerando os fatores de demanda e simultaneidade, a (2) relação de materiais, a (3) cotação dos mesmos e a (4) a diferença de custo entre a instalação com e sem os possíveis circuitos de alimentação para os aquecedores. A partir de entradas variáveis escolhem-se os aquecedores e a potência para a geração de água quente. O ANEXO C - Planilha Dimensionamento Elétrico apresenta, como exemplo 0 resultado do dimensionamento elétrico da edificação de 3 dormitórios com 3 chuveiros elétricos (02 sociais e 01 de serviço) instalados e respectiva lista de material.

Para cada tipologia, considera-se constante a demanda elétrica das cargas de iluminação e tomada de uso geral (TUG) das unidades consumidoras e a demanda da administração (que atende iluminação, tomadas, elevadores e bombas de uso comum ao condomínio). Os pontos para aquecimento de água para diferentes demandas são instalados em tomadas de uso específico (TUE) nas unidades consumidoras. Cada unidade consumidora tem a sua demanda de iluminação e tomadas de uso geral variando com a sua área em conformidade com o mínimo exigido pela Norma Brasileira de Instalações Elétricas em baixa tensão (NBR 5410). Está considerado que as cargas para iluminação e tomadas de uso geral totalizam a potência fixa instalada de 8,4 kVA, 13,64 kVA e 21,62 kVA, respectivamente para os 
apartamentos de 2, 3 e 4 dormitórios, já prevendo o circuito reserva. Nesta potência instalada, estão previstos os equipamentos como forno de microondas e máquina de lavar louça e roupa.

A planilha considera as alterações que ocorrem na lista de material com a inclusão ou retirada da disponibilidade de pontos de uso de água quente nas unidades consumidoras, considerando a mudança do fator de demanda e simultaneidade, desde a entrada de energia à unidade de consumo. $O$ dimensionamento da planilha está em conformidade com a norma técnica NBR 5410 - Execução de Instalações Elétricas de Baixa Tensão - Procedimento e Livro de Instruções Gerais - LIG BT 2005 - Fornecimento de Energia Elétrica em Baixa Tensão, da ELETROPAULO. A Figura 5. 1 apresenta o diagrama unifilar da distribuição para as 3 tipologias.

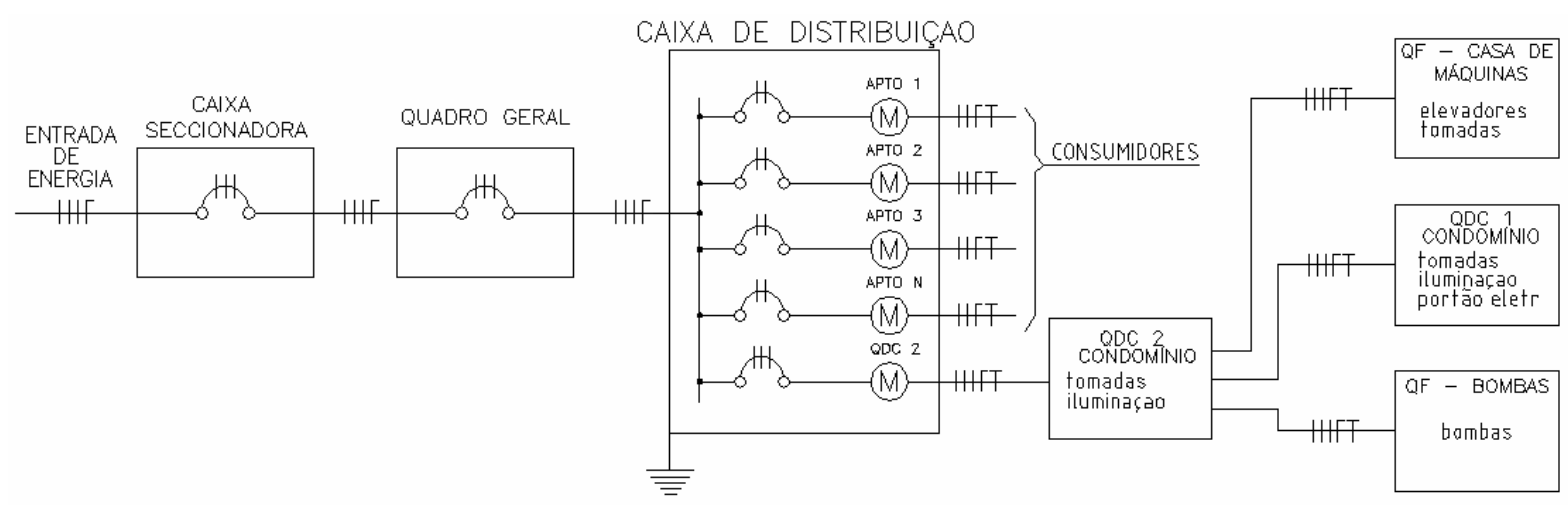

Figura 5.1 - Diagrama unifilar da distribuição das cargas elétricas

A planilha relaciona somente a lista dos materiais elétricos que são inclusos ou alterados com a variação da demanda. Os materiais considerados são cabos, eletrodutos, fusíveis e disjuntores da entrada de energia até o ponto de uso na unidade consumidora. Estes materiais representam $76,78 \%$ do total da infraestrutura elétrica, conforme levantamento feito para análise comparativa entre sistemas a gás e elétrico ${ }^{21}$. O resultado deste levantamento está apresentado no ANEXO C - Materiais representativos nas instalações elétricas. Os materiais de acabamento não foram considerados no total, em função da gama de preços e padrões de qualidade apresentados no mercado.

\footnotetext{
${ }^{21}$ Projeto P\&D - Aquecimento de Água - Sistema Elétrico e Gás Natural nas Edificações Residenciais Comgás -CHAGURI,2006- COMGÀS
} 
5.2.2 Requisitos necessários à infra-estrutura elétrica de água quente

Os aquecedores instantâneos aparecem no mercado com diversas denominações e diferentes aspectos físicos devido aos variados locais de instalação nos ambiente, conforme pode ser observado pela tabela de consumo e eficiência energética disponibilizada pelo Instituto Nacional de Metrologia e Normalização e Qualidade Industrial (INMETRO) 22 .

O aquecedor instantâneo elétrico está ligado diretamente no ponto de uso e aquece a água no instante do uso. A Figura 5. 2 ilustra um aquecedor instantâneo elétrico: Chuveiro elétrico com resistência blindada.

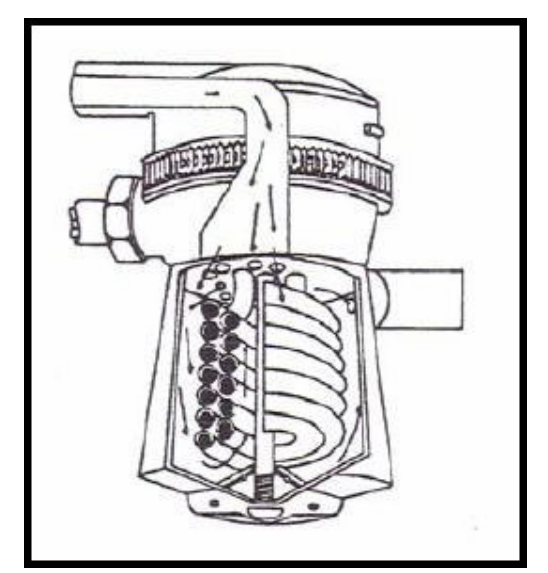

Figura 5.2 Chuveiro elétrico com resistência blindada.

Fonte: (ILHA,S.O.; Gonçalves, O.M.; Kavassaki,Y. 2006)

O aquecedor instantâneo central, normalmente instalado no ambiente de uso, atende a mais de um ponto e o seu controle de potência é comum a todos os pontos. Para as tipologias adotadas, este aquecedor é pouco utilizado por apresentar alta potência sobre um mesmo ponto (TUE). A Figura 5. 3 ilustra uma aplicação de aquecedor central elétrico.

${ }^{22}$ INMETRO - http://www.inmetro.gov.br/consumidor/tabelas.asp 


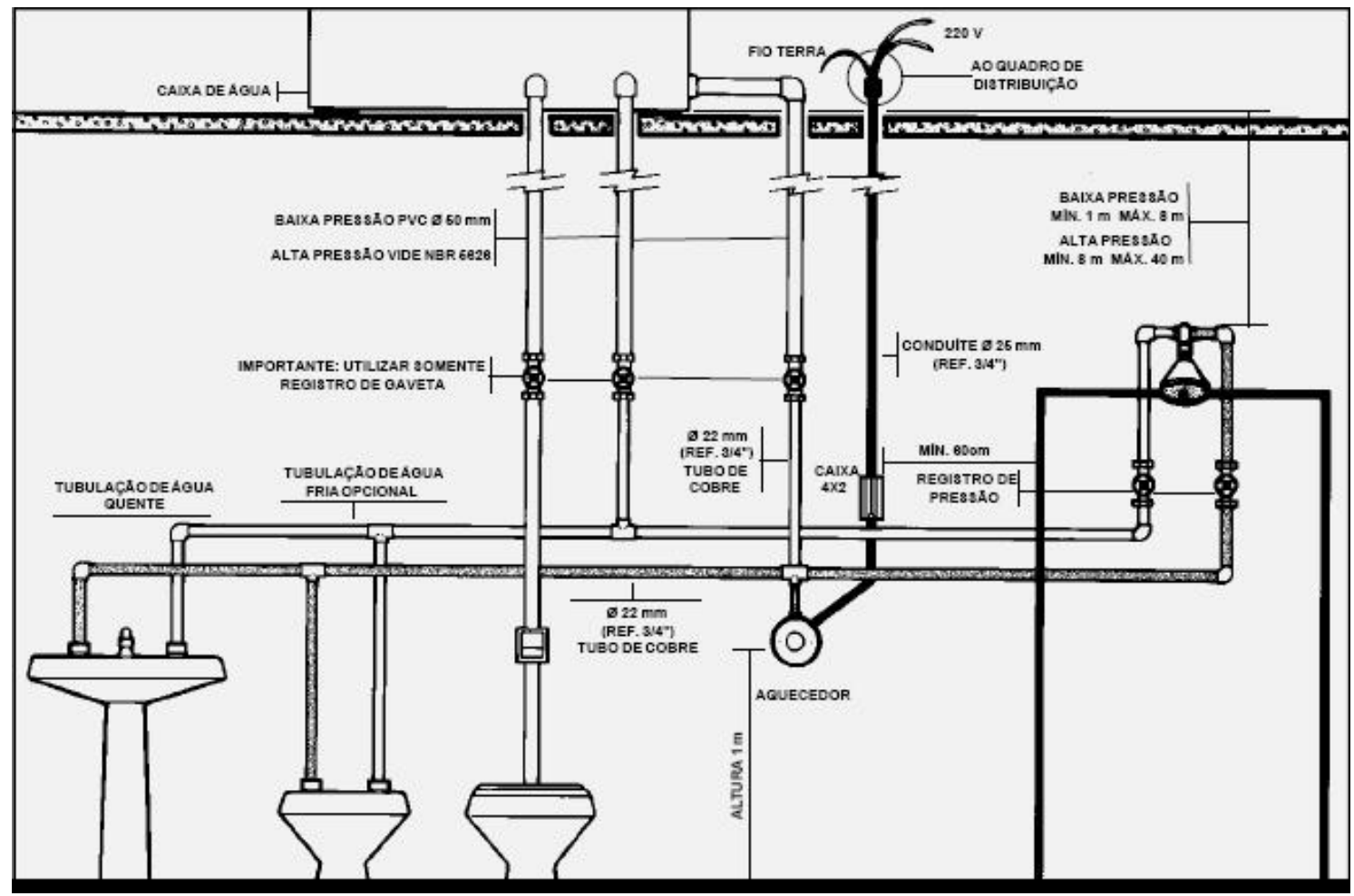

Figura 5.3 - Aquecedor instantâneo central elétrico

Fonte: http://www.cardal.com.br/frmaq_central.html

O aquecedor de acumulação, também conhecido como boiler elétrico, utiliza uma menor quantidade de calor por unidade de tempo (Pn) para aquecer a água, demandando, portanto maior tempo para aquecimento. A água é aquecida e armazenada em reservatório a uma temperatura acima do uso. O volume do reservatório e a capacidade de recuperação devem ser dimensionados em função da demanda prevista.

Para funcionamento de cada um dos aquecedores elétricos, a infra-estrutura deve propiciar no ponto de instalação do mesmo um circuito elétrico individual com uma ou duas fases. Para a proteção do circuito e do usuário o circuito deve possuir condutor ligado à terra e disjuntor diferencial residual (DR) para a circulação da corrente de fuga, e disjuntor termomagnético, na caixa de distribuição da unidade consumidora. A Figura 5. 4 esquematiza o circuito de alimentação e proteção de um aquecedor elétrico instantâneo ou de acumulação. 


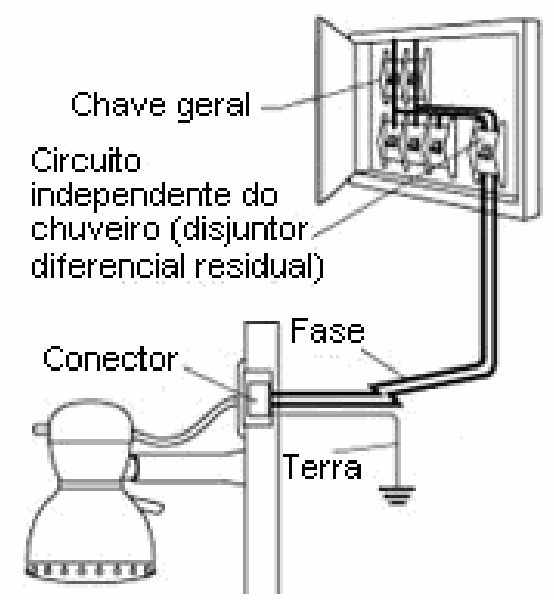

Figura 5.4 Esquema do circuito de alimentação e proteção do aquecedor elétrico.

Fonte: disponível em http:/www. corona.com.br.

\subsection{Infra-estrutura de gás}

\subsubsection{Dimensionamento de gás}

Para o dimensionamento da infra-estrutura de gás, considera-se a potência instalada para cocção e para o sistema de aquecimento de água. Para as 3 tipologias adotadas, este dimensionamento considera um fogão de 6 bocas de potência de $11.000 \mathrm{kcal} /$ hora para cocção e a variação na demanda de gás para o aquecimento. Este dimensionamento considera o fator simultaneidade de uso dos aquecedores para edificações, e está em conformidade com a norma de Instalações internas de gás natural (NBR 13.933). Para instalações dos aquecedores a gás foram contempladas as exigências da NBR 13103: Instalações de aparelhos a gás para uso residencial - Requisitos de instalações. Considerou-se para o projeto duas possibilidades: prumadas individuais com a central de medição no térreo e prumadas coletivas com os medidores localizados dentro dos apartamentos.

Como resultado, a planilha de dimensionamento de gás apresenta a potência total instalada por unidade consumidora e o custo desta infra-estrutura para a distribuição de gás por prumada coletiva e por prumada individual. Este custo representa $80,41 \%$ do total da infra-estrutura de gás, conforme pode ser visto no 
ANEXO E-Materiais representativos nas instalações de gás ${ }^{23}$. A Figura 5. 5 apresenta o custo de infra-estrutura na edificação de gás por potência instalada e na unidade consumidora, para a tipologia de 3 dormitórios, com distribuição de gás por prumada coletiva e prumada individual.

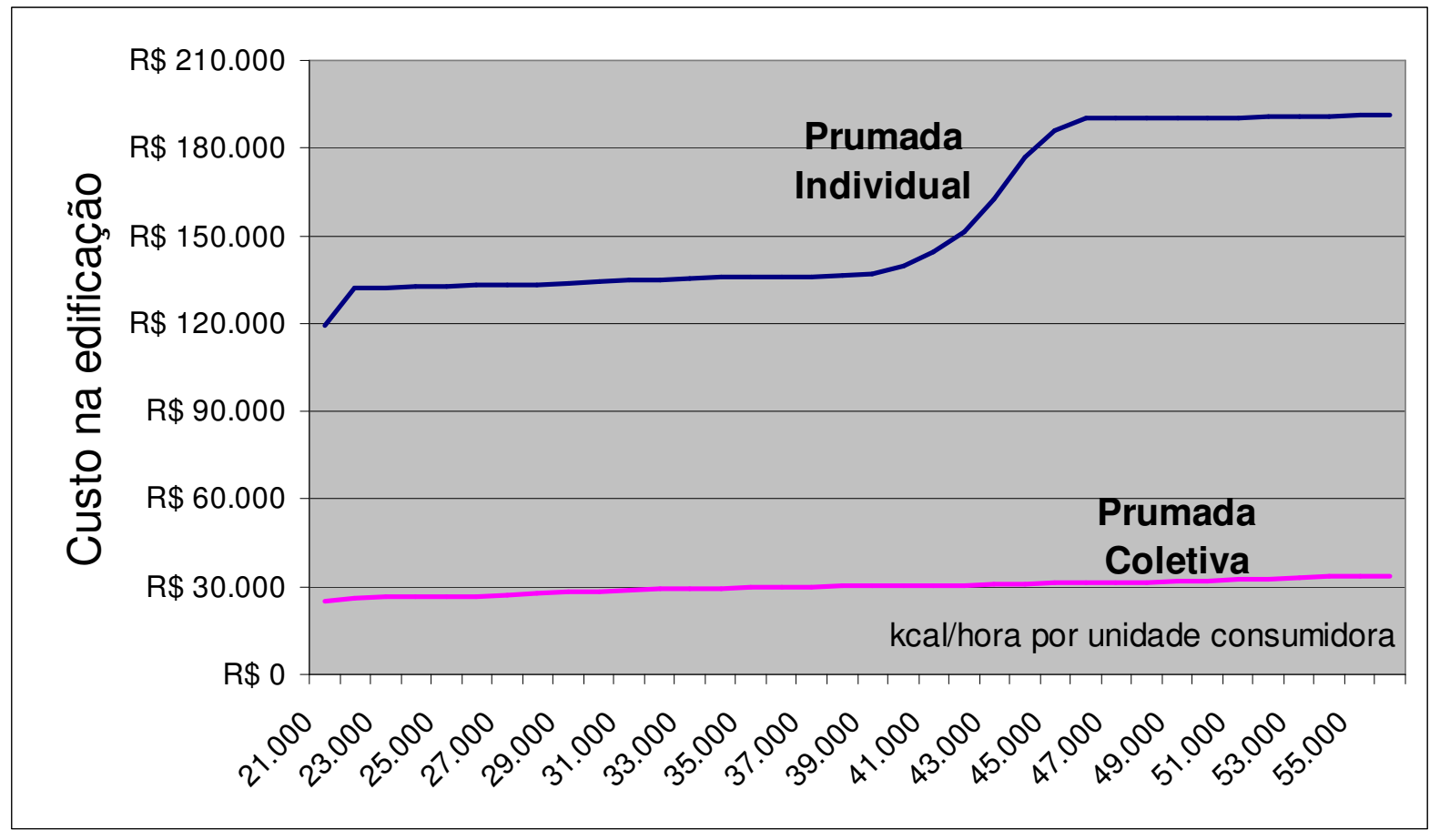

Figura 5.5 Custo na infra-estrutura de gás por potência instalada na unidade consumidora - Tipologia 3 Dormitórios

Fonte: Projeto de P\&D - Aquecimento de Água - Sistema Elétrico e Gás Natural nas Edificações Residenciais (CHAGURI, 2006).

O ANEXO $\mathrm{F}$ apresenta os gráficos do custo na infra-estrutura de gás por potência instalada na unidade consumidora para as tipologias de 2 e 4 dormitórios.

Observa-se que a distribuição de gás por prumada coletiva representa um custo menor de infra-estrutura.

\footnotetext{
${ }^{23}$ Projeto de P\&D - Aquecimento de Água - Sistema Elétrico e Gás Natural nas Edificações Residenciais - CHAGURI, 2006 -COMGAS
} 
5.3.2 Requisitos necessários de infra-estrutura de gás

Os aquecedores a gás podem ser instantâneos ou de acumulação. A diferença entre eles está no trocador de calor e na existência de reservatório. A Figura 5. 6 ilustra o aquecedor instantâneo e o aquecedor de acumulação.

Quando comparado com o aquecedor instantâneo, o aquecedor de acumulação, também conhecido como boiler a gás, gera menor quantidade de calor por unidade de tempo $(\mathrm{Pn})$ demandando maior tempo para aquecer a água quente armazenada no reservatório.

\section{Aquecedor Instantâneo}

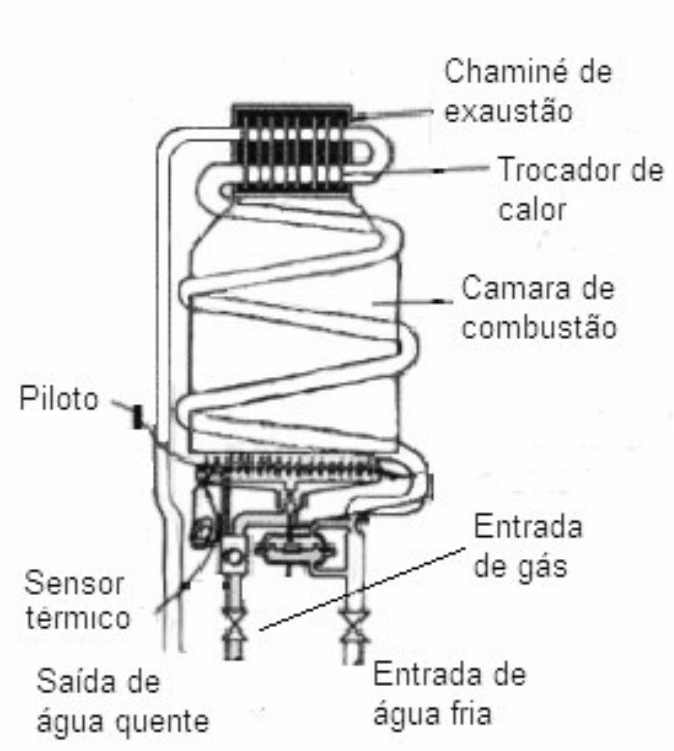

Aquecedor de acumulação

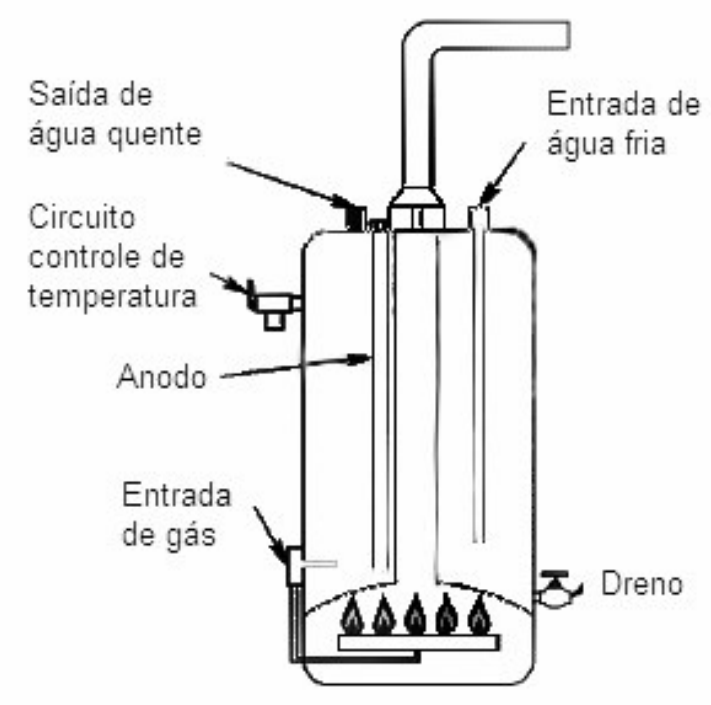

Figura 5.6 llustração do aquecedor instantâneo e de acumulação

O mercado oferece o denominado sistema conjugado, um aquecedor instantâneo acoplado a um reservatório. Este sistema pode ser unifamiliar ou multifamiliar. Unidades multifamiliares podem ter aquecimento de água central com caldeira a gás. Sistema atualmente pouco utilizado.A Figura 5. 7 ilustra o sistema de aquecedor conjugado. 
Esquema de Sistema de Aquecimento Conjugado a Gás

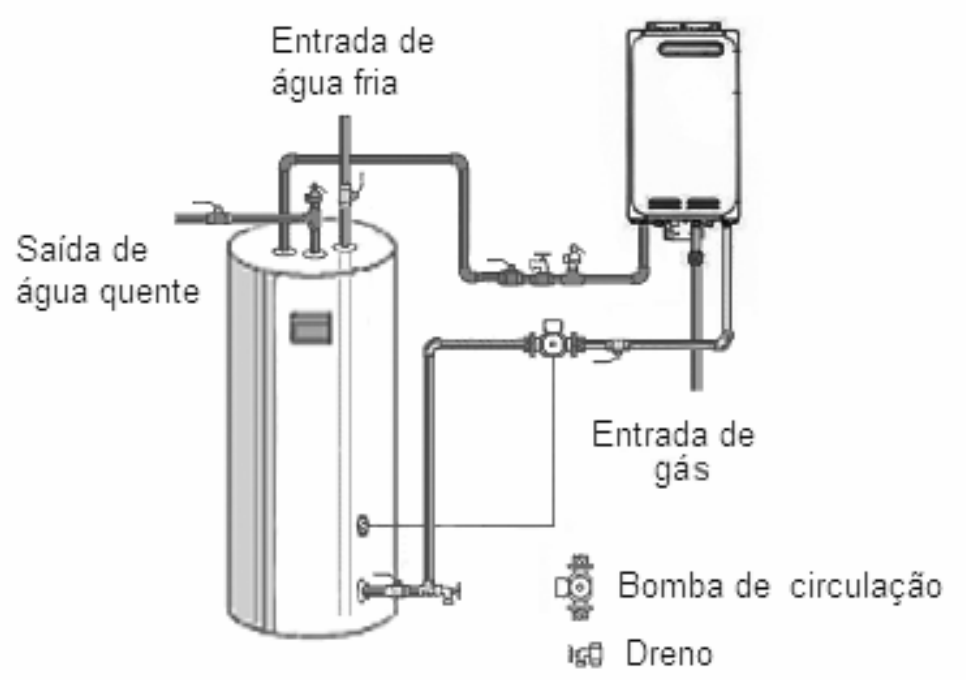

Figura 5.7 Esquema de sistema de aquecimento conjugado a gás

Os aquecedores a gás natural e a gás liquefeito de petróleo devem receber gás com poder calorífico e pressão adequados ao funcionamento. $O$ material utilizado para a execução da rede de distribuição interna de gás é preferencialmente o cobre rígido e flexível ${ }^{24}$.

$\mathrm{Na}$ combustão do gás ocorre a emissão de gases tóxicos, os quais não devem se misturar ao ambiente do usuário. Entre os diversos modelos de aquecedores a gás, o mais utilizado necessita de dutos para exaustão destes gases. A infra-estrutura da edificação deve prever essa ventilação e instalação de duto para exaustão, sendo essa normalmente instalada na área de serviço da unidade consumidora. A norma NBR 13.103 Instalações de aparelhos a gás para uso residencial - Requisitos dos ambientes estabelece as recomendações a este uso (assunto tratado no capítulo 4 Conformidade dos sistemas de aquecimento às regulamentações).

\subsection{Dimensionamento da infra-estrutura de água quente}

O circuito de distribuição de água quente compreende basicamente tubulações, conexões, registros de gaveta, registros de pressão, e deve atender

\footnotetext{
${ }^{24}$ Projeto Norma 402.02-051 - Redes de distribuição interna para gases combustíveis- Projeto e execução. Em consulta pública em 20/03/2007.
} 
aos quesitos de vazão, pressão e velocidade da água em conformidade com as normas de água fria e água quente ${ }^{25}$ e aos pontos de uso. Os materiais utilizados devem ser resistentes às temperaturas de operação do sistema.

A tubulação de água quente transfere energia para o ambiente em forma de calor. O desempenho de perda térmica de cada tubulação é medido através do coeficiente de condutibilidade $-\mathrm{K}$, em $\mathrm{kcal} / \mathrm{m}^{\circ} \mathrm{C}$, normalmente fornecido pelo fabricante. Os materiais disponíveis no mercado e que se mostram adequados ao uso quanto a sua condutibilidade térmica, estão relacionados na tabela 5.1.

Tabela 5. 1 Tubo de água quente e condutividade

\begin{tabular}{lc}
\hline \multicolumn{1}{c}{ Material do Tubo } & $\begin{array}{c}\text { Coeficiente de } \\
\text { condutibilidade térmica }-\mathbf{K} \\
\left(\mathbf{k c a l} / \mathbf{m}^{\circ} \mathbf{C}\right)\end{array}$ \\
\hline Cobre & 332,0 \\
Polietileno reticulado - PEX & 0,40 \\
Polipropileno Copolímero Random - PPR & 0,24 \\
Policloreto de vinila clorado - CPVC & 0,33 \\
\hline \hline
\end{tabular}

Fonte: Manual para Engenharia - Bosch Termotécnica.

Como o cobre é o melhor condutor térmico, no início do uso, a água quente sofre um resfriamento enquanto caminha pela tubulação, demorando a chegar ao ponto de uso. Nos demais materiais, a transferência ocorre de forma mais lenta. Esta dissipação nos tubos de cobre gera a necessidade de redutor térmico.

Quando a água quente permanece sem movimentação no interior da tubulação ocorre perda de calor a um nível tão alto que, no momento do uso, esta deve ser escoada. As edificações multifamiliares com sistema central coletivo a gás e solar, onde gerador e reservatório são localizados distante das unidades consumidoras, apresentam grandes perdas de calor na tubulação. Devido a estas perdas estes sistemas utilizam bomba para circulação de água e contínua reposição de energia, evitando assim que a água permaneça fria na tubulação. Esta circulação de água é controlada pelo monitoramento automático da temperatura.

\footnotetext{
${ }^{25}$ NBR- 5626/95 -Instalações prediais de água fria e NBR 7198/93 - Projeto e execução de instalações prediais de água quente
} 
Para este estudo, a instalação hidráulica de água quente utiliza o cobre por ser o mais difundido, até o momento. O ANEXO G apresenta o resultado do dimensionamento hidráulico de água quente para as tipologias de 2,3 e 4 dormitórios.

\subsection{Dimensionamento dos reservatórios}

Os reservatórios integrantes dos sistemas de acumulação têm como função armazenar a água acima da temperatura confortável de uso e podem atender a vários pontos de uso simultaneamente. Apresentam como características o volume (V) e capacidade de recuperação da água quente (Cr).

Devem possuir volume para suprir o maior pico de demanda e ter capacidade de recuperar temperatura para atender a demanda do próximo uso. O volume do reservatório está associado ao perfil de consumo. Evidencia loshimoto (1990) a ocorrência de dois picos de consumo de água quente, um no início do dia, entre 6 e 8 horas e outro à noite, entre 18 e 21 horas.

Os reservatórios do sistema solar além de possuírem volume para suprir a demanda também podem considerar o armazenamento de um maior volume de água quente devido à intermitência imposta pela fonte termo-solar.

A capacidade de recuperação da temperatura da água no reservatório depende da potência do aquecedor (Cr). Quanto maior a potência útil do aquecedor, maior a capacidade de recuperação. A capacidade é expressa em litros por hora (l/h) ou em graus Celcius por hora ( ${ }^{\circ} \mathrm{C} /$ hora), conforme dados do fabricante (vide Anexo B).

Os reservatórios estão sempre associados a uma fonte de calor. O sistema de acumulação privado elétrico opera com aquecedor de potência nominal em uma faixa de $1,5 \mathrm{~kW}$ a $6,5 \mathrm{~kW}$, não sobrecarregando a instalação elétrica sobre uma mesma tomada de uso específico. Os sistemas de acumulação privado a gás operam com potência nominal em uma faixa de 3.800 a $15.000 \mathrm{kcal} / \mathrm{hora}$.

No mercado aparece o sistema conjugado que combina reservatório e aquecedores instantâneos. Estes sistemas podem ser de acumulação privada ou central. 
Para a caracterização deste estudo, está definido o volume e a capacidade de recuperação dos reservatórios, conforme apresentado no ANEXO $\mathrm{H}$ Dimensionamento dos reservatórios para os sistemas de acumulação para as tipologias de 2, 3 e 4 dormitórios.

Os reservatórios, dos sistemas elétricos e a gás, possuem circuito de controle automático de temperatura da água, mantendo a mesma dentro de limites estabelecidos, comumente entre $50^{\circ} \mathrm{C}$ e $70^{\circ} \mathrm{C}$, acionando e interrompendo o gerador de calor. No caso dos reservatórios do sistema solar, muitas vezes não há controle de temperatura máxima, podendo ocorrer dano a alguns tipos de materiais.

O reservatório é constituído de dois tambores, um interno e outro externo com camada de isolante térmico entre eles, além de "respiro" para evaporação da água quente. A camada denominada de isolante térmico na realidade é um retardador de perda de calor. A perda de calor pode se apresentar em quatro etapas de funcionamento, cada qual com uma variação de temperatura e uma perda térmica. Segundo Petrucci (2002) estas etapas são:

1. Vazão de água quente nula e fonte de calor desligada;

2. Vazão de água quente não nula e fonte de calor desligada;

3. Vazão de água quente não nula e fonte de calor ligada;

4. Vazão de água quente nula e fonte de calor ligada.

5.6. Caracterização da disponibilidade na infra-estrutura elétrica e hidráulica

Para cada tipologia adotada, três diferentes infra-estruturas foram projetadas para permitir diferentes disponibilidades de consumo de água quente. Estas disponibilidades estão aqui denominadas de (a) mínima: que oferece água quente somente nos pontos de banho, (b) média: que oferece água quente nos pontos de banho e em metade de pontos em torneiras existentes e (c) máxima: que oferece pontos de uso para banhos, lavabos e pia de cozinha.

A tabela 5.2 apresenta a quantidade de pontos de uso considerados para dimensionamento das infra-estruturas elétricas, gás e água quente, das 3 tipologias. A disponibilidade mínima está representada pelas letras $A, D, G$ e J, a média representada pelas letras $B, E, H$ e K e a máximo pelas letras $C, F, I$ e $L$. 
Tabela 5.2 Pontos de uso considerados para dimensionamento das instalações elétrica e hidráulica

\begin{tabular}{lllll}
\hline Disponib. & \multicolumn{1}{c}{ 2D } & \multicolumn{1}{c}{$3 \boldsymbol{B}$} & \multicolumn{1}{c}{$\mathbf{4 D}$} \\
\hline Mínima & $\mathrm{A}, \mathrm{D}, \mathrm{G}, \mathrm{J}$ & 1 banho & 3 banhos & 4 banhos \\
Média & $\mathrm{B}, \mathrm{E}, \mathrm{H}, \mathrm{K}$ & 1 banho+ 1 torneira & 3 banhos +1 torneira & 4 banhos +3 torneiras \\
Máxima & $\mathrm{C}, \mathrm{F}, \mathrm{I}, \mathrm{L}$ & 1 banho +2 torneiras & 3 banhos +3 torneiras & 4 banhos +5 torneiras \\
\hline \hline
\end{tabular}

Não está previsto, no estudo de caso, ponto de água quente específico para máquinas de lavar louça e roupa. Não está sendo comparado o ponto de uso da banheira, na tipologia de 4 dormitórios. Este ponto pode ser aquecido por todas as alternativas de sistemas elétricos ou pelo sistema de acumulação coletivo a gás.

Para cada disponibilidade de consumo está calculado, através das planilhas, o custo das instalações elétricas, de gás e água quente para cada um dos sistemas de aquecimento: instantâneo individual, instantâneo central e acumulação privado e coletivo.

\subsection{Potência instalada e custo total exclusivo para aquecimento}

Os custos da infra-estrutura exclusiva para aquecimento elétrico ou a gás estão relacionados nas tabelas 5.3, 5.4 e 5.5, para cada um dos sistemas de aquecimento. A potência instalada está apresentada por unidade consumidora (UC), enquanto o custo é o total na edificação. Os resultados destes custos estão utilizados no capítulo 6- Análise econômica das alternativas.

Nesta análise, o dimensionamento da infra-estrutura considera equipamentos do mercado (em conformidade com o ANEXO B), cuja potência instalada total (conforme disponibilidade) está indicada nas tabelas 5.3, 5.4 e 5.5:

- A infra-estrutura para a alternativa Instantâneo Individual (1) está dimensionada para o uso do popular chuveiro e torneiras elétricas e do chuveiro a gás.

- Enquanto para o sistema Instantâneo (2) a infra-estrutura está preparada para o Instantâneo Central a gás (IC GÁS) e para o Instantâneo Individual elétrico (II ELE). 
Tabela 5.3 Potência Instalada por UC e custo na edificação - 2 Dormitórios

Valores em milR\$

\begin{tabular}{|c|c|c|c|c|c|c|c|}
\hline \multirow[b]{2}{*}{$\begin{array}{c}\text { Sistemas } \\
\text { Tipologia 2D }\end{array}$} & \multirow[b]{2}{*}{ Disp } & \multicolumn{2}{|c|}{$\begin{array}{c}\text { Potência Instalada - } \\
\text { UC }\end{array}$} & \multicolumn{4}{|c|}{ Custos na Infra-estrutura da Edificação } \\
\hline & & $\begin{array}{c}\text { Elétrica } \\
\text { kW } \\
\end{array}$ & $\begin{array}{l}\text { Gás } \\
\text { kcal/h }\end{array}$ & Elétrica & $\begin{array}{c}\text { Gás } \\
\text { Prumada } \\
\text { Individual }\end{array}$ & $\begin{array}{c}\text { Gás } \\
\text { Prumada } \\
\text { Coletiva } \\
\end{array}$ & $\begin{array}{c}\text { Agua } \\
\text { Quente } \\
\text { Coletivo }\end{array}$ \\
\hline - Instantâneo & $(\mathrm{A})$ & 5,4 & 6.127 & 74,3 & 17,3 & 15,7 & - \\
\hline Individual (1) & (B) & 9,8 & - & 93,0 & - & - & - \\
\hline- & (c) & 14,2 & - & 113,7 & - & - & - \\
\hline \multirow{3}{*}{ Instantâneo (2) } & (D) & 6,5 & 11.351 & 77,5 & 43,5 & 18,2 & - \\
\hline & (E) & 10,9 & 20.802 & 94,5 & 78,4 & 38,3 & - \\
\hline & $(\mathrm{F})$ & 15,3 & 20.802 & 120,8 & 78,4 & 38,3 & - \\
\hline Acumulação & (G) & 2,5 & 6.000 & 39,2 & 17,3 & 15,7 & - \\
\hline \multirow{2}{*}{ Privativo (3) } & $(\mathrm{H})$ & 3,0 & 8.200 & 104,1 & 35,4 & 32,8 & - \\
\hline & (I) & 3,5 & 8.200 & 106,1 & 35,4 & 32,8 & - \\
\hline Acumulação & $(\mathrm{J})$ & - & - & - & - & 0 & 25,3 \\
\hline \multirow{2}{*}{$\begin{array}{l}\text { Acumulaçao } \\
\text { Coletivo (4) }\end{array}$} & $(\mathrm{K})$ & - & - & - & - & - & 42,2 \\
\hline & (L) & - & - & - & - & - & 42,2 \\
\hline
\end{tabular}

Tabela 5.4 Potência Instalada por UC e custo na edificação - 3 Dormitórios

Valores em mil $\mathrm{R} \$$

\begin{tabular}{|c|c|c|c|c|c|c|c|}
\hline \multirow[b]{2}{*}{$\begin{array}{c}\text { Sistemas } \\
\text { Tipologia 3D }\end{array}$} & \multirow[b]{2}{*}{ Disp } & \multicolumn{2}{|c|}{$\begin{array}{c}\text { Potência Instalada - } \\
\text { UC }\end{array}$} & \multicolumn{4}{|c|}{ Custos na Infra-estrutura da Edificação } \\
\hline & & $\begin{array}{c}\text { Elétrica } \\
\text { kW }\end{array}$ & $\begin{array}{l}\text { Gás } \\
\text { kcal/h }\end{array}$ & Elétrica & $\begin{array}{c}\text { Gás } \\
\text { Prumada } \\
\text { Individual }\end{array}$ & $\begin{array}{c}\text { Gás } \\
\text { Prumada } \\
\text { Coletiva }\end{array}$ & $\begin{array}{c}\text { Agua } \\
\text { Quente } \\
\text { Coletivo }\end{array}$ \\
\hline - Instantâneo & $(\mathrm{A})$ & 16,2 & 18.384 & 142,7 & 88,6 & 51,8 & $\bar{x}$ \\
\hline Individual (1) & (B) & 20,6 & . & 168,1 & - & - & $x$ \\
\hline- & (c) & 29,4 & - & 223,2 & - & - & $x$ \\
\hline \multirow{3}{*}{ Instantâneo (2) } & (D) & 17,4 & 34.301 & 148,9 & 153,8 & 55,7 & $x$ \\
\hline & (E) & 21,8 & 42.963 & 169,2 & 168,4 & 66,9 & $x$ \\
\hline & $(\mathrm{F})$ & 30,6 & 54.759 & 227,5 & 180,2 & 78,7 & $x$ \\
\hline Acumulação & (G) & 4,0 & 8.200 & 116,0 & 48,8 & 47,4 & $x$ \\
\hline \multirow[t]{2}{*}{ Privativo (3) } & $(\mathrm{H})$ & 4,4 & 10.500 & 133,5 & 79,6 & 56,7 & $x$ \\
\hline & (I) & 5,0 & 13.500 & 144,7 & 107,6 & 69,8 & $x$ \\
\hline Acumulação & $(\mathrm{J})$ & - & - & $\mathrm{x}$ & $x$ & $x$ & 60,6 \\
\hline \multirow[t]{2}{*}{ Coletivo (4) } & (K) & - & - & $\mathrm{x}$ & $\mathrm{x}$ & $x$ & 69,4 \\
\hline & (L) & - & - & $x$ & $x$ & $x$ & 80,7 \\
\hline
\end{tabular}


Tabela 5.5 Potência Instalada por UC e diferença de custo total- 4 Dormitórios

Valores em mil $\mathrm{R} \$$

\begin{tabular}{|c|c|c|c|c|c|c|c|}
\hline \multirow[b]{2}{*}{$\begin{array}{c}\text { Sistemas } \\
\text { Tipologia 4D }\end{array}$} & \multirow[b]{2}{*}{ Disp } & \multicolumn{2}{|c|}{$\begin{array}{c}\text { Potência Instalada - } \\
\text { UC }\end{array}$} & \multicolumn{4}{|c|}{ Custos na Infra-estrutura da Edificação } \\
\hline & & $\begin{array}{c}\text { Elétrica } \\
\text { kW }\end{array}$ & $\begin{array}{l}\text { Gas } \\
\text { kcal/h }\end{array}$ & Elétrica & $\begin{array}{c}\text { GAS } \\
\text { Prumada } \\
\text { Individual }\end{array}$ & $\begin{array}{c}\text { GAS } \\
\text { Prumada } \\
\text { Coletiva }\end{array}$ & $\begin{array}{c}\text { Agua } \\
\text { Quente } \\
\text { Coletivo }\end{array}$ \\
\hline - Instantâneo & $(\mathrm{A})$ & 21,6 & 24.510 & 103,3 & 61,7 & 46,6 & - \\
\hline Individual (1) & (B) & 34,8 & - & 158,4 & - & - & - \\
\hline- & (c) & 51,6 & - & 180,6 & - & - & - \\
\hline \multirow{3}{*}{ Instantâneo (2) } & (D) & 23,9 & 54.759 & 115,3 & 94,1 & 48,7 & - \\
\hline & (E) & 37,1 & - & 165,1 & - & - & - \\
\hline & (F) & 43,8 & - & 199,5 & - & - & - \\
\hline Acumulação & (G) & 5,0 & 13.500 & 98,8 & 52,0 & 45,3 & - \\
\hline \multirow[t]{2}{*}{ Privativo (3) } & $(\mathrm{H})$ & 5,4 & 15.000 & 110,2 & 69,9 & 57,1 & - \\
\hline & (I) & 6,2 & 15.000 & 119,5 & 75,3 & 62,5 & - \\
\hline Acumulação & (J) & - & - & - & - & - & 46,1 \\
\hline \multirow[t]{2}{*}{ Coletivo (4) } & (K) & - & - & - & - & - & 57,5 \\
\hline & (L) & - & - & - & - & - & 62,9 \\
\hline
\end{tabular}

A infra-estrutura de gás está dimensionada para distribuição por prumada coletiva e prumada individual. A infra-estrutura elétrica está dimensionada para distribuição individual de energia.

Vale ressaltar que:

- para alguns níveis de consumo não está disponibilizada a possibilidade de utilizar todos os sistemas de aquecimento;

- as potências entre equipamentos elétricos e a gás não são equivalentes termicamente;

- a configuração de sistemas de aquecimento de água instantânea individual está aqui representada pelo chuveiro elétrico (Ch ELE) e a gás (Ch GÁS), de vazão $31 / \mathrm{min}$ e potência de $5,4 \mathrm{~kW}$ e $4.900 \mathrm{kcal} / \mathrm{h}$ respectivamente;

- a configuração de sistema de aquecimento instantâneo central elétrico está aqui substituída pela "ducha" elétrica (II ELE) de vazão 6l/min e potência de 6,5kW;.

- a simultaneidade dos equipamentos por unidade consumidora e edifício é tratada de forma diferenciada entre o serviço elétrico e o a gás ${ }^{26}$;

${ }^{26}$ De acordo com a LIG 2005 -ELETROPAULO e RIP da COMGAS de 2006. 
- no uso de aquecedores de acumulação o consumidor deve dispor de um espaço físico para a sua instalação e seus acessórios, e no caso do gás, espaço com ventilação;

- no uso do sistema de acumulação coletiva a edificação deve dispor de área comum para a instalação do sistema de aquecimento (reservatório e aquecedor) e prever a medição de água e energia em conformidade com as leis vigentes.

As alternativas aqui apresentadas tentam representar as que o mercado da construção civil e fornecedores de equipamentos disponibilizam para aquecimento de água.

As figuras 5.8, 5.9 e 5.10 apresentam o custo da infra-estrutura, exclusivo para o aquecimento da potência instalada na unidade consumidora (em kilowatt ${ }^{27}$ ), para as diferentes tipologias e disponibilidades adotadas. O sistema acumulação coletivo (AC) apresenta, para efeito comparativo, a mesma potência do sistema de acumulação privado (AP).

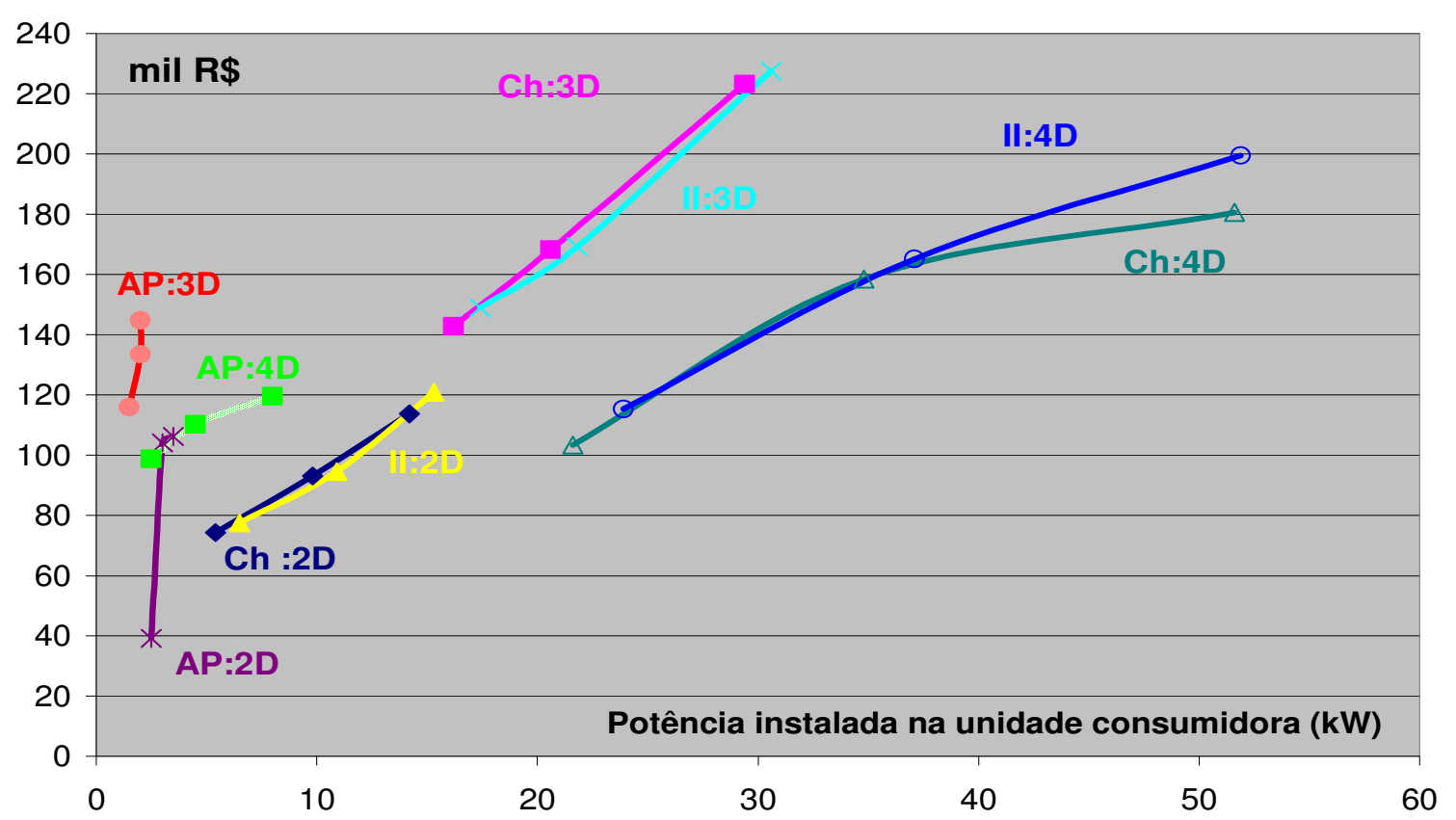

Figura 5.8 Custo da infra-estrutura elétrica da edificação, exclusiva para aquecimento; por potência instalada na unidade consumidora para as tipologias de 2, 3 e 4 Dormitórios

Legenda: Ch = Chuveiro; II = Instantâneo Individual; IC = Instantâneo Central;

$\mathrm{AP}=$ Acumulação Privado; $\mathrm{AC}=$ Acumulação Coletivo; ELE = Elétrico; GAS = Gás

\footnotetext{
${ }^{27}$ Considerado $1 \mathrm{~kW}=860 \mathrm{kcal} / \mathrm{hora}$
} 


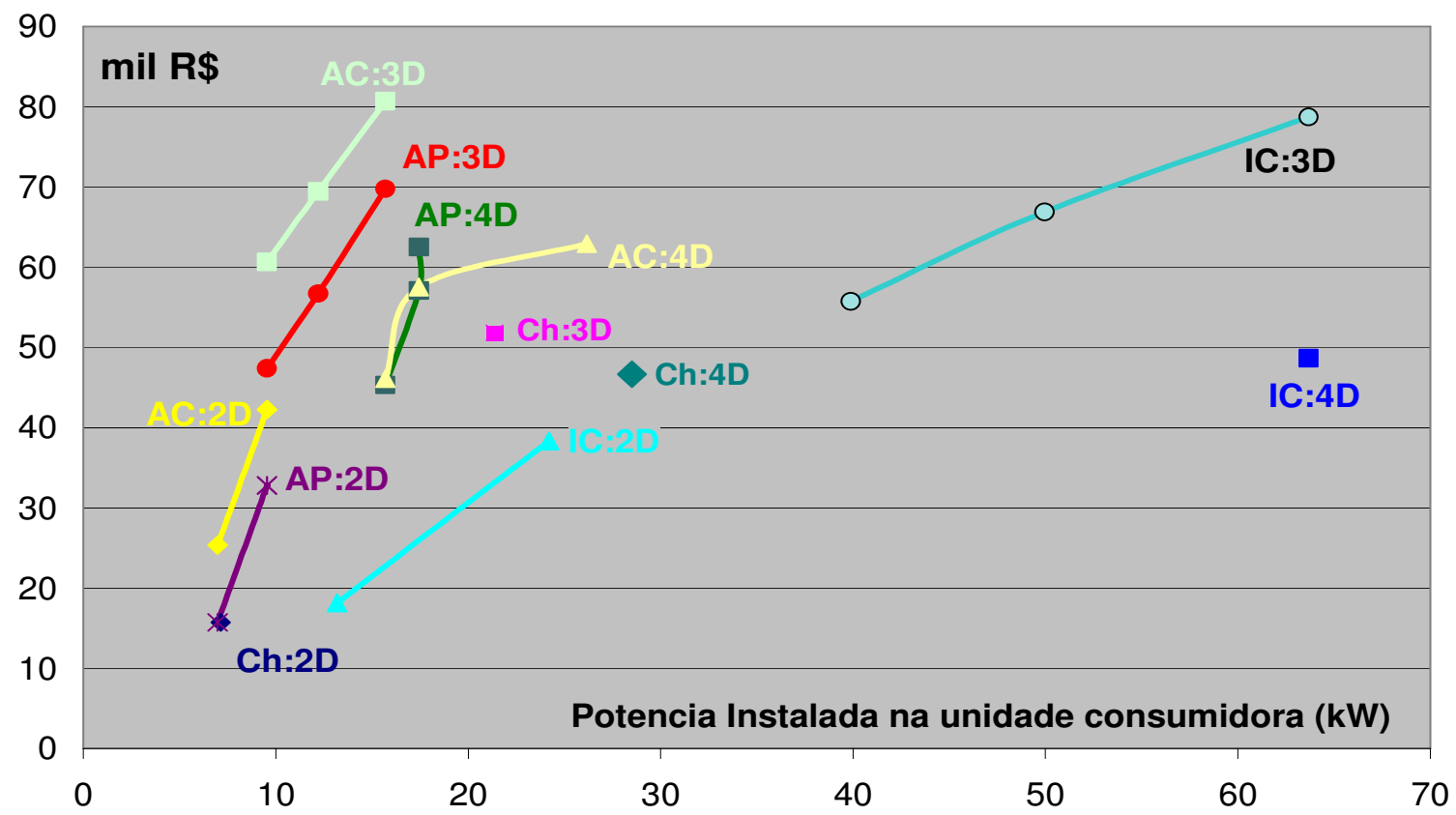

Figura 5.9 Custo da infra-estrutura de gás da edificação, exclusiva para aquecimento; por potência instalada na unidade consumidora para as tipologias de 2, 3 e 4 Dormitórios. Distribuição de gás por prumada coletiva.

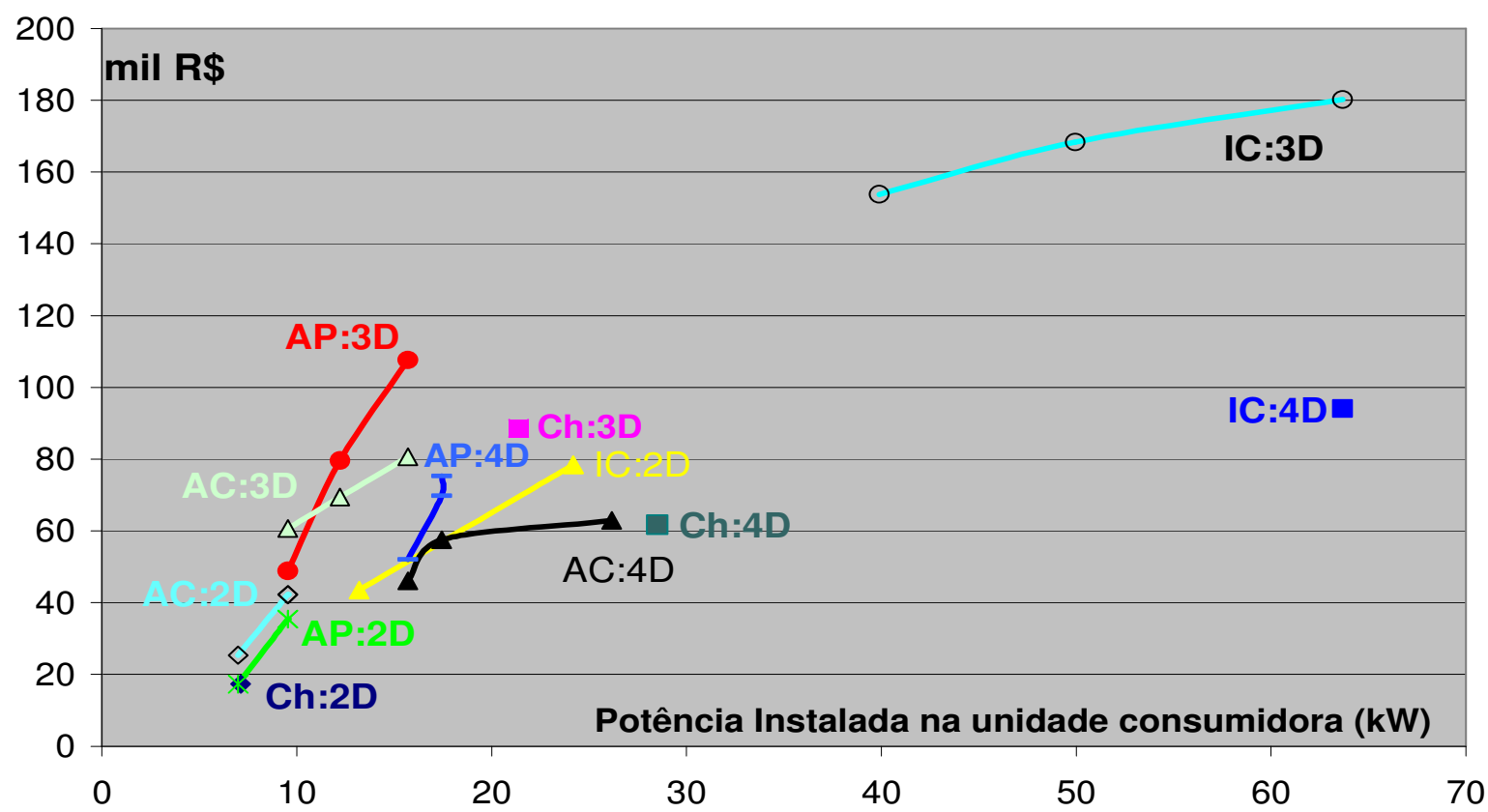

Figura 5.10 Custo da infra-estrutura de gás da edificação, exclusiva para aquecimento; por potência instalada na unidade consumidora para as tipologias de 2, 3 e 4 Dormitórios. Distribuição de gás por prumada individual. 
As figuras $5.11,5.12$ e 5.13 apresentam o custo da infra-estrutura de aquecimento de água para os diferentes Sistemas de Aquecimento, por tipologia, nas disponibilidades mínima, média e máxima. Os custos referentes a gás são os de distribuição por prumada coletiva (PC), pois este apresenta menor custo quando comparado com a distribuição de gás por prumada individual (PI).

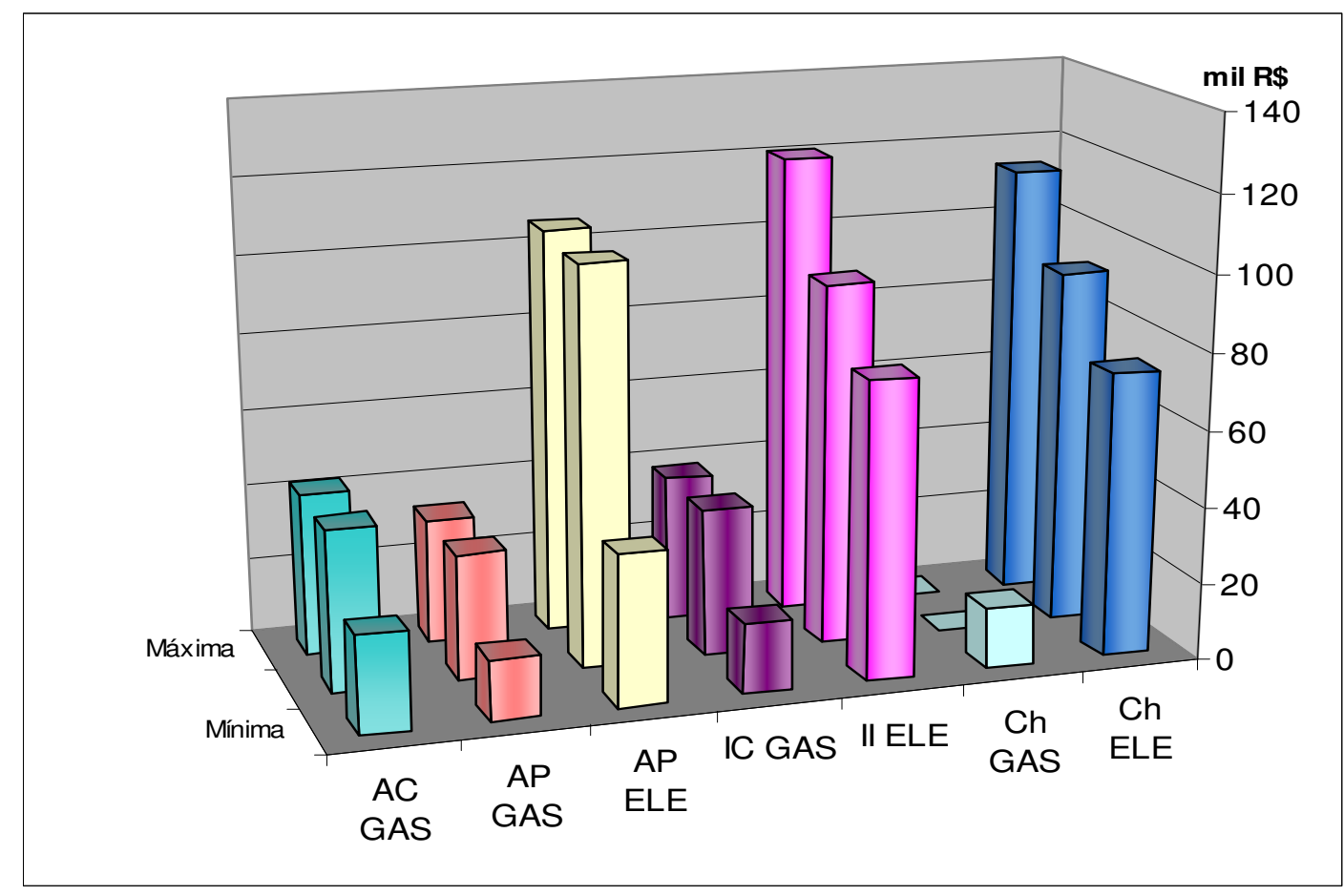

Figura 5.11 Custo da infra-estrutura para aquecimento elétrico e a gás; Tipologia: 2 Dormitórios. 


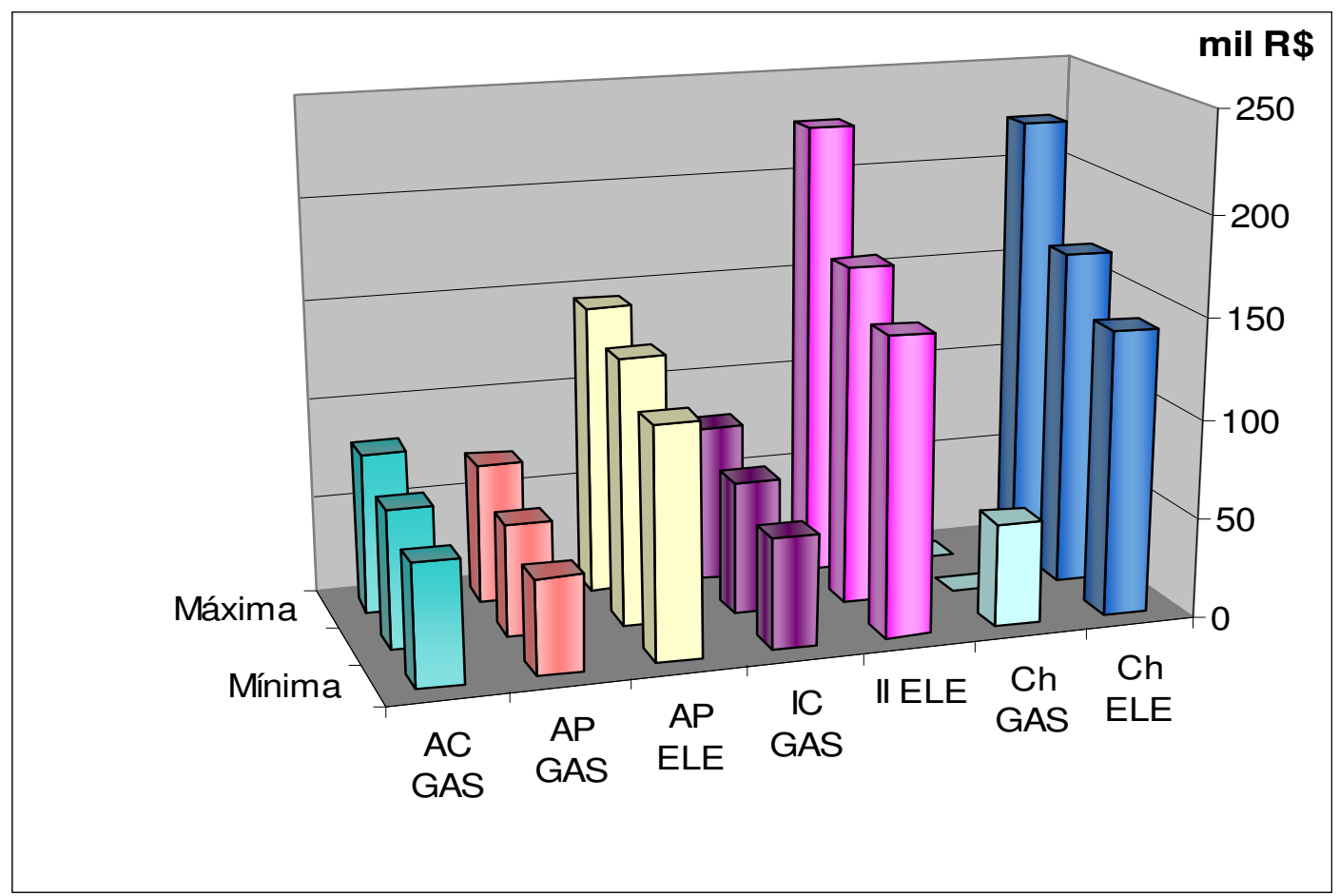

Figura 5.12 Custo da infra-estrutura para aquecimento elétrico e a gás; Tipologia: 3 Dormitórios.

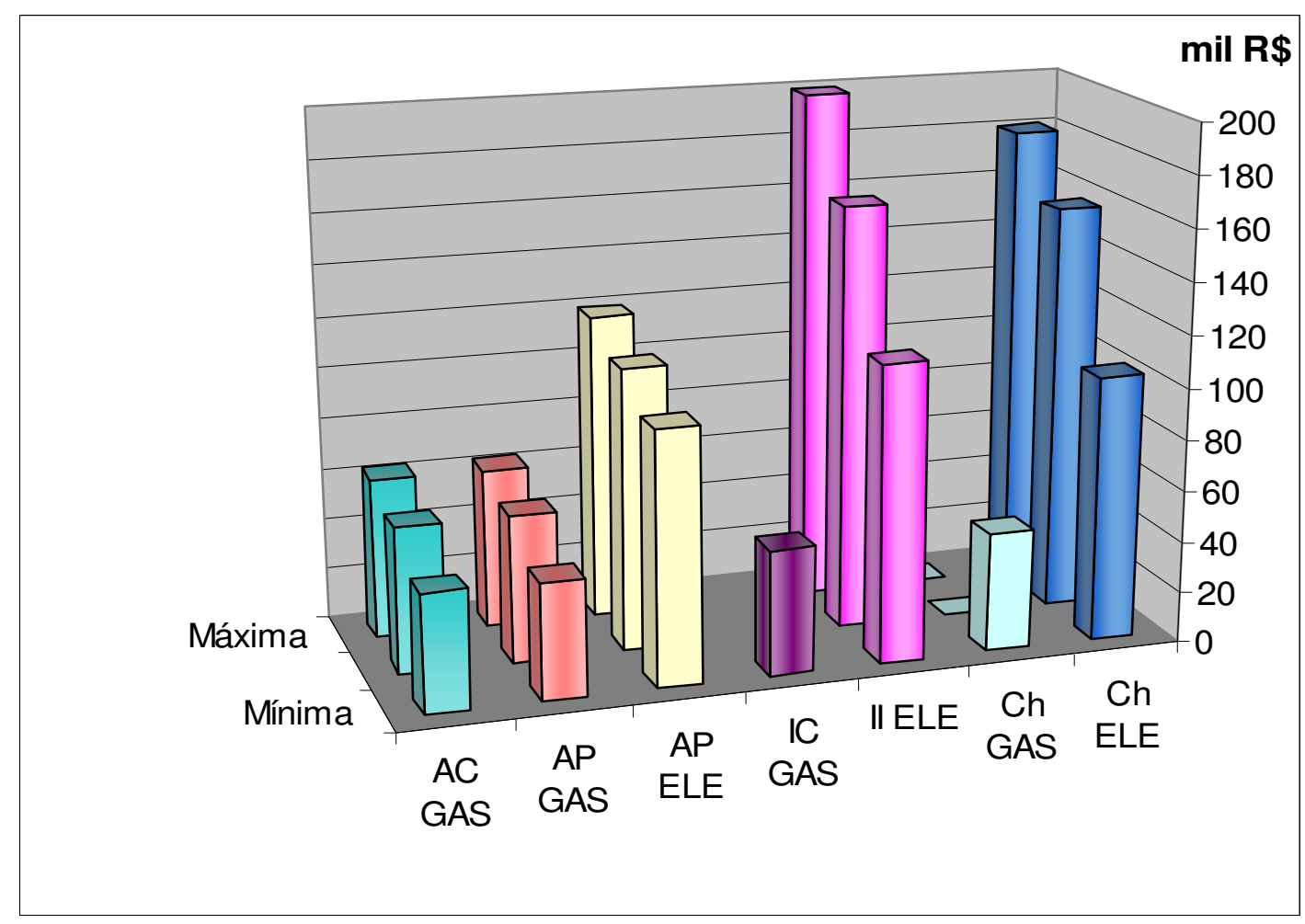

Figura 5.13 Custo da infra-estrutura para aquecimento elétrico e a gás; Tipologia: 4 Dormitórios. 
5.8 Sistema misto de energia final

O mercado da construção civil disponibiliza infra-estruturas com aquecimento de água a gás na área social e chuveiro elétrico no banheiro de serviço, situação denominada, neste trabalho, de sistema misto de energia.

No sistema misto ocorre uma diminuição no custo da infra-estrutura do gás e um acréscimo no custo da elétrica. Este acréscimo de custo é de $R \$ 69.212$ e $R \$$ 58.100 respectivamente para as tipologias de 3 e 4 dormitórios, nas alternativas dos sistemas Instantâneo Central e Acumulação Privativa.

As figuras 5.14 e 5.15 apresentam o comparativo entre o sistema elétrico, a gás e misto (I Misto e A Misto). O ANEXO I apresenta a tabela com os custos da infra-estrutura para os sistemas de alternativa mista de energia final.

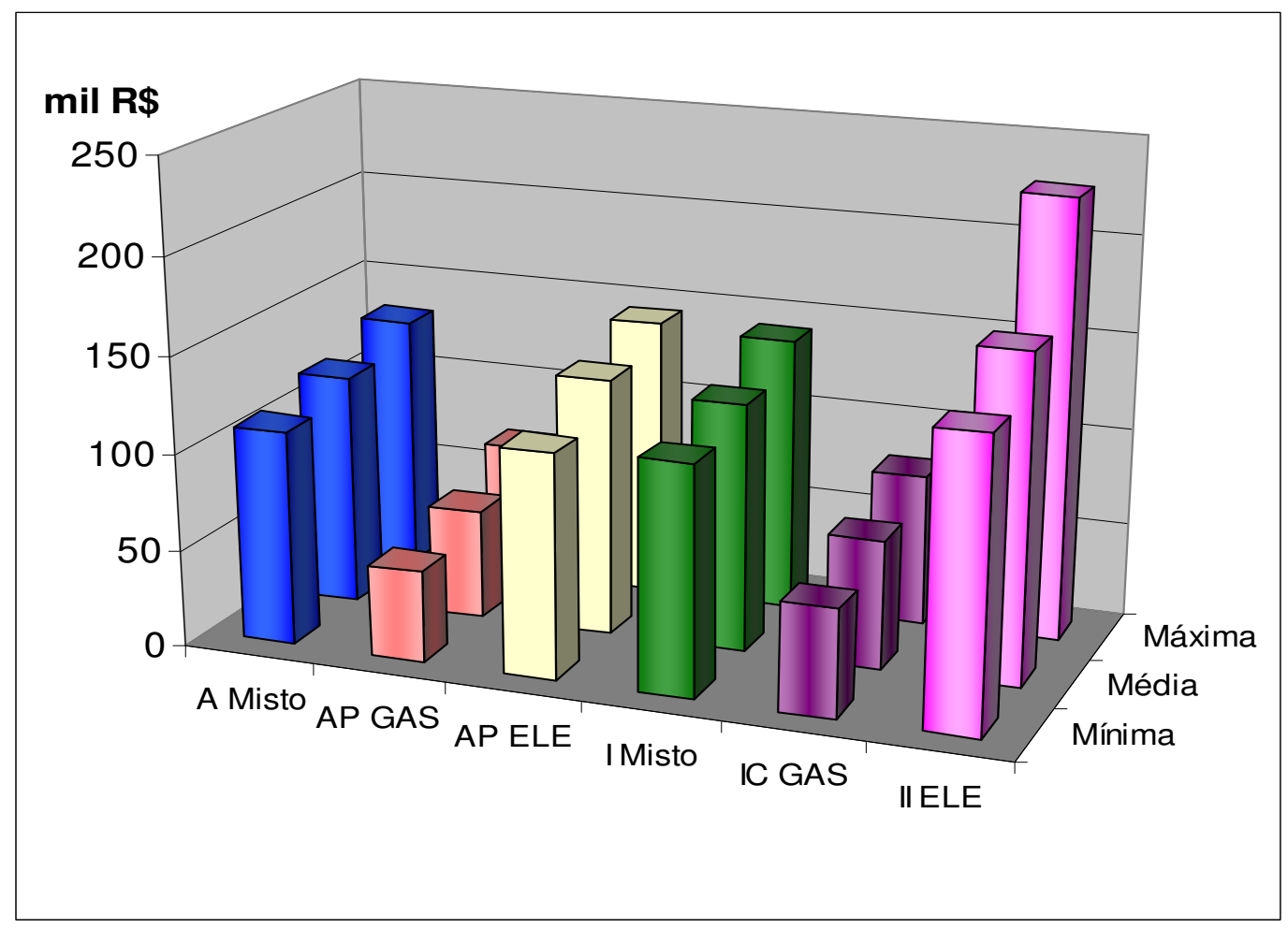

Figura 5.14 Custo infra-estrutura para alternativa mista de energia; Tipologia: 3Dormitórios 


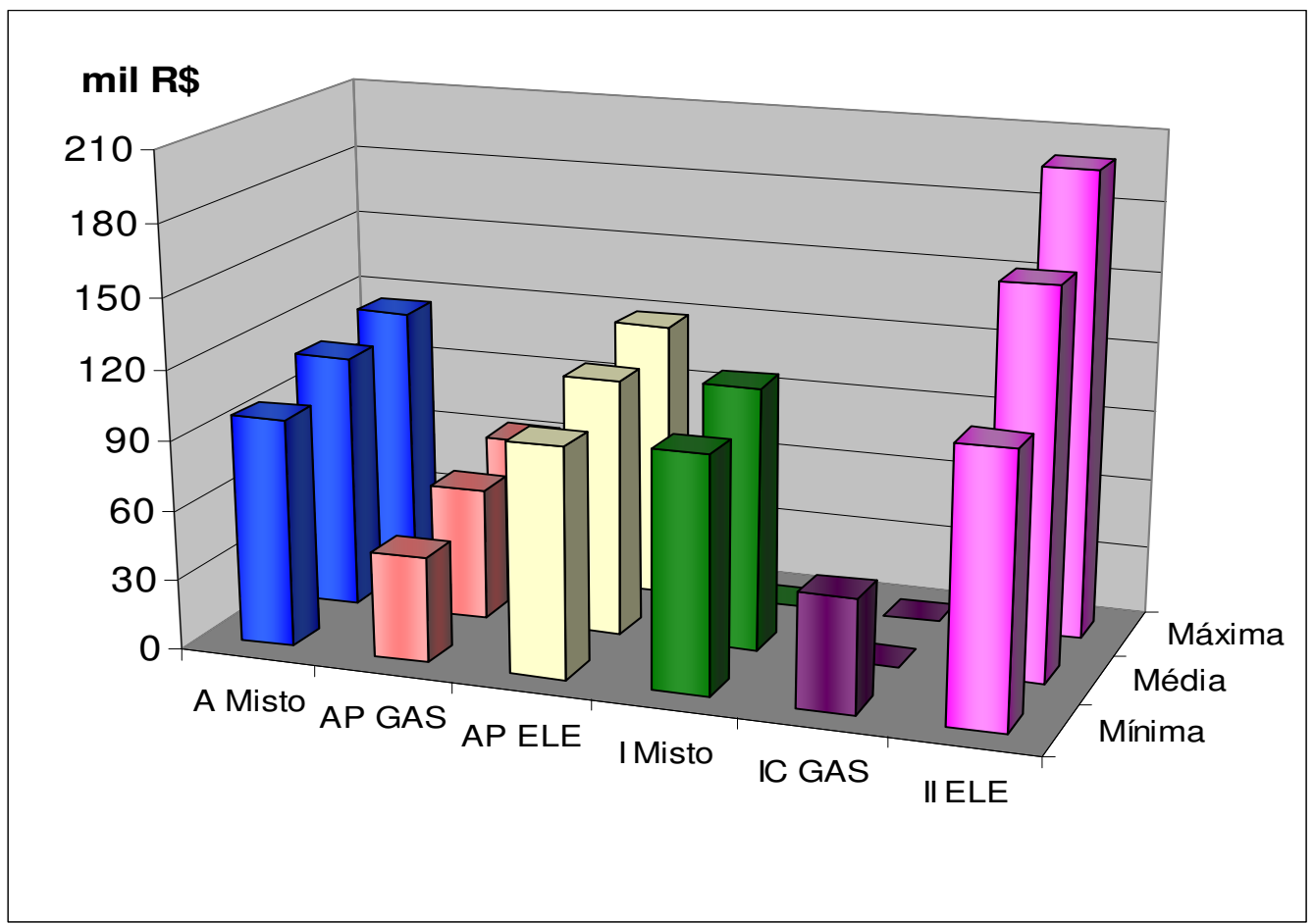

Figura 5.15 Custo infra-estrutura para alternativa mista de energia; Tipologia: 4Dormitórios

Legenda: II = Instantâneo Individual; IC = Instantâneo Central; I Misto = Instantâneo misto $\mathrm{AP}=$ Acumulação Privado; $\mathrm{A}$ Misto = Acumulação Misto; ELE = Elétrico; GAS = Gás

Com a infra-estrutura possibilitando a alternativa mista de fonte de calor para aquecimento de água, o mercado de gás passa a atender unidades consumidoras que requerem demandas que 0 mercado de equipamentos não pode atender. $O$ custo da infra-estrutura para aquecimento de água deve ser analisado como investimento, somado aos custos dos equipamentos e custos de energia final. 


\section{ANÁLISE ECONÔMICA DAS ALTERNATIVAS}

A análise econômica considera os custos de investimento com a infraestrutura necessária para as demandas mínima, média e máxima de água quente das tipologias adotadas de 2, 3 e 4 dormitórios, equipamentos e instalação dos sistemas de aquecimento elétrico e a gás instantâneo e de acumulação. Os custos de investimento somados aos custos de energia aplicados no modelo econômico mostram como resultado, o custo do serviço de aquecimento de água em função das variáveis: volume consumido no ponto de uso.

\subsection{Parâmetros adotados}

Tempo da análise econômica e taxa de desconto, tempo de vida útil da infraestrutura, tempo da vida útil de cada equipamento, custos de infra-estrutura, custo de equipamentos, eficiência na conversão e transporte de calor e preços de energia são os parâmetros definidos e apresentados a seguir.

6.1.1 Tempo de análise e taxa de desconto, vida útil dos equipamentos e infraestrutura

Para esta análise considera-se um horizonte de 10 anos. O Fator de Recuperação de Capital (FRC) anualizado considera a vida útil e as horas de utilização do sistema a uma taxa de desconto ( $r=12 \%$ a.a.). A Tabela 6.1 relaciona a vida útil dos equipamentos adotados. 
Tabela 6.1 Vida útil dos equipamentos

\begin{tabular}{cc}
\hline Equipamento & $\begin{array}{c}\text { Vida Útil } \\
\text { anos }\end{array}$ \\
\hline Chuveiro elétrico & 2 \\
Instantâneo elétrico & 8 \\
Acumulação elétrico* & 10 \\
Chuveiro gás & 2 \\
Instantâneo central gás* & 10 \\
Acumulação gás & 8 \\
Reservatório* & 10 \\
\hline \hline
\end{tabular}

Fonte: * TABORIANSKI (2000)

O tempo de vida útil dos equipamentos depende das condições de uso e manutenções. Dados estes não disponíveis no mercado e aqui estimados.

O popular chuveiro elétrico possui durabilidade e segurança para 3.300 operações que correspondem às operações de uma família de 5 pessoas por aproximadamente 2 anos. $O$ aquecedor instantâneo que possua resistência blindada já possui uma durabilidade de aproximadamente 12.000 operações, que correspondem às operações de aproximadamente $8 \operatorname{anos}^{28}$.

\subsubsection{Custos de equipamentos}

Para aplicação deste modelo econômico o custo do investimento de cada sistema de aquecimento incorpora o custo da infra-estrutura e o custo de cada um dos aquecedores e reservatórios, quando aplicável.

Os custos dos aquecedores foram levantados no mercado varejista de São Paulo em dezembro de 2006. Deve-se considerar que estes preços não levam em conta possíveis variantes no momento da montagem, serviços de instalação, e que uma seleção criteriosa de fornecedores e compra em grandes quantidades levam a uma diminuição do preço final do produto.

Os aquecedores escolhidos para a geração de calor dos sistemas deste estudo de caso estão apresentados no ANEXO J. Este anexo relaciona os aquecedores escolhidos, suas potências e os preços de cada uma das tipologias.

\footnotetext{
${ }^{28}$ Informação ABINEE (2006).
} 
Como para os sistemas individuais instantâneos elétricos ocorre a simultaneidade de uso dos equipamentos, uma potência e vazão média estão adotadas para efeito comparativo de geração de calor por sistema. Também potências e vazões médias estão apresentadas no ANEXO J.

\subsubsection{Eficiência na conversão $\left(\eta_{\mathrm{e}}\right)$ dos aquecedores}

O Programa Brasileiro de etiquetagem (PBE) define as faixas de eficiência na conversão de calor $\left(\eta_{e}\right)$ dos aquecedores, como meta para a conservação de energia elétrica e uso racional de derivados do petróleo. Vale ressaltar que os aquecedores de acumulação privados elétricos e os acumuladores coletivos a gás não estão sendo avaliados pelo PBE até o momento e que os valores apresentados pelo PBE são específicos para testes em laboratório, situação esta, muitas vezes, diferenciada das condições de operação de uso.

A Tabela 6.2 apresenta as faixas de eficiência dos aquecedores, aceitáveis pelo Programa Brasileiro de Etiquetagem (PBE) e aqui adotadas.

Tabela 6.2 Eficiências dos aquecedores

\begin{tabular}{lcc}
\hline \multicolumn{1}{c}{ Aquecedores } & $\begin{array}{c}\text { Eficiência } \\
\text { superior a }\end{array}$ & $\begin{array}{c}\text { Eficiência } \\
\text { adotada }\end{array}$ \\
\hline Instantâneo Individual elétrico & $95 \%$ & 0,95 \\
Instantâneo Central elétrico & $95 \%$ & 0,95 \\
Acumulação Privado elétrico & - & 0,85 \\
Instantâneo Individual gás & $72 \%$ & 0,72 \\
Instantâneo Central gás & $72 \%$ & 0,72 \\
Acumulação Privado a gás & $70 \%$ & 0,7 \\
Acumulação Coletivo a gás & - & 0,7 \\
\hline
\end{tabular}

Fonte: Ministério de Minas e Energia. Programa Brasileiro de Etiquetagem. Regulamento específico para uso da etiqueta nacional de conservação de energia (ENCE). 


\subsubsection{Eficiência no transporte $\left(\eta_{t}\right)$}

As perdas térmicas no transporte de calor dependem do material, diâmetro e comprimento da tubulação, espessura do redutor térmico ${ }^{29}$ e da diferença de temperatura $(\Delta \theta)$ entre a água aquecida (interna à tubulação) e a temperatura ambiente. A temperatura média ambiente adotada para a cidade de São Paulo é de $20^{\circ} \mathrm{C}^{30}$

As tubulações relevantes ao estudo das perdas na infra-estrutura de água quente, utilizada nas tipologias em questão, são de cobre e possuem diâmetro de 22, 35 e 42mm. O comprimento varia de acordo com o número de pontos de consumo para cada uma das tipologias adotadas. Estes parâmetros estão apresentados no ANEXO G- Dimensionamento hidráulico de água quente para as tipologias de 2, 3 e 4 Dormitórios.

Como exercício para este estudo de caso, no modelo econômico as diferenças de temperatura $(\Delta \theta)$ adotadas são:

- $\Delta \theta=20^{\circ} \mathrm{C}$ para os sistemas instantâneo central

- $\Delta \theta=40^{\circ} \mathrm{C}$ para acumulação privado e

- $\Delta \theta=25^{\circ} \mathrm{C}$ para os sistemas de acumulação coletivo

O sistema de acumulação coletivo pode ser programado para produzir água quente com diferentes temperaturas ao longo do dia e da noite, em função da demanda das unidades consumidoras.

A tabela 6.3 relaciona a perda de calor nas tubulações com cada um dos sistemas que utiliza circuito de distribuição de água quente, considerando diâmetro, diferença de temperatura e existência ou não de redutor de calor.

\footnotetext{
${ }^{29}$ Redutor térmico é denominado no mercado da construção como o isolante térmico.

${ }^{30}$ Fonte: www.cptec.inpe.br
} 
Tabela 6.3 Perda de calor nas tubulações

\begin{tabular}{|c|c|c|c|c|c|}
\hline Sistema & $\begin{array}{c}\text { Diâmetro } \\
\text { do tubo } \\
\text { mm }\end{array}$ & $\Delta T$ & $\begin{array}{c}\text { Perda } \\
\text { sem } \\
\text { Redutor } \\
\text { W/m }\end{array}$ & $\begin{array}{c}\text { Perda } \\
\text { Redutor } \\
5 \mathrm{~mm} \\
\mathrm{~W} / \mathrm{m}\end{array}$ & $\begin{array}{c}\text { Perda } \\
\text { Redutor } \\
\text { 10mm } \\
\mathrm{W} / \mathrm{m}\end{array}$ \\
\hline Instantâneo Central & 22 & 20 & 13,8 & 7,6 & 5,6 \\
\hline Acumulação Privado & 22 & 40 & 27,6 & 15,6 & 11,5 \\
\hline Acumulação Coletivo & 42 & 25 & 33 & 16,3 & 11,4 \\
\hline Acumulação Coletivo & 35 & 25 & 27,5 & 14,0 & 9,9 \\
\hline Acumulação Coletivo & 22 & 25 & 17,3 & 9,6 & 7,0 \\
\hline
\end{tabular}

Os resultados acima foram realizados com o auxilio do programa polipex calculation, e confirmados com os dados dos textos técnicos: Sistemas prediais de água quente (ILHA; GONÇALVES; KAVASSAKI; 2006) e Estudo de caso: Consumo de água no edifício Quatiara (IOSHIMOTO, 2005). Na prática é encontrada tubulação de água quente de cobre sem o redutor térmico. $O$ redutor apresenta baixo custo $^{32}$, mas representa economia no uso da energia no sistema como um todo. Este trabalho está considerando um redutor de perda de $5 \mathrm{~mm}$.

\subsubsection{Preço da energia}

Os preços de energia foram pesquisados e considerados para Região Metropolitana de São Paulo. As cobranças de energia elétrica e de gás natural são tarifadas pela Agencia Nacional de Energia Elétrica (ANEEL), Agencia Nacional do Petróleo, Gás Natural e Biocombustíveis (ANP), e Comissão de Serviços Públicos de Energia (CSPE).

\footnotetext{
${ }^{31}$ Empresa brasileira fabricante de isolantes térmicos. Cálculos realizados pelo Software disponibilizado pela POLIPEX..

${ }^{32} \mathrm{R} \$ 0,7 /$ metro e $\mathrm{R} \$ 1,4 /$ metro o redutor de $5 \mathrm{~mm}$ e $15 \mathrm{~mm}$ respectivamente. Fonte: www.polipex.com.br
} 
Os impostos estaduais e federais são estratificados por faixa de consumo. Nestas condições a análise econômica considera que o custo de energia para aquecimento de água aparece considerando um consumo mínimo para iluminação e tomadas e cocção. O acréscimo está considerando como consumo mínimo:

- Energia Elétrica:

Consumo mínimo 200kWh/mês.

Uma família típica do segmento popular necessita consumir entre 150 a 220 kWh/mês (BERMANN, 1999).

- Gás Natural:

Consumo médio de $12 \mathrm{~m}^{3} /$ mês, para a tipologia de 2 dormitórios

Consumo médio de $25 \mathrm{~m}^{3} / \mathrm{mês}$, para a tipologia de 3 e 4 dormitórios (Comgas ${ }^{33}$ )

O valor fixo do preço do gás natural está considerado pago na utilização para a cocção.

- GLP: $1 / 2$ botijão ao mês de GLP de $13 \mathrm{~kg}$ para clientes residenciais com um padrão de consumo muito baixo e com um equipamento instalado de um fogão ${ }^{34}$.

No caso do sistema de acumulação coletivo a gás ocorre o rateio da fatura do consumo de gás e água pelos moradores. O preço da energia distribuída individualmente é diferenciado do coletivo. As considerações de preço estão relacionadas a seguir em valores fixos, na tabela 6.4-Simulação de Preço de Energia.

Tabela 6.4 Simulação de preço de energia com impostos

\begin{tabular}{lcc}
\hline & $\begin{array}{c}\text { Faixa de } \\
\text { consumo }\end{array}$ & Valor \\
& acima 200,1 & $0,40 / \mathrm{kWh}$ \\
\hline Eletricidade & 8,01 a $17 \mathrm{~m} 3$ & $2,61 / \mathrm{m}^{3}$ \\
GN & 17,01 a 40 & $3,22 / \mathrm{m}^{3}$ \\
GN & - & $2,43 / \mathrm{m}^{3}$ \\
GN coletivo & 4,1 a 40 & $2,89 / \mathrm{kg}$ \\
GLP & - & $2,60 / \mathrm{kg}$ \\
GLP coletivo & & \\
\hline
\end{tabular}

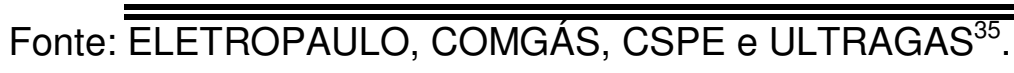

\footnotetext{
${ }^{33}$ Dado empírico fornecido pela COMGAS. Projeto de P\&D - Aquecimento de água Residencial

${ }^{34}$ http://www.cspe.sp.gov.br/downloads/secoes/gas_audiencia/01-2005/Etapa-

I/DocumentacaoGeral/PropostaEstruturaTarifariaGNSPS.pdf
} 
A análise econômica utiliza como custo energia (ce) o valor apresentado em $\mathrm{R} \$ / \mathrm{MWh}$, portanto está considerado que $1 \mathrm{~m}^{3}$ de gás natural corresponde a $10,932 \mathrm{kWh}$ e que $1 \mathrm{~kg}$ de gás liquefeito de petróleo corresponde a 13,721kWh.

Logo, o preço do MWh adotado para a eletricidade, o gás natural e o gás liquefeito de petróleo deste estudo está demostrado na tabela 6.5.

Tabela 6.5 Preço do MWh

\begin{tabular}{lc}
\hline \multicolumn{1}{c}{ Energia } & Preço adotado R\$/MWh \\
\hline Eletricidade & 401,8 \\
$\mathrm{~m}^{3} \mathrm{GN}$ - individual (tipologia 2D) & 238,8 \\
$\mathrm{~m}^{3} \mathrm{GN}$ - individual (tipologias 3 e 4 D) & 294,5 \\
$\mathrm{~m}^{3} \mathrm{GN}$ - coletivo & 222,0 \\
$\mathrm{~kg} \mathrm{GLP} \mathrm{-} \mathrm{individual}$ & 210,6 \\
$\mathrm{Kg}$ GLP - coletivo & 189,5 \\
\hline \hline
\end{tabular}

6.2 Resultados entre custos de serviço de aquecimento de água: Elétrico e Gás Natural

Estes resultados dos custos do serviço de Aquecimento de Água Residencial foram calculados a uma taxa de desconto de 12\%a.a. e foram apresentados para as tipologias de 2, 3 e 4 dormitórios.

$\checkmark$ Para cada tipologia está apresentado o custo das disponibilidades mínima, média e máxima.

$\checkmark$ Os custos estão apresentados em $R \$ / M W h$ e em $R \$$. O custo em $R \$$ corresponde ao valor gasto em 10 anos para o volume de utilização.

$\checkmark$ Nestes resultados a alternativa do sistema Instantâneo Individual (1) utiliza 0 popular chuveiro elétrico ou a gás e está representado por Ch ELE e Ch GN.

${ }^{35}$ Consulta em março de 2007. 
6.2 1 Resultados dos custos de serviço de aquecimento de água: elétrico e a gás natural em função do volume de utilização

Os resultados dos custos do serviço de aquecimento de água residencial em função do volume de utilização estão apresentados da Figuras 6.1 a Figura 6.3, para as tipologias de 2, 3 e 4 Dormitórios.

$\checkmark$ Os custos estão apresentados em R\$/MWh e o correspondente gasto em 10 anos, em $\mathrm{R} \$$. 

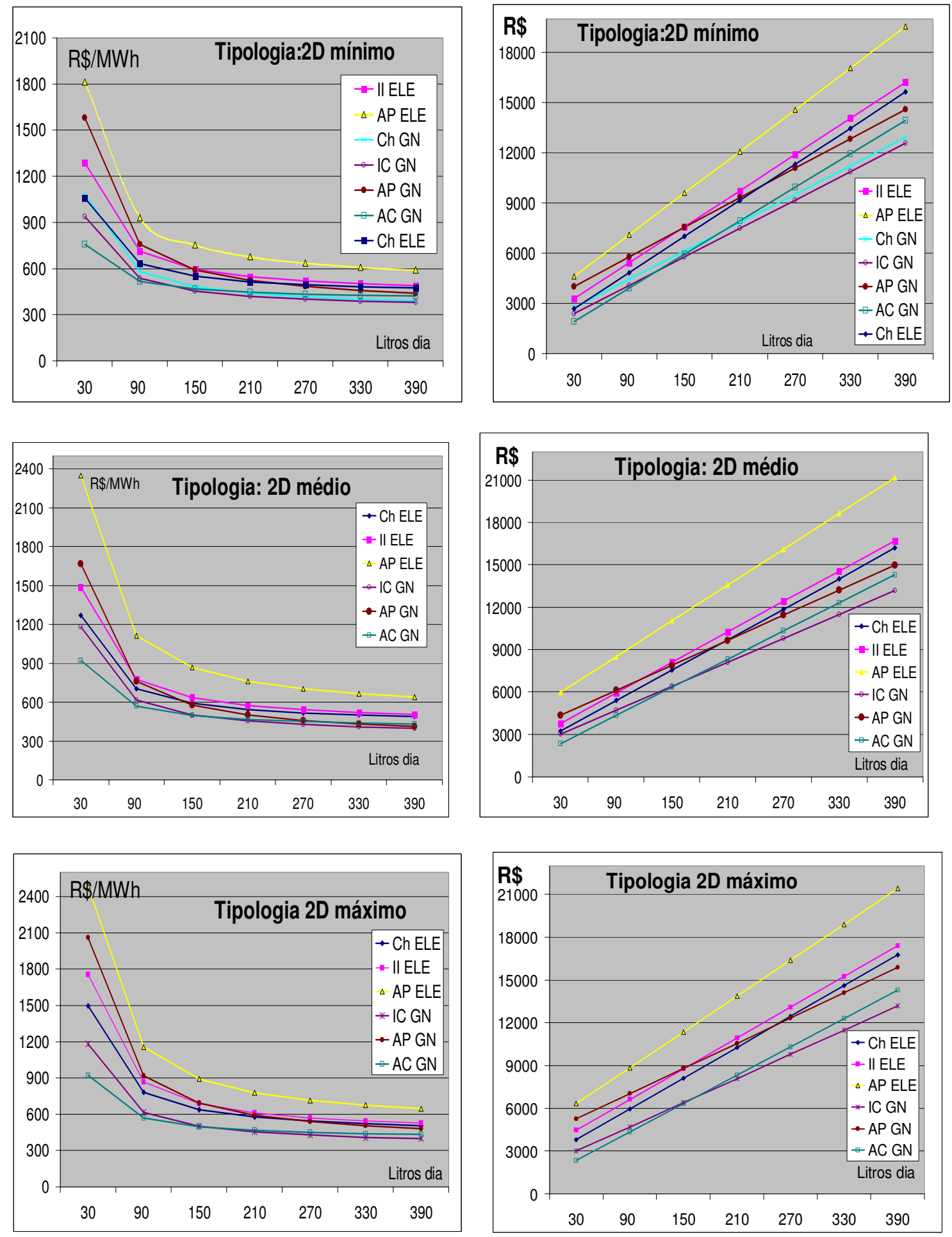

Figura 6.1 Custos do serviço de aquecimento de água residencial em função do volume de utilização; r= 12\%a.a.; Tipologia: 2Dormitórios; Tempo de análise do investimento $=10$ anos; Sistema elétrico e gás natural.

Legenda: $\mathrm{Ch}=$ Chuveiro; II = Instantâneo Individual; IC = Instantâneo Central;

$\mathrm{AP}=$ Acumulação Privado; $\mathrm{AC}=$ Acumulação Coletivo; ELE = Elétrico; GN = Gás Natural 

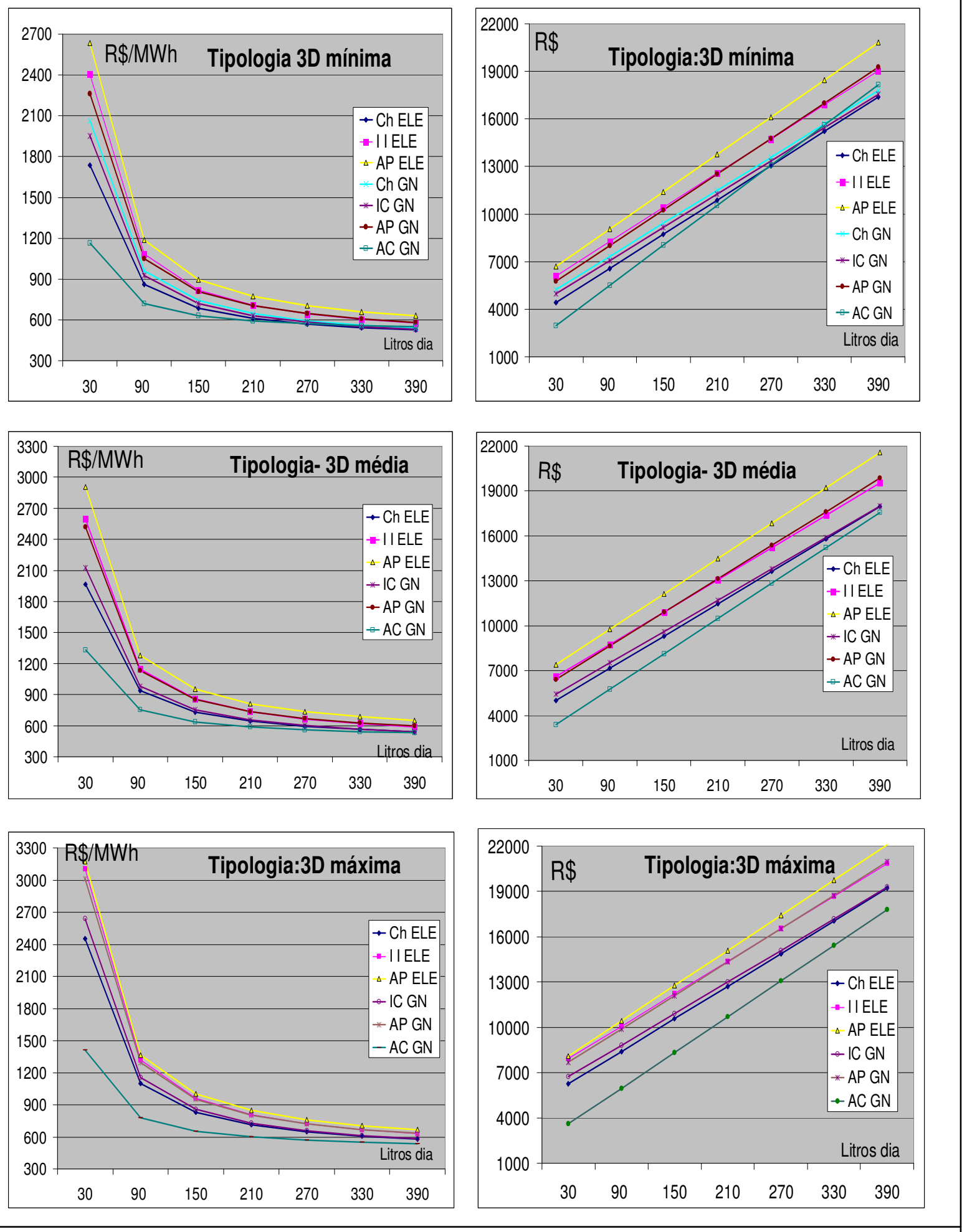

Figura 6.2 Custos do serviço de aquecimento de água residencial em função do volume de utilização, $r=12 \%$ a.a. Tipologia: 3Dormitórios; Tempo de análise do investimento $=10$ anos; Sistema elétrico e gás natural.

Legenda: $\mathrm{Ch}=$ Chuveiro; II = Instantâneo Individual; IC = Instantâneo Central; $\mathrm{AP}=$ Acumulação Privado; $\mathrm{AC}=$ Acumulação Coletivo; ELE = Elétrico; GN = Gás Natural 

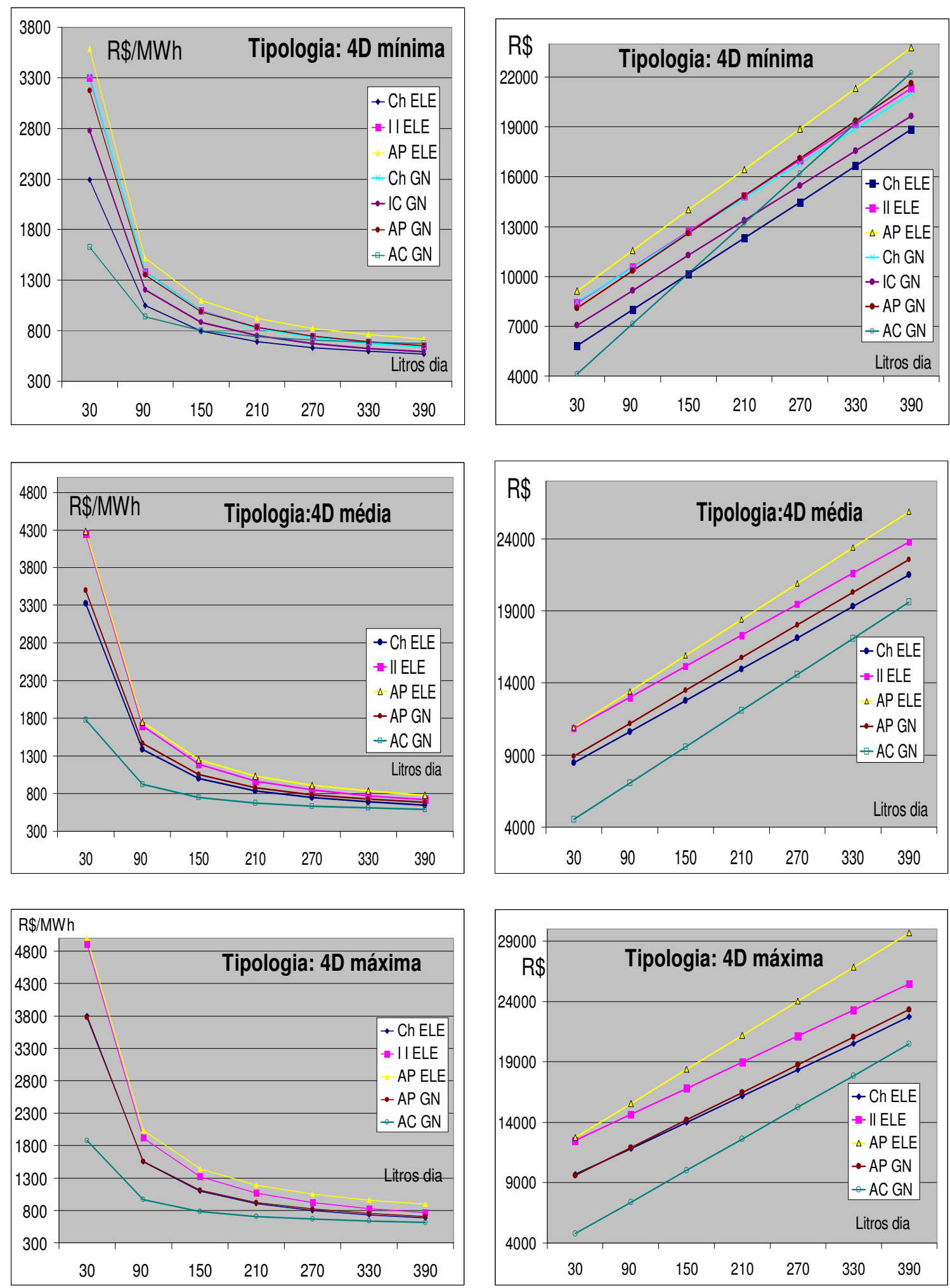

Figura 6.3 Custos do serviço de aquecimento de água residencial em função do volume de utilização, $r=12 \%$ a.a. Tipologia: 4Dormitórios; Tempo de análise do investimento $=10$ anos; Sistema elétrico e gás natural .

Legenda: $\mathrm{Ch}=$ Chuveiro; II = Instantâneo Individual; IC = Instantâneo Central;

AP = Acumulação Privado; AC = Acumulação Coletivo; ELE = Elétrico; GN = Gás Natural 
6.2.2 Resultados entre custos parciais de aquecimento de água: elétrico e a gás natural em função do volume de utilização, desconsiderando infra-estrutura

Estes resultados parciais de custo, desconsiderando o custo da infraestrutura, em função do volume de utilização, estão apresentados nas Figuras 6.4 e 6.5 , respectivamente para as tipologias de 2, 3 e 4 dormitórios.

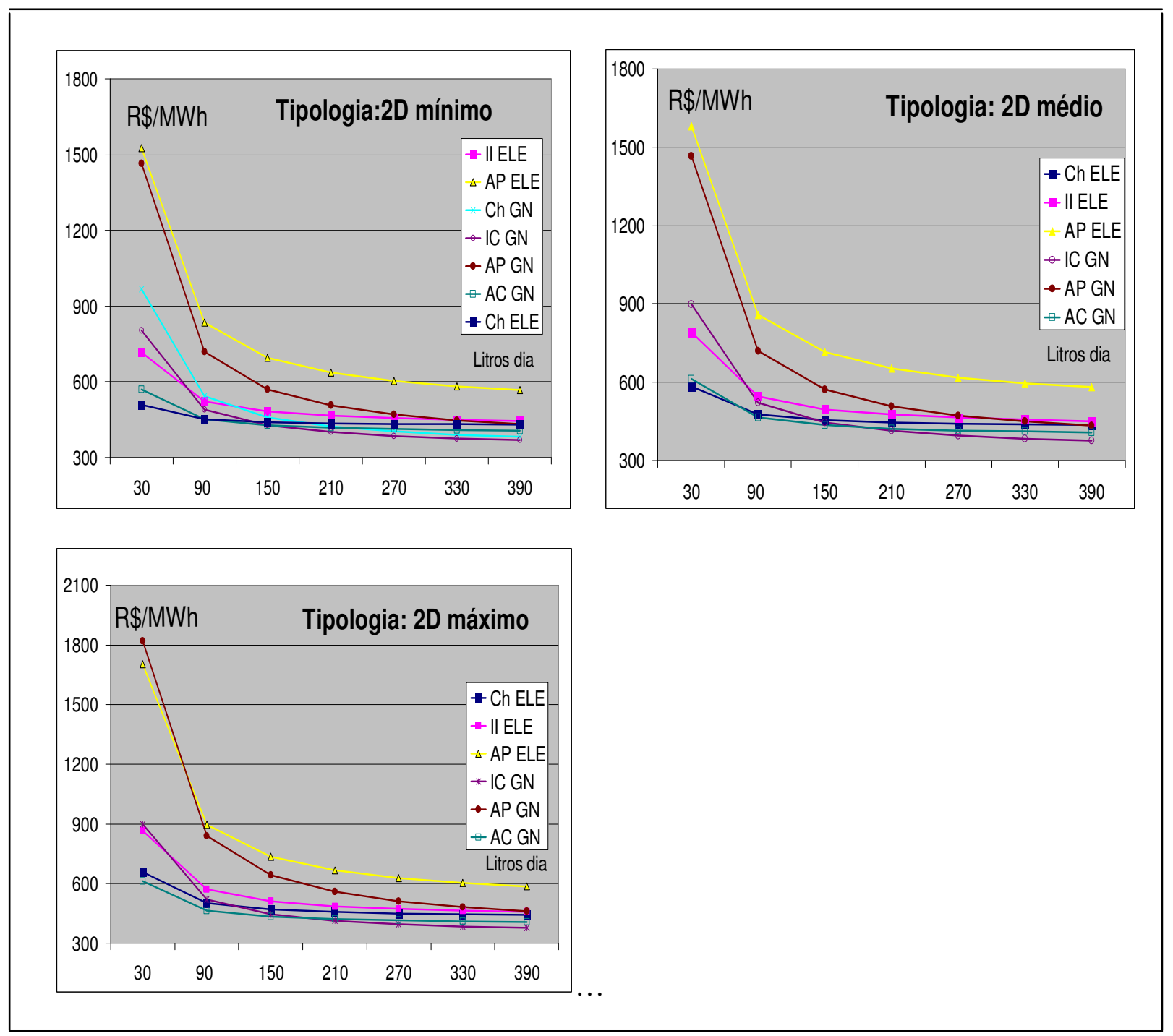

Figura 6.4 Custo parcial considerando custo equipamento e custo energia, em função do volume de utilização, r= 12\%a.a. Tipologia: 2Dormitórios; Tempo de análise do investimento = 10 anos; Sistema elétrico e gás natural .

Legenda: $\mathrm{Ch}=$ Chuveiro; II = Instantâneo Individual; IC = Instantâneo Central;

$\mathrm{AP}=$ Acumulação Privado; $\mathrm{AC}=$ Acumulação Coletivo; ELE = Elétrico; GN = Gás Natural 


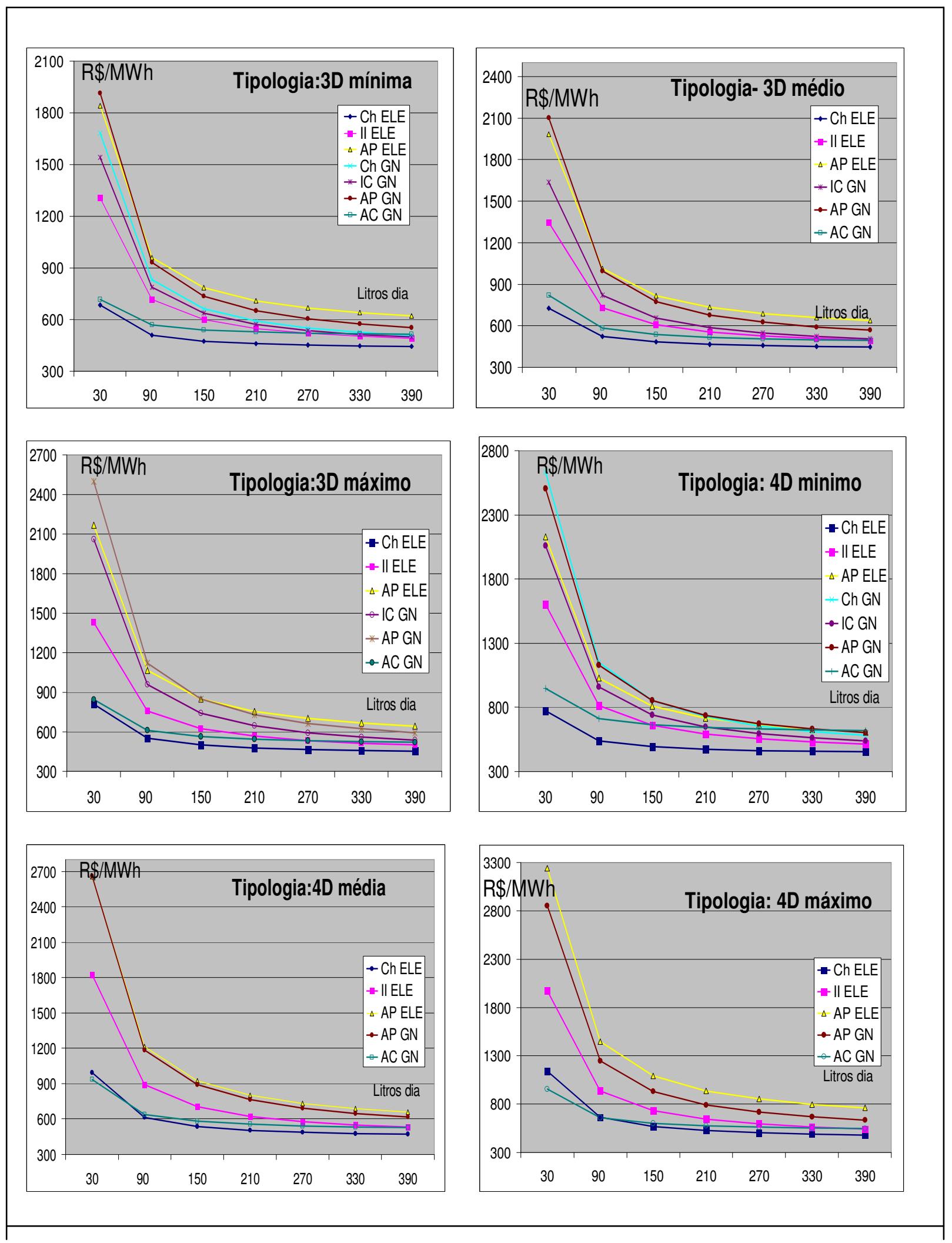

Figura 6.5 Custo parcial considerando custo equipamento e custo energia, em função do volume de utilização, $r=12 \% a$.a. Tipologia: 3 e 4 Dormitórios; Tempo de análise do investimento $=10$ anos; Sistema elétrico e gás natural

Legenda: $\mathrm{Ch}=$ Chuveiro; II = Instantâneo Individual; IC = Instantâneo Central; $\mathrm{AP}=$ Acumulação Privado; $\mathrm{AC}=$ Acumulação Coletivo; ELE = Elétrico; $\mathrm{GN}=$ Gás Natural 
6.2.3 Resultados entre custos de serviço de aquecimento de água: elétrico e a gás natural; por tempo de utilização

Os resultados dos Custos do Serviço de Aquecimento de Água Residencial em função do tempo de utilização estão apresentados nas Figuras 6.6 a 6.7, respectivamente para as tipologias de 2, 3 e 4 dormitórios.

$\checkmark$ Estes custos consideram a vazão dos pontos de uso.

$\checkmark$ Os custos estão apresentados em $R \$$, gastos em 10 anos

$\checkmark$ Para a tipologia de 2, 3 e 4 dormitórios está considerada a utilização de 30, 40 e 50 minutos de uso diário, incluindo banho, torneiras de cozinha e lavabo, quando disponibilizadas na infra-estrutura.

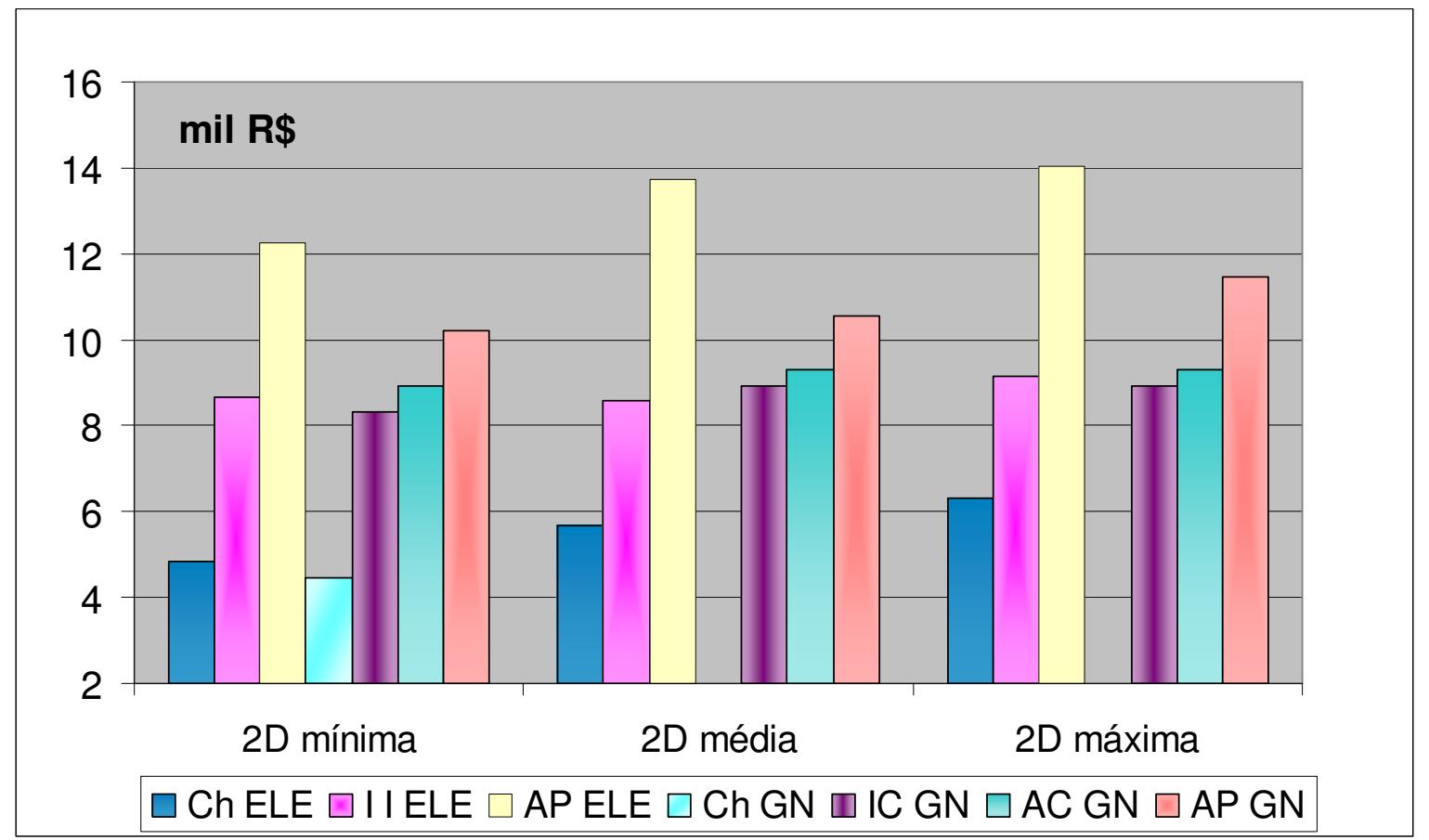

Figura 6.6 . Custo do serviço de aquecimento de água para 30 minutos de uso diário;Tipologia: 2 Dormitórios; r=12\%a.a.; Tempo de análise 10 anos.

Legenda: $\mathrm{Ch}$ = Chuveiro; II = Instantâneo Individual; IC = Instantâneo Central; $\mathrm{AP}=$ Acumulação Privado; $\mathrm{AC}=$ Acumulação Coletivo; ELE = Elétrico; GN = Gás Natural 


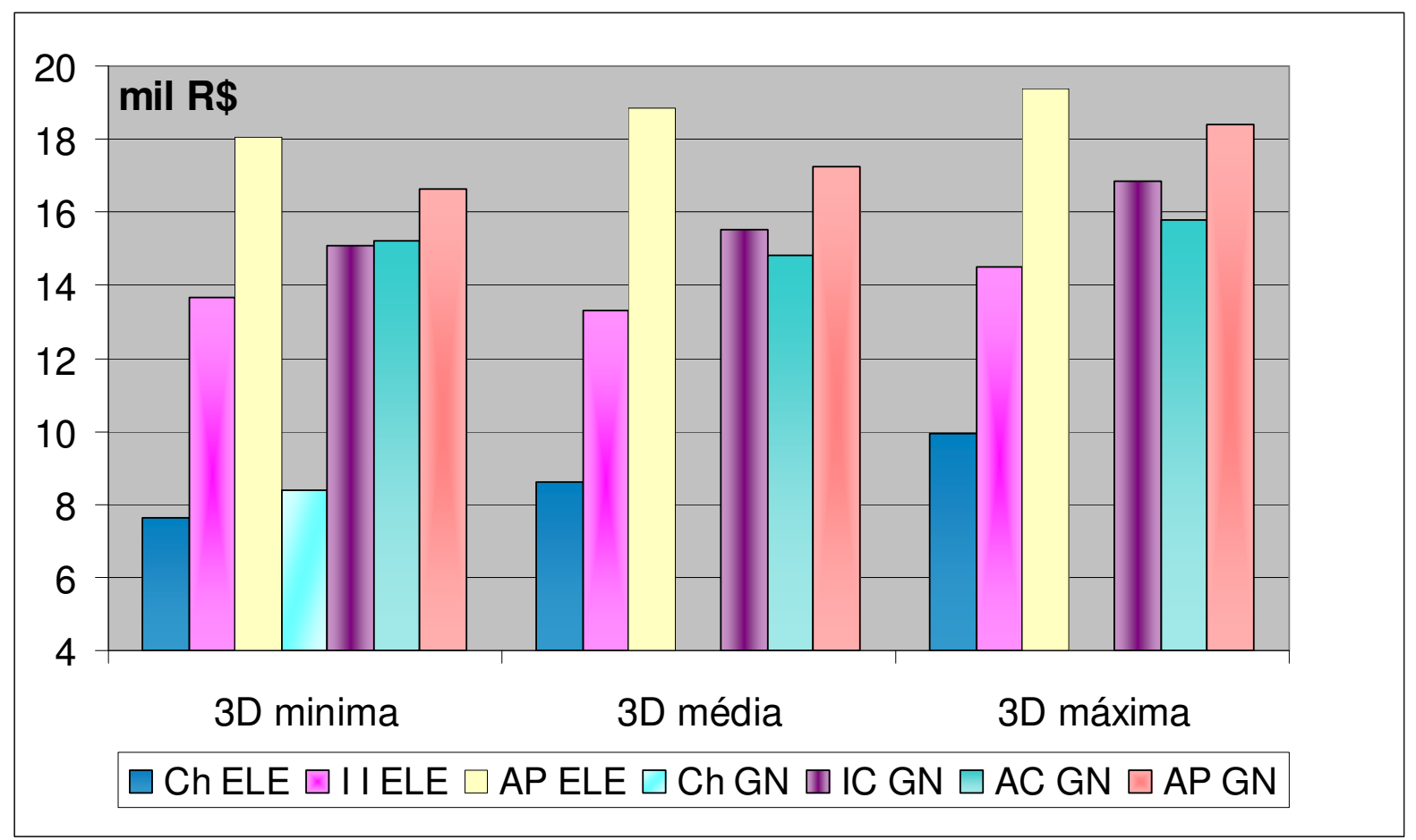

Figura 6.7 . Custo do serviço de aquecimento de água para 40 minutos de uso diário; Tipologia : 3 dormitórios; r=12\%a.a.; Tempo de análise 10 anos.

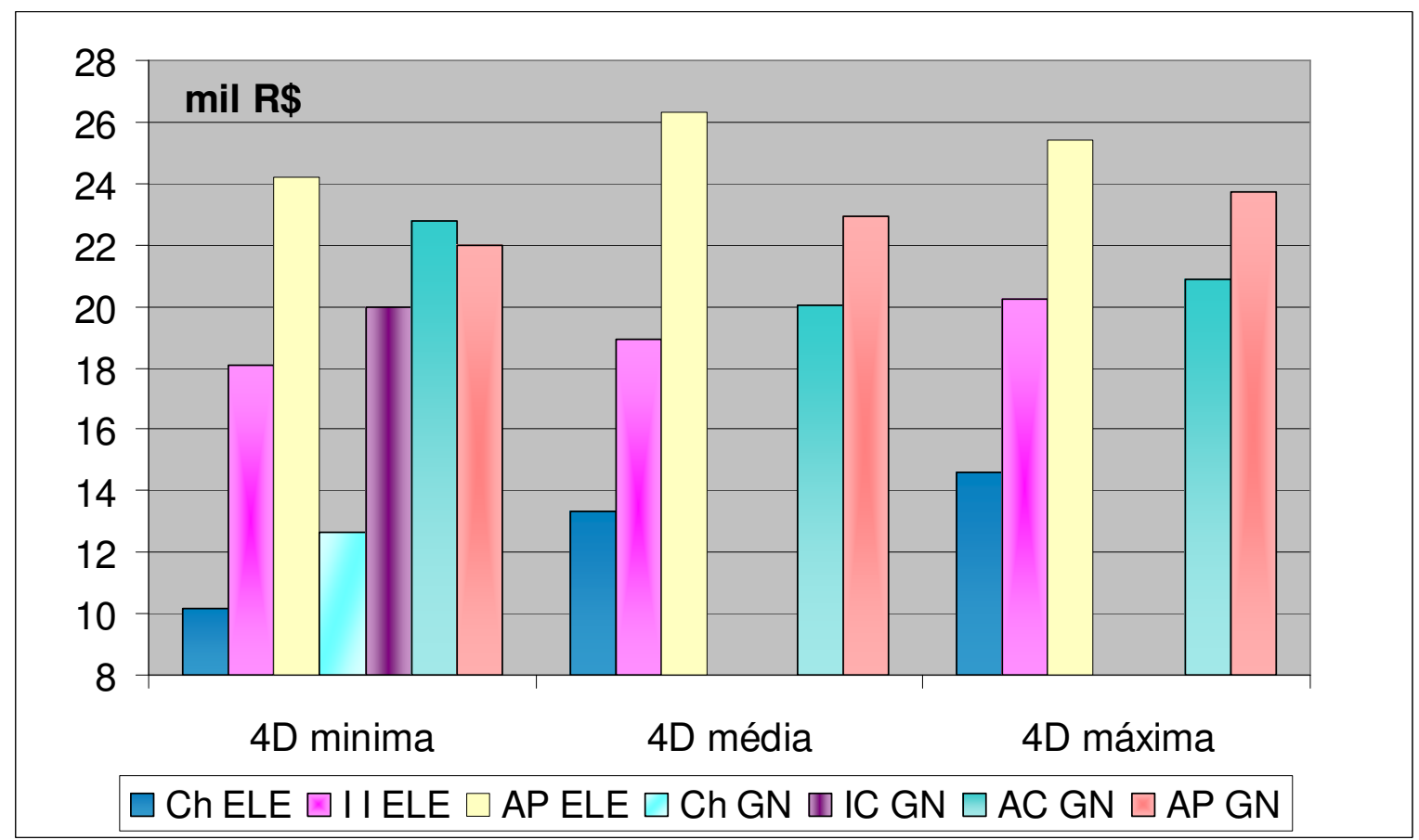

Figura 6.8. Custo do serviço de aquecimento de água para 50 minutos de uso diário; Tipologia: 4 dormitórios; r=12\%a.a.; Tempo de análise 10 anos. 
6.2.4 Resultados entre custos de serviço de aquecimento de água: gás natural e gás liquefeito de petróleo

O projeto de norma CB-09:402.02-051- Redes de distribuição interna de gases combustíveis - Projeto e execução regulamenta a instalação para os diferentes gases do mercado. Apesar de estes apresentarem diferentes características, esta norma prevê uma única instalação de rede interna para os diferentes gases combustíveis propiciando a alternativa do consumidor na escolha do tipo de gás.

Considerando nestas edificações, que a instalação de gás esteja adaptada ao gás natural e ao gás liquefeito de petróleo, a variação do custo de serviço de aquecimento de água (Ct) está no preço da energia final $(\mathrm{Pe})$.

O gás liquefeito de petróleo possui poder calorífico superior (PCS) mais elevado que o gás natural, enquanto $1 \mathrm{~m}^{3}$ de gás natural gera $10,932 \mathrm{kWh}, 1 \mathrm{~kg}$ de gás liquefeito de petróleo gera $13,721 \mathrm{kWh}$. O valor $\mathrm{R} \$ / \mathrm{MWh}$ do gás natural está acima do valor do $\mathrm{R} \$ / \mathrm{MWh}$ do gás liquefeito de petróleo. (vide item 6.1.5 Preço da energia).

A Figura 6.9 apresenta o custo de serviço de aquecimento em função do volume de utilização para o sistema a gás natural e a gás liquefeito de petróleo para a Tipologia 3 dormitórios disponibilidade mínima.

$\checkmark$ Os custos estão apresentados em R\$/MWh e o correspondente gasto em 10 anos, em $R \$$. 

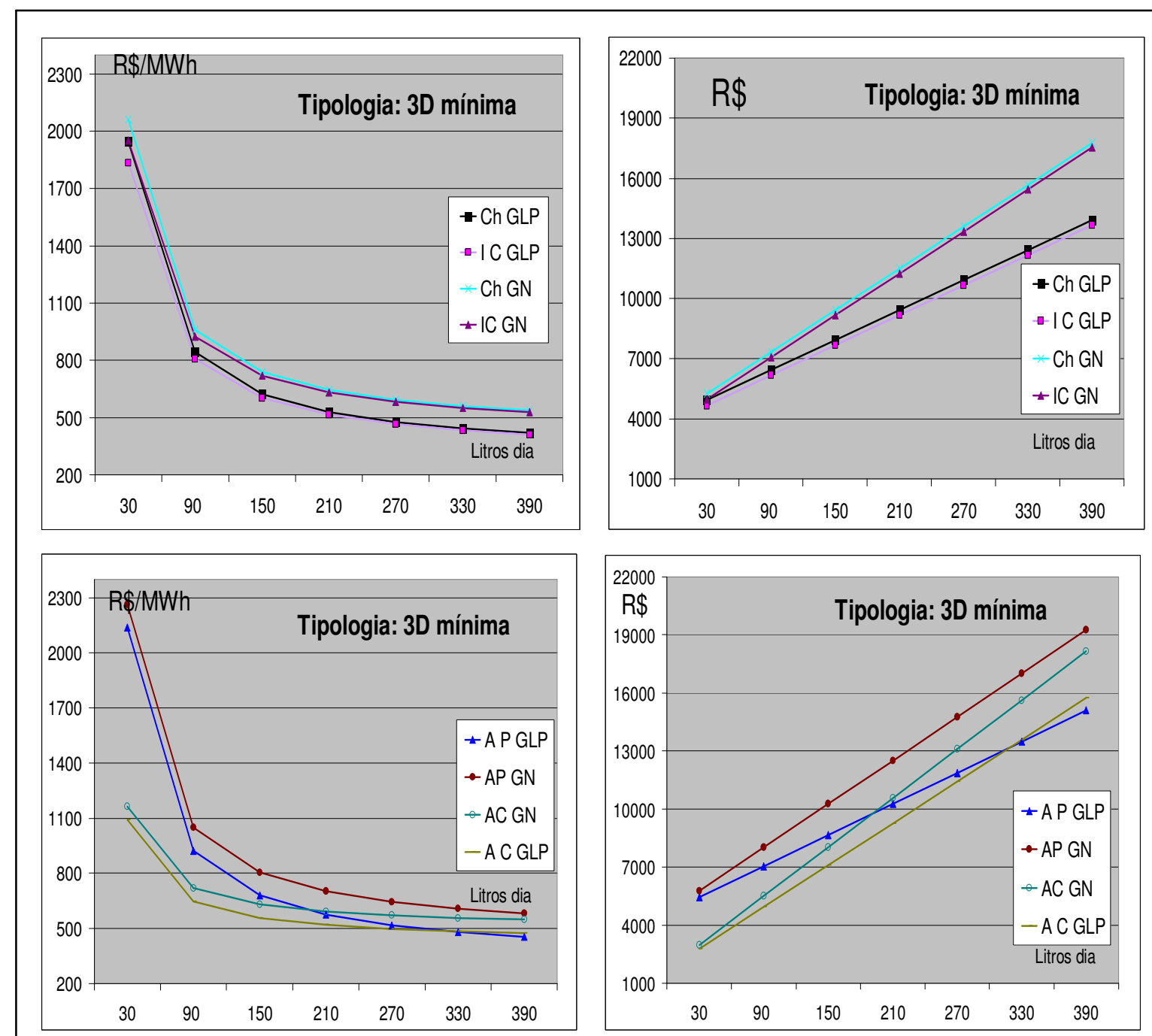

Figura 6.9 Custos do serviço de aquecimento de água residencial em função do volume de utilização; r= 12\%a.a.; Tipologia: 3Dormitórios; Tempo de análise do investimento = 10 anos; Sistema a gás liquefeito de petróleo e gás natural

Legenda: $\mathrm{Ch}=$ Chuveiro; IC = Instantâneo Central; AP = Acumulação Privado; $\mathrm{AC}=$ Acumulação Coletivo; GN = Gás natural; GLP = Gás liquefeito de petróleo 


\section{ENERGIA SOLAR COMO ECONOMIA DE ENERGIA PAGA}

\subsection{Inclusão do sistema de aquecimento solar}

A inserção da energia termo-solar no sistema de aquecimento pode promover o uso de uma alternativa economicamente viável e ambientalmente limpa.

Existe uma tendência em considerar que os sistemas de aproveitamento solar são sempre simples. O não conhecimento das características do sistema de aquecimento solar de água pode levar a uma instalação onde a maior parte da energia solar absorvida não é aproveitada e a energia consumida provém do sistema auxiliar de energia, energia que o consumidor paga (PROGENSA, 1989).

Para uma determinada condição meteorológica, a eficiência instantânea do coletor depende das propriedades físicas dos materiais utilizados para sua fabricação e formato. Coletores instalados em uma mesma localidade podem apresentar diferentes eficiências na conversão da radiação solar em calor. Os coletores de menor eficiência podem apresentar custos mais baixos e acessíveis. Se houver disponibilidade de espaço, pode-se optar por instalar uma maior área de coletores com menor eficiência para aquecer a mesma quantidade de água. A escolha depende da relação custo e benéfico que melhor se adequar ao usuário. (DUFFIE, 1991).

O sistema solar de aquecimento de água não é autônomo, exigindo uma energia auxiliar. Para o bom dimensionamento do sistema e determinação do melhor tempo de retorno do investimento é necessário conhecer a eficiência média diária e a taxa de cobertura solar (TCS). Existe uma grande incerteza na determinação desses parâmetros, que dependem de condições meteorológicas e das características intrínsecas de projeto do coletor e do acumulador. Define-se taxa de cobertura solar (TCS) como sendo a razão entre a energia final evitada e a energia final necessária para a satisfação do consumidor. 
7.2 Avaliação do tempo de retorno dos sistemas de aquecimento solar

Para uma mesma localidade, a área do coletor (A) é diretamente proporcional ao volume de água quente aquecido, conforme pode ser observado (7.1).

$$
A=\left(\frac{m^{*} c^{*} \Delta T}{\eta_{c} * H_{t}}\right)
$$

A energia final evitada ( $E$ ) é obtida pela equação (7.2), onde a $\eta_{e q}$ é a eficiência do equipamento auxiliar, na conversão de energia final em calor.

$$
E=\frac{H t \cdot A \cdot \eta_{c} \cdot T C S}{\eta_{e q}}
$$

Nos sistemas de acumulação, o investimento adicional para incluir a tecnologia solar é sobretudo o acréscimo do coletor solar. Analisando o investimento adicional, o tempo de retorno é calculado pela avaliação do Valor Líquido Presente (VLP), dos desembolsos e economias ao longo da vida útil do coletor.

$$
V P L=-I+\sum_{j=1}^{n} \frac{E E}{(1+i)^{j}}
$$

Onde:

I (Investimento inicial): o custo do coletor solar instalado.

lo é o preço médio do metro quadrado do coletor.

$$
I=A . I o
$$

e

EE (Energia economizada em $\mathrm{R} \$$ ): é o preço da energia final evitada.

$$
E E=E \cdot \text { preço da energia }
$$


i (taxa de juro)

j (período de análise)

O tempo de retorno do investimento ocorre quando o investimento é recuperado, ou seja, no momento em que:

$$
I=\sum_{j=1}^{n} \frac{E E}{(1+i)^{j}}
$$

Substituindo (7.4) e (7.5) em (7.6), tem-se:

$$
A \cdot I o=A \cdot \sum_{j=1}^{n} \frac{H t \cdot \eta \cdot T C S}{\eta e q} \cdot \frac{1}{(1+i)^{j}} \cdot \text { preço da energia }
$$

Pode-se concluir que:

- $\quad$ para qualquer área de coletor o tempo de retorno do investimento é o mesmo.

- para qualquer volume de água aquecida, o tempo de retorno do investimento é o mesmo. Afinal a área do coletor é diretamente proporcional ao volume de água a ser aquecida, em uma mesma localidade, conforme visto em (7.1).

O tempo de retorno do investimento do sistema de aquecimento solar é função da eficiência média do coletor (n), na conversão da radiação solar em calor e do consumo evitado de energia final, eletricidade ou gás (TCS). Raimo (2006) demonstra o tempo de retorno da instalação do coletor solar em função da variação da eficiência (n) e da taxa de cobertura solar (TCS) dos coletores. A variação demonstrada é de 30 a 50\% para a eficiência e de 50 a $90 \%$ para a taxa de cobertura solar. Portanto o produto $\eta \times$ TCS varia de 0,15 a 0,45. As figuras 7.1 e 7.2 apresentam o tempo de retorno do investimento do coletor solar em função do comportamento $\eta \times$ TCS, com energia final auxiliar elétrica e a gás, a uma taxa de juros de $12 \%$ ao ano, para a região metropolitana de São Paulo. Nesta região a radiação média anual sobre o plano inclinado do coletor é de aproximadamente $4.000 \mathrm{Wh} / \mathrm{m}^{2}$ (TIBA,2000). 


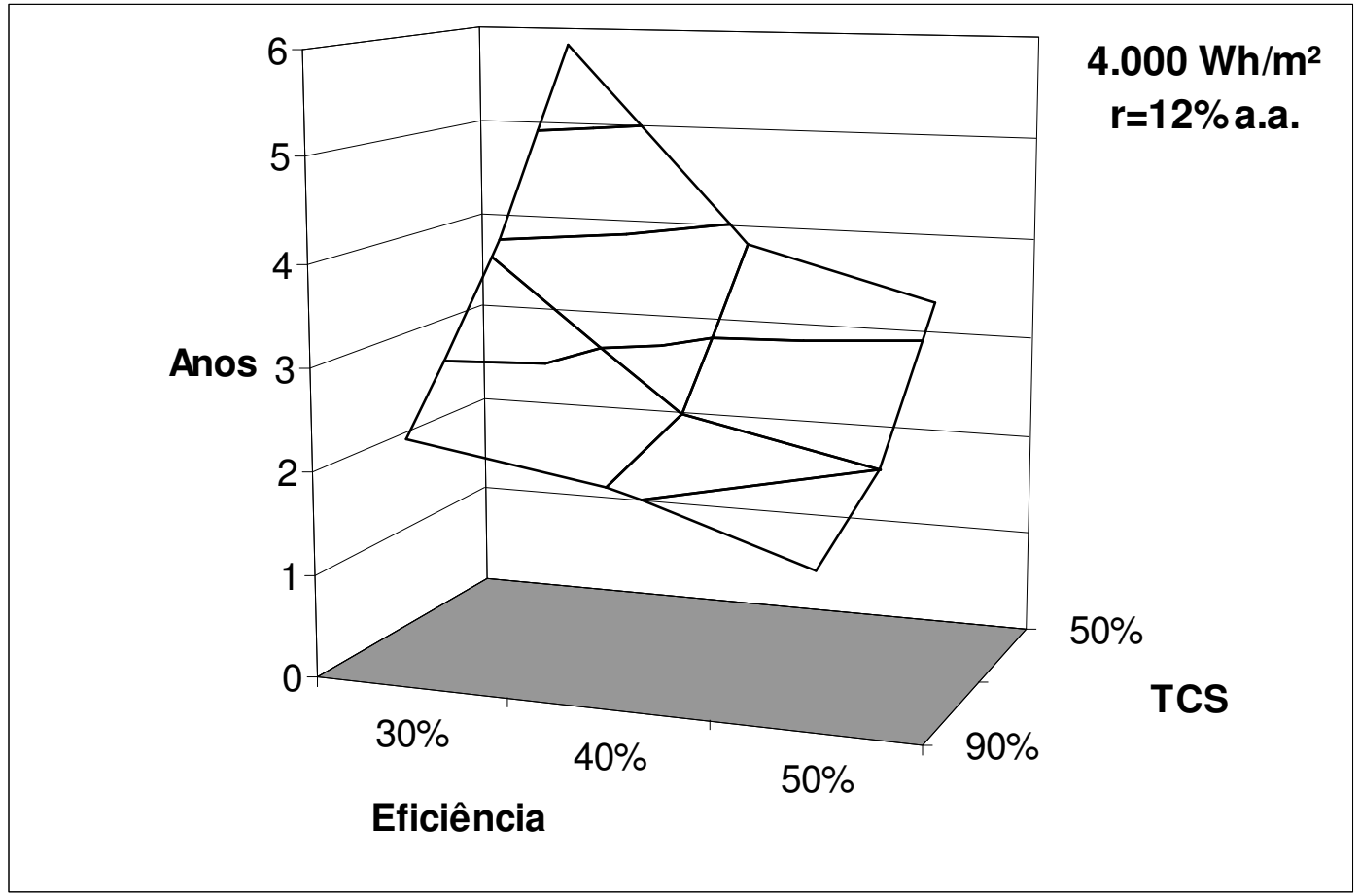

Figura 7.1 Tempo de retorno coletor solar - comportamento $\eta \times$ TCS - com energia final auxiliar elétrica - taxa de juro a $12 \%$ a.a.

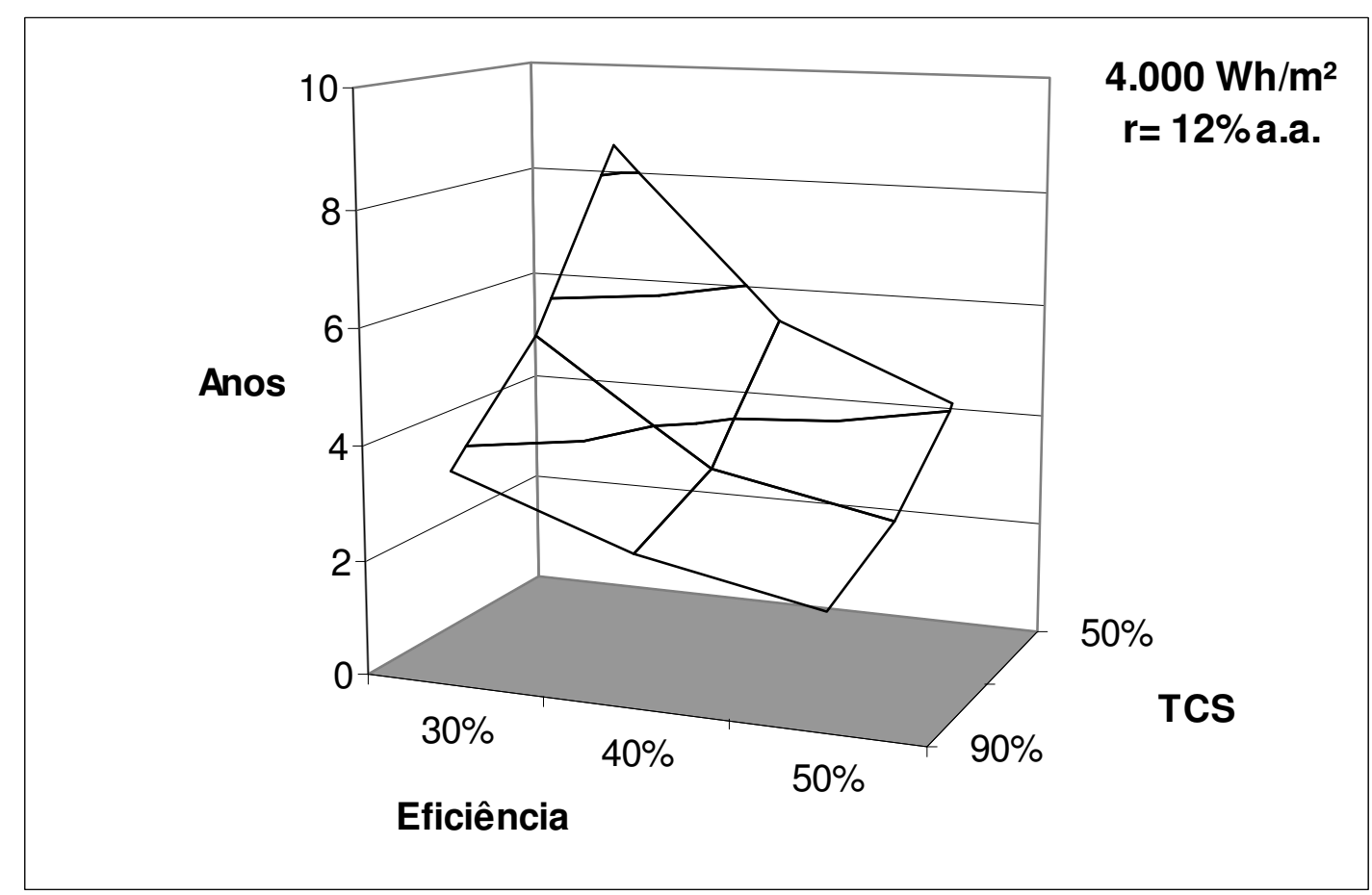

Figura 7.2 Tempo de retorno coletor solar - comportamento $\eta \times$ TCS - com energia final auxiliar a gás - taxa de juro a $12 \%$ a.a. 
A figura 7.3 mostra o resultado do tempo de retorno do investimento do coletor solar, com energia final auxiliar elétrica, para a taxa de juro de $12 \%$ ao ano. Esta comparação é apresentada para o produto da eficiência e taxa de cobertura solar ( $n \times$ TCS) nas localidades onde a radiação média local é de 4.000, 5.000 e $6.000 \mathrm{Wh} / \mathrm{m}^{2}$.

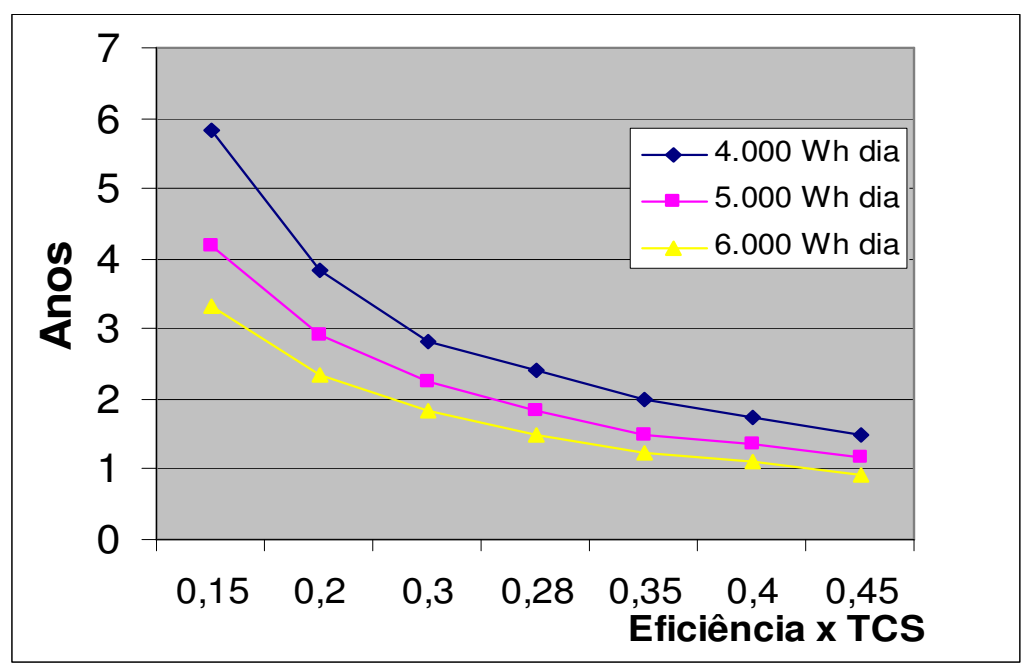

Figura 7.3 Tempo de retorno sistema solar com auxilio elétrico; $r=12 \%$ a.a.

A figura 7.4 mostra o resultado do tempo de retorno do investimento do coletor solar, com energia final auxiliar a gás, para a taxa de juros de $12 \%$ ao ano. Esta comparação é apresentada para o produto da eficiência e taxa de cobertura solar ( $\eta$ x TCS) nas localidades onde a radiação média local é de 4.000, 5.000 e 6.000 $\mathrm{Wh} / \mathrm{m} 2$. Estas figuras mostram os resultados obtidos para as taxas de juros de $12 \%$ a.a.

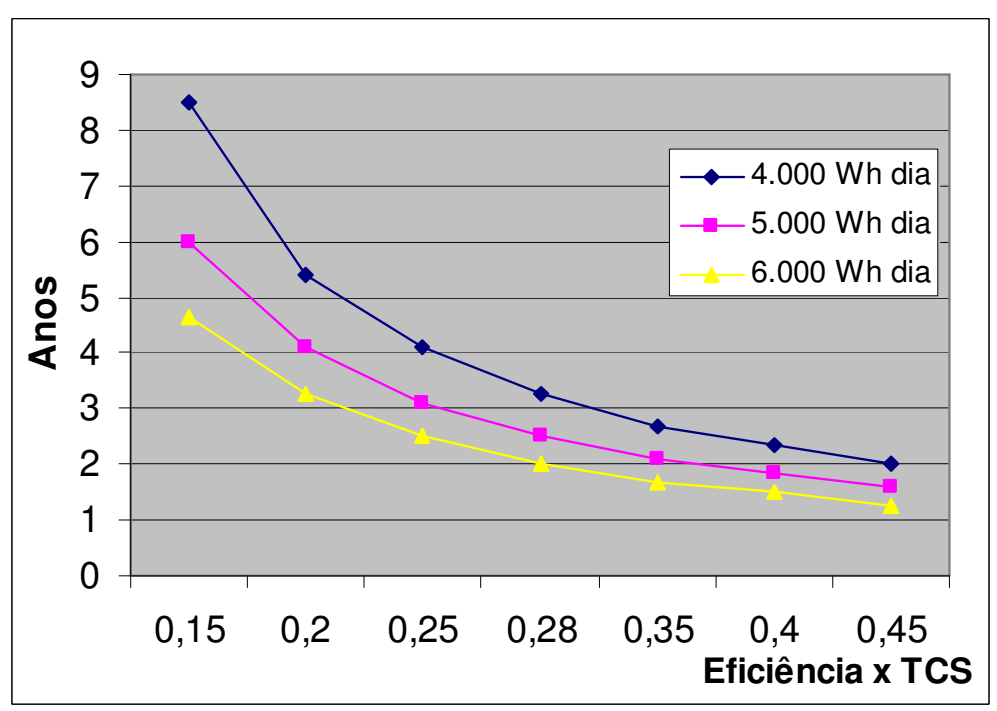

Figura 7.4 Tempo de retorno sistema solar com auxilio a gás; $r=12 \%$ a.a. 
7.3 Análise econômica utilizando energia solar como economia de energia paga

Para a aplicação do modelo econômico, com inclusão do sistema solar, adotam-se os seguintes parâmetros,:

> radiação média solar: esta avaliação é feita para a região metropolitana de São Paulo, onde esta radiação sobre o plano inclinado é de $4,14 \mathrm{kWh}$ dia $/ \mathrm{m}^{2}\left({ }^{36}\right)$.

> Taxa de Cobertura Solar media anual de $68 \%{ }^{37}$.

$>$ eficiência média dos coletores $\left(\eta_{\mathrm{c}}\right): 39,8 \%$. O Inmetro ${ }^{38}$ apresenta a produção de energia específica em média mensal do coletor solar, aplicada ao dia padrão definido para o Brasil.

> custo adicional de infra-estrutura hidráulica: custos da tubulação de água quente para a distribuição nas unidades consumidoras e seus acessórios. Estes valores estão apresentados no ANEXO G - Dimensionamento da Instalação Hidráulica de água quente.

> custo de venda e montagem: Os reservatórios e coletores solares aqui considerados são os de baixa pressão e instalados em locais expostos na cobertura da edificação. Os custos de vendas e montagem englobam serviços diferenciados para a mão de obra, acessórios de montagem e transporte dos equipamentos até o local. As estimativas destes custos estão apresentadas no ANEXO K.

O custo dos equipamentos e sua instalação foram levantados no mercado varejista de São Paulo que está adotando um valor médio, ANEXO K Dimensionamento do Sistema Solar. Deve-se considerar que estes custos de equipamento não levam em conta possível variante no momento da instalação e que uma seleção criteriosa de fornecedores e compra em grandes quantidades levam a uma diminuição do preço final do produto.

\footnotetext{
${ }^{36}$ www. cresesb.cepel.br

${ }^{37}$ Planilha de cálculo da Aquecedores Transsen e Green Solar (2007)

${ }^{38}$ Tabela www. Inmetro.gov.br/consumidor/tabelas. asp e Detalhes de cálculo podem ser vistos no PBE RESP/006 de 10/11/2005
} 
A análise econômica das alternativas utilizando energia solar como economia, inclui os custos de investimento dos equipamentos e infra-estrutura necessária ao sistema solar e os custos de energia.

O dimensionamento dos coletores solares e reservatório do sistema de aquecimento solar, deste estudo considera o valor recomendado pelo projeto de norma ${ }^{39}$ para consumo de água quente (de 6 a 12 litros/minuto/pessoa para banho). Nestas condições esta análise não mostra economia da inclusão do sistema solar no sistema convencional instantâneo individual. O dimensionamento do sistema de aquecimento solar deve considerar as vazões das peças de utilização e o tempo de utilização de água quente diário.

7.4 Resultados entre custos de serviço de aquecimento de água com sistema solar

As Figuras 7.5 a 7.7 comparam o custo do serviço de aquecimento de água (solar e convencional) e a contribuição (economia) que o solar fornece ao sistema, com o custo do sistema convencional (apresentados no item 6.2.3- resultados entre custos de serviço de aquecimento de água elétrico e a gás, por tempo de utilização).

> Para cada tipologia, a figura apresenta o resultado do custo de serviço, gasto em 10 anos, em mil $R \$$, e a porcentagem correspondente. $O$ custo do serviço de aquecimento de água convencional corresponde ao custo de $100 \%$.

> Para a tipologia de 2, 3 e 4 dormitórios está considerada a utilização de 30, 40 e 50 minutos de uso diários, respectivamente, para a infra-estrutura de disponibilidade máxima.

${ }^{39}$ Projeto Norma 55:003.01-002 - Sistemas de aquecimento solar de água em circuito direto Projeto e Instalação. 

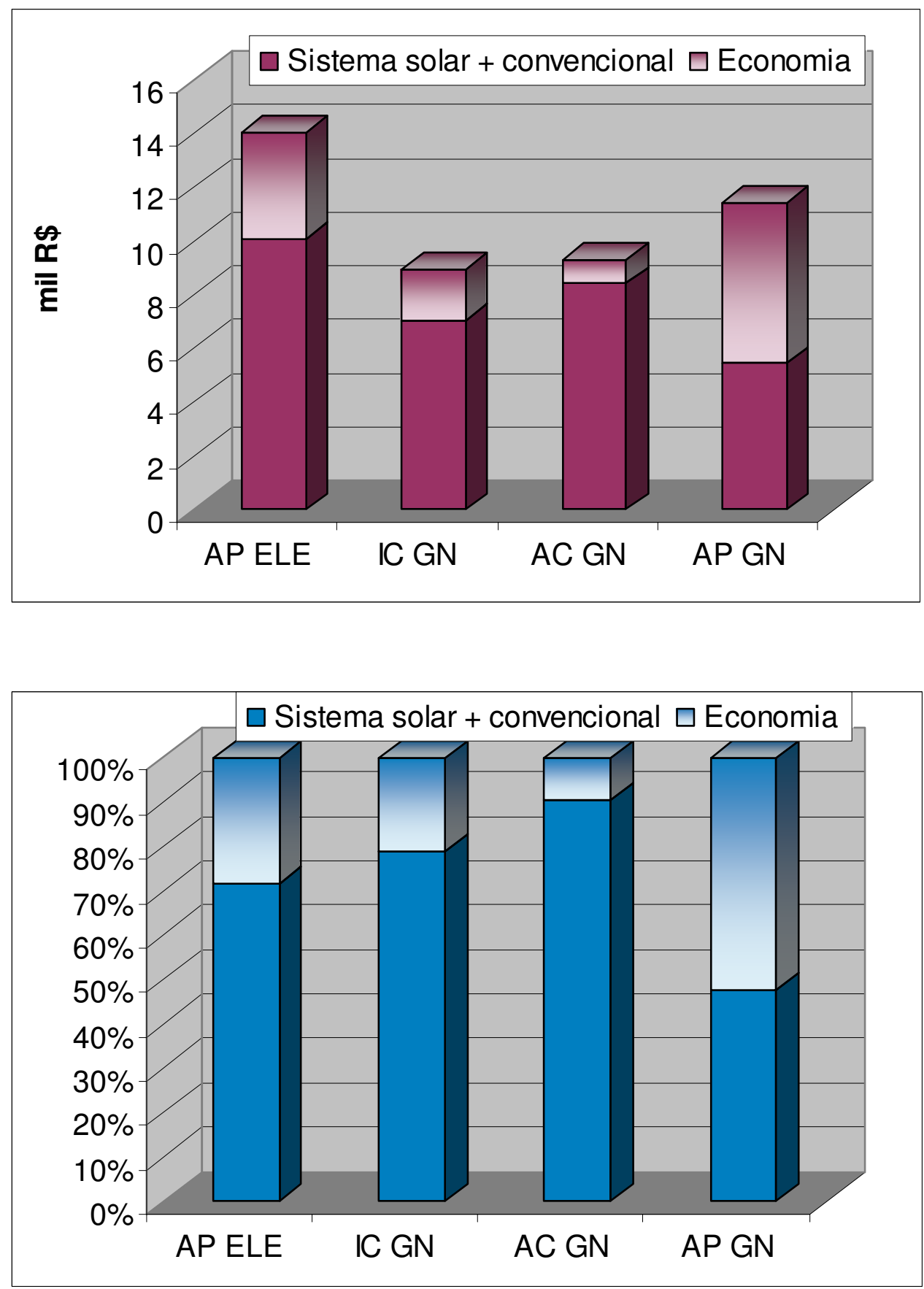

Figuras 7.5 Custo do serviço de aquecimento de água solar comparado ao convencional; Tipologia 2Dormitórios; 30 minutos diários.

Legenda: $\mathrm{Ch}$ = Chuveiro; II = Instantâneo Individual; IC = Instantâneo Central; $\mathrm{AP}=$ Acumulação Privado; $\mathrm{AC}=$ Acumulação Coletivo; ELE = Elétrico; GAS = Gás 


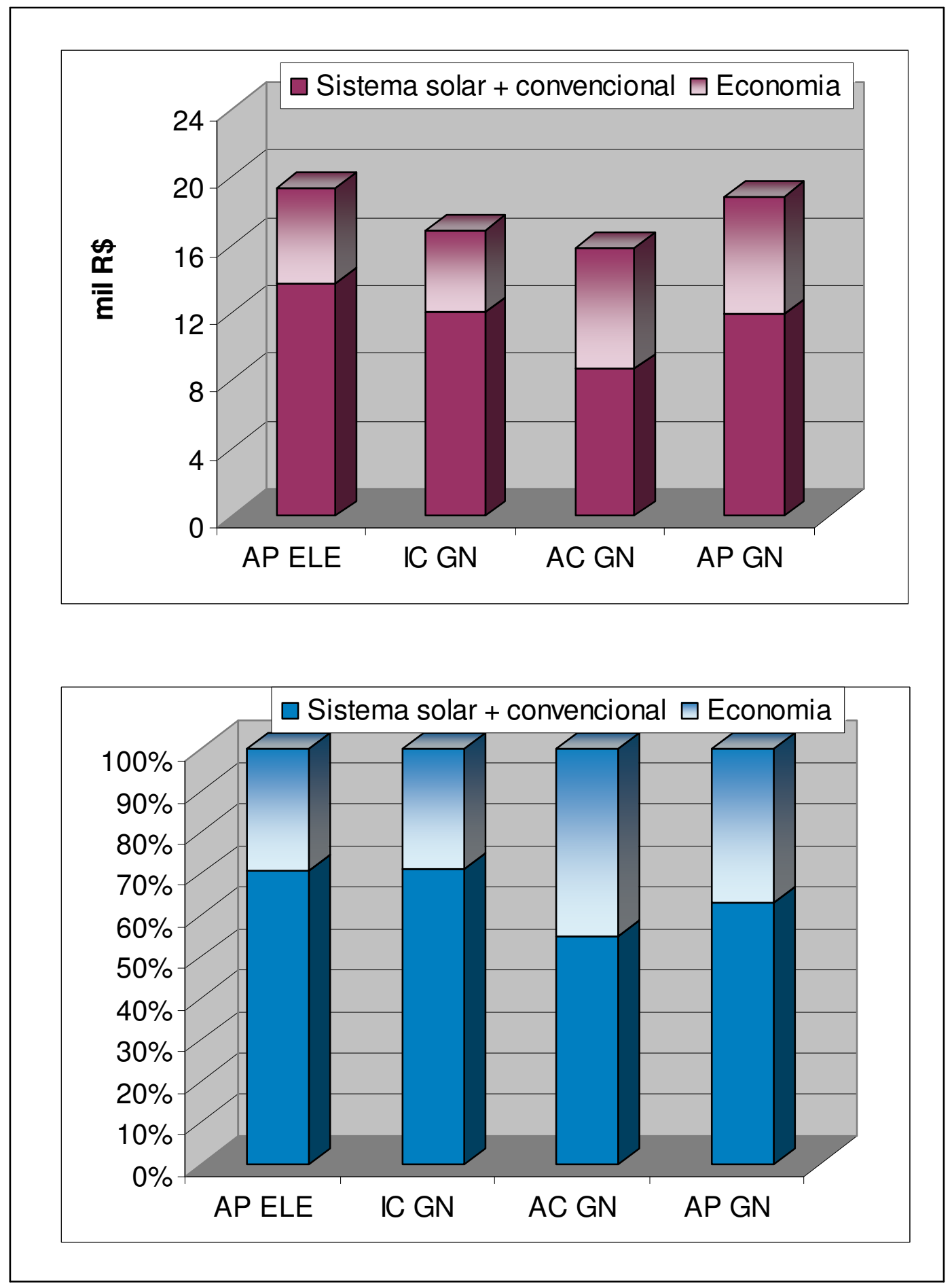

Figuras 7.6 Custo do serviço de aquecimento de água solar comparado ao convencional; Tipologia 3Dormitórios; 40 minutos diários.

Legenda: $\mathrm{Ch}=$ Chuveiro; II = Instantâneo Individual; IC = Instantâneo Central; $\mathrm{AP}=$ Acumulação Privado; $\mathrm{AC}=$ Acumulação Coletivo; ELE = Elétrico; GAS = Gás 

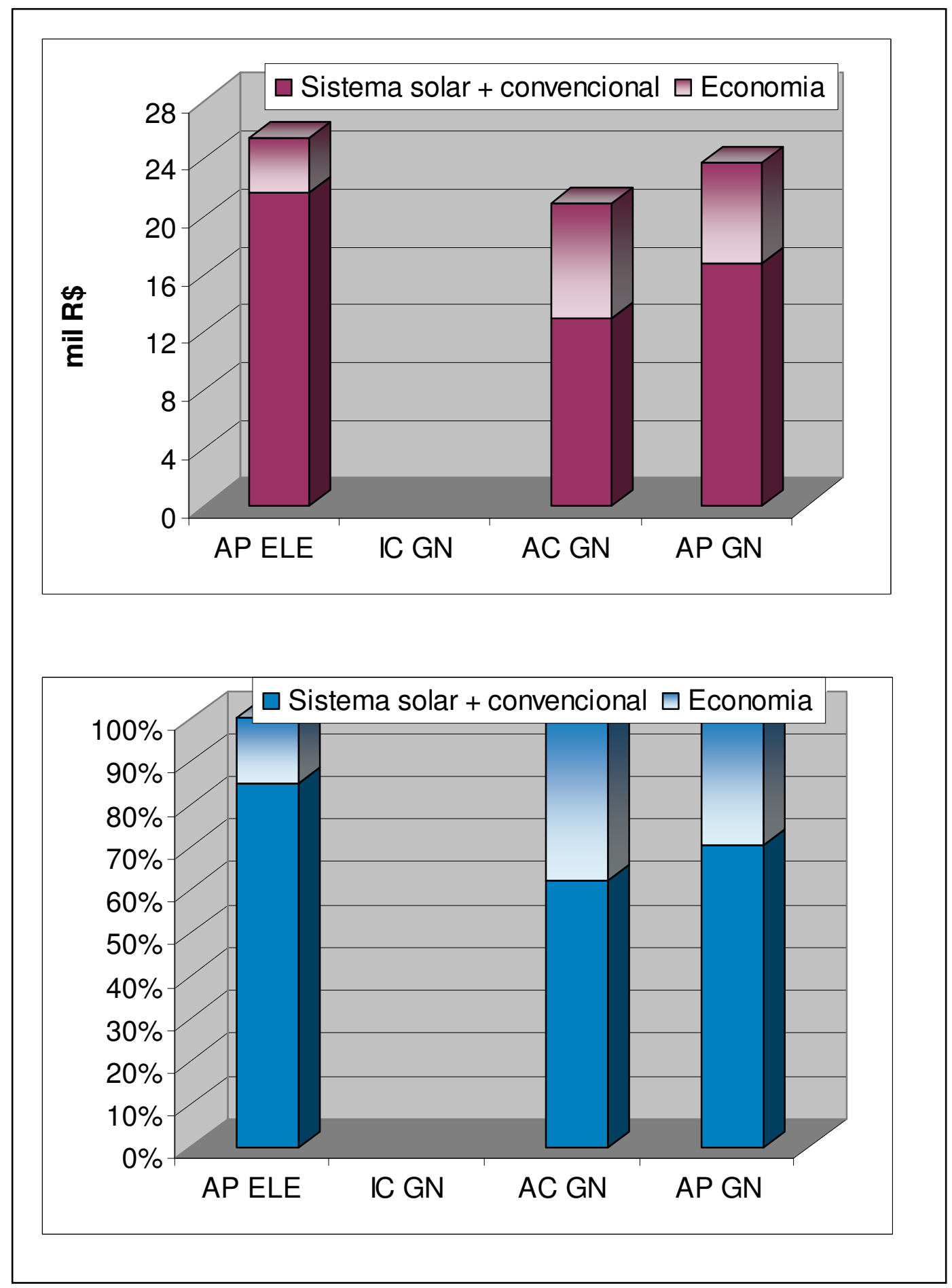

Figuras 7.7 Custo do serviço de aquecimento de água solar comparado ao convencional ; Tipologia 4Dormitórios; 50 minutos diários.

Legenda: $\mathrm{Ch}=$ Chuveiro; II = Instantâneo Individual; IC = Instantâneo Central; $\mathrm{AP}=$ Acumulação Privado; $\mathrm{AC}=$ Acumulação Coletivo; ELE = Elétrico; GAS = Gás 


\section{CONCLUSÃO}

A análise econômica elaborada neste trabalho apresenta diferentes resultados para as alternativas de aquecimento de água elétrico, a gás e solar, para as diferentes disponibilidades de uso e níveis de consumo.

A análise do custo de investimento da infra-estrutura, exclusiva para a disponibilidade de água quente nas edificações, mostra menor custo para o gás, o que pode induzir o mercado da construção civil em adotar esta alternativa.

Considerando o custo total do serviço de aquecimento em função do nível de consumo (volume de água produzida), observa-se o alto impacto do custo do investimento (infra-estrutura e equipamentos) para pequenos volumes de utilização. À medida que o nível de consumo aumenta, o custo da energia passa a ser mais significativo. Esta análise também mostra que para um mesmo nível de consumo, o custo do serviço de aquecimento para as diferentes disponibilidades e tipologias aumenta de forma crescente e significativa.

Como resultado da análise do custo total em função do nível de consumo, a utilização do sistema a gás liquefeito de petróleo como fonte de calor para o serviço de aquecimento de água em edificações mostra uma tendência de menor custo, quando comparado ao sistema a gás natural, que por sua vez se mostra mais econômico que o sistema elétrico.

A análise econômica do custo do serviço de aquecimento em função do tempo de utilização apresenta o sistema de aquecimento instantâneo individual elétrico e a gás mais econômico. Este sistema apresenta pequeno consumo de água quente no instante de uso, necessitando portanto menor energia final. Este sistema representa economia de custo ao consumidor.

A inclusão da utilização do sistema de aquecimento solar no sistema de acumulação e instantâneo central convencional apresenta economia para varias taxas de cobertura solar.

Neste estudo foram detectados parâmetros que merecem análises no planejamento do sistema de aquecimento de água para o setor residencial, tais como vazão de água nos pontos de uso, seu custo e a perda de energia no transporte de água pela tubulação. 
Pelo resultado da análise econômica do custo total dos sistemas em função do tempo de utilização, observa-se a importância da vazão de água no ponto de uso, pois apesar do alto custo de investimento para produção de pequenos volumes. A Região Metropolitana de São Paulo apresenta escassez de água potável necessitando de uso racional deste recurso. Políticas públicas vêm sendo tomadas neste sentido, tal como obrigatoriedade de medição de consumo individualizada deste recurso, com o intuito de inibir desperdício.

A perda de energia no transporte da água quente na infra-estrutura da edificação deve ser inserida nas avaliações dos programas de conservação de energia.

Esta pesquisa mostra a relevância do planejamento para aquecimento de água no setor residencial, pois embora o gás e a energia termo-solar sejam mais compatíveis, sob o ponto de vista termodinâmico, ao processo de transformação de energia primária em calor, o custo do serviço de aquecimento de água, utilizando estas fontes de calor, em algumas alternativas, é mais elevado que o custo do serviço elétrico. Nestas alternativas o consumidor estará sempre pagando mais quando substitui a energia elétrica.

Em um momento em que o planejamento energético preconiza a racionalidade de consumo de energia primária, redução da demanda de energia elétrica no horário de ponta, as políticas devem conduzir a um planejamento que permita a reversão da eletrotermia no setor residencial. Com uma política de preços de energia e incentivos, o setor energético pode obter economia de energia elétrica com a inclusão dos sistemas de aquecimento de água a gás e do sistema termosolar no setor residencial. 


\section{REFERÊNCIAS BIBILIOGRÁFICAS}

AGENCIA NACIONAL DO PETRÓLEO. Informativo de tarifas. <http://www.anp.gov.br/petro/petroleo.asp >. Acesso: jan 2007.

ASSOCIAÇÃO BRASILEIRA DE AQUECEDORES A GÁS. Eficiência energética do seu aquecedor homologado. São Paulo : ABAGAS, 2006.

ASSOCIAÇÃO BRASILEIRA DA INDÚSTRIA ELÉTRICA E ELETRÔNICA (ABINEE). Informativo técnico. Disponível em: http://www.abinee.org.br/programas/prog03.htm Acesso em out 2006.

ASSOCIAÇÃO BRASILEIRA DE REFRIGERAÇÃO, AR-CONDICIONADO, VENTILAÇÃO E AQUECIMENTO . Boletim técnico Departamento de Economia e de Aquecimento Solar. [mensagem pessoal] Enviada por CAFÉ, Diretoria DASOL. Acesso: 14 de agosto de 2006.

ASSOCIAÇÃO BRASILEIRA DE NORMAS TÉCNICAS NBR 5626: Instalações Prediais de Água Fria, São Paulo, 1998.

NBR 8130: Aquecedores de Água a Gás Tipo Instantâneo. São Paulo, 2006. Acesso à revisão no Comitê Brasileiro de gás CB - 09 em: 30 de agosto de 2006.

NBR-5410: Instalações elétricas de baixa tensão. Execução de Instalações Elétricas de Baixa Tensão - Procedimento. São Paulo, 2004.

NBR 7198: Projeto e execução de instalações prediais de água quente.

Brasília, 1993 
NBR 13103: Instalações de aparelhos a gás para uso residencial Requisitos dos ambientes. São Paulo, 2006. Acesso à revisão no Comitê Brasileiro de gás CB-09 em março de 2006.

NBR 13.523: Central de Gás Liquefeito de Petróleo. São Paulo, 2005.

Projeto Norma 402.02-051- Redes de distribuição interna de gases combustíveis - Projeto e execução. São Paulo,2007. Em consulta pública até 20/03/2007, Disponível em: http://www.abntnet.com.br/consultanacional/default.aspx

Projeto de revisão NBR 12.269: Instalação de sistemas de aquecimento solar de água em circuito direto - Procedimento. São Paulo,2006.

Projeto Norma 55:003.01-002: Sistemas de aquecimento solar de água em circuito direto - Projeto e Instalação. São Paulo, 2006. Acesso à revisão no Comitê Brasileiro de refrigeração, Ar-condicionado, Ventilação e Aquecimento CB-55 em novembro de 2006.

ALMEIDA, A.;Lopes, A.; Carvalho, A.; Mariano, J.; Nunes, C. Evaluation of fuelswitching in the residencial sector. Revista Energy and Buildings, n.36, 2004a. Editora Elsevier. Disponível em: <http:// www. Sciencedirect.com>. Acesso em: 27 abril 2005.

ALTENER. Energia Solar Térmica, manual sobre tecnologias e instalações.Projeto GREENPRO, Comissão Européia. Europa. 2004.

BENDERS,R.M.J; KOK,R; MOLL,H.C.; WIERSMA,G.; NOORMAN, K.J.; New approaches for household energy conservation - In search of personal household energy budgets and energy reduction options, Energy Police, v.34, n.18, dez., p. 3612-3622,2006.

BERMANN, C.; Energia no Brasil: para que? Para quem? : crise e alternativas para um país sustentável. 2.ed. São Paulo: Livraria da Física, 2002. 
BOSCH Termotécnica. Manual para Engenharia. Aquecedores de água a gás. $<$ www.bosch.com.br> . Acesso em: 5 março 2004.

BRASIL. Presidência da república. Decreto 4.059 de 19 de dezembro de 2001, prescreve: Eficiência

BRASIL. Ministério do desenvolvimento Industria e comercio exterior. Importação. 2003 Site: http://aliceweb.desenvolvimento.gov.br/default.asp . Acesso em 12/01/2007.

BRASIL. Ministério de Minas E Energia. Programa Brasileiro de Etiquetagem. Regulamento específico para uso da etiqueta nacional de conservação de energia (ENCE).

RESP/002 - AAQ - Linha de aparelhos elétricos fixos de aquecimento instantâneo de água

RESP/006- SOL - Sistema e Equipamentos para aquecimento Solar de água

Coletores Solares Planos, reservatório Térmico e Sistemas Acoplados., Rev. 7, 10/11/2005

RESP/009 - AQC Aquecedores de água a gás tipo instantâneo e de acumulação

. Balanço energético nacional. Brasília,2006.

CARDAL. Manual de Instruções. São Paulo,2006. Disponível em:

<http:/www.cardal.com.br/frmaq_central.html>. Acesso em : set 2006.

CENTRO DE REFERÊNCIA PARA ENERGIA SOLAR E EÓLICA SERGIO DE SALVO BRITO (CRESESB). Potencial energético solar. Dados de irradiação solar. Disponível em< http://www.cresesb.cepel.br/>. Acesso: março 2006.

COMPANHIA DISTRIBUIDORA DE GÁS DO RIO DE JANEIRO (CEG). Informação verbal fornecida por Departamento Gerencia Norte, CEG em maio de 2004. 
COHEN,C.; LENZEN,M.; SCHAEFFER,R.; Energy requirements of households in Brazil. Energy Police, n.33, p.555-562, 2005.

COMPANHIA DE GÁS DE SÃO PAULO. Projeto de P\&D de capacitação de profissionais no Tema: Aquecimento de água. São Paulo. 2007. No prelo.

. Regulamento de instalações prediais de gás. São Paulo, 2006.

CORONA. Manual de instalação. São Paulo, 2007. Disponível em $<$ http://www.corona.com.br/produtos quatroestacoes.php $>$. Acesso: outubro de 2006

COMISSÃO DE SERVIÇOS PÚBLICOS DE ENERGIA (CSPE) . Revisão Tarifária. Disponível em:< www.cspe.sp.org.br>. Acesso: fev 2007.

CUMULUS. Manual de aquecedor de acumulação. Disponível em: <http://www. cumulus.com.br>. Acesso em: setembro 2006.

DIAKOULAKI,D. et al. Cost benefit analysys for solar water heating systems. Energy Conversion \& Management, n.42, p.1727-1739, nov.2001.

DUFFIE,J. A., BECKMAN, W. A. (1991).; Solar Engineering of Thermal Process. 2ed. New York: John Wiley\&Sons, 1991,919p.

ELETROPAULO. LIG BT 2005: Livro de Instruções Gerais, Fornecimento de Energia Elétrica em Baixa Tensão. São Paulo, 2005. Disponível em: <www.eletropaulo.com.br> . Acesso em: agosto de 2006.

ENERGY INFORMATION ADMINISTRATION (US Dept. of Energy). (EIA)- Solar Heat Worldwide. Markets and contribution to the energy supply. EUA. 2004. <http://www.eia.doe.gov>. Acesso em: 24 maio 2005. 
EUROPA. European Solar Thermal Industry Federation (ESTIF) . Gravity on the rise. Sun\&Wind Energy . v.1/2004, p.28-32, 2004. Special issue.

FANTELLI, J. T.; Difusão da tecnologia termossolar na moradia de interesse social. Campinas, 2006. 272p. Tese (Doutorado em Planejamento de Sistemas Energéticos). Faculdade de Engenharia Mecânica. Universidade Estadual de Campinas.

FARIA,C.F.C.; O mercado brasileiro de aquecedores solares: importância, panorama e linhas gerais. São Paulo. ABRAVA, 2006. 24p.

FOSSA, A.J.; Chaguri, J. J.; Santos, E.M.; Utilização de gás para aquecimento de água em instalações prediais - estudo de viabilidade técnica e econômica. $V$ Congresso Brasileiro de Planejamento energético. Políticas públicas para a Energia: Desafios para o próximo quadriênio, 5, 2006. Brasília . Anais. p 1465

ILHA,S.O.; Estudo de parâmetros de Água Quente. Dissertação de Mestrado. Departamento de engenharia de Construção Civil, Escola Politécnica da USP. São Paulo, 1991. p204

ILHA,S.O.; Gonçalves, O.M.; Kavassaki,Y.; Sistemas prediais de Água Quente. Texto Técnico. Departamento de engenharia de Construção Civil, Escola Politécnica da USP. São Paulo,2006. p46

INSTITUTO NACIONAL DE METROLOGIA, NORMALIZAÇÃO E QUALIDADE INDUSTRIAL (INMETRO), Programa Brasileiro de etiquetagem (PBE) Regulamento específico para uso da etiquetagem Nacional de Conservação de Energia - ENCE, Tabela de consumo e eficiência energética. Disponível em : <http://www.inmetro.gov.br/consumidor/tabelas.asphttp>; Acesso; janeiro 2006.

INSTITO BRASILEIRO DE GEOGRAFIA E ESTATÍSTICA (IBGE) . Pesquisa anual. Produção e vendas dos produtos e ou serviços segundo classes de atividade e descrição de produtos. Brasília. 2003. Disponível em: 
http://www.ibge.gov.br/home/estatistica/economia/industria/pia/produtos/produto2003 /pprodutos2003.pdf Acesso: dez 2006.

INSTITUTO NACIONAL DE METEOROLOGIA (INMET). Climatologia. Disponível em: http:// www. inmet.gov.br . Acesso: dezembro 2006.

IOSHIMOTO, E.; Consumo de água quente no edifício Quatiara, Estudo de caso. Departamento de engenharia de Construção Civil, Escola Politécnica da USP São Paulo, 2006.

- Formulação de Metodologia para análise de projetos de sistemas prediais de gás combustível. 1990. 312p. Tese de doutorado, Escola Politécnica da USP.

MATAJS, Roberto Ramos. Demanda, consumo, e custo das alternativas ao chuveiro elétrico. 1997. 189p. Dissertação (Mestrado em Energia) São Paulo, Instituto de Energia e Eletricidade IEE, Universidade de São Paulo. São Paulo.

PETROBRAS. P044 : Avaliação e desenvolvimento de novos equipamentos domésticos para o uso de GN (NAEDGN), [Informação pessoal], Rio de Janeiro, 2004. 1 CD ROM.

PETRUCCI,A.L.;Modelo para previsto do comportamento de aquecedores de acumulação em sistemas. 1998. 312p. Tese de doutorado, Escola Politécnica da USP.

PROGENSA, - Instalaciones de Energia Solar - Curso programado. 1.ed. Sevilla, Espanha, Promotora General de Estúdios, S.A. 1989.

POLIPEX INDÚSTRIA E COMÉRCIO LTDA . Simulador de projeto. Polipex Calculation Insolation. Disponível em http://www.polipex.com.br/. Acesso em fevereiro de 2007. 
RAIMO,P.A.; FAGÁ, M.T.W.; Avaliação do tempo de retorno dos sistemas de aquecimento solar de água no setor residencial. Congresso Brasileiro de Energia (XI CBE). Fontes Renováveis de Energia, Vol.II,pg 835. Rio de Janeiro, 2006.

ROLAND, J. H., FRANCIS X. J., RICHARD E. Brown., JAMES W.H., JONATHAN G. Koomey. Residencial Appliance Data, Assumptions and Methodology for endUse Forecasting whith EPRI - REEPS 2.1 University of California, 1994.

SANTOS, E.M. Gás Natural: estratégias para uma energia nova no Brasil. 9.ed. São Paulo, Editora Annablume, Fapesp, Petrobras,2002.

SÂO PAULO. Secretaria de Energia, Recursos Hídrico e Saneamento do Estado de São Paulo. Balanço energético do estado de São Paulo. 2006.

SÃO PAULO. Lei n 11.228 de 25 de junho de 1992 e Decreto $n^{\circ} 32.329$ de 23 de setembro de 1992 Dispões sobre Código de obras e edificações do Município de São Paulo. DOE, SP.

SINDICATO DAS EMPRESAS DE COMPRA, VENDA, LOCAÇÃO E ADMINISTRAÇÃO DE IMÓVEIS RESIDENCIAIS E COMERCIAIS DE SÃO PAULO (SECOVI-SP) . Balanço do Mercado Imobiliário, 1ำ trimestre de 2006 . Disponível em:<http://ww.secovi.com.br/empty.php?local=/pesquisa/mercado/index.htm>.

Setembro de 2006. Acesso em: ago de 2006.

STRAPASSON, A.B.; A Energia Térmica e o Paradoxo da Eficiência EnergéticaDesafios para um Novo Modelo de Planejamento Energético. Dissertação de Mestrado. Programa Interunidades de Pós -Graduação em energia da USP. São Paulo,2004.

TABELA DE COMPOSIÇÃO DE PREÇOS PARA ORÇAMENTOS (TCPO 10). 10 ed. São Paulo. Editora PINI. 2002.

TIBA el al: Atlas Solarimérico do Brasil: Banco de dados terrestres - Ed. Universitária UFPE, 2000. 
TOBORIANSKI,V.M.; Avaliação da contribuição das tipologias de aquecimento de água residencial para a variação do estoque de gases de efeito estufa na atmosfera. Dissertação de mestrado. Escola Politécnica de São Paulo. Universidade de São Paulo, 2002.

TRANSSEN Aquecedor Solar. Dimensionamento de sistemas de aquecimento solar. [mensagem pessoal]. Mensagem recebida por <sally@transsen.com.br >. Acesso em: 27 de fevereiro de 2007.

TRANSSEN Aquecedor Solar. Orçamento de sistemas de aquecimento. [Mensagem pessoal]. Mensagem recebida por <laudemirjr@transsen.com.br >. Acesso em: 17 de abril de 2007.

ULTRAGÁS. Dados diversos. <http://www.ultragas.com.br> Acesso em: 21 junho 2007.

WONG, J.K.W; WANG, S.W; LI,H. Intelligent Building (24/08/2004). Automation in Construction, V14(1) pp.143-159 (SCl journal) Disponível em: <http://www. Sciencedirect.com>. Acesso em jul 2005. 


\section{ANEXOS}

ANEXO A - Características das tipologias adotadas

ANEXO B - Relação dos Equipamentos e suas características

ANEXO C - Exemplo da Planilha Dimensionamento elétrico para tipologia 3

Dormitórios.

ANEXO D - Materiais representativos nas instalações elétricas

ANEXO E - Materiais representativos nas instalações de gás

ANEXO F - Curvas de variação de potência instalada $x$ custo de infra-estrutura de gás, para as tipologias de 2 e 4 Dormitórios

ANEXO G - Dimensionamento da instalação hidráulica de água quente.

ANEXO H - Dimensionamento dos reservatórios para os sistemas de acumulação

ANEXO I - Diferença de custos da alternativa mista de fonte de calor

ANEXO J - Aquecedor, potências e preços dos equipamentos do estudo de caso

ANEXO K - Dimensionamento Sistema Solar 
ANEXO A

Características das tipologias adotadas

\section{TIPOLOGIA 2 DORMITÓRIOS}

Desenhos sem escala

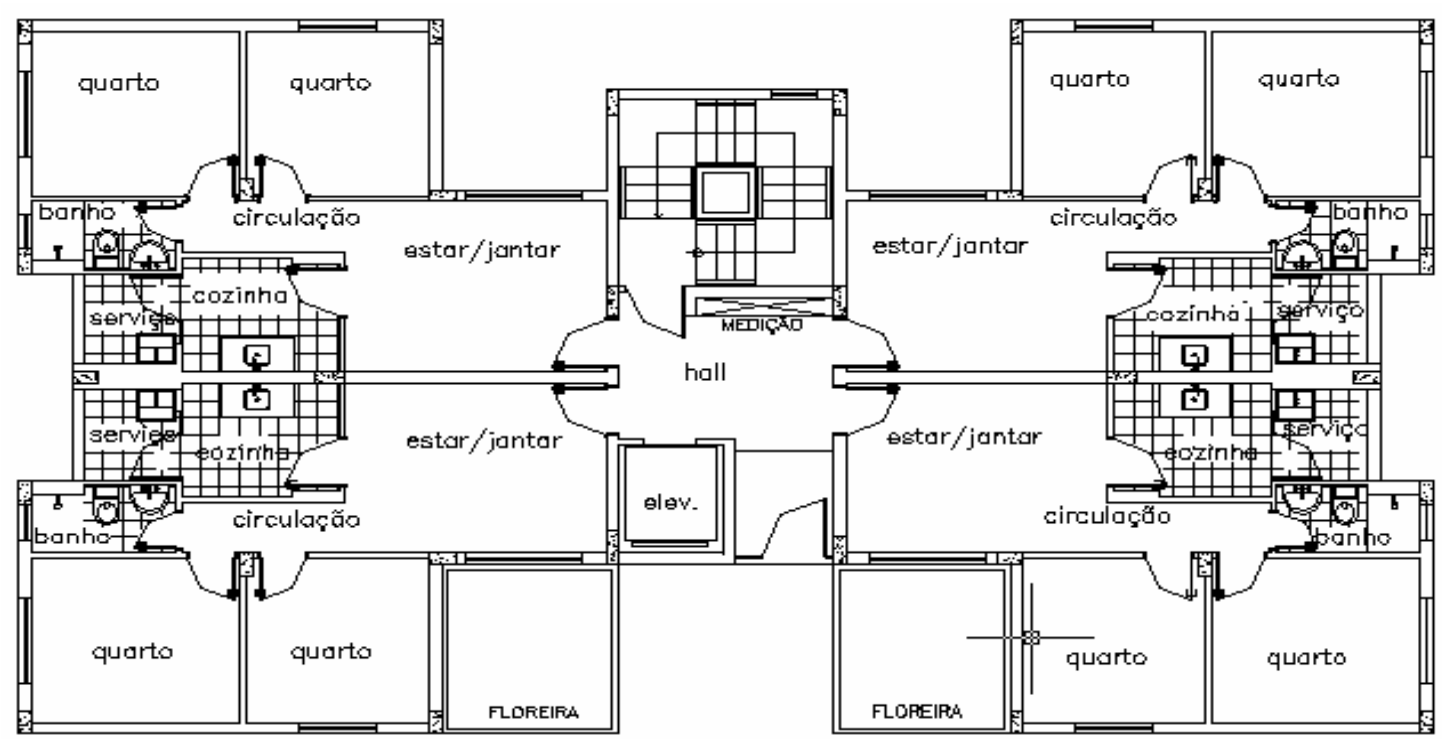

Figura 1.A - Planta Baixa Pavimento Típico

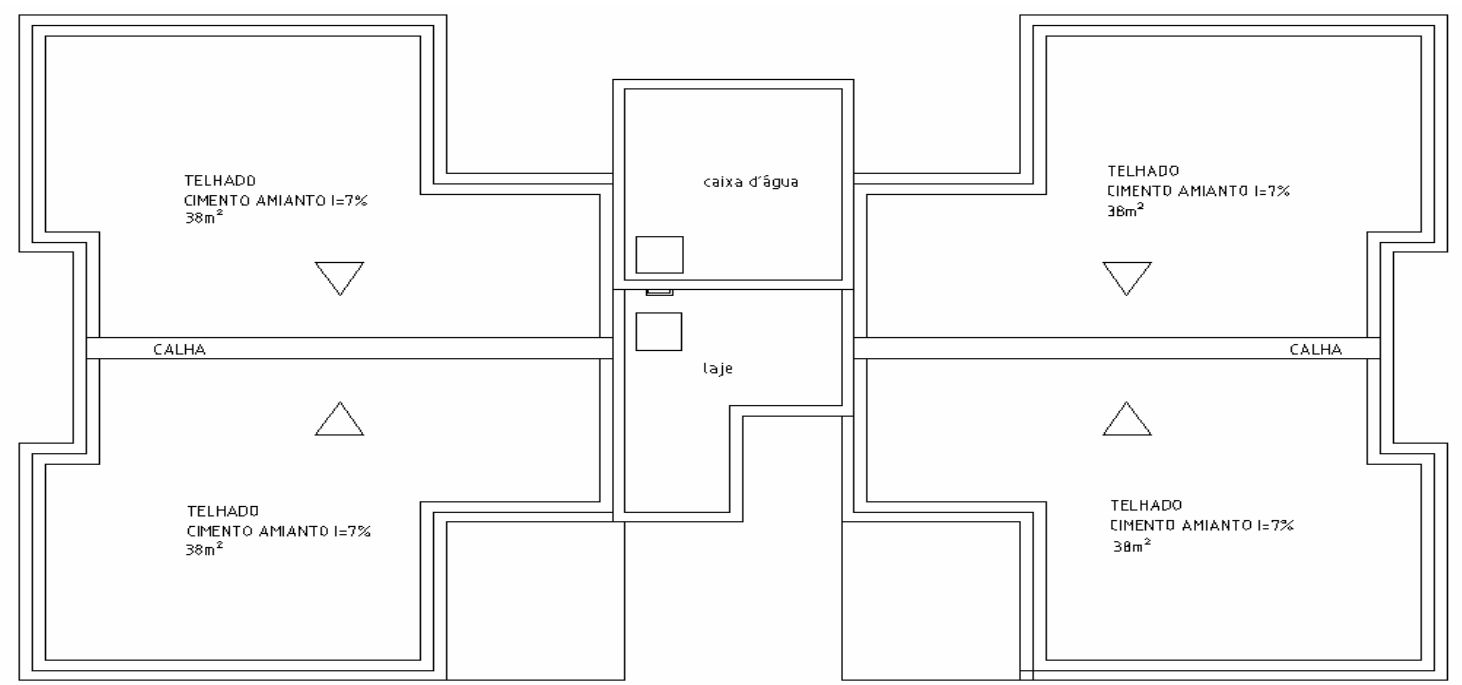

Figura 2.A - Planta Cobertura

\section{Dados do Edifício}

\begin{tabular}{lrlr} 
Andares & 16 & área útil do apt: & $42,16 \mathrm{~m}^{2}$ \\
apts/andar & 4 & área útil Admins & $1351 \mathrm{~m}^{2}$ \\
Total de apts & 64 & & \\
\hline \hline
\end{tabular}


TIPOLOGIA 3 DORMITÓRIOS

Desenhos sem escala

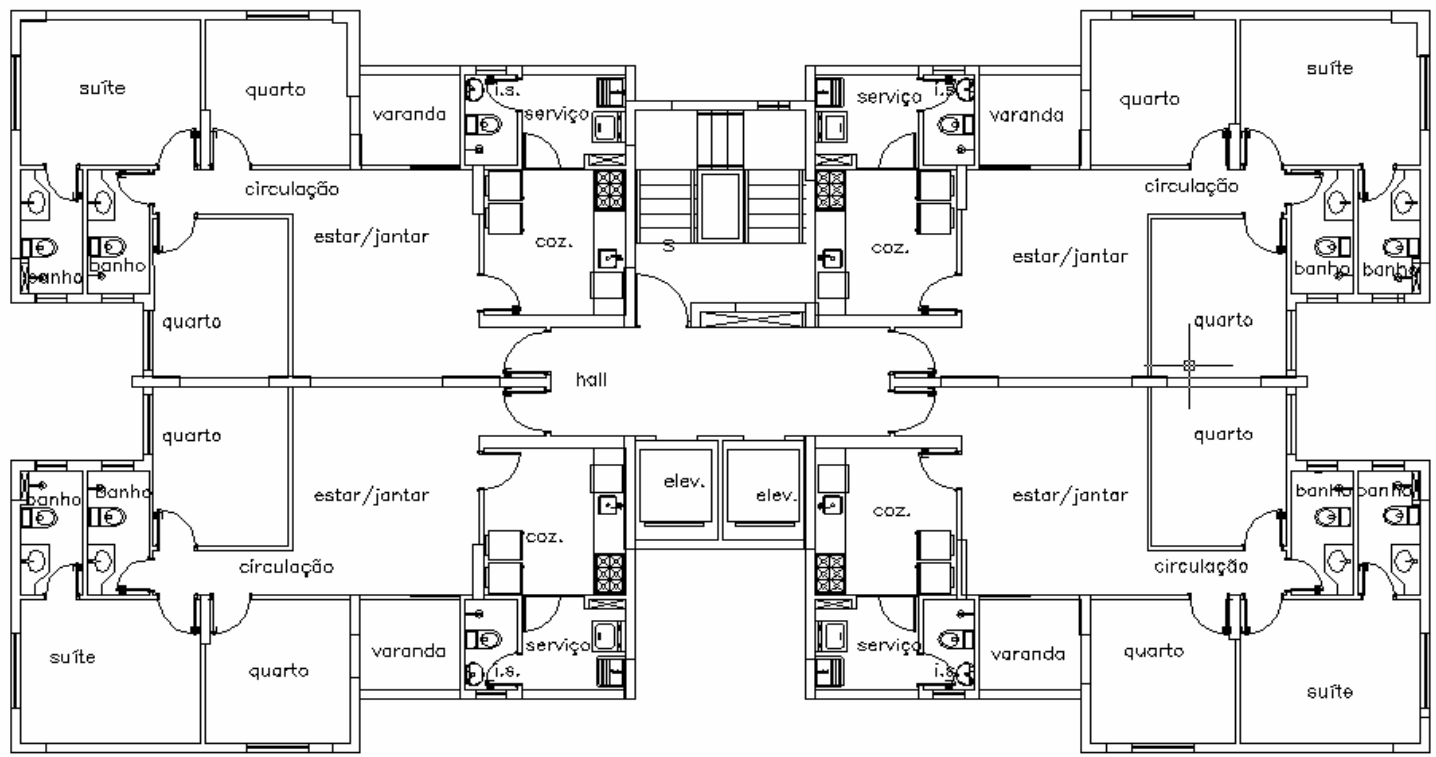

Figura 3.A - Planta Baixa Pavimento Típico

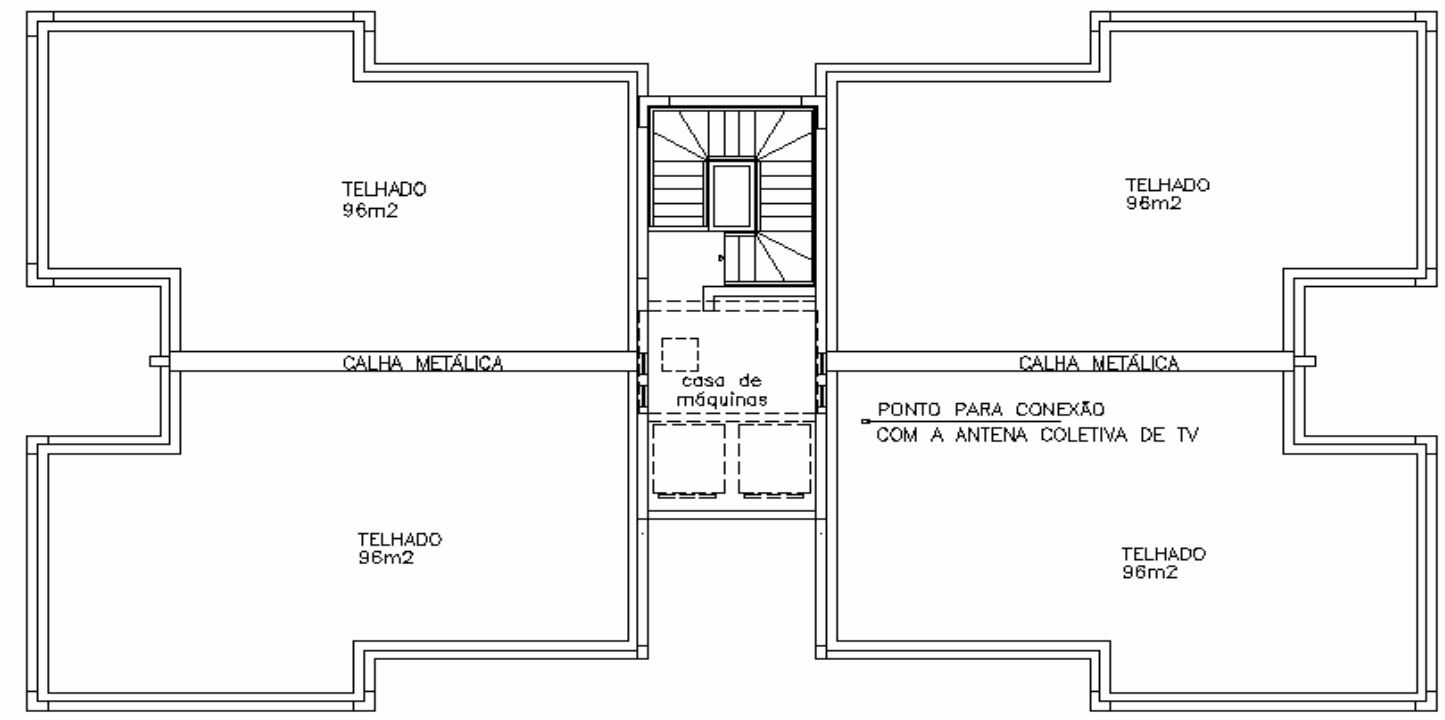

Figura 4.A - Planta Cobertura

\section{Dados do Edifício}

\begin{tabular}{lrlr}
\hline & & & \\
Andares & 16 & área útil do apt: & $106,44 \mathrm{~m}^{2}$ \\
apts/andar & 4 & área útil Admins & $10562,07 \mathrm{~m}^{2}$ \\
Total de apts & 64 & & \\
\hline \hline
\end{tabular}




\section{TIPOLOGIA 4 DORMITÓRIOS}

Desenhos sem escala

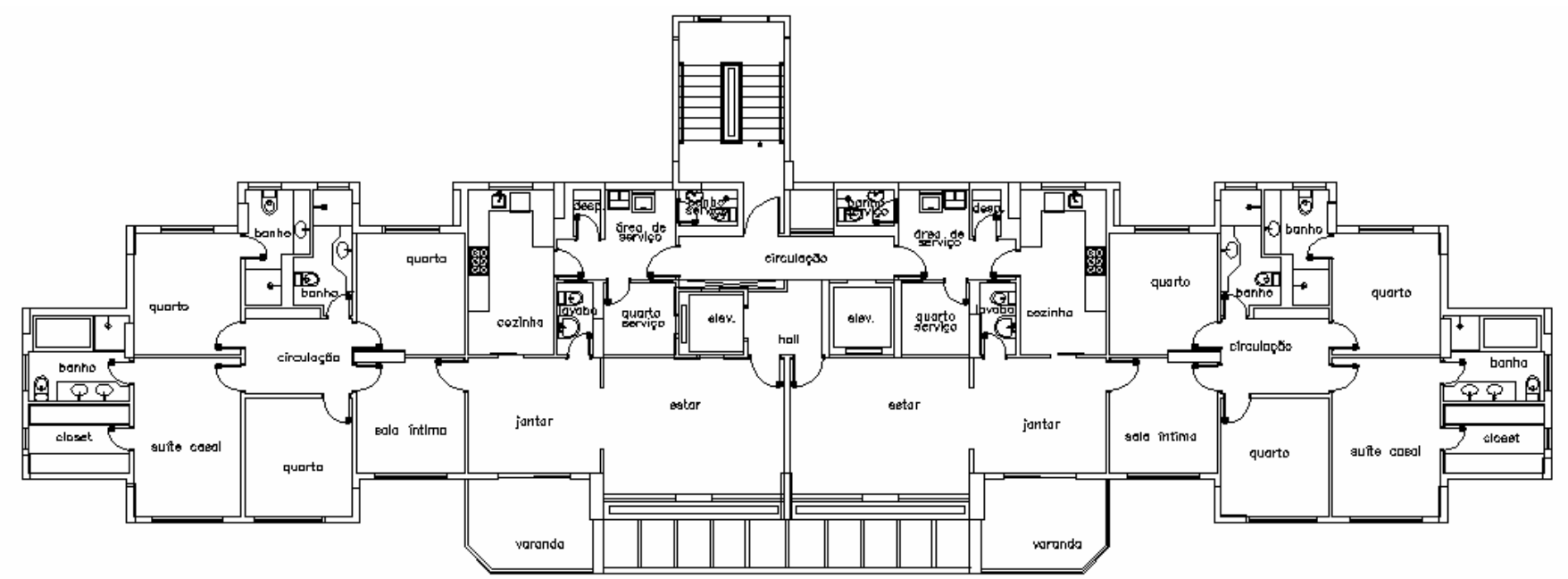

Figura 5.A - Planta Baixa Pavimento Típico

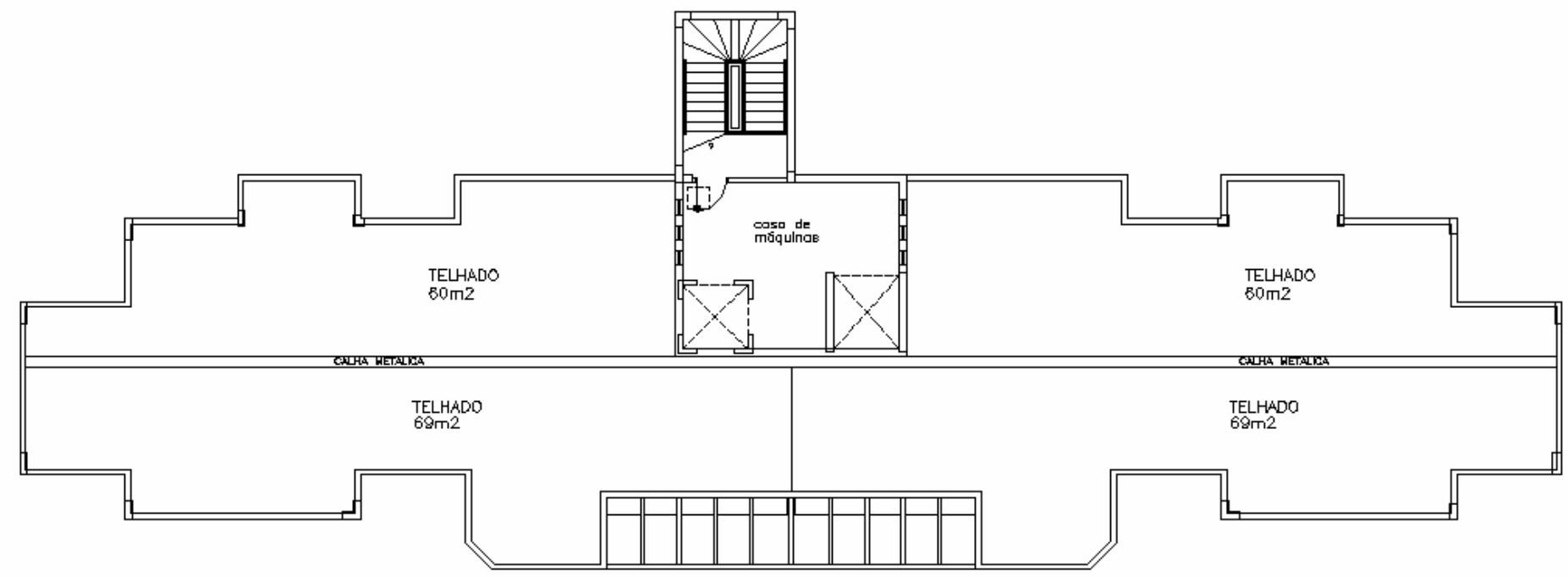

Figura 6.A - Planta Cobertura

Dados do Edifício

\begin{tabular}{lrlr} 
Andares & 16 & área útil do apt: & $147,8 \mathrm{~m}^{2}$ \\
apts/andar & 2 & área útil Admins & $10542 \mathrm{~m}^{2}$ \\
Total de apts & 32 & & \\
\hline \hline
\end{tabular}


ANEXO B Relação dos equipamentos e suas características ${ }^{40}$

B.1. Aquecedor Instantâneo Individual e Central Elétrico

B.1. 1 Instantâneo Individual - Chuveiro

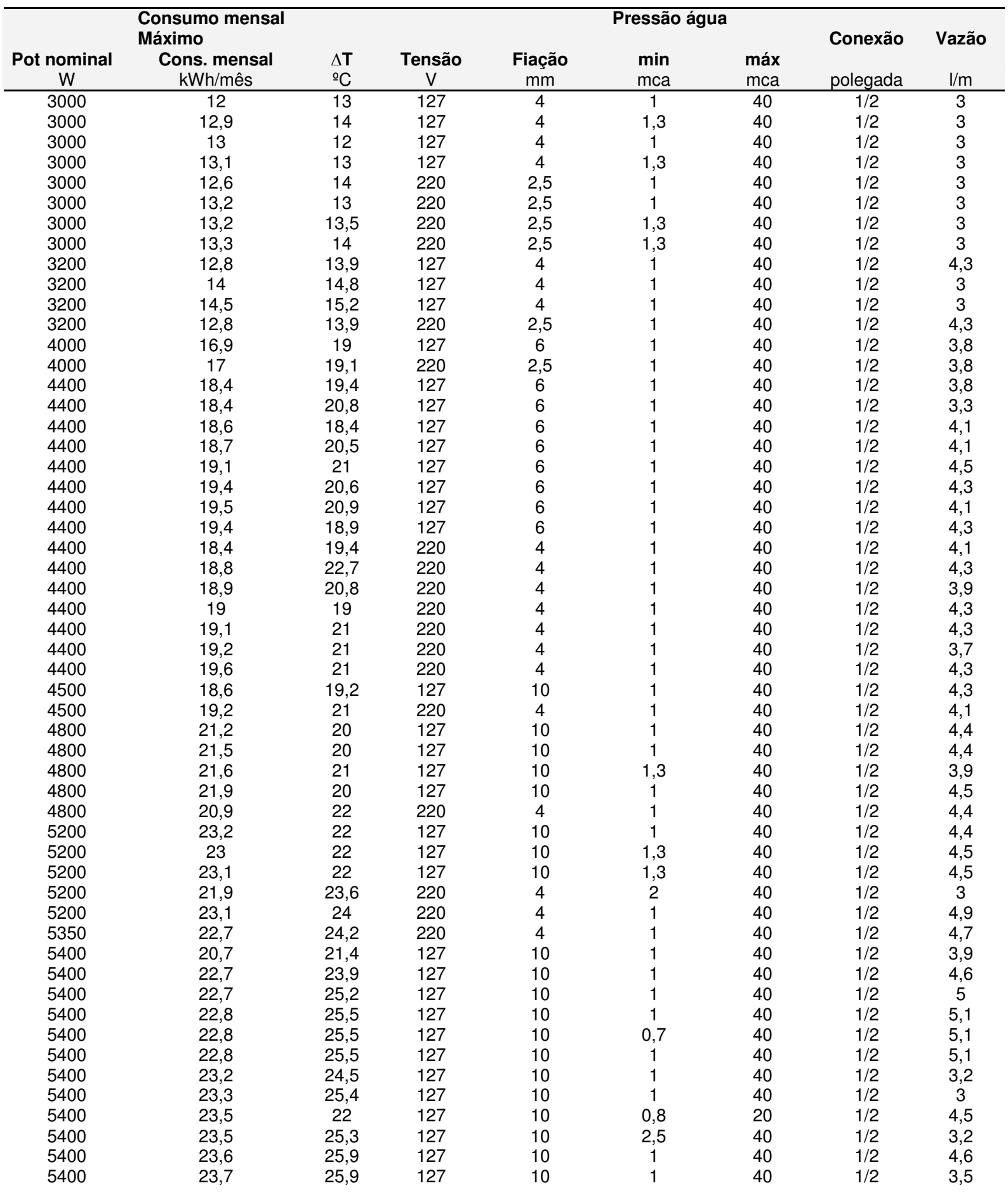

${ }^{40}$ Esta relação foi realizada junto a Associação Brasileira da Indústria Elétrica e Eletrônica (ABINEE), Associação Brasileira de Aquecimento a Gás (ABAGAS), Associação Brasileira de Refrigeração, $\mathrm{Ar}$ condicionado, Ventilação e Aquecimento (ABRAVA), Programa Brasileiro de Etiquetagem (PBE), Instituto Nacional de Metrologia, Normalização e Qualidade Industrial (INMETRO), e fabricantes ou revendedores de equipamentos. Levantamento realizado entre agosto e outubro de 2006. 


\begin{tabular}{|c|c|c|c|c|c|c|c|c|}
\hline \multirow{4}{*}{$\begin{array}{c}\text { Pot nominal } \\
W\end{array}$} & \multicolumn{3}{|l|}{ Consumo mensal } & \multicolumn{3}{|c|}{ Pressão água } & \multirow[b]{2}{*}{ Conexão } & \multirow[t]{3}{*}{ Vazão } \\
\hline & Máximo & & & & & & & \\
\hline & Cons. mensal & $\Delta \mathbf{T}$ & Tensão & Fiação & $\min$ & máx & & \\
\hline & $\mathrm{kWh} / \mathrm{mês}$ & $\stackrel{\circ}{ } \mathrm{C}$ & $\mathrm{V}$ & $\mathrm{mm}$ & $\mathrm{mca}$ & $\mathrm{mca}$ & polegada & $\mathrm{l} / \mathrm{m}$ \\
\hline 5400 & 23,7 & 25,1 & 127 & 10 & 0,7 & 2,5 & $1 / 2$ & 3,2 \\
\hline 5400 & 23,9 & 25,6 & 127 & 10 & 1 & 40 & $1 / 2$ & 4,6 \\
\hline 5400 & 24 & 25,2 & 127 & 10 & 0,7 & 2,5 & $1 / 2$ & 3,2 \\
\hline 5400 & 24,3 & 23,4 & 127 & 10 & 1 & 40 & $1 / 2$ & 3,3 \\
\hline 5500 & 22,8 & 24,2 & 127 & 10 & 2 & 40 & $1 / 2$ & 3 \\
\hline 5500 & 22,8 & 24,2 & 127 & 10 & 2 & 40 & $1 / 2$ & 3 \\
\hline 5500 & 22,8 & 24,2 & 127 & 10 & 2 & 40 & $1 / 2$ & 3 \\
\hline 5500 & 22,8 & 24,2 & 127 & 10 & 2 & 40 & $1 / 2$ & 3 \\
\hline 5500 & 23,4 & 25,8 & 127 & 10 & 0,7 & 40 & $1 / 2$ & 5,2 \\
\hline 5500 & 23,4 & 25,8 & 127 & 10 & 0,7 & 40 & $1 / 2$ & 5,2 \\
\hline 5500 & 23,4 & 25,8 & 127 & 10 & 0,7 & 40 & $1 / 2$ & 5,2 \\
\hline 5500 & 23,4 & 25,8 & 127 & 10 & 0,7 & 40 & $1 / 2$ & 5,2 \\
\hline 5500 & 23,5 & 23,7 & 127 & 10 & 1 & 40 & $1 / 2$ & 3,4 \\
\hline 5500 & 23,6 & 24,9 & 127 & 10 & 2,5 & 40 & $1 / 2$ & 3 \\
\hline 5500 & 24,2 & 25,1 & 127 & 10 & 1 & 40 & $1 / 2$ & 4,9 \\
\hline 5500 & 24,3 & 24,8 & 127 & 10 & 1 & 40 & $1 / 2$ & 4,9 \\
\hline 5500 & 18,2 & 18,8 & 220 & 4 & 1 & 40 & $1 / 2$ & 3,8 \\
\hline 5500 & 23,4 & 25,8 & 220 & 4 & 1 & 40 & $1 / 2$ & 5,2 \\
\hline 5500 & 24 & 23,4 & 220 & 4 & 1 & 40 & $1 / 2$ & 3,2 \\
\hline 6400 & 27,8 & 30,5 & 220 & 6 & 1 & 40 & $1 / 2$ & 3,7 \\
\hline 6400 & 28,3 & 27,1 & 220 & 6 & 1 & 40 & $1 / 2$ & 3,5 \\
\hline 6465 & 28,8 & 27,3 & 220 & 6 & 0,3 & 2,5 & $1 / 2$ & 3,5 \\
\hline 6500 & 26,4 & 28 & 220 & 6 & 1 & 40 & $1 / 2$ & 3,4 \\
\hline 6500 & 26,9 & 29,2 & 220 & 6 & 1,2 & 40 & $1 / 2$ & 3,4 \\
\hline 6500 & 26,9 & 29,2 & 220 & 6 & 1,2 & 40 & $1 / 2$ & 3,4 \\
\hline 6500 & 26,9 & 29,2 & 220 & 6 & 1,2 & 40 & $1 / 2$ & 3,4 \\
\hline 6500 & 27,4 & 27,9 & 220 & 6 & $?$ & $?$ & $?$ & 3,4 \\
\hline 6500 & 27,9 & 28 & 220 & 6 & 1 & 40 & $1 / 2$ & 3,4 \\
\hline 6500 & 28,5 & 30,1 & 220 & 6 & 0,7 & 40 & $1 / 2$ & 3,1 \\
\hline 6600 & 29,4 & 29,2 & 220 & 6 & 1 & 40 & $1 / 2$ & 3,2 \\
\hline 6800 & 27,7 & 27,2 & 220 & 6 & 1 & 40 & $1 / 2$ & 3,5 \\
\hline 7000 & 30,1 & 30 & 220 & 6 & 0,8 & 20 & $1 / 2$ & 3 \\
\hline 7500 & 31,7 & 32,3 & 220 & 6 & 0,7 & 40 & $1 / 2$ & 3,4 \\
\hline 7500 & 31,7 & 32,3 & 220 & 6 & 0,7 & 40 & $1 / 2$ & 3,4 \\
\hline 7500 & 31,7 & 32,3 & 220 & 6 & 0,7 & 40 & $1 / 2$ & 3,4 \\
\hline 7500 & 31,7 & 32,3 & 220 & 6 & 0,7 & 40 & $1 / 2$ & 3,4 \\
\hline 7500 & 32,5 & 35,6 & 220 & 6 & 2,5 & 40 & $1 / 2$ & 3 \\
\hline 7500 & 34,5 & 35,7 & 220 & 6 & 1 & 40 & $1 / 2$ & 3 \\
\hline 7500 & 32,4 & 33,6 & 220 & 6 & 2,5 & 40 & $1 / 2$ & 3 \\
\hline 7500 & 32,6 & 35,5 & 220 & 6 & 0,7 & 4 & $1 / 2$ & 3 \\
\hline 7500 & 33 & 34,1 & 220 & 6 & 1 & 40 & $1 / 2$ & 3 \\
\hline 7500 & 33,3 & 35,4 & 220 & 6 & 1 & 40 & $1 / 2$ & 3 \\
\hline 7500 & 33,8 & 36,4 & 220 & 6 & 0,7 & 2,5 & $1 / 2$ & 3 \\
\hline 7500 & 34 & 36 & 220 & 6 & 2,5 & 40 & $1 / 2$ & 3 \\
\hline 7600 & 31,7 & 33,6 & 220 & 6 & 2,5 & 40 & $1 / 2$ & 3,4 \\
\hline 7600 & 31,8 & 33,8 & 220 & 6 & 1,2 & 40 & $1 / 2$ & 3,4 \\
\hline 7600 & 31,8 & 33,8 & 220 & 6 & 1,2 & 40 & $1 / 2$ & 3,4 \\
\hline 7600 & 31,8 & 33,8 & 220 & 6 & 1,2 & 40 & $1 / 2$ & 3,4 \\
\hline 7600 & 31,8 & 33,8 & 220 & 6 & 1,2 & 40 & $1 / 2$ & 3,4 \\
\hline 7600 & 31,8 & 33,8 & 220 & 6 & 1,2 & 40 & $1 / 2$ & 3,4 \\
\hline 7600 & 32,1 & 33,1 & 220 & 6 & 2,5 & 40 & $1 / 2$ & 3,4 \\
\hline
\end{tabular}

\section{B.1.2 Torneira e aquecedores elétricos}

\begin{tabular}{|c|c|c|c|c|c|c|c|c|}
\hline \multirow{3}{*}{$\begin{array}{c}\text { Pot nominal } \\
\text { W }\end{array}$} & \multicolumn{2}{|c|}{ Consumo mens. Máx.(1) } & \multirow{3}{*}{$\begin{array}{c}\text { Tensão } \\
\text { V }\end{array}$} & \multirow{3}{*}{$\begin{array}{c}\text { Fiação } \\
\text { mm }\end{array}$} & \multicolumn{2}{|c|}{ Pressão água } & \multirow{3}{*}{$\begin{array}{l}\text { Conexao } \\
\text { polegada }\end{array}$} & \multirow{3}{*}{$\begin{array}{c}\text { vazão } \\
\text { l/m }\end{array}$} \\
\hline & Cons. mensal & $\Delta \mathbf{T}$ & & & $\min$ & máx & & \\
\hline & kWh/mês & $\stackrel{\circ}{\mathrm{C}}$ & & & mca & mca & & \\
\hline 2500 & 1,3 & 12,9 & 127 & 4 & 2 & 40 & $1 / 2$ & 3,8 \\
\hline 2500 & 1,29 & 12,9 & 220 & 2,5 & 2 & 40 & $1 / 2$ & 3,9 \\
\hline 4000 & 2,1 & 19,1 & 127 & 6 & 2 & 40 & $1 / 2$ & 5,8 \\
\hline 4000 & 2 & 19,1 & 220 & 2,5 & 2 & 40 & $1 / 2$ & 5,7 \\
\hline 4400 & 2,1 & 19,6 & 127 & 6 & 2 & 40 & $1 / 2$ & 4,1 \\
\hline 4400 & 2,2 & 21 & 127 & 6 & 1 & 40 & $1 / 2$ & 4,4 \\
\hline 4400 & 2,2 & 21,6 & 127 & 6 & 1 & 40 & $1 / 2$ & 3,9 \\
\hline 4400 & 2,25 & 22 & 127 & 6 & 2 & 40 & $1 / 2$ & 4,4 \\
\hline 4400 & 2,29 & 22,2 & 127 & 6 & 2 & 40 & $1 / 2$ & 6,9 \\
\hline
\end{tabular}




\begin{tabular}{|c|c|c|c|c|c|c|c|c|}
\hline $\begin{array}{c}\text { Pot nominal } \\
\mathrm{W}\end{array}$ & $\begin{array}{l}\text { Consumo mens. } \\
\text { Máx.(1) } \\
\text { Cons. mensal } \\
\text { kWh/mês } \\
\end{array}$ & $\begin{array}{l}\Delta \mathbf{T} \\
\stackrel{\circ}{\circ} \mathrm{C} \\
\end{array}$ & $\begin{array}{c}\text { Tensão } \\
\mathrm{V}\end{array}$ & $\begin{array}{l}\text { Pressão } \\
\text { água } \\
\text { Fiação } \\
\text { mm }\end{array}$ & $\begin{array}{l}\text { min } \\
\mathrm{mca}\end{array}$ & $\begin{array}{l}\text { máx } \\
\text { mca }\end{array}$ & $\begin{array}{l}\text { Conexao } \\
\text { polegada }\end{array}$ & $\begin{array}{c}\text { vazão } \\
\mathrm{l} / \mathrm{m}\end{array}$ \\
\hline 4400 & 2,2 & 21 & 220 & 4 & 1,5 & 40 & 1,2 & 5,4 \\
\hline 4400 & 2.26 & 22,9 & 220 & 4 & 2 & 40 & $1 / 2$ & 6.8 \\
\hline 4800 & 2,45 & 22 & 127 & 10 & 2 & 40 & $1 / 2$ & 4,5 \\
\hline 4800 & 2,53 & 20,5 & 127 & 10 & 2 & 40 & $1 / 2$ & 3 \\
\hline 4800 & 2,45 & 22 & 220 & 4 & 2 & 40 & $1 / 2$ & 4,5 \\
\hline 4800 & 2,47 & 22 & 220 & 4 & 2 & 40 & $1 / 2$ & 3 \\
\hline 5100 & 2,6 & 23,4 & 127 & 10 & 1 & 8 & $1 / 2$ & 7,4 \\
\hline 5100 & 2,6 & 23,4 & 127 & 10 & 8 & 40 & $1 / 2$ & 7,4 \\
\hline 5200 & 2,7 & 23,9 & 220 & 4 & 1 & 8 & $1 / 2$ & 7,5 \\
\hline 5200 & 2,7 & 23,9 & 220 & 4 & 8 & 40 & $1 / 2$ & 7,5 \\
\hline 5200 & 2,7 & 24 & 220 & 4 & 1 & 8 & $1 / 2$ & 7,6 \\
\hline 5200 & 2,7 & 24 & 220 & 4 & 8 & 40 & $1 / 2$ & 7,6 \\
\hline 5400 & 2,76 & 26,2 & 127 & 10 & 2 & 40 & $1 / 2$ & 7,9 \\
\hline 5400 & 2,6 & 24,7 & 220 & 4 & 2 & 40 & $1 / 2$ & 4,5 \\
\hline 5400 & 2,7 & 28 & 220 & 4 & 2 & 40 & $1 / 2$ & 4,7 \\
\hline 5400 & 2,74 & 27 & 220 & 4 & 2 & 40 & $1 / 2$ & 4,7 \\
\hline 5400 & 2,79 & 28 & 220 & 4 & 2 & 40 & $1 / 2$ & 3 \\
\hline 5400 & 2,82 & 26,5 & 220 & 4 & 2 & 40 & $1 / 2$ & 7,9 \\
\hline 5500 & 2,7 & 24,4 & 127 & 10 & 1 & 40 & $1 / 2$ & 3 \\
\hline 5500 & 2,7 & 24,4 & 127 & 10 & & & & 3 \\
\hline 5500 & 2,8 & 25 & 127 & 10 & 1 & 8 & $1 / 2$ & 3,2 \\
\hline 5500 & 2,8 & 25 & 127 & 10 & 8 & 40 & $1 / 2$ & 3,2 \\
\hline 5500 & 2,7 & 24,4 & 220 & 4 & 1 & 40 & $1 / 2$ & 3 \\
\hline 5500 & 2,78 & 28,1 & 220 & 4 & 2 & 40 & $1 / 2$ & 4,6 \\
\hline 5500 & 2,8 & 25 & 220 & 4 & 1 & 8 & $1 / 2$ & 3,4 \\
\hline 5500 & 2,8 & 25 & 220 & 4 & 8 & 40 & $1 / 2$ & 3,4 \\
\hline 5500 & 3,3 & 29,7 & 220 & 4 & 1 & 8 & $1 / 2$ & 3,4 \\
\hline 5500 & 3,3 & 29,7 & 220 & 4 & 8 & 40 & $1 / 2$ & 3,4 \\
\hline 9000 & 4,7 & 40,5 & 220 & 10 & 1 & 8 & $1 / 2$ & 3 \\
\hline 9000 & 4,7 & 40,5 & 220 & 10 & 8 & 40 & $1 / 2$ & 3 \\
\hline 10560 & & & 220 & 10 & 10 & 400 & $1 / 2$ & 3 \\
\hline
\end{tabular}

\section{B.1.3 Hidromassagem - elétrico}

\begin{tabular}{|c|c|c|c|c|c|c|c|c|}
\hline \multirow{3}{*}{$\begin{array}{c}\text { Pot nominal } \\
\text { W }\end{array}$} & \multicolumn{2}{|c|}{ Consumo mens. Máx.(1) } & \multirow{3}{*}{$\begin{array}{c}\text { Tensão } \\
V\end{array}$} & \multirow{3}{*}{$\begin{array}{c}\text { Fiação } \\
\text { mm }\end{array}$} & \multicolumn{2}{|c|}{ Pressão água } & \multirow{3}{*}{$\begin{array}{l}\text { Conexao } \\
\text { polegada }\end{array}$} & \multirow{3}{*}{$\begin{array}{c}\text { vazão } \\
\mathrm{l} / \mathrm{m}\end{array}$} \\
\hline & Cons. mensal & $\Delta \mathbf{T}$ & & & $\min$ & máx & & \\
\hline & kWh/mês & $\stackrel{\circ}{ }$ & & & mca & mca & & \\
\hline 5000 & 2,9 & 11,3 & 127 & 10 & & & $11 / 2$ & \\
\hline 5000 & 2,51 & 20,1 & 220 & 4 & & & & \\
\hline 5000 & 2,9 & 11,3 & 220 & 4 & & & $11 / 2$ & 6,8 \\
\hline 5100 & 2,6 & 23,3 & 127 & 10 & 1 & 8 & $1 / 2$ & 7,1 \\
\hline 5200 & 2,7 & 23,3 & 220 & 4 & 1 & 8 & $1 / 2$ & 7,6 \\
\hline 8000 & 3,84 & 31,9 & 220 & 6 & & & & 11,4 \\
\hline 8000 & 3,9 & 12,6 & 220 & 6 & & & $11 / 2$ & 9,6 \\
\hline 8200 & 4,3 & 36,6 & 220 & 6 & 1 & 8 & $1 / 2$ & 11,8 \\
\hline
\end{tabular}

\section{B.2 Aquecedor de Acumulação Privado Elétrico}

\section{B.2.1 Baixa Pressão}

\begin{tabular}{|c|c|c|c|c|c|c|c|c|}
\hline \multirow[b]{2}{*}{ Volume } & \multirow[b]{2}{*}{ Potência } & \multirow[b]{2}{*}{$\begin{array}{l}\text { Perda } \\
\text { espec }\end{array}$} & \multirow[b]{2}{*}{ Eficiência } & \multirow[b]{2}{*}{$\begin{array}{l}\text { Capacidade } \\
\text { recuper. }\end{array}$} & \multirow[b]{2}{*}{ Capacidade } & \multirow[b]{2}{*}{ Tensão } & \multicolumn{2}{|c|}{ Água } \\
\hline & & & & & & & Pressão & $\begin{array}{c}\text { Conexão } \\
\text { E/S }\end{array}$ \\
\hline litros & $\mathrm{kW}$ & kWh/mês & $\%$ & $\stackrel{\circ}{\mathrm{C} / \text { hora }}$ & $\mathrm{L} / \mathrm{min}$ & V & kPa máx & polegada \\
\hline 50 & 1,5 & & & & & 220 & 40 & $1 "$ \\
\hline 75 & 1,5 & & & & & 220 & 40 & $1 "$ \\
\hline 100 & 2 & 0,25 & & & & 220 & 50 & \\
\hline 100 & 1,5 & & & 13 & & 220 & & 3/4" \\
\hline 125 & 1,5 & & & & & 220 & 40 & $1 "$ \\
\hline 150 & 3 & 0,21 & & & & 220 & 30 & $28 \mathrm{~mm} / 1 "$ \\
\hline 150 & 2,5 & & & 14 & & 220 & & $1 "$ \\
\hline 150 & 1,5 & & & & & 220 & 40 & $1 "$ \\
\hline 175 & 1,5 & & & & & 220 & 40 & $1 "$ \\
\hline
\end{tabular}




\begin{tabular}{ccccccccc}
\hline Volume & Potência & $\begin{array}{c}\text { Perda } \\
\text { espec }\end{array}$ & Eficiência & $\begin{array}{c}\text { Capacidade } \\
\text { recuper. }\end{array}$ & Capacidade & Tensão & \multicolumn{2}{c}{$\begin{array}{c}\text { Água } \\
\text { Pressão }\end{array}$} \\
Conexão \\
E/S
\end{tabular}

\section{B.2.2 Alta Pressão}

\begin{tabular}{|c|c|c|c|c|c|c|c|c|}
\hline \multirow[b]{2}{*}{ Volume } & \multirow[b]{2}{*}{ Potência } & \multirow[b]{2}{*}{$\begin{array}{l}\text { Perda } \\
\text { espec }\end{array}$} & \multirow[b]{2}{*}{ Eficiência } & \multirow[b]{2}{*}{$\begin{array}{l}\text { Capacidade } \\
\text { recuper. }\end{array}$} & \multirow[b]{2}{*}{ Capacidade } & \multirow[b]{2}{*}{ Tensão } & \multicolumn{2}{|c|}{ Água } \\
\hline & & & & & & & Pressão & $\begin{array}{c}\text { Conexão } \\
\text { E/S }\end{array}$ \\
\hline litros & $\mathrm{kW}$ & kWh/mês & $\%$ & ${ }^{\circ} \mathrm{C} /$ hora & $\mathrm{L} / \mathrm{min}$ & V & kPa máx & polegada \\
\hline 200 & 2,5 & 0,19 & 81 & & & 220 & 392 & \\
\hline 300 & 2,5 & 0,17 & 83 & & & 220 & 392 & \\
\hline 300 & 7 & 0,23 & 77 & & & 220 & 400 & \\
\hline 400 & 2,5 & 0,14 & 86 & & & 220 & 392 & \\
\hline 400 & 7 & 0,22 & 78 & & & 220 & 400 & \\
\hline 500 & 2,5 & 0,16 & 84 & & & 220 & 392 & \\
\hline 500 & 3,5 & 0,19 & 81 & & & 220 & 400 & \\
\hline 600 & 2,5 & 0,15 & 85 & & & 220 & 392 & \\
\hline 600 & 7 & 0,2 & 80 & & & 220 & 400 & \\
\hline 1000 & 4 & 0,13 & 87 & & & 220 & 392 & \\
\hline
\end{tabular}

B.3.1 Aquecedor Instantâneo Individual e Central a gás

B.3.1.1 Aquecedores homologados

\begin{tabular}{|c|c|c|c|c|c|c|c|c|c|c|}
\hline $\begin{array}{c}\text { Potência } \\
\text { Nominal } \\
\text { KW }\end{array}$ & $\begin{array}{c}\text { Potência } \\
\text { Nominal } \\
\mathrm{Kcal} / \mathrm{h}\end{array}$ & $\begin{array}{c}\text { Eficiência } \\
\%\end{array}$ & $\begin{array}{c}\text { Capacidade } \\
\text { I/min }\end{array}$ & Gás & $\begin{array}{c}\text { Pressão } \\
\text { min:gn/glp } \\
\text { mmca }\end{array}$ & $\begin{array}{c}\text { Gás } \\
\text { Pressão } \\
\text { max } \\
\text { mmca } \\
\end{array}$ & $\begin{array}{c}\text { Conexão/ } \\
\text { polegada }\end{array}$ & $\begin{array}{c}\text { Pressão } \\
\text { min } \\
\text { mca }\end{array}$ & $\begin{array}{c}\text { Água } \\
\text { Pressão } \\
\text { max } \\
\text { mca }\end{array}$ & $\begin{array}{c}\text { Conexões } \\
\text { E/S } \\
\text { polegada }\end{array}$ \\
\hline 63,7 & 54759 & 81,3 & 38 & GN/GLP & $200 / 280$ & $250 / 330$ & 1/2" & 10 & 100 & $3 / 4 "$ \\
\hline 59,7 & 51307 & 79,6 & 35,5 & GN/GLP & $200 / 281$ & & & & & \\
\hline 59,2 & 50931 & 83,1 & 37 & GN/GLP & $200 / 280$ & & $1 / 2^{\prime \prime}$ & 10 & 50 & 3/4" \\
\hline 57,6 & 49527 & 80,6 & 34 & GN/GLP & $200 / 280$ & $250 / 330$ & $1 / 2^{\prime \prime}$ & 10 & 100 & $1 / 2^{\prime \prime}$ \\
\hline 53,6 & 46087 & 81,2 & 32 & GN/GLP & $200 / 280$ & & $1 / 2 "$ & 5 & 60 & $1 / 2 "$ \\
\hline 50,0 & 42963 & 81,6 & 30 & GN/GLP & $200 / 280$ & & 3/4"/1/2" & 10 & 50 & 3/4" \\
\hline 39,9 & 34301 & 81,8 & 24,5 & GN/GLP & $200 / 280$ & & $1 / 2^{\prime \prime}$ & 7 & 40 & $1 / 2^{\prime \prime}$ \\
\hline 37,6 & 32336 & 81 & 22 & GN/GLP & $200 / 280$ & & $1 / 2^{\prime \prime}$ & 5 & 60 & $1 / 2 "$ \\
\hline 36,9 & 31759 & 81,5 & 22 & GN/GLP & $200 / 280$ & $250 / 330$ & 3/4" & 5 & 100 & $1 / 2 "$ \\
\hline 35,9 & 30852 & 73,6 & 19 & GN/GLP & $200 / 280$ & & $1 / 2 "$ & 5 & 125 & $1 / 2 "$ \\
\hline 34,4 & 29580 & 81,9 & 21 & GN/GLP & $200 / 280$ & & & 13 & 120 & \\
\hline 34,4 & 29580 & 81,9 & 21 & GN/GLP & $200 / 280$ & & & 17 & 120 & \\
\hline 31,8 & 27335 & 80,3 & 19 & GN/GLP & $200 / 280$ & & $1 / 2^{\prime \prime}$ & 5 & 125 & $1 / 2^{\prime \prime}$ \\
\hline 30,1 & 25888 & 81,7 & 18 & GN/GLP & $200 / 280$ & & $1 / 2^{\prime \prime}$ & 7 & 40 & $1 / 2^{\prime \prime}$ \\
\hline 29,1 & 25026 & 81,2 & 17 & GN/GLP & $200 / 280$ & & $1 / 2 "$ & 5 & 60 & $1 / 2^{\prime \prime}$ \\
\hline
\end{tabular}




\begin{tabular}{|c|c|c|c|c|c|c|c|c|c|c|}
\hline $\begin{array}{c}\text { Potência } \\
\text { Nominal } \\
\text { KW }\end{array}$ & $\begin{array}{c}\text { Potência } \\
\text { Nominal } \\
\text { Kcal/h }\end{array}$ & $\begin{array}{c}\text { Eficiência } \\
\%\end{array}$ & $\begin{array}{c}\text { Capacidade } \\
\text { I/min }\end{array}$ & Gás & $\begin{array}{c}\text { Gás } \\
\text { Pressão } \\
\text { min:gn/glp } \\
\text { mmca } \\
\end{array}$ & $\begin{array}{c}\text { Água } \\
\text { Pressão } \\
\text { max } \\
\text { mmca }\end{array}$ & $\begin{array}{l}\text { Conexão/ } \\
\text { polegada }\end{array}$ & $\begin{array}{c}\text { Pressão } \\
\text { min } \\
\text { mca }\end{array}$ & $\begin{array}{c}\text { Pressão } \\
\text { max } \\
\text { mca }\end{array}$ & $\begin{array}{c}\text { Conexões } \\
\text { E/S } \\
\text { polegada }\end{array}$ \\
\hline 29,0 & 24911 & 77,2 & 16 & GN/GLP & $200 / 280$ & $250 / 330$ & $3 / 4 "$ & 10 & 100 & 1/2" \\
\hline 28,3 & 24360 & 81,1 & 17 & GN/GLP & $200 / 280$ & & & 8 & 120 & \\
\hline 27,9 & 24025 & 81,9 & 17 & GN/GLP & $200 / 280$ & & $1 / 2^{\prime \prime}$ & 3,5 & 80 & $1 / 2 "$ \\
\hline 27,9 & 24000 & 77,4 & 16 & GN/GLP & $200 / 280$ & & & 10 & 120 & \\
\hline 27,9 & 23974 & 83,2 & 17 & GLP & 280 & & $1 / 2^{\prime \prime}$ & 2 & 40 & $1 / 2 "$ \\
\hline 27,6 & 23772 & 80,4 & 16,5 & GN/GLP & $200 / 280$ & & $1 / 2^{\prime \prime}$ & 5 & 60 & $1 / 2^{\prime \prime}$ \\
\hline 27,4 & 23564 & 82,6 & 16,5 & GN/GLP & $200 / 280$ & & $1 / 2^{\prime \prime}$ & 5 & 60 & 1/2" \\
\hline 26,1 & 22484 & 83 & 16 & GN/GLP & $200 / 280$ & & $1 / 2^{\prime \prime}$ & 7 & 40 & $1 / 2 "$ \\
\hline 26,1 & 22484 & 83 & 16 & GN/GLP & $200 / 280$ & & $1 / 2 "$ & 10 & 50 & 1/2" \\
\hline 25,9 & 22274 & 84,8 & 16 & GN/GLP & $200 / 280$ & & $1 / 2^{\prime \prime}$ & 5 & 60 & $1 / 2 "$ \\
\hline 25,8 & 22198 & 80,7 & 15,5 & GN/GLP & $200 / 280$ & & $1 / 2 "$ & 7 & 40 & 1/2" \\
\hline 25,1 & 21575 & 82,05 & 15 & GN/GLP & $200 / 280$ & & $1 / 2^{\prime \prime}$ & 5 & 125 & $1 / 2 "$ \\
\hline 24,7 & 21246 & 81,1 & 15 & GN/GLP & $200 / 280$ & & $1 / 2^{\prime \prime}$ & 3,5 & 80 & 1/2" \\
\hline 24,7 & 21222 & 81,2 & 15 & GN/GLP & $200 / 280$ & & $1 / 2 "$ & 2 & 100 & 1/2" \\
\hline 24,6 & 21121 & 80,7 & 14,5 & GN/GLP & $200 / 280$ & & $1 / 2^{\prime \prime}$ & 5 & 125 & $1 / 2^{\prime \prime}$ \\
\hline 24,3 & 20911 & 80,2 & 14,5 & GN/GLP & $200 / 280$ & & $1 / 2 "$ & 10 & 50 & 1/2" \\
\hline 24,2 & 20802 & 80,1 & 14 & GN/GLP & $200 / 280$ & $250 / 330$ & $3 / 4 "$ & 10 & 100 & 1/2" \\
\hline 24,0 & 20642 & 82,7 & 14,5 & GN & 180 & & $1 / 2^{\prime \prime}$ & 2 & 40 & $1 / 2^{\prime \prime}$ \\
\hline 23,8 & 20502 & 83,8 & 15 & GLP & 280 & & $1 / 2 "$ & 2 & 40 & 1/2" \\
\hline 23,4 & 20090 & 81,5 & 14 & GN/GLP & $200 / 280$ & & $1 / 2^{\prime \prime}$ & 5 & 125 & $1 / 2 "$ \\
\hline 23,1 & 19902 & 82,1 & 14 & GN/GLP & $200 / 280$ & & $1 / 2 "$ & 10 & 60 & 1/2" \\
\hline 22,7 & 19512 & 85,2 & 14,5 & GN & 180 & & $1 / 2^{\prime \prime}$ & 2 & 40 & $1 / 2^{\prime \prime}$ \\
\hline 22,5 & 19387 & 75 & 12 & GN/GLP & $200 / 280$ & & $1 / 2 "$ & 5 & 60 & 1/2" \\
\hline 22,1 & 19020 & 83,7 & 13,5 & GN/GLP & $200 / 280$ & & & 6 & 120 & \\
\hline 21,5 & 18506 & 78 & 12,5 & GN/GLP & $200 / 280$ & & $1 / 2^{\prime \prime}$ & 5 & 60 & $1 / 2 "$ \\
\hline 20,1 & 17286 & 81,2 & 12 & GN/GLP & $190 / 280$ & & $1 / 2 "$ & 5 & & 1/2" \\
\hline 19,7 & 16975 & 80,5 & 11,5 & GN/GLP & $200 / 280$ & & $1 / 2^{\prime \prime}$ & 5 & 60 & $1 / 2^{\prime \prime}$ \\
\hline 19,7 & 16942 & 82,5 & 12 & GN/GLP & $200 / 280$ & & $1 / 2 "$ & 5 & 60 & 1/2" \\
\hline 19,7 & 16906 & 82,2 & 12 & GLP & 280 & & $1 / 2 "$ & 2 & 40 & 1/2" \\
\hline 19,2 & 16528 & 79,7 & 11,5 & GN/GLP & $200 / 280$ & & $1 / 2 "$ & 7 & 40 & 1/2" \\
\hline 19,2 & 16523 & 81,4 & 11,5 & GN/GLP & $200 / 280$ & & $1 / 2 "$ & 5 & 125 & 1/2" \\
\hline 18,4 & 15844 & 82,7 & 11 & GN/GLP & $200 / 280$ & & $1 / 2^{\prime \prime}$ & 5 & 125 & $1 / 2 "$ \\
\hline 17,5 & 15078 & 84,7 & 11 & GLP & 280 & & $1 / 2 "$ & 2 & 40 & 1/2" \\
\hline 17,4 & 14996 & 80,4 & 10 & GLP & 280 & & $1 / 2^{\prime \prime}$ & 2 & 40 & 1/2" \\
\hline 16,7 & 14375 & 80,3 & 10 & GN & 200 & & $1 / 2^{\prime \prime}$ & 2 & 40 & $1 / 2 "$ \\
\hline 15,2 & 13088 & 78 & 8,5 & GN/GLP & $200 / 280$ & & $1 / 2 "$ & 4,5 & 80 & 1/2" \\
\hline 15,2 & 13072 & 85 & 9,5 & GN/GLP & $200 / 280$ & & $1 / 2^{\prime \prime}$ & 5 & 60 & 1/2" \\
\hline 14,9 & 12851 & 79 & 8,5 & GN/GLP & $190 / 280$ & & $1 / 2 "$ & 5 & & $1 / 2 "$ \\
\hline 14,4 & 12366 & 82,6 & 8,5 & GN/GLP & $200 / 280$ & & $1 / 2 "$ & 7 & 40 & 1/2" \\
\hline 14,2 & 12225 & 74,8 & 7,5 & GN/GLP & $200 / 280$ & & $1 / 2 "$ & 5 & 100 & 1/2" \\
\hline 13,2 & 11351 & 85,2 & 8,5 & GN/GLP & $200 / 280$ & & $1 / 2 "$ & 4 & 80 & 1/2" \\
\hline 12,4 & 10680 & 90,4 & 8 & GN/GLP & $200 / 280$ & & & 5 & 100 & \\
\hline 11,9 & 10270 & 77 & 6,5 & GN/GLP & $200 / 280$ & & $1 / 2 "$ & 5 & 60 & 1/2" \\
\hline 11,6 & 9954 & 77,9 & 6,5 & GN/GLP & $200 / 280$ & & $1 / 2^{\prime \prime}$ & 2 & 100 & $1 / 2^{\prime \prime}$ \\
\hline 11,3 & 9751 & 77,1 & 6,5 & GN/GLP & $200 / 280$ & & $1 / 2^{\prime \prime}$ & 2 & 100 & $1 / 2 "$ \\
\hline 10,3 & 8855 & 85,1 & 6 & GN/GLP & $200 / 280$ & $250 / 330$ & $1 / 2 "$ & 2 & 100 & 1/2" \\
\hline 10,1 & 8721 & 78,5 & 6 & GN/GLP & $200 / 280$ & & $1 / 2^{\prime \prime}$ & 4,5 & 80 & 1/2" \\
\hline 9,8 & 8396 & 78 & 5,5 & GN & 200 & & $1 / 2 "$ & 2 & 40 & $1 / 2 "$ \\
\hline 9,7 & 8342 & 75,2 & 5 & GN/GLP & $200 / 280$ & & $1 / 2^{\prime \prime}$ & 5 & 100 & 1/2" \\
\hline 7,2 & 6212 & 76,2 & 4 & GN & 200 & & $1 / 2^{\prime \prime}$ & 2 & 40 & $1 / 2 "$ \\
\hline 7,0 & 6002 & 75,2 & 3,9 & GN & 200 & & $1 / 2^{\prime \prime}$ & 2 & 40 & 1/2" \\
\hline 6,5 & 5568 & 76,3 & 3,7 & GLP & & & $1 / 2^{\prime \prime}$ & 2 & 40 & $1 / 2 "$ \\
\hline 6,5 & 5555 & 82,8 & 4 & GN & & & & & & \\
\hline 5,7 & 4944 & 72 & 3 & GN & & & $1 / 2^{\prime \prime}$ & 2 & 40 & 1/2" \\
\hline 5,6 & 4787 & 74 & 3 & GLP & & & & & & \\
\hline 5,3 & 4564 & 83,3 & 3 & GN & & & & & & \\
\hline 5,3 & 4517 & 83,2 & 3 & GN & & & & & & \\
\hline 5,1 & 4377 & 78,9 & 3 & GLP & & & & & & \\
\hline 5,1 & 4376 & 80 & 3 & GLP & & & & & & \\
\hline
\end{tabular}


B.3.2 Aquecedores em homologação

\begin{tabular}{|c|c|c|c|c|c|c|c|c|c|c|}
\hline $\begin{array}{c}\text { Potência } \\
\text { Nominal } \\
\text { KW }\end{array}$ & $\begin{array}{c}\text { Potência } \\
\text { Nominal } \\
\text { Kcal/h }\end{array}$ & $\begin{array}{c}\text { Eficiência } \\
\%\end{array}$ & $\begin{array}{c}\text { Capacidade } \\
\text { I/min }\end{array}$ & Gás & $\begin{array}{c}\text { Pressão } \\
\text { min:gn/glp } \\
\text { mmca }\end{array}$ & $\begin{array}{c}\text { Gás } \\
\text { Pressão } \\
\text { max } \\
\text { mmca }\end{array}$ & $\begin{array}{l}\text { Conexão/ } \\
\text { polegada }\end{array}$ & $\begin{array}{l}\text { Pressão } \\
\text { min } \\
\text { mca }\end{array}$ & $\begin{array}{c}\text { Água } \\
\text { Pressão } \\
\text { max } \\
\text { mca }\end{array}$ & $\begin{array}{c}\text { Conexões } \\
\text { E/S } \\
\text { polegada }\end{array}$ \\
\hline 53,2 & 45750 & 80 & 32 & GN/GLP & & & & & & \\
\hline 44,6 & 38314 & 80 & 25 & GN/GLP & & & & & & \\
\hline 42,9 & 36855 & 80 & 25 & GN/GLP & & & & & & \\
\hline 39,4 & 33907 & 80 & 23 & GN/GLP & & & & & & \\
\hline 32,1 & 27630 & 80 & 19 & GN/GLP & $200 / 280$ & & $1 / 2^{\prime \prime}$ & 5 & 125 & 1/2" \\
\hline 31,4 & 27000 & 80 & 18,5 & GN/GLP & & & & & & \\
\hline 30,0 & 25798 & 80 & 18 & GN & $200 / 280$ & & $1 / 2^{\prime \prime}$ & 2 & 40 & 1/2" \\
\hline 30,0 & 25798 & 80 & 18 & GLP & $200 / 280$ & & $1 / 2^{\prime \prime}$ & 2 & 40 & $1 / 2^{\prime \prime}$ \\
\hline 27,7 & 23792 & 80 & 16,5 & GLP & $200 / 280$ & & $1 / 2^{\prime \prime}$ & 2 & 40 & $1 / 2^{\prime \prime}$ \\
\hline 26,7 & 22931 & 80 & 16 & GN/GLP & $200 / 280$ & & $1 / 2^{\prime \prime}$ & 7 & 40 & $1 / 2^{\prime \prime}$ \\
\hline 26,4 & 22726 & 80 & 15,5 & GN/GLP & $190 / 280$ & & $1 / 2^{\prime \prime}$ & 5 & & $1 / 2^{\prime \prime}$ \\
\hline 25,9 & 22300 & 80 & 15 & GN/GLP & $200 / 280$ & & $1 / 2^{\prime \prime}$ & 5 & 125 & $1 / 2^{\prime \prime}$ \\
\hline 25,0 & 21535 & 80 & 15 & GN/GLP & & & & & & \\
\hline 24,7 & 21222 & 80 & 14,5 & GN/GLP & $200 / 280$ & & $1 / 2^{\prime \prime}$ & 2 & 100 & $1 / 2^{\prime \prime}$ \\
\hline 24,7 & 21222 & 80 & 14,5 & GN/GLP & $200 / 280$ & & $1 / 2^{\prime \prime}$ & 2 & 100 & $1 / 2^{\prime \prime}$ \\
\hline 24,4 & 20995 & 80 & 14,5 & GN/GLP & $190 / 280$ & & $1 / 2^{\prime \prime}$ & 5 & & $1 / 2^{\prime \prime}$ \\
\hline 23,5 & 20200 & 80 & 14 & GLP & 280 & & $1 / 2^{\prime \prime}$ & 2 & 40 & $1 / 2^{\prime \prime}$ \\
\hline 23,3 & 20000 & 80 & 14 & $\mathrm{GN}$ & 180 & & $1 / 2^{\prime \prime}$ & 2 & 40 & $1 / 2^{\prime \prime}$ \\
\hline 23,3 & 20000 & 80 & 14 & GLP & 280 & & $1 / 2^{\prime \prime}$ & 2 & 40 & $1 / 2^{\prime \prime}$ \\
\hline 23,3 & 20000 & 80 & 14 & $\mathrm{GN}$ & 180 & & $1 / 2^{\prime \prime}$ & 2 & 40 & $1 / 2^{\prime \prime}$ \\
\hline 21,6 & 18577 & 80 & 13 & GN & 180 & & $1 / 2^{\prime \prime}$ & 2 & 40 & $1 / 2^{\prime \prime}$ \\
\hline 21,6 & 18577 & 80 & 13 & GLP & 280 & & $1 / 2^{\prime \prime}$ & 2 & 40 & $1 / 2^{\prime \prime}$ \\
\hline 21,3 & 18282 & 80 & 12,5 & GN/GLP & $200 / 280$ & & $1 / 2^{\prime \prime}$ & 2 & 100 & $1 / 2^{\prime \prime}$ \\
\hline 20,5 & 17589 & 80 & 12 & GN/GLP & & & & & & \\
\hline 19,2 & 16500 & 80 & 11,5 & GN/GLP & $180 / 280$ & & $1 / 2^{\prime \prime}$ & 5 & 50 & $1 / 2^{\prime \prime}$ \\
\hline 17,5 & 15007 & 80 & 10 & GLP & 280 & & $1 / 2^{\prime \prime}$ & 2 & 40 & $1 / 2^{\prime \prime}$ \\
\hline 17,1 & 14700 & 80 & 10 & GN/GLP & $180 / 280$ & & $1 / 2^{\prime \prime}$ & 5 & 50 & $1 / 2^{\prime \prime}$ \\
\hline 12,9 & 11100 & 80 & 7,5 & GN/GLP & $180 / 280$ & & $1 / 2^{\prime \prime}$ & 5 & 50 & $1 / 2^{\prime \prime}$ \\
\hline 12,1 & 10440 & 80 & 7 & GN/GLP & & & & & & \\
\hline 12,0 & 10327 & 80 & 7 & GN/GLP & $190 / 280$ & & $1 / 2^{\prime \prime}$ & 5 & & $1 / 2^{\prime \prime}$ \\
\hline 11,7 & 10020 & 80 & 7 & GN & $200 / 280$ & & $1 / 2^{\prime \prime}$ & 2 & 40 & $1 / 2^{\prime \prime}$ \\
\hline 11,7 & 10020 & 80 & 7 & GN & $200 / 280$ & & $1 / 2^{\prime \prime}$ & 2 & 40 & $1 / 2^{\prime \prime}$ \\
\hline 11,3 & 9750 & 80 & 6,5 & GLP & $200 / 280$ & & $1 / 2^{\prime \prime}$ & 2 & 40 & $1 / 2^{\prime \prime}$ \\
\hline 11,3 & 9750 & 80 & 6,5 & GLP & $200 / 280$ & & $1 / 2^{\prime \prime}$ & 2 & 40 & $1 / 2^{\prime \prime}$ \\
\hline 11,2 & 9600 & 80 & 6,5 & GN/GLP & & & & & & \\
\hline 11,0 & 9423 & 80 & 6,5 & GN/GLP & $190 / 200$ & & $1 / 2^{\prime \prime}$ & 3 & & $1 / 2^{\prime \prime}$ \\
\hline 10,6 & 9120 & 80 & 6 & GN/GLP & $216 / 280$ & & 3/4" & 1,5 & 50 & $1 / 2^{\prime \prime}$ \\
\hline 10,5 & 9000 & 80 & 6 & GN/GLP & $216 / 280$ & & 3/4" & 1,5 & 50 & $1 / 2^{\prime \prime}$ \\
\hline 10,2 & 8814 & 80 & 6 & GN & 180 & & $1 / 2^{\prime \prime}$ & 2 & 40 & $1 / 2^{\prime \prime}$ \\
\hline 10,2 & 8814 & 80 & 6 & GLP & 280 & & $1 / 2^{\prime \prime}$ & 2 & 40 & $1 / 2^{\prime \prime}$ \\
\hline 7,0 & 6000 & 80 & 4 & GN & 180 & & $1 / 2^{\prime \prime}$ & 2 & 40 & $1 / 2^{\prime \prime}$ \\
\hline 6,3 & 5435 & 80 & 3,5 & GLP & 280 & & $1 / 2^{\prime \prime}$ & 2 & 40 & $1 / 2^{\prime \prime}$ \\
\hline 5,7 & 4900 & 80 & 3 & GN & 180 & & $1 / 2^{\prime \prime}$ & 2 & 40 & $1 / 2^{\prime \prime}$ \\
\hline
\end{tabular}

B.3.3 Aquecedor de Acumulação Privado a gás

\begin{tabular}{|c|c|c|c|c|c|c|c|c|c|c|c|}
\hline \multirow[b]{2}{*}{ Volume } & \multirow[b]{2}{*}{$\begin{array}{l}\text { Potência } \\
\text { Nominal }\end{array}$} & \multirow[b]{2}{*}{$\begin{array}{l}\text { Potência } \\
\text { Nominal }\end{array}$} & \multirow[b]{2}{*}{$\begin{array}{c}\text { Efic } \\
\%\end{array}$} & \multicolumn{2}{|c|}{ Consumo maximo } & \multirow{2}{*}{$\begin{array}{l}\text { Capacidade } \\
\text { de } \\
\text { recuperação } \\
\left(\Delta t 50^{\circ} C\right)\end{array}$} & \multirow[b]{2}{*}{ Capacidade } & \multicolumn{2}{|c|}{ Gás } & \multicolumn{2}{|c|}{ Água } \\
\hline & & & & GN & GLP & & & $\begin{array}{c}\text { Pressão } \\
\text { min } \\
\text { mmca }\end{array}$ & Conexão & $\begin{array}{l}\text { Pressão } \\
\text { max }\end{array}$ & $\begin{array}{c}\text { Conexões } \\
\text { E/S }\end{array}$ \\
\hline litros & $\mathrm{kW}$ & $\mathrm{kcal} / \mathrm{h}$ & & $\mathrm{m}^{3} / \mathrm{h}$ & $\mathrm{kg} / \mathrm{h}$ & $\mathrm{l} / \mathrm{h}$ & $\mathrm{I} / \mathrm{min}$ & GN/GLP & polegada & mca & polegada \\
\hline 50 & 4,3993 & 3786 & 75 & 0,4 & 0,32 & 57 & & $200 / 280$ & $1 / 2$ & 40 & 1 \\
\hline 75 & 6,9732 & 6001 & 75 & 0,63 & 0,51 & 90 & & $200 / 280$ & $1 / 2$ & 40 & 1 \\
\hline 80 & 6,9720 & 6000 & 76 & 0,56 & 0,5 & & & $180 / 280$ & & 45 & \\
\hline 80 & 5,2290 & 4500 & & 0,47 & 0,4 & & & $200 / 280$ & $3 / 8$ & 40 & $3 / 4$ \\
\hline 100 & 21,8456 & 18.800 & & & 1,6 & & 15 & $200 / 280$ & $1 / 2$ & 40 & 1 \\
\hline 110 & 9,4691 & 8149 & 75 & 0,86 & 0,69 & 122 & & $200 / 280$ & $1 / 2$ & 40 & 1 \\
\hline 110 & 9,4800 & 8149 & 75 & 0,72 & 0,7 & 122 & & $190 / 280$ & $1 / 2$ & 40 & 1 \\
\hline 120 & 7,2044 & 6200 & & 0,65 & 0,55 & & & $200 / 280$ & $3 / 8$ & 40 & $3 / 4$ \\
\hline 130 & 9,2960 & 8000 & 76 & 0,74 & 0,67 & & & $180 / 280$ & & 45 & \\
\hline 150 & 9,4691 & 8149 & 80,3 & 0,87 & 0,69 & 131 & & $200 / 280$ & $1 / 2$ & 40 & 1 \\
\hline 150 & 9,4800 & 8149 & 75 & 0,72 & 0,7 & 122 & & $190 / 281$ & $1 / 2$ & 40 & 1 \\
\hline 150 & 7,2044 & 6200 & & 0,65 & 0,55 & & & $200 / 280$ & $3 / 8$ & 40 & 1 \\
\hline 160 & 9,2960 & 8000 & 76 & 0,74 & 0,67 & & & $180 / 280$ & & 45 & \\
\hline 175 & 9,4691 & 8149 & 75 & 0,86 & 0,69 & 122 & & $200 / 280$ & $1 / 2$ & 40 & 1 \\
\hline 175 & 7,2044 & 6200 & & 0,65 & 0,55 & & & $200 / 280$ & $3 / 8$ & 40 & 1 \\
\hline 190 & 11,2714 & 9700 & 76 & 1 & 0,82 & & & $180 / 280$ & & 40 & \\
\hline
\end{tabular}




\begin{tabular}{|c|c|c|c|c|c|c|c|c|c|c|c|}
\hline \multirow[b]{2}{*}{ Volume } & \multirow[b]{2}{*}{$\begin{array}{l}\text { Potência } \\
\text { Nominal }\end{array}$} & \multirow[b]{2}{*}{$\begin{array}{l}\text { Potência } \\
\text { Nominal }\end{array}$} & \multirow[b]{2}{*}{ Efic } & \multicolumn{2}{|c|}{ Consumo Máximo } & \multirow{2}{*}{$\begin{array}{c}\text { Capacidade } \\
\text { de } \\
\text { recuperação } \\
\left(\Delta t 50^{\circ} \mathrm{C}\right)\end{array}$} & \multirow[b]{2}{*}{ Capacidade } & \multicolumn{2}{|c|}{ Gás } & \multicolumn{2}{|c|}{ Água } \\
\hline & & & & GN & GLP & & & $\begin{array}{l}\text { Pressão } \\
\text { min } \\
\text { mmca }\end{array}$ & Conexão & $\begin{array}{c}\text { Pressão } \\
\text { max }\end{array}$ & $\begin{array}{c}\text { Conexões } \\
\text { E/S }\end{array}$ \\
\hline litros & $\mathrm{kW}$ & $\mathrm{kcal} / \mathrm{h}$ & $\%$ & $\mathrm{~m}^{3} / \mathrm{h}$ & $\mathrm{kg} / \mathrm{h}$ & $\mathrm{l} / \mathrm{h}$ & $1 / \min$ & GN/GLP & polegada & mca & polegada \\
\hline 200 & 12,2010 & 10500 & 70,3 & 1,1 & 0,89 & 148 & & $200 / 280$ & $1 / 2$ & 40 & 1 \\
\hline 200 & 12,2000 & 10500 & 70,3 & 0,98 & 0,89 & 158 & & 190/282 & $1 / 2$ & 40 & 1 \\
\hline 200 & 25,9417 & 22.325 & & & 1,9 & & 18 & $200 / 280$ & $1 / 2$ & 40 & 1 \\
\hline 200 & 8,7150 & 7500 & & 0,8 & 0,66 & & & $200 / 280$ & $3 / 8$ & 40 & 1 \\
\hline 250 & 15,6870 & 13500 & 72 & 1,42 & 1,14 & 84 & & $200 / 280$ & $1 / 2$ & 40 & 1 \\
\hline 250 & 52,2900 & 45.000 & & 4 & 4,2 & & 15 & & $1 / 2$ & 40 & 1 \\
\hline 300 & 17,4300 & 15000 & 75 & 1,57 & 1,27 & 255 & & $200 / 280$ & $1 / 2$ & 40 & $11 / 2$ \\
\hline 300 & 25,9417 & 22.325 & & & 2,3 & & 20 & $200 / 280$ & $1 / 2$ & 40 & 1 \\
\hline 300 & 8,7150 & 7500 & & 0,8 & 0,66 & & & $200 / 280$ & $3 / 8$ & 40 & 1 \\
\hline 400 & 32,2804 & 27.780 & & & 2,3 & & 20 & $200 / 280$ & $1 / 2$ & 40 & 1 \\
\hline 500 & 32,2804 & 27.780 & & & 2,3 & & 20 & $200 / 280$ & $1 / 2$ & 40 & 1 \\
\hline 1000 & 52,2900 & 45.000 & & 4 & 4,2 & & 15 & & $3 / 4$ & 40 & 2 \\
\hline 1000 & 104,5800 & 90.000 & & 8 & 8,3 & & 30 & & $3 / 4$ & 40 & 2 \\
\hline 500 & 52,2900 & 45.000 & & 4 & 4,2 & & 15 & & $3 / 4$ & 40 & $11 / 2$ \\
\hline 500 & 104,5800 & 90.000 & & 8 & 8,3 & & 30 & & $3 / 4$ & 40 & $11 / 2$ \\
\hline
\end{tabular}

\section{B.4 Coletor Solar}

\begin{tabular}{|c|c|c|c|c|c|c|}
\hline \multicolumn{2}{|c|}{$\begin{array}{c}\text { PRESSÃO DE } \\
\text { FUNCIONAMENTO }\end{array}$} & \multirow{2}{*}{$\begin{array}{c}\text { ÁREA } \\
\text { EXTERNA DO } \\
\text { COLETOR } \\
\text { m2 }\end{array}$} & \multicolumn{2}{|c|}{$\begin{array}{c}\text { PRODUÇÃO MÉDIA MENSAL DE } \\
\text { ENERGIA }\end{array}$} & \multirow{2}{*}{$\begin{array}{c}\text { EFICIÊNCIA } \\
\text { ENERGÉTICA } \\
\text { MÉDIA (\%) }\end{array}$} & \multirow{2}{*}{$\begin{array}{l}\text { MATERIAL SUPERFÍCIE } \\
\text { ABSORVEDORA }\end{array}$} \\
\hline $\mathrm{kPa}$ & (mca) & & $\begin{array}{l}\text { POR } \\
\text { COLETOR } \\
\text { kWh/mês }\end{array}$ & $\begin{array}{l}\text { ESPECÍFICA } \\
\text { (PMS) } \\
\text { kWh/mês.m² } \\
\end{array}$ & & \\
\hline \multicolumn{7}{|l|}{ BANHO } \\
\hline 392 & 40 & 1,56 & 111,7 & 71,6 & 51 & ALUMINIO \\
\hline 400 & 40,8 & 1 & 73,6 & 73,6 & 53,7 & COBRE \\
\hline 400 & 40,8 & 1,42 & 106,8 & 75,2 & 54,7 & COBRE \\
\hline 400 & 40,8 & 1,95 & 146,6 & 75,2 & 54,7 & COBRE \\
\hline 400 & 40,8 & 1,42 & 93,2 & 65,6 & 48,1 & ALUMINIO \\
\hline 400 & 40,8 & 1,95 & 127,9 & 65,6 & 48,1 & ALUMINIO \\
\hline 400 & 40,8 & 1 & 77,3 & 77,3 & 55,6 & COBRE \\
\hline 400 & 40,8 & 1,42 & 109,8 & 77,3 & 55,6 & COBRE \\
\hline 400 & 40,8 & 1,68 & 129,9 & 77,3 & 55,6 & COBRE \\
\hline 400 & 40,8 & 2,81 & 222,3 & 79,1 & 56,7 & COBRE \\
\hline 392 & 40 & 2 & 143,6 & 71,8 & 52 & ALUMINIO \\
\hline 392 & 40 & 3 & 215,4 & 71,8 & 52 & ALUMINIO \\
\hline 392 & 40 & 2 & 143,6 & 71,8 & 52 & ALUMINIO \\
\hline 297 & 30,3 & 1,99 & 131,9 & 66,3 & 50,8 & ALUMINIO \\
\hline 400 & 40,8 & 1 & 85,3 & 85,3 & 60,6 & COBRE \\
\hline 400 & 40,8 & 1,4 & 119,4 & 85,3 & 60,6 & COBRE \\
\hline 400 & 40,8 & 1,5 & 128 & 85,3 & 60,6 & COBRE \\
\hline 400 & 40,8 & 1,7 & 145 & 85,3 & 60,6 & COBRE \\
\hline 400 & 40,8 & 2 & 170,6 & 85,3 & 60,6 & COBRE \\
\hline 400 & 40,8 & 1 & 79,9 & 79,9 & 56,6 & COBRE \\
\hline 400 & 40,8 & 1,4 & 111,9 & 79,9 & 56,6 & COBRE \\
\hline 400 & 40,8 & 1,5 & 119,9 & 79,9 & 56,6 & COBRE \\
\hline 400 & 40,8 & 1,7 & 135,8 & 79,9 & 56,6 & COBRE \\
\hline 400 & 40,8 & 2 & 159,8 & 79,9 & 56,6 & COBRE \\
\hline 392 & 40 & 2,8 & 241,6 & 86,3 & 61,4 & COBRE \\
\hline 392 & 40 & 1,1 & 89,1 & 81 & 57,6 & COBRE \\
\hline 392 & 40 & 2 & 134,8 & 67,4 & 49,3 & COBRE \\
\hline 392 & 40 & 1,79 & 133 & 74,3 & 56,9 & ALUMINIO \\
\hline 392 & 40 & 1,79 & 133 & 74,3 & 55,7 & ALUMINIO \\
\hline 400 & 40,8 & 1 & 79,9 & 79,9 & 56,6 & COBRE \\
\hline 400 & 40,8 & 1,5 & 119,9 & 79,9 & 56,6 & COBRE \\
\hline 400 & 40,8 & 2 & 159,8 & 79,9 & 56,6 & COBRE \\
\hline 392 & 40 & 1,99 & 159,4 & 80,1 & 58 & COBRE \\
\hline 392 & 40 & 1,99 & 147 & 73,9 & 53,1 & ALUMINIO \\
\hline 392 & 40 & 1,02 & 60,3 & 59,1 & 43,3 & COBRE \\
\hline 392 & 40 & 1,02 & 63,2 & 62 & 46,3 & ALUMINIO \\
\hline 392 & 40 & 1,42 & 88 & 62 & 46,3 & ALUMINIO \\
\hline 392 & 40 & 1,72 & 106,6 & 62 & 46,3 & ALUMINIO \\
\hline 392 & 40 & 2,02 & 125,2 & 62 & 46,3 & ALUMINIO \\
\hline 392 & 40 & 1,42 & 88 & 62 & 46,3 & ALUMINIO \\
\hline
\end{tabular}




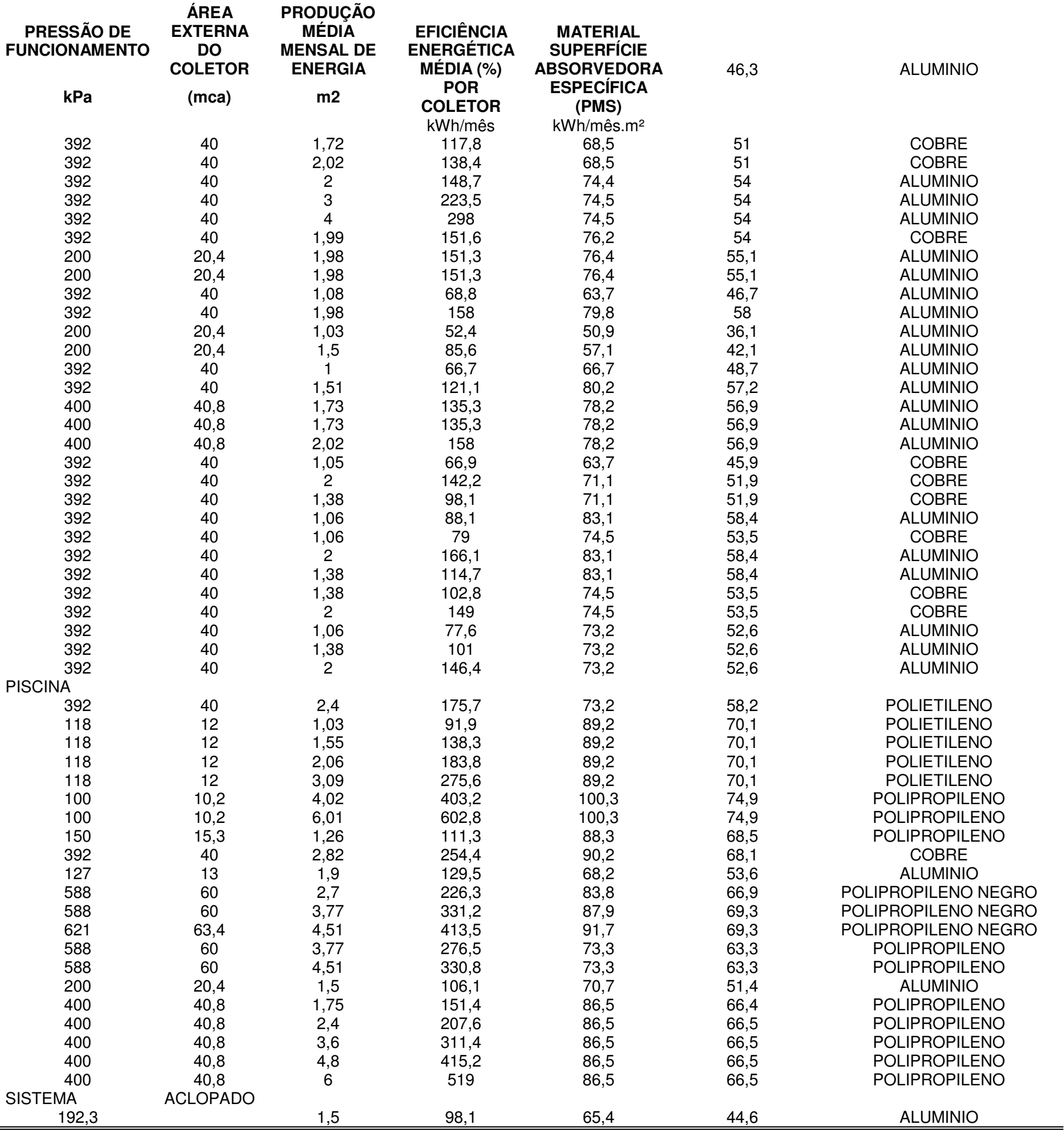




\section{B.5. Reservatório solar}

B.5.1 Reservatórios para Baixa Pressão

\begin{tabular}{|c|c|c|c|c|c|c|c|c|}
\hline $\begin{array}{c}\text { Volume } \\
\text { litros }\end{array}$ & $\begin{array}{c}\text { Potência } \\
\text { ELE } \\
\text { kW }\end{array}$ & $\begin{array}{c}\text { Perda } \\
\text { reservatório }\end{array}$ & $\begin{array}{c}\text { Pressão } \\
\text { kPa }\end{array}$ & $\mathrm{mca}$ & $\begin{array}{c}\text { Dimensões } \\
\text { Externas } \\
\text { compr } \\
\text { mm }\end{array}$ & diâmetro & $\begin{array}{c}\text { Material } \\
\text { Corpo 1nterno }\end{array}$ & Isolante térmico \\
\hline 100 & 2 & 0,25 & 50 & 5 & 840 & 530 & AÇO INOX & POLIURETANO \\
\hline 200 & $x$ & 0,2 & $x$ & $\mathrm{x}$ & 970 & 680 & POLIETILENO & POLIURETANO \\
\hline 200 & 3 & 0,19 & 40 & 4,1 & 790 & 715 & ACCO INOX & POLIURETANO \\
\hline 200 & 2 & 0,21 & 50 & 5,1 & 1300 & 500 & AÇO INOX & POLIURETANO \\
\hline 200 & 2 & 0,21 & 20 & 2,0 & 1320 & 560 & AḈO INOX & POLIURETANO \\
\hline 200 & 3 & 0,21 & 40 & 4,1 & 1140 & 620 & ACCO INOX & POLIURETANO \\
\hline 200 & 2 & 0,25 & 50 & 5,1 & 1576 & 547 & AÇO INOX & LÃ DE ROCHA \\
\hline 200 & 2,5 & 0,2 & 50 & 5,1 & 840 & 675 & AÇO INOX & POLIURETANO \\
\hline 200 & 2,5 & 0,25 & 50 & 5,1 & 840 & 675 & ACCO INOX & POLIURETANO \\
\hline 200 & 3 & 0,16 & 50 & 5,1 & 870 & 700 & AÇO INOX & POLIURETANO \\
\hline 200 & $\mathrm{x}$ & 0,23 & $x$ & $x$ & 650 & 800 & ACCO INOX & POLIURETANO \\
\hline 200 & 3 & 0,2 & 30 & 3,1 & 870 & 715 & AÇO INOX & POLIURETANO \\
\hline 200 & 2 & 0,24 & 50 & 5,1 & 990 & 610 & AÇO INOX & POLIURETANO \\
\hline 200 & 2,5 & 0,27 & 50 & 5,1 & 1550 & 490 & ACO INOX & POLIURETANO \\
\hline 200 & 3 & 0,21 & 20 & 2,0 & 660 & 725 & AÇO INOX & POLIURETANO \\
\hline 200 & 3,5 & 0,22 & 20 & 2,0 & 1050 & 660 & COBRE & POLIURETANO \\
\hline 200 & 3,5 & 0,26 & 20 & 2,0 & 1020 & 600 & COBRE & POLIURETANO \\
\hline 200 & 2 & 0,2 & 50 & 5,1 & 1330 & 530 & AÇO INOX & POLIURETANO \\
\hline 200 & 2,5 & 0,19 & 40 & 4,1 & 875 & 705 & ACO INOX & POLIURETANO \\
\hline 200 & 2,5 & 0,23 & 40 & 4,1 & 1435 & 520 & AḈO INOX & POLIURETANO \\
\hline 250 & 2,5 & 0,25 & 40 & 4,1 & 1700 & 520 & ACCO INOX & POLIURETANO \\
\hline 300 & 2 & 0,26 & 20 & 2 & 1820 & 560 & COBRE & POLIURETANO \\
\hline 300 & 3 & 0,25 & 40 & 4,1 & 1460 & 610 & AÇO INOX & POLIURETANO \\
\hline 300 & 2,5 & 0,18 & 50 & 5,1 & 1350 & 675 & AÇO INOX & POLIURETANO \\
\hline 300 & 2,5 & 0,18 & 50 & 5,1 & 1350 & 675 & AÇO INOX & POLIURETANO \\
\hline 300 & 3 & 0,19 & 20 & 2 & 1175 & 690 & ACCO INOX & POLIURETANO \\
\hline 300 & 3,5 & 0,23 & 20 & 2 & 1440 & 660 & COBRE & POLIURETANO \\
\hline 300 & 2 & 0,27 & 50 & 5,1 & 1480 & 610 & AÇO INOX & POLIURETANO \\
\hline 300 & 2,5 & 0,17 & 40 & 4,1 & 1110 & 705 & ACO INOX & POLIURETANO \\
\hline 400 & 3 & 0,13 & 40 & 4,1 & 1390 & 715 & AÇO INOX & POLIURETANO \\
\hline 400 & 2 & 0,19 & 20 & 2 & 2320 & 560 & COBRE & POLIURETANO \\
\hline 400 & 3 & 0,15 & 20 & 2 & 1760 & 630 & COBRE & POLIURETANO \\
\hline 400 & 3 & 0,22 & 40 & 4,1 & 1640 & 705 & ACCO INOX & POLIURETANO \\
\hline 400 & 3 & 0,16 & 50 & 5,1 & 1843 & 739 & AÇO INOX & LÃ DE ROCHA \\
\hline 400 & 2,5 & 0,15 & 50 & 5,1 & 1610 & 675 & AÇO INOX & POLIURETANO \\
\hline 400 & 3 & 0,16 & 50 & 5,1 & 1450 & 760 & ACO INOX & POLIURETANO \\
\hline 400 & 3 & 0,15 & 30 & 3,1 & 1500 & 715 & AÇO INOX & POLIURETANO \\
\hline 400 & 2 & 0,22 & 50 & 5,1 & 1840 & 610 & ACCO INOX & POLIURETANO \\
\hline 400 & 2 & 0,18 & 50 & 5,1 & 1176 & 760 & ACCO INOX & POLIURETANO \\
\hline 400 & 2 & 0,16 & 50 & 5,1 & 1150 & 760 & AÇO INOX & POLIURETANO \\
\hline 400 & 2,5 & 0,17 & 70 & 7,1 & 1520 & 675 & ACO INOX & POLIURETANO \\
\hline 400 & 3 & 0,2 & 20 & 2 & 1310 & 680 & AÇO INOX & POLIURETANO \\
\hline 400 & 3,5 & 0,22 & 20 & 2 & 1780 & 660 & COBRE & POLIURETANO \\
\hline 400 & 3 & 0,19 & 50 & 5,1 & 1520 & 690 & AÇO INOX & POLIURETANO \\
\hline 400 & 2,5 & 0,14 & 40 & 4,1 & 1440 & 705 & AÇO INOX & POLIURETANO \\
\hline 500 & 3 & 0,11 & 40 & 4,1 & 1430 & 790 & ACO INOX & POLIURETANO \\
\hline 500 & 3 & 0,14 & 50 & 5,1 & 1770 & 710 & AÇO INOX & POLIURETANO \\
\hline 500 & 3 & 0,18 & 50 & 5,1 & 1700 & 670 & ACCO INOX & POLIURETANO \\
\hline 500 & 3 & 0,16 & 20 & 2 & 2145 & 630 & COBRE & POLIURETANO \\
\hline 500 & 3 & 0,12 & 101 & 10,3 & 1484 & 800 & AÇO INOX & POLIURETANO \\
\hline 500 & 3 & 0,16 & 50 & 5,1 & 1843 & 739 & AÇO INOX & LÂ DE ROCHA \\
\hline 500 & 2,5 & 0,21 & 50 & 5,1 & 2050 & 675 & AÇO INOX & POLIURETANO \\
\hline 500 & 2,5 & 0,21 & 50 & 5,1 & 2050 & 675 & ACO INOX & POLIURETANO \\
\hline 500 & 3 & 0,14 & 70 & 7,1 & 1560 & 765 & AÇO INOX & POLIURETANO \\
\hline 500 & 3 & 0,17 & 20 & 2 & 1450 & 775 & ACCO INOX & POLIURETANO \\
\hline 500 & 3,5 & 0,19 & 20 & 2 & 2140 & 660 & COBRE & POLIURETANO \\
\hline 500 & 3 & 0,21 & 50 & 5,1 & 1820 & 690 & AÇO INOX & POLIURETANO \\
\hline 500 & 2,5 & 0,18 & 40 & 4,1 & 1880 & 705 & ACCO INOX & POLIURETANO \\
\hline 600 & 3 & 0,12 & 40 & 4,1 & 1990 & 715 & AÇO INOX & POLIURETANO \\
\hline 600 & 3 & 0,11 & 50 & 5,1 & 1970 & 670 & AÇO INOX & POLIURETANO \\
\hline 600 & 2 & 0,16 & 20 & 2 & 2575 & 630 & COBRE & POLIURETANO \\
\hline 600 & 3 & 0,11 & 101 & 10,3 & 1729 & 800 & AÇO INOX & POLIURETANO \\
\hline 600 & 3 & 0,17 & 40 & 4,1 & 1660 & 840 & ACO INOX & POLIURETANO \\
\hline 600 & 2,5 & 0,2 & 50 & 5,1 & 2350 & 675 & ACO INOX & POLIURETANO \\
\hline 600 & 2,5 & 0,2 & 50 & 5,1 & 2350 & 675 & ACO INOX & POLIURETANO \\
\hline
\end{tabular}




\begin{tabular}{|c|c|c|c|c|c|c|c|c|}
\hline Volume & $\begin{array}{l}\text { Potência } \\
\text { ELE }\end{array}$ & $\begin{array}{c}\text { Perda } \\
\text { reservatório }\end{array}$ & Pressão & & $\begin{array}{c}\text { Dimensões } \\
\text { Externas } \\
\text { compr }\end{array}$ & diâmetro & $\begin{array}{c}\text { Material } \\
\text { Corpo 1nterno }\end{array}$ & Isolante térmico \\
\hline litros & kW & & $\mathrm{kPa}$ & mca & $\mathrm{mm}$ & & & \\
\hline 600 & 2 & 0,2 & 50 & 5,1 & 1657 & 760 & AÇO INOX & POLIURETANO \\
\hline 600 & 4 & 0,17 & 50 & 5,1 & 1640 & 760 & AÇO INOX & POLIURETANO \\
\hline 600 & 3 & 0,12 & 50 & 5,1 & 1610 & 830 & AÇO INOX & POLIURETANO \\
\hline 600 & 3 & 0,17 & 20 & 2 & 1570 & 780 & AḈO INOX & POLIURETANO \\
\hline 600 & 3,5 & 0,14 & 20 & 2 & 2530 & 660 & COBRE & POLIURETANO \\
\hline 600 & 3,5 & 0,2 & 20 & 2 & 2500 & 600 & COBRE & POLIURETANO \\
\hline 600 & 3 & 0,16 & 50 & 5,1 & 2120 & 690 & AÇO INOX & POLIURETANO \\
\hline 600 & 2,5 & 0,15 & 40 & 4,1 & 2180 & 705 & AÇO INOX & POLIURETANO \\
\hline 800 & 3 & 0,1 & 40 & 4,1 & 2230 & 790 & AÇO INOX & POLIURETANO \\
\hline 800 & 3 & 0,1 & 101 & 10,3 & 2184 & 800 & AÇO INOX & POLIURETANO \\
\hline 800 & 3 & 0,12 & 50 & 5,1 & 2590 & 670 & AÇO INOX & POLIURETANO \\
\hline 800 & 3 & 0,16 & 40 & 4,1 & 1518 & 935 & ACCO INOX & POLIURETANO \\
\hline 800 & 5 & 0,15 & 50 & 5,1 & 2300 & 810 & AÇ̧O INOX & POLIURETANO \\
\hline 800 & 5 & 0,15 & 50 & 5,1 & 2300 & 810 & AÇO INOX & POLIURETANO \\
\hline 800 & 3 & 0,09 & 30 & 3,1 & 1560 & 1000 & AÇO INOX & POLIURETANO \\
\hline 800 & 4 & 0,15 & 50 & 5,1 & 2130 & 760 & AÇO INOX & POLIURETANO \\
\hline 800 & 5 & 0,14 & 50 & 5,1 & 2135 & 790 & AÇO INOX & POLIURETANO \\
\hline 800 & 3,5 & 0,2 & 50 & 5,1 & 1940 & 800 & AÇO INOX & POLIURETANO \\
\hline 800 & 4 & 0,16 & 50 & 5,1 & 2270 & 770 & AÇO INOX & POLIURETANO \\
\hline 800 & 3 & 0,1 & 39 & 4 & 1520 & 960 & AÇO INOX & POLIURETANO \\
\hline 1000 & 3 & 0,1 & 40 & 4,1 & 2650 & 790 & AÇO INOX & POLIURETANO \\
\hline 1000 & 6 & 0,12 & 50 & 5,1 & 1965 & 900 & ACO INOX & POLIURETANO \\
\hline 1000 & 3 & 0,12 & 100 & 10,2 & 2820 & 800 & AÇO INOX & POLIURETANO \\
\hline 1000 & 3 & 0,13 & 40 & 4,1 & 1620 & 1030 & AÇO INOX & POLIURETANO \\
\hline 1000 & 5 & 0,14 & 50 & 5,1 & 2850 & 810 & AÇO INOX & POLIURETANO \\
\hline 1000 & 5 & 0,14 & 50 & 5,1 & 2850 & 810 & AÇO INOX & POLIURETANO \\
\hline 1000 & 3 & 0,09 & 30 & 3,1 & 1570 & 1083 & AÇO INOX & POLIURETANO \\
\hline 1000 & 4 & 0,21 & 50 & 5,1 & 2720 & 760 & AÇO INOX & POLIURETANO \\
\hline 1000 & 4 & 0,15 & 50 & 5,1 & 2630 & 760 & AÇO INOX & POLIURETANO \\
\hline 1000 & 3 & 0,14 & 50 & 5,1 & 2650 & 800 & AÇO INOX & POLIURETANO \\
\hline 1000 & 5 & 0,15 & 20 & 2 & 2530 & 795 & AÇO INOX & POLIURETANO \\
\hline 1000 & 4 & 0,2 & 50 & 5,1 & 2680 & 770 & AÇO INOX & POLIURETANO \\
\hline 1000 & 4 & 0,1 & 39 & 4 & 1780 & 960 & AḈO INOX & POLIURETANO \\
\hline
\end{tabular}

\section{B.5.2 Reservatórios para Alta Pressão}

\begin{tabular}{|c|c|c|c|c|c|c|c|c|}
\hline $\begin{array}{c}\text { Volume } \\
\text { litros }\end{array}$ & $\begin{array}{c}\text { Potência } \\
\text { Elétrica } \\
\text { kW }\end{array}$ & $\begin{array}{c}\text { Perda } \\
\text { reservatório }\end{array}$ & $\begin{array}{c}\text { Pressão } \\
\text { kPa }\end{array}$ & mca & $\begin{array}{c}\text { Dimensões } \\
\text { Externas } \\
\text { compr } \\
\mathrm{mm}\end{array}$ & diâmetro & $\begin{array}{c}\text { Material } \\
\text { corpo 1nterno }\end{array}$ & isolante térmico \\
\hline 200 & 2,5 & 0,2 & 400 & 40,8 & 840 & 675 & AÇO INOX & POLIURETANO \\
\hline 200 & 2,5 & 0,27 & 400 & 40,8 & 1330 & 560 & AÇO INOX & LÃ DE BASALTO \\
\hline 200 & 2,5 & 0,19 & 392 & 40 & 875 & 705 & AÇO INOX & POLIURETANO \\
\hline 300 & 2,5 & 0,18 & 400 & 40,8 & 1350 & 675 & AÇO INOX & POLIURETANO \\
\hline 300 & 7 & 0,23 & 400 & 40,8 & 1250 & 600 & AÇO INOX & POLIURETANO \\
\hline 300 & 2 & 0,26 & 400 & 40,8 & 1480 & 610 & AÇO INOX & POLIURETANO \\
\hline 300 & 2,5 & 0,17 & 392 & 40 & 1110 & 705 & AÇO INOX & POLIURETANO \\
\hline 400 & 2,5 & 0,15 & 400 & 40,8 & 1610 & 675 & AÇO INOX & POLIURETANO \\
\hline 400 & 7 & 0,22 & 400 & 40,8 & 1620 & 600 & AÇO INOX & POLIURETANO \\
\hline 400 & 3 & 0,19 & 400 & 40,8 & 1520 & 690 & AÇO INOX & POLIURETANO \\
\hline 400 & 2,5 & 0,14 & 392 & 40 & 1440 & 705 & AÇO INOX & POLIURETANO \\
\hline 500 & 2,5 & 0,21 & 400 & 40,8 & 2050 & 675 & AÇ'O INOX & POLIURETANO \\
\hline 500 & 3,5 & 0,19 & 400 & 40,8 & 2040 & 600 & AÇO INOX & POLIURETANO \\
\hline 500 & 3 & 0,23 & 400 & 40,8 & 1820 & 690 & AÇO INOX & POLIURETANO \\
\hline 500 & 2,5 & 0,16 & 392 & 40 & 1880 & 705 & AÇO INOX & POLIURETANO \\
\hline 600 & 2,5 & 0,2 & 400 & 40,8 & 2350 & 675 & AÇO INOX & POLIURETANO \\
\hline 600 & 3 & 0,15 & 392 & 40 & 1900 & 760 & AÇO INOX & POLIURETANO \\
\hline 600 & 7 & 0,2 & 400 & 40,8 & 2370 & 600 & AÇO INOX & POLIURETANO \\
\hline 600 & 3 & 0,16 & 400 & 40,8 & 2120 & 690 & AÇO INOX & POLIURETANO \\
\hline 600 & 2,5 & 0,15 & 392 & 40 & 2180 & 705 & AÇO INOX & POLIURETANO \\
\hline 800 & 5 & 0,15 & 400 & 40,8 & 2300 & 810 & AÇO INOX & POLIURETANO \\
\hline 800 & 3 & 0,14 & 392 & 40 & 2380 & 760 & AÇO INOX & POLIURETANO \\
\hline 800 & 3 & 0,13 & 392 & 40 & 2665 & 705 & AÇO INOX & POLIURETANO \\
\hline 1000 & 5 & 0,14 & 400 & 40,8 & 2850 & 810 & AÇ'O INOX & POLIURETANO \\
\hline 1000 & 4 & 0,13 & 392 & 40 & 3045 & 705 & AÇO INOX & POLIURETANO \\
\hline
\end{tabular}




\section{ANEXO C \\ Planilha de dimensionamento elétrico}

\section{C.1- Dimensionamento Elétrico}

\begin{tabular}{lrl}
\hline Dados do Edifício & & \\
\hline Andares & 16 & área útil do apt: $106,44 \mathrm{~m}^{2}$ \\
apts/andar & 4 & área útil Administração:10562,07m² \\
Total de apts & 64 &
\end{tabular}

\begin{tabular}{|c|c|c|c|c|c|c|c|c|c|c|c|}
\hline $\begin{array}{l}\text { Cargas } \\
\text { Relação das cargas /APT }\end{array}$ & \multicolumn{3}{|c|}{$\begin{array}{l}\text { Para cálculo do QDL } \\
\text { No apartamento }\end{array}$} & FD & $\begin{array}{c}\text { Pot } \\
\text { deman }\end{array}$ & \multicolumn{3}{|c|}{ Para Cálculo de Demanda geral } & \multicolumn{3}{|l|}{ Por ramal sec } \\
\hline Ilum+tug & & & 13,6 & 0,2 & 3,3 & $x$ & $\mathrm{x}$ & $x$ & $x$ & $\mathrm{x}$ & $x$ \\
\hline Chuv & 3 & 5,4 & 16,2 & 0,6 & 9,1 & 192 & 0,2 & 217,7 & 48,6 & 194,4 & 64,8 \\
\hline Torneira elétrica & 0 & 3,2 & 0,0 & 0,0 & 0,0 & 0 & 0,0 & 0,0 & 0,0 & 0,0 & 0,0 \\
\hline Aq central passag & 0 & 9,0 & 0,0 & 0,0 & 0,0 & 0 & 0,0 & 0,0 & 0,0 & 0,0 & 0,0 \\
\hline Aq. Central Acumu & 0 & 3,5 & 0,0 & 0,0 & 0,0 & 0 & 0,0 & 0,0 & 0,0 & 0,0 & 0,0 \\
\hline Total: & 3 & & 29,8 & & 12,3 & 192 & & 217,7 & 48,6 & 194,4 & 64,8 \\
\hline
\end{tabular}

\begin{tabular}{|c|c|c|c|c|c|}
\hline \multicolumn{3}{|c|}{ Relação cargas ADMINISTRAÇÃO } & \multirow[b]{2}{*}{ Pot total } & \multirow[b]{2}{*}{ FD } & \multirow{2}{*}{$\begin{array}{c}\text { Pot } \\
\text { deman }\end{array}$} \\
\hline & Qt & Pot & & & \\
\hline \multicolumn{6}{|l|}{ Ilum +TUG } \\
\hline elevador (trif) & 1 & 15,0 & 15,0 & 1,0 & 15,0 \\
\hline elevador (trif) & 1 & 15,0 & 15,0 & 0,5 & 7,5 \\
\hline bomba d'água (trif) & 1 & 13,3 & 13,3 & 0,5 & 6,6 \\
\hline motor portão eletrônico & 1 & 1,2 & 1,2 & 0,5 & 0,6 \\
\hline Bomba de incêndio & 1 & 2,8 & 2,8 & 0,5 & 1,4 \\
\hline TotaL: & & & & & 31,1 \\
\hline
\end{tabular}

\section{I- DEMANDA GERAL DA ENTRADA (Dg)}

\section{Referente ao $\mathrm{n}^{\circ}$ total de APTS}

a) llum + TUG

$\mathrm{Da}=\left(\mathrm{n}^{\circ}\right.$ apts $\mathrm{x}$ área útil $\left.\times 5 \mathrm{~W} / \mathrm{m}^{2}\right) / F$ pot

$\mathrm{Da}(\mathrm{apt})=\quad 34,1 \mathrm{kVA}$

b) Referente a aparelhos (TUE) FD

$\mathrm{Db}=\Sigma\left\{\mathrm{n}\right.$-apts $\times \Sigma \mathrm{P} \times$ FD $\Sigma \mathrm{n}^{\circ} \mathrm{T}$ TUE no total de apts $\}$

Considerando fator simultaneidade de apt + ADM

$\mathrm{D}$ apt $=\quad 169$ kVA

\section{Referente a ADM}

a) Ilum + TUG

$$
\begin{array}{lr}
\mathrm{Da}= & 52,8 \quad \mathrm{kVA} \\
\text { b) Aparelhos especiais } & 5 \mathrm{kVA} \\
\mathrm{xxx} & 5
\end{array}
$$

C) referente a motores

$\mathrm{Dc}=$

$\mathrm{D}$ adm $=$

$\mathrm{I} \mathrm{adm}=$

$31,09 \mathrm{kVA}$

88,9kVA

$234 \mathrm{~A}$

$\mathrm{Dg}=\mathrm{Dapt}+\mathrm{Dadm}=$

257,6kVA kVA

$\mathrm{IDg}=$
II - ENTRE CX DE PROTEÇÃO E MANOBRA E CAIXAS DE MEDIÇÃO DAS UC

Demanda do ramal de distribuição principal (Drdp)

a) Ilum + TUG

$\mathrm{Da}=12 \times$ Área útil $\times 5 / \mathrm{FP}$

$\mathrm{Da}=\quad 6,39 \mathrm{kVA}$

b) Referente a aparelhos (TUE)

$\mathrm{Db}=\sum \mathrm{Qt} \times \mathrm{Pot} / \mathrm{FP} \times \mathrm{FD}$ por ramal

$\mathrm{Db}=\quad 48,6$

Dral $=\mathrm{Da}+\mathrm{Db} \quad 55,0 \quad \mathrm{kVA}$

Idral $=\quad 144,3 \quad \mathrm{~A}$

III- Demanda do ramal alimentador da unidade de consumo (Dral) Referente ao APTS

Dral $=\mathrm{Da}+\mathrm{Db} \quad 12,35 \mathrm{kVA}$

ldral $=\quad 56,12 \mathrm{~A}$ 


\section{C.2 Lista de Materiais com inclusão do aquecimento}

\section{MATERIAIS PARA POSTE DE ENTRADA E QUADRO DE PROTEÇÃ}

Item Discriminação

1 ELETRODUTO DE AÇO GALV.A FOGO

2 CABO DE COBRE, SINGELO, PVC - $750 \mathrm{~V}$; \# m²

3 CABO DE COBRE, SINGELO, PVC - $750 \mathrm{~V}$; \# m²

4 Caixa " " uso externo, com porta

5 CHAVE SECC. COM CARGA

6 FUSIVEL DA CHAVE SECCIONADORA ACIMA IN=(A) SUb TOTAL

\section{MATERIAL DA ENTRADA AO CENTRO DE MEDIÇÃO}

1 CABO DE COBRE, SINGELO, PVC-750V, \#mm2
Item Discriminação

2 CABO DE COBRE, SINGELO, PVC-750V, N \#mm2

3 ELETRODUTO Corrugado ou aço extra, DIÂMETRO \#mm Sub Total

Esp

95

50

60

3. CAIXA DE DISTRIBUIÇÃO, Proteção e Manobra

Item Discriminação

1 Caixa " " uso externo, com porta

2 CHAVE SECC. COM CARGA

3 FUSIVEL DA CHAVE SECCIONADORA ACIMA IN=(A)

4 CABO DE COBRE, SINGELO, PVC-750V, F \#mm2

5 CABO DE COBRE, SINGELO, PVC-750V, N \#mm2

6 ELETRODUTO Corrugado ou aço extra, DIÂMETRO \#mm Sub total

4. Da Cx de proteção e manobra para cada uma das caixa de medição adotada

Ramal de Distribuição Principal (Drdp)

Item Discriminação

1 CABO DE COBRE, SINGELO, PVC-750V, \# mm2 FASE

2 CABO DE COBRE, SINGELO, PVC-750V, \# mm2 NEUTRO

3 CABO DE COBRE, SINGELO, PVC-750V, \# mm2 TERRA

4 ELETRODUTO DE PVC RÍGIDO ROSQUEÁVEL, DIÂMETRO mm Sub total

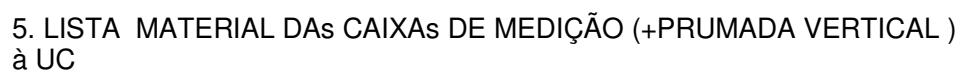

Item Discriminação

1.1 Tipo de caixas

CAIXA DE MEDIÇÃO TIPO "L", CHAPA N¹4, FUNDO MADEIRA DE

$120 \mathrm{~mm}$

CAIXA DE MEDIÇÃO TIPO "N", CHAPA N¹4, FUNDO MADEIRA DE

$220 \mathrm{~mm}$

1.2 Condutores até $7^{\circ}$ andar

1 CABO DE COBRE ISOLADO 750V - FASE - \# mm²

2 CABO DE COBRE ISOLADO $750 \mathrm{~V}$ - NEUTRO - \# $\mathrm{mm}^{2}$

3 CABO DE COBRE ISOLADO $750 \mathrm{~V}$ - TERRA - \# $\mathrm{mm}^{2}$

1.3 Condutores acima do $7^{\circ}$ andar

1 CABO DE COBRE ISOLADO 750V - FASE - \# mm²

CABO DE COBRE ISOLADO $750 \mathrm{~V}$ - NEUTRO - \# $\mathrm{mm}^{2}$

3 CABO DE COBRE ISOLADO $750 \mathrm{~V}$ - TERRA - \# mm²

1.4 - ELETRODUTOS

1 ELETRODUTO EM PVC RÍGIDO ROSQUEÁVEL 25mm

2 ELETRODUTO EM PVC RÍGIDO ROSQUEÁVEL 25mm 1.5 Disjuntores dos medidores

\begin{tabular}{clrr} 
Qt & Uni & \multicolumn{1}{c}{$\begin{array}{c}\text { Preço } \\
\text { Unitário }\end{array}$} & \multicolumn{1}{l}{ Preço } \\
36 & $\mathrm{~m}$ & 226,5 & 8154,2 \\
108 & $\mathrm{~m}$ & 49,0 & 5289,5 \\
36 & $\mathrm{~m}$ & 29,1 & 1046,1 \\
1 & $\mathrm{cj}$ & 71,8 & 71,8 \\
3 & pç & 1826,5 & 5479,6 \\
9 & pç & 30,4 & 273,2 \\
& & & 20314,4
\end{tabular}

Preço Preço

Unitário Total

$38,5 \quad 5717,7$

$22,1 \quad 1094,0$

$53,3 \quad 2636,1$

9447,8

\begin{tabular}{rr} 
Preço & \multicolumn{2}{l}{ Preço } \\
Unitário & \multicolumn{1}{l}{ Total } \\
100,0 & 100,0 \\
1826,5 & 5479,6 \\
30,4 & 273,2 \\
38,5 & 3049,4 \\
22,1 & 583,5 \\
53,3 & 1405,9 \\
& 10891,7
\end{tabular}

Preço Preço

\begin{tabular}{ccrr} 
Qt & Uni & Unitário & \multicolumn{1}{c}{ Total } \\
138,6 & $\mathrm{~m}$ & 15,6 & 2166,6
\end{tabular}

$46,2 \quad m \quad 11,8 \quad 546,6$

$46,2 \quad m \quad 8,5 \quad 393,9$

$\begin{array}{llll}46,2 & m & 22,5 & 1039,7\end{array}$

4146,8

Esp

Qt Uni

Preço Preço

L

$\mathrm{N}$

$1 \quad$ pç

63,1

63,1

5 pç

$71,8 \quad 359,0$

$369 \mathrm{~m}$

$184,5 \quad \mathrm{~m}$

$184,5 \mathrm{~m}$

$1426 \mathrm{~m}$

$712,3 \quad \mathrm{~m}$

$712,3 \quad \mathrm{~m}$

0,0

$15,6 \quad 5768,3$

$11,8 \quad 2182,7$

$8,5 \quad 1573,0$

0,0

$22,1 \quad 31507,7$

$11,8 \quad 8426,6$

$11,8 \quad 8426,6$ 
2 DISJUNTOR TERMOMAGNÉTICO BIPOLAR (A) -250V

6. LISTA MATERIAL dos apartamentos

1.1 Chuveiros Serviço

Item Discriminação

CABO DE COBRE ISOLADO 750V - FASE - \# FFmm²

CABO DE COBRE ISOLADO 750V - TERRA, NA COR VERDE - \# $\mathrm{Tmm}^{2}$

ELETRODUTO DE PVC RÍGIDO ROSQUEÁVEL, DIÂMETRO =mm DISJUNTOR RESIDUAL TERMOMAGNÉTICO BIPOLAR A-250V

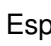

4

4

16

50

1.1 Chuveiros 2

Item Discriminação

CABO DE COBRE ISOLADO 750V - FASE - \# FFmm²

CABO DE COBRE ISOLADO 750V - TERRA, NA COR VERDE - \#

$\mathrm{Tmm}^{2}$

ELETRODUTO DE PVC RÍGIDO ROSQUEÁVEL, DIÂMETRO 20mm DISJUNTOR RESIDUAL TERMOMAGNÉTICO BIPOLAR A-250V

1.2 Torneira elétrica

Item Discriminação

CABO DE COBRE ISOLADO 750V - FASE - \# FFmm²

CABO DE COBRE ISOLADO 750V - TERRA, NA COR VERDE - \#

$\mathrm{Tmm}^{2}$

ELETRODUTO DE PVC RÍGIDO ROSQUEÁVEL, DIÂMETRO 20mm DISJUNTOR RESIDUAL TERMOMAGNÉTICO BIPOLAR A-250V

1.3 Aquec individual

Item Discriminação

CABO DE COBRE ISOLADO 750V - FASE - \# FFmm²

CABO DE COBRE ISOLADO 750V - TERRA, NA COR VERDE - \# $\mathrm{Tmm}^{2}$

ELETRODUTO DE PVC RÍGIDO ROSQUEÁVEL, DIÂMETRO 20mm DISJUNTOR RESIDUAL TERMOMAGNÉTICO BIPOLAR A-250V

1.4 Aq central passag

Item Discriminação

CABO DE COBRE ISOLADO 750V - FASE - \# FFmm²

CABO DE COBRE ISOLADO 750V - TERRA, NA COR VERDE - \#

$\mathrm{Tmm}^{2}$

ELETRODUTO DE PVC RÍGIDO ROSQUEÁVEL, DIÂMETRO $20 \mathrm{~mm}$ DISJUNTOR RESIDUAL TERMOMAGNÉTICO BIPOLAR A-250V

1.5 Aq. Central Acumu

Item Discriminação

CABO DE COBRE ISOLADO 750V - FASE - \# FFmm²

CABO DE COBRE ISOLADO 750V - TERRA, NA COR VERDE - \# $\mathrm{Tmm}^{2}$

ELETRODUTO DE PVC RÍGIDO ROSQUEÁVEL, DIÂMETRO 20mm DISJUNTOR RESIDUAL TERMOMAGNÉTICO BIPOLAR A-250V

especificações
4
4
20
50

$\begin{array}{cc}\text { Qt } & \text { Uni } \\ 15 & \mathrm{~m} \\ 7,5 & \mathrm{~m} \\ 7,5 & \mathrm{~m} \\ 1 & \mathrm{pç}\end{array}$

$$
\begin{array}{rr}
\begin{array}{r}
\text { Preço } \\
\text { Unitário }
\end{array} & \multicolumn{2}{l}{\begin{array}{l}
\text { Preço } \\
\text { Total }
\end{array}} \\
3,8 & 56,3 \\
& \\
3,8 & 28,2 \\
5,2 & 38,7 \\
59,6 & 59,6 \\
& 11703,5
\end{array}
$$

\begin{tabular}{|c|c|}
\hline $\begin{array}{l}\text { Preço } \\
\text { Unitário }\end{array}$ & $\begin{array}{l}\text { Preço } \\
\text { Total }\end{array}$ \\
\hline 3,8 & \\
\hline 3,8 & \\
\hline 7,5 & \\
\hline 59,6 & \\
\hline
\end{tabular}

\begin{tabular}{|c|c|}
\hline $\begin{array}{l}\text { Preço } \\
\text { Unitário }\end{array}$ & $\begin{array}{l}\text { Preço } \\
\text { Total }\end{array}$ \\
\hline 3,8 & \\
\hline 3,8 & \\
\hline 7,5 & \\
\hline 59,6 & \\
\hline
\end{tabular}

\begin{tabular}{|c|c|}
\hline $\begin{array}{l}\text { Preço } \\
\text { Unitário }\end{array}$ & $\begin{array}{l}\text { Preço } \\
\text { Total }\end{array}$ \\
\hline 8,1 & 0,0 \\
\hline 8,1 & 0,0 \\
\hline 9,6 & 0,0 \\
\hline 59,6 & 0,0 \\
\hline & 0,0 \\
\hline
\end{tabular}

\begin{tabular}{rr} 
Preço & \multicolumn{2}{c}{ Preço } \\
Unitário & \multicolumn{2}{c}{ Total } \\
3,8 & 366,6 \\
3,8 & 46,9 \\
7,5 & 93,3 \\
59,6 & 119,3 \\
& 40067,7
\end{tabular}

Preço Preço Unitário Total $3,8 \quad 0,0$

$3,8 \quad 0,0$

$7,5 \quad 0,0$

$59,6 \quad 0,0$ 
ANEXO D - Materiais representativos das instalações elétricas

\begin{tabular}{|c|c|c|c|}
\hline Descrição do Produto & $\begin{array}{c}\% \\
\text { simples }\end{array}$ & $\begin{array}{c}\% \\
\text { acumulada }\end{array}$ & $\begin{array}{c}\% \text { produto } \\
\text { aquecimento }\end{array}$ \\
\hline Armação secundária c/ roldana & $0,0174 \%$ & $8,0479 \%$ & \\
\hline Barra chata de alumínio 3/4" X 1/4" X 3,00 m & $0,8339 \%$ & & \\
\hline Barra de aço galvanizado a fogo $3 / 8 "$ X 3,00 m & $4,8819 \%$ & & \\
\hline Bucha e arruela de alumínio $\varnothing 1$ 1/2" & $0,0211 \%$ & & \\
\hline Bucha e arruela de alumínio $\varnothing 1$ 1/4" & $0,0022 \%$ & & \\
\hline Bucha e arruela de alumínio $\varnothing 1 "$ & $0,0255 \%$ & & \\
\hline Bucha e arruela de alumínio $\varnothing 2 "$ & $0,0147 \%$ & & \\
\hline Bucha e arruela de alumínio Ø 3" & $0,0147 \%$ & & \\
\hline Bucha e arruela de alumínio $\varnothing 3 / 4 "$ & $0,2275 \%$ & & \\
\hline Bucha e arruela de alumínio $\varnothing 4 "$ & $0,1605 \%$ & & \\
\hline Canaleta para BL-I & $0,0343 \%$ & & \\
\hline Conector c/ furo vertical & $0,0516 \%$ & & \\
\hline Curva $90^{\circ}$ em barra chata de alumínio 3/4" X 1/4" & $1,0316 \%$ & & \\
\hline Braçadeira p/ cabo BC-1 e BC-3 & $0,0118 \%$ & $32,6957 \%$ & \\
\hline Cabo de cobre isolamento $1 \mathrm{kV}$, tipo Sintenax, \# $150 \mathrm{~mm}^{2}$ & $11,7607 \%$ & & $32,0772 \%$ \\
\hline Cabo de cobre isolamento $1 \mathrm{kV}$, tipo Sintenax, \# 2,5 mm² & $0,0794 \%$ & & \\
\hline Cabo de cobre isolamento $1 \mathrm{kV}$, tipo Sintenax, \# $240 \mathrm{~mm}^{2}$ & $2,3068 \%$ & & \\
\hline Cabo de cobre isolamento $1 \mathrm{kV}$, tipo Sintenax, \# $25 \mathrm{~mm}^{2}$ & $13,1148 \%$ & & \\
\hline Cabo de cobre isolamento $1 \mathrm{kV}$, tipo Sintenax, \# $4 \mathrm{~mm}^{2}$ & $3,2282 \%$ & & \\
\hline Cabo de cobre isolamento $1 \mathrm{kV}$, tipo Sintenax, \# $50 \mathrm{~mm}^{2}$ & $0,2925 \%$ & & \\
\hline Cabo de cobre anti-chama, isolamento $750 \mathrm{~V}, \# 10 \mathrm{~mm}^{2}$ & $0,0801 \%$ & & \\
\hline Cabo de cobre anti-chama, isolamento $750 \mathrm{~V}, \# 16 \mathrm{~mm}^{2}$ & $0,0968 \%$ & & \\
\hline Cabo de cobre anti-chama, isolamento $750 \mathrm{~V}$, \# $25 \mathrm{~mm}^{2}$ & $0,0000 \%$ & & \\
\hline Cabo de cobre anti-chama, isolamento $750 \mathrm{~V}$, \# $50 \mathrm{~mm}^{2}$ & $0,0000 \%$ & & \\
\hline Cabo de cobre nu \# $16 \mathrm{~mm}^{2}$ & $0,0597 \%$ & & \\
\hline Cabo de cobre nu \# $25 \mathrm{~mm}^{2}$ & $0,0000 \%$ & & \\
\hline Cabo de cobre nu \# $35 \mathrm{~mm}^{2}$ & $1,0354 \%$ & & \\
\hline Cabo de cobre nu \# $6 \mathrm{~mm}^{2}$ & $0,0227 \%$ & & \\
\hline Presilha para cabo de cobre $35 \mathrm{~mm}^{2}$ & $0,0889 \%$ & & \\
\hline Caixa CP-4 & $0,0052 \%$ & $13,8531 \%$ & \\
\hline Caixa de descarga plástica de sobrepor $12 \mathrm{I}$ & $0,1003 \%$ & & \\
\hline Caixa de madeira $80 \times 60 \mathrm{~cm}$ & $0,1003 \%$ & & \\
\hline Caixa de passagem metálica $15 \times 15 \times 12 \mathrm{~cm}, \mathrm{c} /$ tampa & $0,0797 \%$ & & \\
\hline Caixa de passagem metálica $20 \times 20 \times 12 \mathrm{~cm}, \mathrm{c} /$ tampa & $0,2389 \%$ & & \\
\hline Caixa estampada em ferro esmaltado $3 \times 3 "$ & $0,0818 \%$ & & \\
\hline Caixa estampada em ferro esmaltado $4 \times 2 "$ & $0,7866 \%$ & & \\
\hline Caixa estampada em ferro esmaltado $4 \times 4 "$ & $0,1465 \%$ & & \\
\hline Caixa estampada em ferro esmaltado $4 \times 4$ " octog. F. M. & $0,5145 \%$ & & \\
\hline Caixa p/ derivação pavimentos $34,5 \times 21 \times 97 \mathrm{~cm}$ & $0,7004 \%$ & & \\
\hline Caixa p/ medidor e disjuntor $34,5 \times 21 \times 46 \mathrm{~cm}$ & $2,6754 \%$ & & \\
\hline Caixa para ligações equipotenciais & $0,7358 \%$ & & \\
\hline Caixa proteção disj. e barram. $60 \times 40 \times 100 \mathrm{~cm}$ & $0,3815 \%$ & & \\
\hline QDC-C1 (Condomínio 1) & $0,0785 \%$ & & \\
\hline QDC-C2 (Condomínio 2) & $0,0785 \%$ & & \\
\hline QDC-Quadro distribuição circuitos (aptºs) & $6,2787 \%$ & & \\
\hline QF (Bombas) & $0,0654 \%$ & & \\
\hline QF-CM (Casa máquinas elevadores) & $0,0654 \%$ & & \\
\hline Quadro comando iluminação c/ interruptores - QI & $0,1472 \%$ & & \\
\hline Disjuntor tripolar $120 \mathrm{~A}$ & $1,7532 \%$ & $7,0729 \%$ & $7,0729 \%$ \\
\hline Disjuntor tripolar $150 \mathrm{~A}$ & $0,1096 \%$ & & \\
\hline Disjuntor tripolar $225 \mathrm{~A}$ & $0,8175 \%$ & & \\
\hline Disjuntor tripolar $30 \mathrm{~A}$ & $0,0231 \%$ & & \\
\hline Disjuntor tripolar $300 \mathrm{~A}$ & $0,9763 \%$ & & \\
\hline Disjuntor tripolar $70 \mathrm{~A}$ & $3,3933 \%$ & & \\
\hline Eletroduto flexível corrugado $\varnothing 3 / 4 "$ & $8,3127 \%$ & $14,7018 \%$ & $14,7018 \%$ \\
\hline Eletroduto PVC rígido roscável Ø 3" & $0,1285 \%$ & & \\
\hline Eletroduto PVC rígido roscável Ø 4" & $0,8005 \%$ & & \\
\hline Eletroduto PVC rígido roscável Ø 3/4" & $1,6285 \%$ & & \\
\hline Eletroduto PVC rígido roscável $\varnothing 1$ 1/2" & $1,2950 \%$ & & \\
\hline Eletroduto PVC rígido roscável $\varnothing 1$ 1/4" & $0,2339 \%$ & & \\
\hline Eletroduto PVC rígido roscável $\varnothing 1 "$ & $1,7934 \%$ & & \\
\hline Eletroduto PVC rígido roscável $\varnothing$ 1/2" & $0,0011 \%$ & & \\
\hline Eletroduto PVC rígido roscável $\varnothing 2$ 1/2" & $0,0000 \%$ & & \\
\hline Eletroduto PVC rígido roscável Ø 2" & $0,5082 \%$ & & \\
\hline Fio de cobre anti-chama, isolamento $750 \mathrm{~V}, \# 2,5 \mathrm{~mm}^{2}$ & $17,0977 \%$ & $23,6286 \%$ & $22,9310 \%$ \\
\hline Fio de cobre anti-chama, isolamento $750 \mathrm{~V}$, \# $4 \mathrm{~mm}^{2}$ & $0,7122 \%$ & & \\
\hline Fio de cobre anti-chama, isolamento $750 \mathrm{~V}$, \# $6 \mathrm{~mm}^{2}$ & $5,1210 \%$ & & \\
\hline Fita isolante/serra copo/lâmina serra & $0,1308 \%$ & & \\
\hline
\end{tabular}


ANEXO E - Materiais representativos das instalações hidráulicas

\begin{tabular}{|c|c|c|c|}
\hline Descrição do Produto & $\begin{array}{c}\% \\
\text { simples }\end{array}$ & $\begin{array}{c}\% \\
\text { acumulada }\end{array}$ & $\begin{array}{c}\% \text { produto } \\
\text { aquecimento }\end{array}$ \\
\hline Bucha de redução cobre $\varnothing 28 \times 15 \mathrm{~mm}$ & $0,0296 \%$ & $37,5142 \%$ & $19,5563 \%$ \\
\hline Cap cobre $\varnothing 28 \mathrm{~mm}$ & $0,0182 \%$ & & \\
\hline Conector cabo/haste $\mathrm{p} /$ cabo nu \# $16 \mathrm{~mm}^{2}$ & $0,0127 \%$ & & \\
\hline Conector cabo-cabo $\mathrm{p} / 35 \mathrm{~mm}^{2}$ & $0,0467 \%$ & & \\
\hline Conector cobre ponta $\mathrm{x}$ bolsa $\varnothing 28 \mathrm{~mm} \times 1 "$ & $0,1348 \%$ & & \\
\hline Conector cobre ponta $x$ bolsa $\varnothing 35 \mathrm{~mm} \times 1$ 1/4" & $1,3596 \%$ & & \\
\hline Conector cobre ponta x bolsa $\varnothing 42 \mathrm{~mm} \times 1$ 1/2" & $0,9377 \%$ & & \\
\hline Conector cobre ponta x bolsa Ø $54 \mathrm{~mm} \times 2 "$ & $0,1711 \%$ & & \\
\hline Conector cobre ponta x bolsa $\varnothing 66 \mathrm{~mm} \times 2$ 1/2" & $4,0438 \%$ & & \\
\hline Conector cobre ponta x bolsa Ø $79 \mathrm{~mm} \times 3 "$ & $0,9467 \%$ & & \\
\hline Cotovelo $90^{\circ}$ cobre bolsa $\times$ bolsa $\varnothing 15 \mathrm{~mm}$ & $2,6123 \%$ & & \\
\hline Cotovelo $90^{\circ}$ cobre bolsa $\times$ bolsa $\varnothing 28 \mathrm{~mm}$ & $0,0776 \%$ & & \\
\hline Cotovelo $90^{\circ}$ cobre bolsa $\times$ bolsa $\varnothing 35 \mathrm{~mm}$ & $0,0000 \%$ & & \\
\hline Cotovelo $90^{\circ}$ cobre bolsa $\times$ bolsa $\varnothing 42 \mathrm{~mm}$ & $0,0000 \%$ & & \\
\hline Cotovelo $90^{\circ}$ cobre bolsa x bolsa $\varnothing 54 \mathrm{~mm}$ & $0,0000 \%$ & & \\
\hline Cotovelo $90^{\circ}$ cobre bolsa $\times$ bolsa $\varnothing 66 \mathrm{~mm}$ & $11,8970 \%$ & & \\
\hline Cotovelo $90^{\circ}$ cobre bolsa $\times$ bolsa $\varnothing 79 \mathrm{~mm}$ & $1,1515 \%$ & & \\
\hline Curva $45^{\circ}$ cobre bolsa $\times$ bolsa $\varnothing 66 \mathrm{~mm}$ & $0,2656 \%$ & & \\
\hline Lâmina de serra/solda/pasta de soldar & $1,1640 \%$ & & \\
\hline Luva cobre $\varnothing 15 \mathrm{~mm}$ & $0,8087 \%$ & & \\
\hline Luva cobre $\varnothing 28 \mathrm{~mm}$ & $0,0665 \%$ & & \\
\hline Niple duplo cobre $\varnothing 28 \mathrm{~mm}$ & $0,0441 \%$ & & \\
\hline Niple duplo cobre $\varnothing 35 \mathrm{~mm}$ & $0,0000 \%$ & & \\
\hline Niple duplo cobre $\varnothing 42 \mathrm{~mm}$ & $0,0000 \%$ & & \\
\hline Tê $90^{\circ}$ cobre bolsa $\times$ bolsa $\times$ bolsa $\varnothing 28 \mathrm{~mm}$ & $0,0684 \%$ & & \\
\hline Tê $90^{\circ}$ cobre bolsa $\times$ bolsa $\times$ bolsa $\varnothing 35 \mathrm{~mm}$ & $0,0000 \%$ & & \\
\hline Tê $90^{\circ}$ cobre bolsa $\times$ bolsa $\times$ bolsa $\varnothing 42 \mathrm{~mm}$ & $0,0000 \%$ & & \\
\hline Tê $90^{\circ}$ cobre bolsa $\times$ bolsa $\times$ bolsa $\varnothing 54 \mathrm{~mm}$ & $0,2974 \%$ & & \\
\hline Tê $90^{\circ}$ soldável / bucha de latão $\varnothing 20$ mm x 1/2" & $0,8044 \%$ & & \\
\hline Tê de redução $90^{\circ}$ cobre bolsa $\times$ bolsa $\times$ bolsa $\varnothing 28 \times 15 \mathrm{~mm}$ & $2,6477 \%$ & & \\
\hline Tê red. $90^{\circ}$ cobre bolsa $\times$ bolsa $\times$ bolsa $\varnothing 66$ × $35 \mathrm{~mm}$ & $0,0000 \%$ & & \\
\hline Tê red. $90^{\circ}$ cobre bolsa $\times$ bolsa $\times$ bolsa $\varnothing 66 \times 42 \mathrm{~mm}$ & $0,0000 \%$ & & \\
\hline União assento cônico bronze cobre $\varnothing 28 \mathrm{~mm}$ & $0,1477 \%$ & & \\
\hline União assento cônico bronze $\varnothing$ 2" & $0,6804 \%$ & & \\
\hline União cobre $\varnothing 35 \mathrm{~mm}$ & $0,0000 \%$ & & \\
\hline União cobre $\varnothing 42 \mathrm{~mm}$ & $0,0000 \%$ & & \\
\hline União cobre $\varnothing 54 \mathrm{~mm}$ & $0,0000 \%$ & & \\
\hline União cobre $\varnothing 66 \mathrm{~mm}$ & $4,0895 \%$ & & \\
\hline União cobre $\varnothing 79$ mm & $2,9905 \%$ & & \\
\hline Registro de esfera de $\varnothing 1 / 2 "$ & $3,4282 \%$ & $3,6135 \%$ & \\
\hline Válvula de esfera Ø 1" & $0,1853 \%$ & & $3,6135 \%$ \\
\hline Tubo de cobre cl. A Ø $15 \mathrm{~mm}$ & $34,7969 \%$ & $58,8723 \%$ & \\
\hline Tubo de cobre cl. A Ø $28 \mathrm{~mm}$ & $1,6325 \%$ & & $57,2397 \%$ \\
\hline & $0,0000 \%$ & & \\
\hline \multirow{2}{*}{ Tubo de cobre classe E $\varnothing 66 \mathrm{~mm}$} & $22,4428 \%$ & & \\
\hline & $100,0000 \%$ & & $80,4096 \%$ \\
\hline
\end{tabular}


ANEXO F - Variação de potência instalada e custo de infra-estrutura de gás

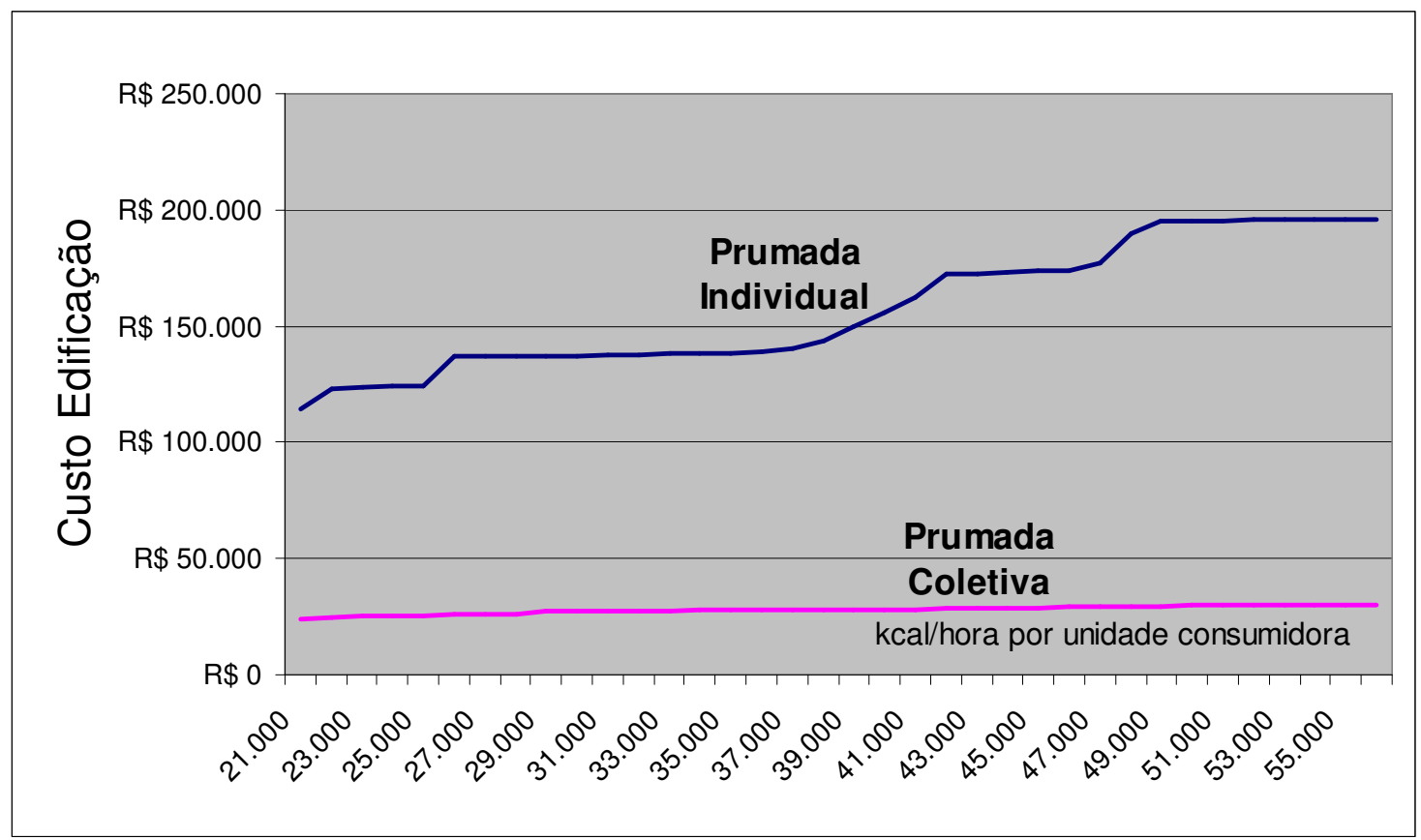

Figura E.1 Curvas de variação de potência instalada e custo de infra-estrutura de gás, para as tipologias de 2 dormitórios.

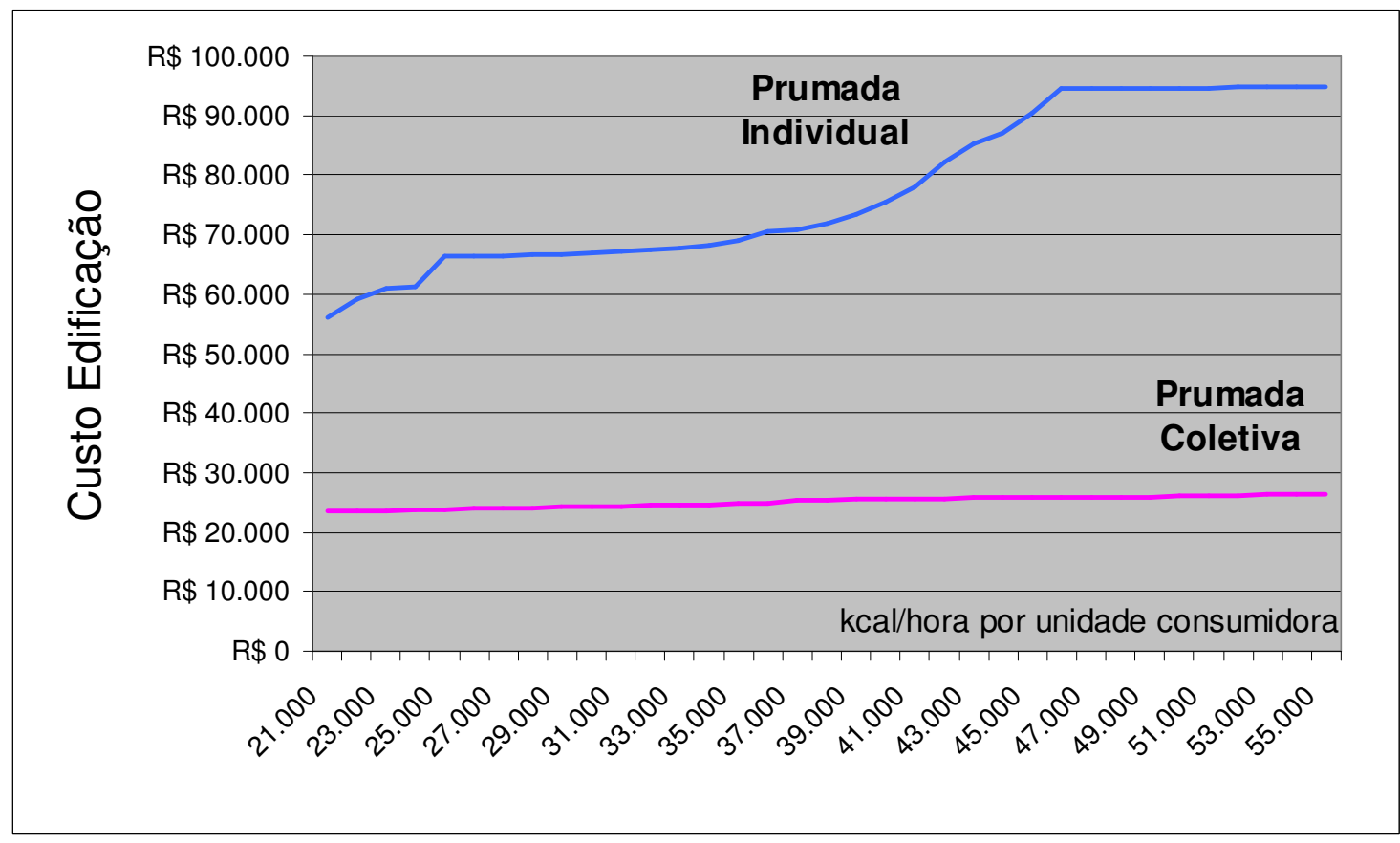

Figura E.1 Curvas de variação de potência instalada e custo de infra-estrutura de gás, para as tipologias de 2 dormitórios.

Fonte: Projeto P\&D : Aquecimento de água - Sistemas elétrico e gás natural (COMGÁS, 2007) 


\section{ANEXO G \\ Dimensionamento da Instalação Hidráulica de Água Quente}

Tabela G.1 Dimensionamento no ramal horizontal da unidade consumidora ** utilizado tubo de $22 \mathrm{~mm}^{\text {** }}$

\begin{tabular}{ccccc}
\hline Tipologia & Dispon. & $\begin{array}{c}\text { Na uni } \\
\text { consum. } \\
\boldsymbol{m}\end{array}$ & $\begin{array}{c}\text { Total } \\
\text { edificação } \\
\boldsymbol{m}\end{array}$ & $\begin{array}{c}\text { Custo na } \\
\text { Edificação } \\
\boldsymbol{R} \boldsymbol{\$}\end{array}$ \\
\hline \multirow{3}{*}{ 2D } & Mínimo & 4,4 & 282 & 8.679 \\
& Médio & 8,0 & 512 & 16.905 \\
& Máximo & 8,0 & 512 & 16.905 \\
3D & Mínimo & 20,3 & 1299 & 40.163 \\
& Médio & 23,8 & 1523 & 48.952 \\
& Máximo & 27,8 & 1779 & 60.192 \\
4D & Mínimo & 35,78 & 1145 & 16.897 \\
& Médio & 45,38 & 1452 & 21.019 \\
& Máximo & 49,39 & 1580 & 26.290 \\
\hline \hline
\end{tabular}

Tabela G.2 Dimensionamento total para o sistema central coletivo ** utilizado tubo de $22 \mathrm{~mm}$ na unidade + tubo de $42 \mathrm{~mm}$ para circulação principal e + tubo de $22 \mathrm{~mm}$ no retorno +tubo de $35 \mathrm{~mm}$ **

* não está cotado a circulação forçada de água*

\begin{tabular}{ccccc}
\hline Tipologia & Dispon. & $\begin{array}{c}\text { Na uni } \\
\text { consum. } \\
\boldsymbol{m}\end{array}$ & $\begin{array}{c}\text { Para } \\
\text { circulação } \\
\boldsymbol{m}\end{array}$ & $\begin{array}{c}\text { Custo } \text { na } \\
\text { Edificação } \\
\boldsymbol{R} \$\end{array}$ \\
\hline \multirow{4}{*}{ 2D } & Mínimo & 4,4 & & 25.343 \\
& Médio & 8,0 & 300 & 33.569 \\
& Máximo & 8,0 & & 33.569 \\
3D & Mínimo & 20,3 & & 60.643 \\
& Médio & 23,8 & 366 & 69.432 \\
& Máximo & 27,8 & & 80.672 \\
4D & Mínimo & 35,78 & & 41.421 \\
& Médio & 45,38 & 254 & 48.082 \\
& Máximo & 49,39 & & 53.487 \\
\hline \hline
\end{tabular}

Fonte: Projeto P\&D: Aquecimento de água - Sistemas Elétrico e a gás natural (COMGÁS, 2007). 


\section{ANEXO H}

\section{Dimensionamento dos Reservatórios para os sistemas de acumulação}

Para este dimensionamento, foi utilizado a seguinte consideração:

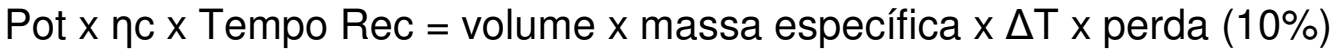

1. Reservatório Sistema Acumulação Privado $\Delta \mathrm{T}=40^{\circ} \mathrm{C} \quad \eta \mathrm{C}(\mathrm{ELE})=0,85 \quad \eta_{\mathrm{c}}(\mathrm{GAS})=0,7$

\begin{tabular}{|c|c|c|c|c|c|c|c|}
\hline \multirow[b]{2}{*}{ Tipologia } & \multirow[b]{2}{*}{$\begin{array}{c}\text { Volume } \\
\text { litros }\end{array}$} & \multicolumn{3}{|c|}{ Sistema elétrico } & \multicolumn{3}{|c|}{ Sistema a gás } \\
\hline & & $\begin{array}{c}\text { Pot. Elétrica } \\
\mathrm{kW}\end{array}$ & $\begin{array}{l}\mathrm{Cr} \\
\mathrm{l} / \mathrm{h}\end{array}$ & $\begin{array}{c}\text { Tempo Rec } \\
\text { hora }\end{array}$ & $\begin{array}{c}\text { Pot. Gás } \\
\text { kcal/hora }\end{array}$ & $\begin{array}{l}\mathrm{Cr} \\
\mathrm{l} / \mathrm{h}\end{array}$ & $\begin{array}{c}\text { Tempo Rec } \\
\text { hora }\end{array}$ \\
\hline \multirow{3}{*}{$2 \mathrm{D}$} & 100 & 2,5 & 45,7 & 2,2 & 6.000 & 105,0 & 1,0 \\
\hline & 120 & 3 & 54,8 & 2,2 & 8.200 & 143,5 & 0,8 \\
\hline & 150 & 3,5 & 64,0 & 2,3 & 8.200 & 143,5 & 1,0 \\
\hline \multirow{3}{*}{$3 D$} & 175 & 4 & 73,1 & 2,4 & 8.200 & 143,5 & 1,2 \\
\hline & 200 & 4,4 & 80,4 & 2,5 & 10.500 & 183,8 & 1,1 \\
\hline & 250 & 5 & 91,4 & 2,7 & 13.500 & 236,3 & 1,1 \\
\hline \multirow{3}{*}{$4 \mathrm{D}$} & 250 & 5 & 91,4 & 2,7 & 13.500 & 236,3 & 1,1 \\
\hline & 300 & 5,4 & 98,7 & 3,0 & 15.000 & 262,5 & 1,1 \\
\hline & 400 & 6,2 & 113,3 & 3,5 & 15.000 & 262,5 & 1,5 \\
\hline
\end{tabular}

2. Reservatórios dos Sistemas de Acumulação Coletivo (GÁS)

$\Delta \mathrm{T}=25^{\circ} \mathrm{C} \quad \eta_{\mathrm{c}}(\mathrm{GAS})=0,7 \quad$ e $\quad$ Fator de simultaneidade $=1 / 3$, na determinação do volume do reservatório

\begin{tabular}{ccccc}
\hline Tipologia & $\begin{array}{c}\text { Volume } \\
\text { litros }\end{array}$ & $\begin{array}{c}\text { Pot. Gás } \\
\text { kcal/hora }\end{array}$ & $\begin{array}{c}\text { Cr } \\
\mathrm{l} / \mathrm{h}\end{array}$ & $\begin{array}{c}\text { Tempo Rec } \\
\text { hora }\end{array}$ \\
\hline \multirow{3}{*}{ 2D } & 4000 & 45.000 & 1145,5 & 3,5 \\
& 6000 & 60.600 & 1542,5 & 3,9 \\
& 6000 & 60.600 & 1542,5 & 3,9 \\
\multirow{3}{*}{ 3D } & 6000 & 60.600 & 1542,5 & 3,9 \\
& 8000 & 90.000 & 2290,9 & 3,5 \\
$\cdots$ & 8000 & 90.000 & 2290,9 & 3,5 \\
\multirow{3}{*}{ 4D } & 4000 & 45.000 & 1145,5 & 3,5 \\
& 6000 & 60.600 & 1542,5 & 3,9 \\
& 6000 & 60.600 & 1542,5 & 3,9 \\
\hline \hline
\end{tabular}




\section{ANEXO I \\ Dimensionamento do Sistema Misto de Aquecimento de Água}

Chuveiro elétrico no banheiro de serviço e aquecimento a gás nas demais dependências

\begin{tabular}{|c|c|c|c|c|}
\hline \multirow[b]{2}{*}{$\begin{array}{l}\text { Sistemas } \\
\text { Tipologia 3D }\end{array}$} & \multirow[b]{2}{*}{ Disp } & \multicolumn{2}{|c|}{$\begin{array}{l}\text { Potência Instalada - } \\
\text { Sistema Misto-UC }\end{array}$} & \multirow{2}{*}{$\begin{array}{c}\text { Custos } \\
\text { Misto } \\
\text { milR } \$\end{array}$} \\
\hline & & Elétrica & $\begin{array}{c}\text { Gas } \\
\mathrm{kcal} / \mathrm{h}\end{array}$ & \\
\hline \multirow{3}{*}{ Instantâneo (2) } & (D) & & 29.580 & 119 \\
\hline & $(E)$ & $5,4 \mathrm{~kW}$ & 34.301 & 129 \\
\hline & $(F)$ & & 42.963 & 142 \\
\hline \multirow{3}{*}{ Acumulação Privativo (3) } & (G) & & 6.000 & 111 \\
\hline & $(\mathrm{H})$ & & 8.200 & 120 \\
\hline & $(\mathrm{I})$ & & 10.500 & 132 \\
\hline
\end{tabular}

\begin{tabular}{|c|c|c|c|c|}
\hline \multirow[b]{2}{*}{$\begin{array}{c}\text { Sistemas } \\
\text { Tipologia 4D } \\
\end{array}$} & \multirow[b]{2}{*}{ Disp } & \multicolumn{2}{|c|}{$\begin{array}{l}\text { Potência Instalada - } \\
\text { Sistema Misto UC }\end{array}$} & \multirow{2}{*}{$\begin{array}{c}\text { Custos } \\
\text { Misto } \\
\text { milR } \$\end{array}$} \\
\hline & & Elétrica & $\begin{array}{c}\text { Gas } \\
\mathrm{kcal} / \mathrm{h}\end{array}$ & \\
\hline \multirow{3}{*}{ Instantâneo (2) } & (D) & & 49.527 & 101 \\
\hline & (E) & $5,4 \mathrm{~kW}$ & 54.759 & 113 \\
\hline & $(F)$ & & - & - \\
\hline \multirow{3}{*}{ Acumulação Privativo (3) } & (G) & & 10.500 & 98 \\
\hline & $(\mathrm{H})$ & & 13.500 & 109 \\
\hline & (I) & & 15.000 & 115 \\
\hline
\end{tabular}




\section{ANEXO J}

\section{Aquecedores, Reservatórios e Preços dos Equipamentos do Estudo de Caso}

Tabela J.1 Aquecedores, reservatórios, potência, vazões e preço médio

\begin{tabular}{lccc}
\hline \multicolumn{4}{c}{ 1. Sistema Elétrico } \\
Equipamento & $\begin{array}{c}\text { Potencia } \\
\text { kW }\end{array}$ & $\begin{array}{c}\text { Vazão } \\
\text { l/min }\end{array}$ & $\begin{array}{c}\text { Preço } \\
\text { R\$ }\end{array}$ \\
\hline Chuveiro elétrico & 5.400 & 3 & 37 \\
Torneira & 4.400 & 4 & 70 \\
Aquecedor/ducha & 6.500 & 6 & 500 \\
Acumulação 100l & 2.500 & 8 & 2.200 \\
Acumulação125 & 3.000 & 8 & 2.300 \\
Acumulaçãoo 150l & 3.500 & 8 & 2.500 \\
Acumulação 175I & 4.000 & 8 & 2.800 \\
Acumulação 200I & 4.400 & 8 & 3.100 \\
Acumulação 200। & 5.000 & 8 & 3.100 \\
Acumulação 250l & 5.000 & 8 & 3.500 \\
Acumulação 300I & 5.400 & 8 & 4.600 \\
Acumulação 400। & 6200 & 8 & 5.700 \\
\hline \hline
\end{tabular}

\begin{tabular}{lccc}
\hline \multicolumn{4}{c}{ 2. Sistema a gás } \\
Equipamento & $\begin{array}{c}\text { Potencia } \\
\text { kcal/h }\end{array}$ & $\begin{array}{l}\text { Vazão } \\
\text { l/min }\end{array}$ & $\begin{array}{c}\text { Preço } \\
\text { R }\end{array}$ \\
\hline Chuveiro a gás & 6.200 & 3 & 800 \\
Instantâneo central & 14.375 & 8 & 1.300 \\
Instantâneo central & 17.000 & 10 & 1.400 \\
Instantâneo central & 20.000 & 12 & 2.700 \\
Instantâneo central & 43.000 & 30 & 3.000 \\
Instantâneo central & 50.000 & 34 & 3.200 \\
Instantâneo central & 55.000 & 38 & 3.600 \\
Acumulação 100l & 6.000 & 8 & 1.900 \\
Acumulação 120l & 8.200 & 8 & 1.900 \\
Acumulação 150l & 8.200 & 8 & 2.500 \\
Acumulação 175I & 8.200 & 8 & 2.500 \\
Acumulação 200I & 10.500 & 8 & 2.820 \\
Acumulação 250| & 13.500 & 8 & 3.200 \\
Acumulação 300| & 15.000 & 8 & 4.200 \\
Acumulação 400l & 15.000 & 8 & 5.100 \\
\hline \hline
\end{tabular}

Tabela J.2 Potência e vazões média consideradas para o sistema Instantâneo Individual elétrico, que utiliza para banho e torneiras, equipamentos de diferentes vazões

\begin{tabular}{|c|c|c|c|}
\hline Tipologia & & $\begin{array}{c}\begin{array}{c}\text { Potência } \\
\text { kW }\end{array} \\
\end{array}$ & $\begin{array}{c}\text { Vazão } \\
\text { l/min }\end{array}$ \\
\hline & & 5.400 & 3,00 \\
\hline 2D & Ch ELE (1) & $\begin{array}{l}5.127 \\
5.066\end{array}$ & $\begin{array}{l}3,27 \\
3,33\end{array}$ \\
\hline & & 6.500 & 6,00 \\
\hline 2D & II ELE (2) & $\begin{array}{l}5.927 \\
5.800\end{array}$ & $\begin{array}{l}5,45 \\
5,33\end{array}$ \\
\hline & & 5.400 & 3,00 \\
\hline 3D & Ch ELE (1) & $\begin{array}{l}5.127 \\
5.066\end{array}$ & $\begin{array}{l}3,27 \\
3,33\end{array}$ \\
\hline 3D & II ELE (2) & $\begin{array}{l}6.500 \\
5.882 \\
5.800\end{array}$ & $\begin{array}{l}6,00 \\
5,41 \\
5,33\end{array}$ \\
\hline 4D & Ch ELE (1) & $\begin{array}{l}5.400 \\
5.096 \\
5.067\end{array}$ & $\begin{array}{l}3,00 \\
3,30 \\
3,33\end{array}$ \\
\hline 4D & II ELE (2) & $\begin{array}{l}6.500 \\
6.350 \\
5.698\end{array}$ & $\begin{array}{c}6,00 \\
5.1 \\
4,8\end{array}$ \\
\hline
\end{tabular}




\section{ANEXO K \\ Dimensionamento Sistema Solar}

Considerações:

1Consumo diário estimado por pessoa: 60 litros para banho

12 litros para torneira de cozinha

4 litros para torneira de lavabo

2. № de pessoas estimada por tipologia: 3pessoas para tipologia de 2D; 4 pessoas para tipologia de 3D; e 5 pessoas para tipologia de 4D (na disponibilidade máxima).

3. Demanda diária $=$ volume água $\times$ calor específico da água $\times \Delta T \times$ perdas

(volume $\times 4,18 \times 20 \times 1,1 / 3600$ )

onde, volume de água quente é o do reservatório, c é o calor específico da água,

o diferencial de temperatura deve ser de $20^{\circ} \mathrm{C}$ e perdas de $10 \%$

4. Coletor solar com área de $2 \mathrm{~m}^{2}$ e produção de energia de $99 \mathrm{kWh} / \mathrm{mês}$ para a

RMSP, o que resulta em uma eficiência de coletor de 0,398.

5. Taxa de cobertura Solar de $68 \%$ para região metropolitana de São Paulo.

\begin{tabular}{|c|c|c|c|c|c|c|c|}
\hline Tipologia & $\begin{array}{c}\text { Reservatório } \\
\mathrm{fs}=1\end{array}$ & $\begin{array}{l}\text { Demanda } \\
\text { kWh mês }\end{array}$ & $\begin{array}{c}\text { Coletores } \\
\text { dimensionados } \\
\mathrm{m}^{2}\end{array}$ & $\begin{array}{c}\text { Área } \\
\text { disponivel } \\
\text { cobertura } \\
\mathrm{m}^{2} \\
\end{array}$ & $\begin{array}{c}\text { CS } \\
\mathrm{R} \$ 280 / \mathrm{m} 2\end{array}$ & $\begin{array}{c}\text { RESERV } \\
\mathrm{R} \$\end{array}$ & $\begin{array}{c}\text { Mão de } \\
\text { obra } \\
\mathrm{R} \$\end{array}$ \\
\hline 2D & 15000 & 11878 & $240^{41}$ & 152 & 67190 & 50000 & 15000 \\
\hline 3D & 20000 & 15838 & 320 & 384 & 89586 & 61400 & 15000 \\
\hline 4D & 12200 & 9661 & 195 & 238 & 54648 & 35000 & 15000 \\
\hline
\end{tabular}

Fontes: Instituto Nacional de Metereologia -INMET, 2006

GREEN Solar / INMETRO, 2006

TRANSSEN, 2007

\footnotetext{
${ }^{41}$ Para a tipologia de 2 dormitórios há necessidade de área externa da cobertura para instalação dos coletores solares para que ocorra a TCS igual a $68 \%$
} 